\title{
Pseudo-nitzschia in the Gulf of Maine: investigating bloom dynamics, species introduction, and climate change implications with observations and models
}

\author{
by \\ Suzanna C. Clark \\ B.S. Environmental Science, University of California, Los Angeles, 2013 \\ Submitted to the Department of Earth, Atmospheric, and Planetary Sciences \\ in partial fulfillment of the requirements for the degree of \\ Doctor of Philosophy \\ at the \\ MASSACHUSETTS INSTITUTE OF TECHNOLOGY \\ and the \\ WOODS HOLE OCEANOGRAPHIC INSTITUTION
}

June 2021

(C) 2021 Suzanna Clark. All rights reserved.

The author hereby grants to MIT and WHOI permission to reproduce and to distribute publicly paper and electronic copies of this thesis document in whole or in part in any medium now known or hereafter created.

Author

Joint Program in Oceanography/Applied Ocean Science and Engineering

Massachusetts Institute of Technology and Woods Hole Oceanographic Institution

March 23, 2021

Certified by

Dr. Dennis J. McGillicuddy, Jr. Thesis Supervisor

Woods Hole Oceanographic Institution
Dr. David K. Ralston Thesis Supervisor Woods Hole Oceanographic Institution

Accepted by

Professor Glenn Flierl

Chair, Joint Committee for Physical Oceanography Massachusetts Institute of Technology 


\title{
Pseudo-nitzschia in the Gulf of Maine: investigating bloom dynamics, species introduction, and climate change implications with observations and models
}

\author{
by \\ Suzanna C. Clark \\ Submitted to the Department of Earth, Atmospheric, and Planetary Sciences \\ on March 23, 2021 \\ in partial fulfillment of the requirements for the degree of Doctor of Philosophy in \\ Physical Oceanography
}

\begin{abstract}
The apparent global increase in harmful algal blooms (HABs) includes Pseudo-nitzschia blooms in the Gulf of Maine, where shellfishery closures can cost millions of dollars. Temperatures in the gulf are warming, which can affect the severity of some HABs. Yet Pseudo-nitzschia in the region are understudied.

Pseudo-nitzschia bloom dynamics, P. australis introduction, and potential future changes thereof were investigated in the Gulf of Maine. Data from ship surveys and moorings were used, as well as hydrodynamic, climate, and Lagrangian particle tracking models. Pseudonitzschia bloom toxicity was driven primarily by species composition, not environmental factors. P. australis was introduced to the region in 2016 via a coastal current from the Scotian Shelf. Climate change might intensify Pseudo-nitzschia blooms, shift bloom timing 1-2 weeks earlier in the spring or 4-6 weeks later in the fall, or lengthen the growing season by 3 weeks. It might also affect species composition and connectivity within the gulf. This work has implications for the monitoring of current and future blooms in the Gulf of Maine and for our understanding of HAB introduction to the region. It can also be used to develop predictive models for Pseudo-nitzschia, which could be applied to other HABs.
\end{abstract}

Thesis Co-Supervisor: Dennis McGillicuddy, Senior Scientist

Thesis Co-Supervisor: David Ralston, Associate Scientist 


\section{Acknowledgements}

This research was funded by the National Science Foundation (Grants OCE-1314642 and OCE-1840381), the National Institute of Environmental Health Sciences (Grants 1P01ES021923-01 and P01 ES028938-01), the Woods Hole Center for Oceans and Human Health, WHOI Academic Programs Funds, the Vannevar Bush Faculty Fellowship, and the National Oceanic and Atmospheric Administration's HAB Event Response Program (2012 and 2016).

Thank you to my advisors, Dr. Dennis J. McGillicuddy and Dr. David K. Ralston, for their time, patience, expertise, and guidance throughout this process. Thank you to Dr. Katherine Hubbard, who was a de facto third advisor and contributed as much of her time and expertise as anybody else. Thank you also to Dr. Donald Anderson and Professor Michael Follows for serving on my committee, and to Drs. Steve Elgar and Britt Raubenheimer for funding and guiding me through my first two years in the Joint Program. I am also indebted to the countless other scientists at WHOI who happily answered questions both inside and outside the classroom to help my scientific skills grow.

Thank you to Professor David Townsend and Maura Thomas at the University of Maine for support with data collection and analysis. Thank you also to Kohl Kanwit, Anna Farrell, Jane Disney, Hannah Mogenson, Steve Archer, and Bruce Keafer for collecting samples and data used in the thesis. Thank you to Maya Robert, Christina Chadwick, Laura Markley, Stephanie Keller Abbe, Karen Henschen, Emily Olesin, Steven Bruzek, Sheila O'Dea, April Granholm, Leanne Flewelling, and Elizabeth Racicot at the Florida Fish and Wildlife Conservation Commission-Fish and Wildlife Research Institute for processing samples. Thank you to Dr. Sugandha Shankar, Christina Chadwick, and Alexandra DeSmidt for conducting physiology experiments. Thank you also to the Department of Fisheries and Oceans Canada and their Atlantic Zone Monitoring Program for sharing their field data. Thank you to Drs. Michael Alexander, Enrique Curchitser, and Charles Stock for sharing their climate simulations and answering my questions.

Finally, a personal thank you to the friends and family who have supported me on this journey. Your encouragement, love, and support mean more than you can ever know. Thank you to the JP Jellyfish, PO students, and COFDL students in particular, and to Rachel Housego and Joleen Heiderich, for being the best graduate school friends I could ask for. Thank you to my friends who have known me since long before I decided to pursue a PhD, especially Sarah Tegenfeldt and Tessa Calahan, who have been by my side for 15 years. Thank you to my family, especially Brian Clark, Tracy Clark, Lauren Rad, Dave Clark, Ramin Rad, and Caroline Rad for encouraging me and always reminding me of what is really important. And most importantly, thank you to my husband, Aleksandr Shkoruta. We met at the very beginning at MIT orientation and he has been there through every high and every low. This degree belongs to him as much as it does to me. 
This page intentionally left blank. 


\section{Contents}

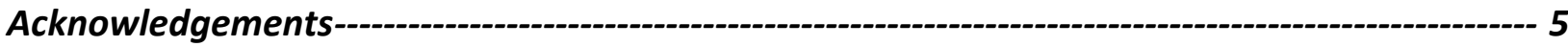

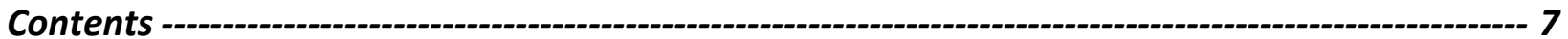

1 Introduction --- 13

1.1 Introduction to Harmful Algal Blooms and Pseudo-nitzschia -

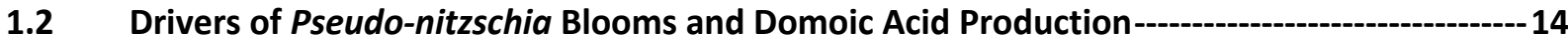

1.3 Historic and Predicted Changes to Pseudo-nitzschia Community Composition -------------16

1.4 Harmful Algal Blooms, Pseudo-nitzschia, and the Gulf of Maine----

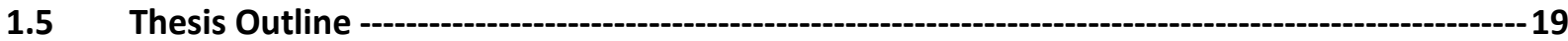

2 Pseudo-nitzschia Bloom Dynamics in the Gulf of Maine: 2012-2016 --

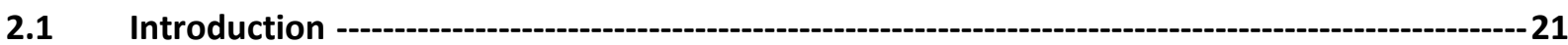

2.2 Methods -

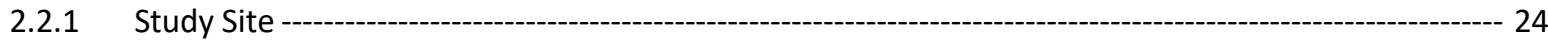

2.2.2 Biological Data - Ship Surveys --- 25

2.2.3 Particulate Domoic Acid--- 26

2.2.4 Biological Data - Mt. Desert Island Time Series-- 27

2.2.5 Physicochemical Data---o- 28

2.2.6 Descriptive and Statistical Analyses - 30

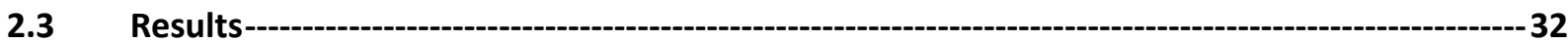

2.3.1 Biogeography prior to 2016 - 32

2.3.2 2016 event --- 38

2.3.3 Domoic Acid-- 39

2.3.4 Statistical Analysis ---o- 42

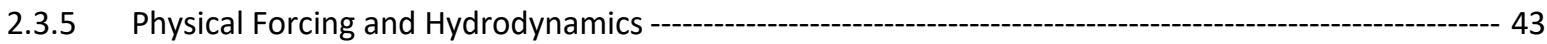

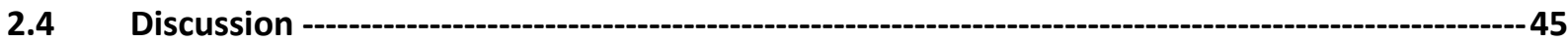

2.4.1 Pseudo-nitzschia Biogeography -

2.4.2 Cruise Results in the Context of Temporal Variability -- 45

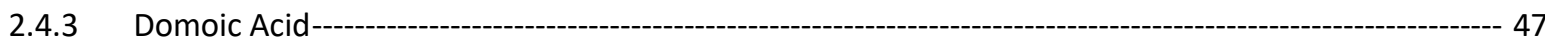

2.4.4 The 2016 Event--- 49

2.5 Conclusion-10

$3 \quad$ Investigating Pseudo-nitzschia australis introduction to the Gulf of Maine with

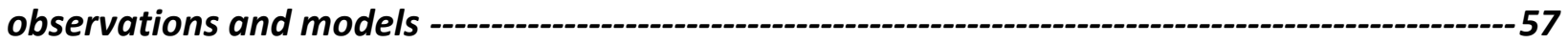

3.1 Introduction --

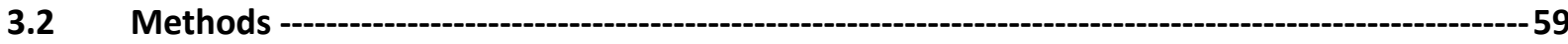

3.2.1 Study Site - The Gulf of Maine -- 59

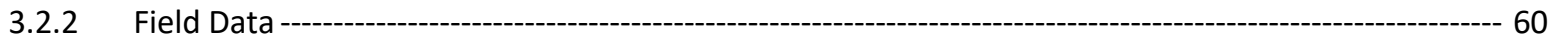

3.2.3 Models ----o 61

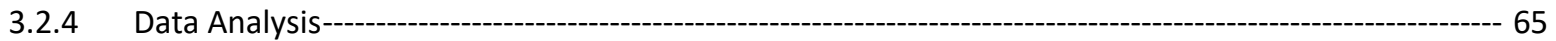

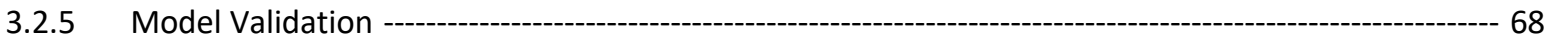




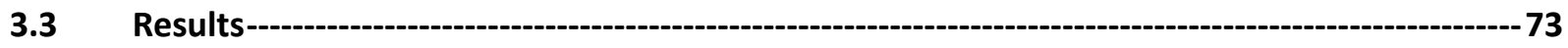

3.3.1 Hydrodynamics from ROMS Output and Observations ---

3.3.2 LTRANS -- 75

3.4 Discussion ---------------------------------------------------------------------------------------------------85

3.4.1 Likely P. australis Introduction Pathway --------------------------------------------------- 85

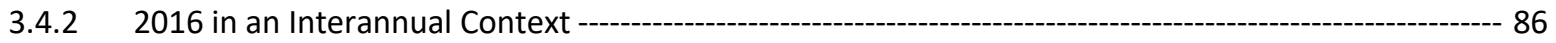

3.4.3 Changes Upstream ------------------------ 88

3.4.4 Looking to the Future: Persistence vs. Persistent Introduction -- 94

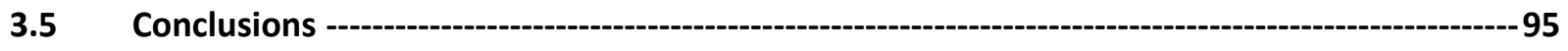

4 Potential effects of climate change on Pseudo-nitzschia bloom dynamics in the Gulf of

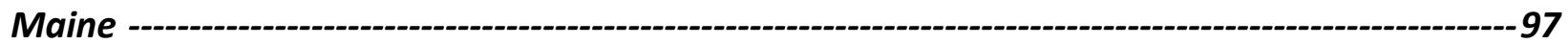

4.1 Introduction --1

4.2 Methods - 100

4.2.1 Region of Study -

4.2.2 Models ---

4.2.3 Experimental Setup --- 107

4.2.4 Analysis----

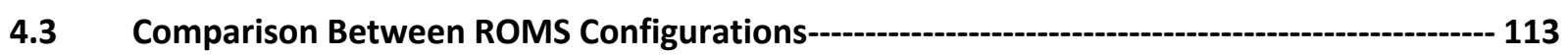

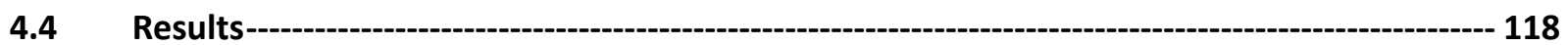

4.4.1 Hydrodynamics--------- 118

4.4.2 Predicted Changes to Pseudo-nitzschia Growth ---o--123

4.5 Discussion -- 127

4.5.1 Mechanisms Behind Changing Hydrodynamics ---

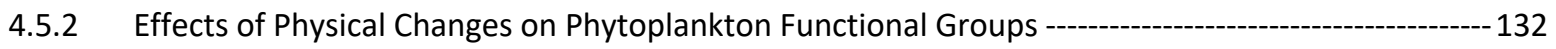

4.5.3 P. australis Potential Growth -- 133

4.5.4 P. australis in the Eastern Gulf of Maine---

4.5.5 Pseudo-nitzschia Community Composition ---

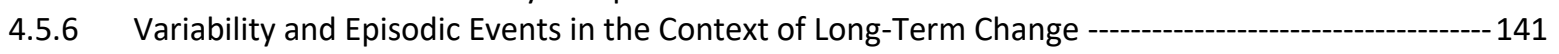

4.6 Conclusions -- 142

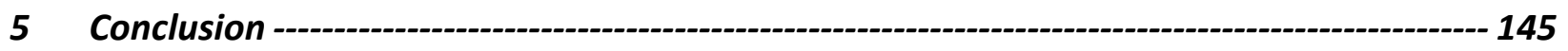

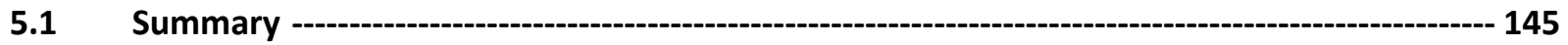

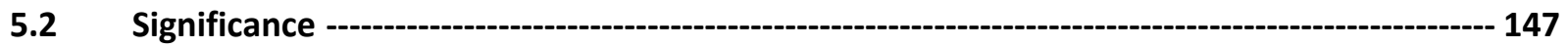

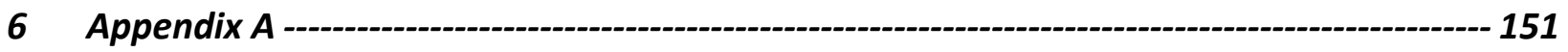

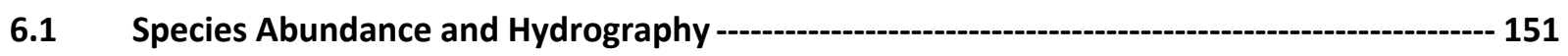

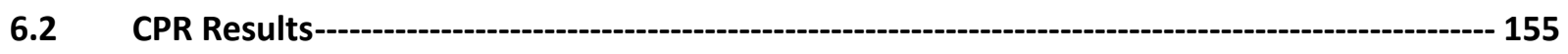

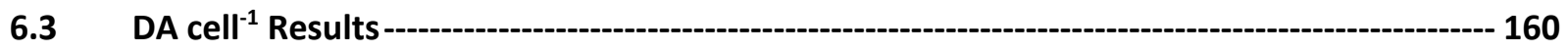

6.4 Linear Regression Results -

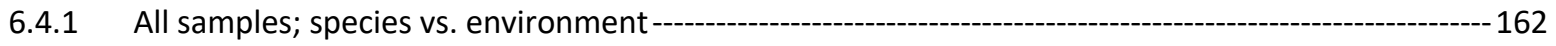

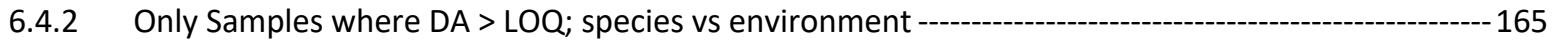

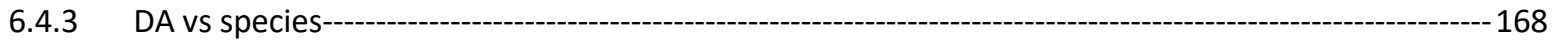

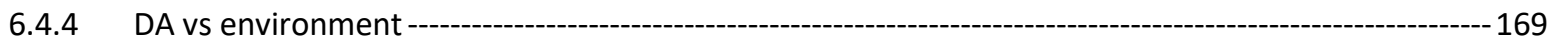


6.5 Wilcoxon Signed Rank Test Results - 170

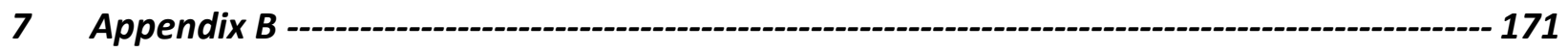

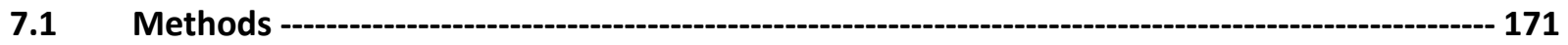

7.1.1 Model-Data Comparison-- 171

7.2 Results-- 177

7.2.1 ROMS and Field Data --177

7.2.2 Transport ---

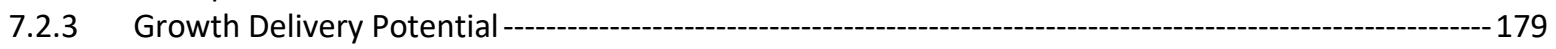

7.3 Discussion - 182

7.3.1 Likely P. australis Introduction Pathways --- 182

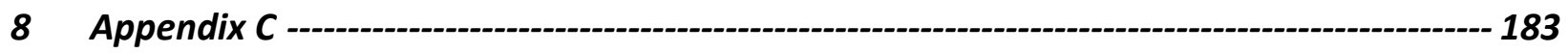

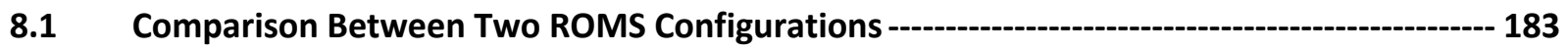

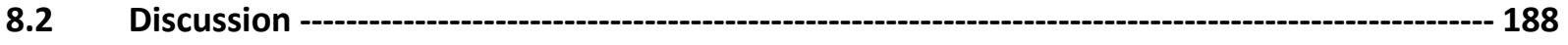

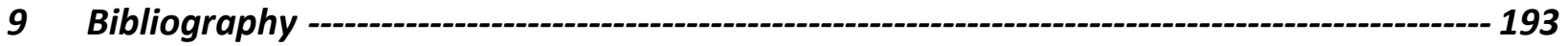


This page intentionally left blank. 
In theory there is no difference between practice and theory.

In practice there is. 
This page intentionally left blank. 


\section{Introduction}

\subsection{Introduction to Harmful Algal Blooms and Pseudo-nitzschia}

A Harmful Algal Bloom (HAB) is a bloom of algae that threatens the environment, public health, or socioeconomic interests, through either toxin production or large biomass (Backer and McGillicuddy, 2006; Glibert et al., 2005). HABs can threaten the environment by causing fish kills and poisoning large marine animals such as dolphins, manatees, and sea lions (Glibert et al., 2005). Threats to human health from HABs occur via contaminated shellfish, ciguatera poisoning, and acute respiratory distress, such as with Karenia brevis blooms (Backer and McGillicuddy, 2006). A wide range of toxins cause a variety of illnesses, including amnesic shellfish poisoning, azaspiracid poisoning, diarrhetic shellfish poisoning, neurotoxic shellfish poisoning, and paralytic shellfish poisoning (Backer and McGillicuddy, 2006). During a HAB, shellfisheries might be closed to avoid a public health crisis, leading to millions of dollars in economic losses. A widespread P. australis bloom on the U.S. West Coast in 2015, for example, led to multimonth closures of Dungeness crab fisheries (McCabe et al., 2016) and $\$ 97.5$ million in economic losses in 2015 (Trainer et al., 2020).

HABs gained national attention in the 1980s and have been the subject of research, monitoring, and technological development since (Anderson et al., 2012). HABs have apparently increased in frequency, magnitude, and spatial extent since this field was established, although the degree to which this is a real increase or an apparent increase because of improved measurement methods is not clear (Anderson et al., 2012; Glibert et al., 2005). HABs are frequently attributed to human activities such as anthropogenic eutrophication, which boosts the supply of limiting nutrients in coastal seas (Anderson et al., 2008), altered habitats through climate change (Anderson et al., 2012), introduction of invasive species through ship ballast water, or aquaculture. 
Many HABs are caused by dinoflagellates, single-celled phytoplankton that swim with flagellae (Backer and McGillicuddy, 2006). One of the few diatoms to cause HABs is Pseudo-nitzschia, a lightly-silicified diatom genus of more than 52 species, about half of which are confirmed toxin producers (Bates et al., 2018). Pseudo-nitzschia can produce domoic acid (DA), a potent neurotoxin responsible for Amnesic Shellfish Poisoning (ASP) (Backer and McGillicuddy, 2006). The symptoms of ASP include stomach pain, shortterm memory loss, and - in extreme cases - death (Backer and McGillicuddy, 2006; Perl et al., 1990). Domoic acid was first discovered in 1987 when contaminated mussels harvested near Prince Edward Island, Canada, led to hundreds of illnesses and three deaths (Bates et al., 1989; Perl et al., 1990).

Pseudo-nitzschia are frequently described as "cosmopolitan" in nature because they can tolerate a wide range of temperature and salinity conditions (Hasle, 2002). P. delicatissima, for example, has been observed in the field in temperatures ranging from 11 to $17.5^{\circ} \mathrm{C}$ (Thorel et al., 2017). P. multiseries, P. pungens, P. calliantha, P. cuspidata, and $P$. fraudulenta have all been observed in temperatures from $2-21^{\circ} \mathrm{C}$ in the Chesapeake Bay (Thessen and Stoecker, 2008). Pseudo-nitzschia species can be found in salinities as low as 10 PSU (Thessen and Stoecker, 2008) or as high as 37 PSU (Cerino et al., 2005). This is not to suggest that all Pseudo-nitzschia species can grow at all of the temperature and salinities in these ranges, but interspecies and inter-strain variation explain why Pseudo-nitzschia are found in estuaries, coasts, and the open ocean (Bates et al., 2018; Trainer et al., 2012).

\subsection{Drivers of Pseudo-nitzschia Blooms and Domoic Acid Production}

Pseudo-nitzschia blooms have been linked to hydrodynamic forcing in multiple locations. Off the coast of Washington, the Juan de Fuca Eddy acts as an incubation site for Pseudonitzschia blooms (Marchetti et al., 2004), which can lead to coastal shellfish contamination

if an eddy filament detaches and flows toward the coast (Trainer et al., 2009b). In the Santa Barbara Channel, convergent eddies were found to aggregate pre-existing, low 
density blooms until their densities grew from $5^{*} 10^{5}$ to more than $2^{*} 10^{6}$ cells L $\mathrm{L}^{-1}$ (Anderson et al., 2006). Bloom transport has also been connected to wind direction and resulting upwelling or downwelling conditions. Upwelling can initiate a Pseudo-nitzschia HAB by transporting optimal temperature, salinity, or nutrient conditions to the surface (Palma et al., 2010), or by transporting sub-surface Pseudo-nitzschia cells themselves (Cusack et al., 2016, 2015; Seegers et al., 2015). In some cases, such as off the coast of Washington, downwelling-favorable winds can advect offshore blooms toward the coast, where they are more likely to contaminate shellfish populations (Giddings, 2014).

Pseudo-nitzschia absolute and relative species abundance are also affected by physicochemical factors such as temperature, salinity, nutrients, and nutrient ratios. In general, Pseudo-nitzschia need nitrogen to sustain growth, and have a competitive advantage in environments with low silica-to-nitrogen ratios, because they require less silica than other diatoms (Marchetti et al., 2004; Parsons et al., 2002). Pseudo-nitzschia blooms can be locally specific phenomena, however, with interregional variability. In the English Channel, Pseudo-nitzschia blooms are thought to be controlled by temperature and nitrogen and phosphorus concentrations (Downes-Tettmar et al., 2013), while in Scottish waters, Pseudo-nitzschia blooms are dependent on photoperiod and salinity (Fehling et al., 2006). In the Bay of Seine, P. australis grew best when salinity was between 30 and 35 PSU (Ayache et al., 2018), and in the Southern California Bight, Pseudo-nitzschia concentrations were positively correlated with salinity and inversely correlated with river runoff (Schnetzer et al., 2007). In addition to interregional variability, interspecies variability can exist at one location. In the Bay of Fundy, seven different Pseudo-nitzschia species correlated to different degrees with nitrate concentration, water column depth, and phosphate concentration (Kaczmarska et al., 2007). Near the Tunisian coast, the abundance of six different Pseudo-nitzschia species correlated differentially with temperature, salinity, nitrate, silicate, and turbidity (Sahraoui et al., 2012). 
The physicochemical environment affects not only Pseudo-nitzschia abundance, but also DA production, which varies as a result of species composition (Bowers et al., 2018; Lema et al., 2017), nutrient concentrations (Fehling et al., 2006, 2004b, 2004a; Lema et al., 2017), nutrient ratios (Marchetti et al., 2004), temperature (Zhu et al., 2017), salinity (Ayache et al., 2018), toxin exposure (Maldonado et al., 2002), pH (Lundholm et al., 2004), and even predatory pressure (Hardardóttir et al., 2015). Low concentrations of phosphorous (Fehling et al., 2004a; Lema et al., 2017), silica (Fehling et al., 2004b), and iron (Maldonado et al., 2002) can all induce DA production or release. Nutrient concentrations can also act synergistically with stressors to enhance DA production, such as when increased pCO2 and low Phosphorous concentrations together led to more DA production than when pCO2 was increased alone (Sun et al., 2011). The effect of pH on DA production is contested, with some studies arguing that increased $\mathrm{pH}$ enhances DA production (Lundholm et al., 2004), and others arguing that decreased pH leads to DA production (Tatters et al., 2012). In addition to the physical environment, predatory pressure can induce DA production, as found in a study that exposed Pseudo-nitzschia to copepodites (Hardardóttir et al., 2015). Because of the complex nature of DA production and interspecies and inter-strain variability, it is difficult to apply laboratory findings directly to field data.

\subsection{Historic and Predicted Changes to Pseudo-nitzschia Community Composition}

Not only does the ambient environment influence Pseudo-nitzschia abundance on bloom time scales, but it can drive interdecadal regime shifts in diatom and Pseudo-nitzschia abundance. In the North Atlantic, increasing temperatures and increasingly windy summer storms have contributed to increasing abundance of diatoms relative to dinoflagellates since 1960 (Hinder et al., 2012). In Southern California, the North Pacific Gyre Oscillation caused a shift toward greater frequency, higher magnitude, and greater relative abundance of Pseudo-nitzschia blooms, and higher DA concentrations in the 1990s 
(Sekula-Wood et al., 2011). In Danish waters, Lundholm et al. (2010) proposed that increased temperature and ammonium-to-nitrate ratios caused a shift in Pseudo-nitzschia species composition. In the Gulf of Mexico, interdecadal increases in absolute Pseudonitzschia abundance correlated with an overall increase in nutrient loading and a decrease in the silica-to-nitrogen ratio (Parsons et al., 2002).

In addition to historical shifts in Pseudo-nitzschia abundance, climate change is predicted to affect Pseudo-nitzschia bloom dynamics around the world. Climate change will likely increase ocean temperatures, enhance stratification, decrease ocean $\mathrm{pH}$, alter patterns of upwelling or downwelling, and change patterns of storms and precipitation (Anderson et al., 2012; Hallegraeff, 2010). These changes can occur simultaneously and will vary with location, creating a complex synergistic problem for the prediction of HABs (Hallegraeff, 2010; Ralston and Moore, 2020). Possible consequences include range expansion of warm water HABs, species-specific changes in seasonality and bloom timing, and a phenological mismatch between phytoplankton and their predators (Hallegraeff, 2010).

Pseudo-nitzschia might be directly affected by climate change, particularly by increased temperatures. Increased temperatures have been found to increase $P$. australis and P. delicatissima abundance relative to other phytoplankton (Zhu et al., 2017). DA production by $P$. australis can also be positively correlated with temperature (Thorel et al., 2014; Zhu et al., 2017), and DA on the U.S. West Coast was found to correlate with warm phases of the Pacific Decadal Oscillation and Ocean Niño Index (McKibben et al., 2017). Indeed, the widespread P. australis bloom on the U.S. West Coast in 2015 was caused partly by a $2.5^{\circ} \mathrm{C}$ increase in surface temperatures above the mean, combined with intermittent upwelling (McCabe et al., 2016; Ryan et al., 2017). Trainer et al. (2020) argued that this bloom suggests that $P$. australis is more competitive in warm environments and better suited to survive low-nutrient conditions, which would make it competitive in a warmer, more stratified ocean. There is therefore precedent to indicate that Pseudo-nitzschia species might become both more competitive and more toxic as a 
result of climate change. To understand how climate change might affect Pseudo-nitzschia HABs, however, it is necessary to understand their ecological niche in the present day.

\subsection{Harmful Algal Blooms, Pseudo-nitzschia, and the Gulf of Maine}

In the Gulf of Maine, the dinoflagellate Alexandrium catenella (formerly A. fundyense), has bloomed regularly for the past several decades. These blooms typically begin in the spring and terminate mid-summer ( $\mathrm{Li}$ et al., 2009). In 2005, an historic bloom of A. catenella was declared a natural disaster that led to $\$ 50$ million in economic losses in the state of Massachusetts alone (Jin et al., 2008). These HABs are well-studied (Anderson, 1997; Franks and Anderson, 1992) and modeled (He et al., 2008; McGillicuddy et al., 2011; Stock et al., 2005), with a forecast model run annually by the National Oceanic and Atmospheric Administration ${ }^{1}$.

In recent years, however, Pseudo-nitzschia blooms in the Gulf of Maine have received increased attention (Fernandes et al., 2014). Fourteen species had been identified in the region as of 2014, several of which are confirmed DA producers (Fernandes et al. 2014). In contrast to A. fundyense blooms, Pseudo-nitzschia blooms in the region typically occur from late spring to early fall (Fernandes et al. 2014). In 2016, shellfisheries in the region were closed for the first time in history because of DA concentrations above the regulatory limit (Bates et al., 2018). The Gulf of Maine is also warming, with "marine heat waves" recorded in both 2012 (Pershing et al., 2015) and 2016 (Pershing et al., 2018).

These changes in the GOM threaten both the oceanic ecosystem and society. Human society in the region is closely tied to the ocean, where commercial fishing has been part of the regional economy for over 400 years (Kurlansky, 1997). In 2009, the combined value of all commercial fisheries in the GOM, including groundfish, herring, lobster, scallop, soft-shell clam, and tuna, was $\$ 114.5$ million (Lapointe, 2013). The beaches, coastal cities,

\footnotetext{
${ }^{1}$ https://coastalscience.noaa.gov/research/stressor-impacts-mitigation/hab-monitoring-system/gulf-ofmaine-alexandrium-catenella-predictive-models/
} 
and seaside nature also draw tourists to the region, which support $16 \%$ of the jobs in the state of Maine and contribute about $\$ 600$ million in state tax revenue per year (Maine Office of Tourism, 2018). These societal, economic, and ecological systems all rely on a healthy ocean environment, and they emphasize the need to understand HABs, including Pseudo-nitzschia, in the GOM.

Despite the evidence that the GOM is warming, and that Pseudo-nitzschia might become more competitive or toxic with climate change, this HAB genus is understudied in the region. Historical shifts in Pseudo-nitzschia abundance have already occurred in other parts of the world and are possible in the GOM, but the cosmopolitan nature of the genus makes it difficult to translate results from other studies to a specific location. It is therefore necessary to use data from the GOM to understand existing Pseudo-nitzschia bloom dynamics. Once these are better understood, models can be used to make predictions about how Pseudo-nitzschia blooms in the region might change as a result of climate change.

\subsection{Thesis Outline}

This thesis is divided into three parts. The first part is a five-year, historical, observational study about Pseudo-nitzschia dynamics in the GOM from 2012 to 2016 (published in Harmful Algae, Clark et al., 2019). It explores factors driving Pseudo-nitzschia species composition and DA-producing Pseudo-nitzschia blooms, and is focused on the event scale and nearshore processes in the eastern GOM. The second part expands upon the temporal and spatial range of the first to include the entire GOM, the Scotian Shelf, and all eight years from 2012 to 2019 (submitted to Continental Shelf Research, 2021). Through data and modeling, Pseudo-nitzschia introduction to the GOM and hydrodynamics driving Pseudo-nitzschia transport are investigated. The third part uses climate modeling spanning 50 years (25 in the hindcast and 25 in the forecast) to consider the effects of processes farther upstream than the Scotian Shelf. Potential effects of climate change on Pseudo-nitzschia dynamics in the GOM are explored. 
This page intentionally left blank. 


\section{Pseudo-nitzschia Bloom Dynamics in the Gulf of Maine: 2012-2016}

\subsection{Introduction}

Domoic acid (DA) first came to international attention in 1987, when hundreds of people were poisoned and three people died after eating contaminated shellfish harvested on Prince Edward Island, Canada. The diatom Nitzschia pungens was identified as the culprit (Bates et al., 1989). Since then, Nitzschia pungens has been re-classified as Pseudonitzschia multiseries, 52 more Pseudo-nitzschia species have been identified, and 26 species have been shown to produce DA (Bates et al., 2018). Pseudo-nitzschia are typically lightlysilicified, cosmopolitan diatoms (Hasle, 2002) that have been found along the coastlines of every continent in the world (Trainer et al., 2012) and can tolerate a broad range of environmental conditions. Some species, such as P. seriata, can grow in temperatures from $4^{\circ} \mathrm{C}$ (Hansen et al., 2011) to $15^{\circ} \mathrm{C}$ (Fehling et al., 2004b), and others, such as P. multiseries, can grow in salinities from 20 to 40 (Doucette et al., 2008; Thessen and Stoecker, 2008).

Toxic Pseudo-nitzschia blooms are traditionally associated with upwelling regions, but the genus has also been observed in oligotrophic gyres (Guannel et al., 2015), bays (Thorel et al., 2017) and shelf seas (Bresnan et al., 2015). Regime shifts in Pseudo-nitzschia absolute and relative abundance have been connected to changes in nutrient ratios (Lundholm et al., 2010; Parsons et al., 2002), remote physical forcing (Sekula-Wood et al., 2011), and temperature (Lundholm et al., 2010). In recent years, globally and regionally recordbreaking blooms (in terms of DA concentrations and the extent of shellfishery closures) have occurred (McCabe et al., 2016; Bates et al., 2018). In the Gulf of Maine (GOM), 14 unique species of Pseudo-nitzschia had been identified as of 2014 (Fernandes et al., 2014) and in 2016 an unprecedented bloom of $P$. australis led to the first regional observations of shellfish DA concentrations exceeding the regulatory limit of $20 \mu \mathrm{g} \mathrm{DA} \mathrm{g}^{-1}$ shellfish 
tissue (Bates et al., 2018). Beginning in mid-September, DA in shellfish tissue in the Bay of Fundy exceeded $18 \mu \mathrm{g} \mathrm{DA} \mathrm{g}^{-1}$ shellfish tissue and it remained elevated through the end of the month (Canadian Food Inspection Agency, 2016). Along the coast of Maine, clam and mussel harvesting was suspended sequentially from the northeast to the southwest, beginning with Cobscook Bay at the Canadian border on September 27, continuing to Mount Desert Island by September 30, and eventually growing to include Penobscot Bay by the first week of October (refer to Figure 2-1 for location references) (Rappaport, 2016).

Threats to economic and human health, along with Pseudo-nitzschia's apparent growing presence, have motivated studies about the factors - biogeochemical, ecological, and physical - controlling Pseudo-nitzschia blooms. Studies on Pseudo-nitzschia growth have argued that, because Pseudo-nitzschia are often lightly silicified relative to other diatoms, they are most competitive in waters with low silicate-(or silicic acid)-to-nitrate ratios (Marchetti et al., 2004; Parsons et al., 2002), in that they thrive when there is sufficient nitrogen to support protein synthesis, but too little silicic acid for other diatom species. Other studies have connected species-specific growth rates to specific temperatures (Santiago-Morales and García-Mendoza, 2011) or salinities (Doucette et al., 2008). Pseudo-nitzschia have been linked to hydrodynamic features, such as the Juan de Fuca Eddy, which acts as an incubation site for Pseudo-nitzschia blooms (Trainer et al., 2002). In the Santa Barbara Channel, convergent eddies were found to aggregate pre-existing, low density blooms until their densities increased from $5^{*} 10^{5}$ to more than $2^{*} 10^{6}$ cells $\mathrm{L}^{-1}$ (Anderson et al., 2006). Bloom development and transport has also been connected to wind direction and upwelling conditions in Washington (MacFadyen et al., 2005), California (Schnetzer et al., 2013), Portugal (Palma et al., 2010), and Ireland (Cusack et al., 2015).

Cell growth is not the only factor controlling DA concentrations in a Pseudo-nitzschia bloom: inter- and intraspecific variation in DA production depends on environmental 
conditions. DA production has been connected to iron limitation, low silicic acid concentrations, increased $\mathrm{pH}$, increased salinity, the presence of predators, light availability, and sometimes even multiple, compounding factors (as reviewed in Bates et al., 2018; Trainer et al., 2012). In addition, laboratory studies do not always translate to the field, where multiple factors change simultaneously and pathways towards DA production are complex. Several field studies have concluded that Pseudo-nitzschia DA production in the field cannot be attributed to one single environmental parameter (Smith et al., 2017; Trainer et al., 2009a).

Pseudo-nitzschia in the GOM have not been extensively studied, but their growing presence and particularly the DA event in 2016 motivate the need to understand the dynamics of the genus in this region. DA poses a threat both to the economy and to human health. However, because of the disconnect between laboratory results and field observations, the varied theories about DA production, and the range of possible Pseudonitzschia growth conditions in the field, it is challenging to draw conclusions on Pseudonitzschia or DA dynamics based entirely on information from the literature.

This study explores the biogeography of Pseudo-nitzschia species in the GOM from 2012-2016. Environmental factors controlling species composition and toxic Pseudonitzschia blooms are explored through descriptive and statistical analysis of genetic species, nutrient, and hydrodynamic data. The effects of environmental factors and species composition on DA are analyzed. Special attention is given to explaining the 2016 bloom and exploring factors that led to the highest pDA concentrations ever recorded in the GOM. 


\subsection{Methods}

\subsubsection{Study Site}

The GOM is a coastal sea on the North American East Coast that stretches from Cape Cod, Massachusetts at $42^{\circ} \mathrm{N}$ to the Bay of Fundy at $44.5^{\circ} \mathrm{N}$ (Figure 2-1A). Mean sea surface temperature ranges from $\sim 6^{\circ} \mathrm{C}$ in February to $\sim 22.5^{\circ} \mathrm{C}$ in August, and salinity ranges from 29 to 33.5 ( $\mathrm{Li}$ and He, 2014). The five largest rivers that feed into the GOM are, in order of decreasing volume flux, the St. John River, Penobscot River, Kennebec River, Androscoggin River, and Merrimack River (Li et al., 2014). Because of resonance of the M2 tide, the GOM is home to some of the largest tidal amplitudes in the world: tidal amplitudes at the northern end of the Bay of Fundy can reach $6 \mathrm{~m}$ (Lynch and Naimie, 1993). This tidal energy can fully mix the water column in the Northeastern Gulf, Bay of Fundy, Eastern Maine Coastal Current, and on the crest of Georges Bank, providing an important mechanism to transport nutrients to the surface (Townsend et al., 2014).

The GOM is comprised of three deep basins, Jordan Basin, Georges Basin, and Wilkinson Basin, which are each deeper than $200 \mathrm{~m}$. Exchange between the GOM and the Atlantic shelf sea is restricted by the shallow $(<100 \mathrm{~m})$ Browns Bank and Georges Bank. Inflows occur via slope water from the North Atlantic entering through the Northeast Channel or Scotian Shelf Water flowing around the tip of Nova Scotia towards the Bay of Fundy, and outflows occur through both the South Channel and the Northeast Channel (Xue et al., 2000). The general circulation in the GOM is cyclonic, with anti-cyclonic flow around Georges Bank.

Alongshore transport in the GOM is driven by the coastal-trapped river plume and the Gulf of Maine Coastal Current (GMCC) (Bisagni et al., 1996; Pettigrew et al., 2005). The pressure-gradient-driven GMCC connects the eastern GOM to the western GOM, and has 
been shown to be important to A. catenella bloom dynamics (Keafer et al., 2005; Li et al., 2009), but the strength of the connection varies interannually (Pettigrew et al., 2005). As shown by McGillicuddy et al. (2011), several hydrodynamic processes, including upwelling winds, stratification, and alongshore transport, influence HAB dynamics in the GOM; anomalies in one process, in addition to biological factors, could create conditions for an extremely large bloom, or none at all.

\subsubsection{Biological Data - Ship Surveys}

Shipboard surveys were conducted on the $R / V$ Tioga on August $4^{\text {th }}-5^{\text {th }} 2012$, July $25^{\text {th }}-27^{\text {th }} 2014$, and August $2^{\text {nd }}-5^{\text {th }} 2015$, and on the $R / V$ Gulf Challenger on October $5^{\text {th }}-7^{\text {th }} 2016$. Sample stations were arranged in offshore transects centered on Mount Desert Island, Maine, and extended up to $60 \mathrm{~km}$ offshore (Figure 2-1B). The number and locations of sample stations varied depending on weather and in response to Pseudo-nitzschia bloom locations: 25 stations were sampled in 2012, 36 in 2014, 40 in 2015, and 21 in 2016. At each station, discrete water samples were collected with Niskin bottles at 1, 10, 20, 30, 40 and 50+ m (site depending). Casts with a CTD Sea-Bird 9 recorded temperature $\left({ }^{\circ} \mathrm{C}\right)$, salinity, conductivity (siemens $\left.\mathrm{m}^{-1}\right)$, transmissivity $\left(1 \mathrm{~m}^{-1}\right)$, turbidity (NTU), dissolved oxygen $\left(\mathrm{ml} \mathrm{L}^{-1}\right)$, and pressure (dbar).

\subsubsection{Pseudo-nitzschia Data}

Cell Counts. For cruise samples, $125 \mathrm{~mL}$ whole seawater samples from 1, 10, and $20 \mathrm{~m}$ were preserved with Lugol's fixative. A 3-mL aliquot was added to a 5-mL Nunc Lab-Tek 2-chamber counting chamber (ThermoFisher) and Pseudo-nitzschia cells were enumerated with a Zeiss Axiovert inverted light microscope at 200-400x magnification and categorized into two size categories, small $(<3 \mu \mathrm{m}$ in width) and large ( $>3 \mu \mathrm{m}$ in width), and two orientations, chain or single-celled. In 2016, an intermediate size category ( $\sim 3 \mu \mathrm{m}$ in width) was added. The limit of detection (LOD) for cell counts by light microscopy was 
333 cells $\mathrm{L}^{-1}$. Absolute cell abundance was recorded as the total of all sizes and cell orientations.

\section{Relative Species Abundance}

Water samples were also analyzed for species composition via Automated Ribosomal Intergenic Spacer Analysis (ARISA) (Hubbard et al., 2014). After filtration of $125 \mathrm{~mL}$ of seawater onto $0.45 \mu \mathrm{m}$ pore size nitrocellulose filters (Millipore), filters were frozen shipboard with liquid nitrogen and stored at $-80^{\circ} \mathrm{C}$ until extraction. DNA was extracted with a DNeasy Plant Mini Kit (Qiagen Inc.), amplified via polymerase chain reaction (PCR) with the Pseudo-nitzschia-specific ITS1 primer set PnALL F/R, and purified using MultiScreen PCR 96 filter plates (Millipore) as described in Hubbard et al., 2014. For ARISA, PCR products were standardized and 1 ng DNA was analyzed on an ABI 3730 XL. Electropherograms were analyzed using DAx software (Van Mierlo Software Consultancy, Eindhoven, Netherlands) to characterize amplicon sizes (for species association) and relative peak heights (for quantitative assessments) according to Hubbard et al., (2014). Amplicon sizes characterized by ARISA were identified by comparing results with the GenBank nucleotide (nr/nt) database and regional studies (summarized in and including Fernandes et al., (2014)). For the 2016 event, P. australis was identified using ITS1 sequencing (targeting the ARISA amplicon) of DNA from live chains (placed in $5 \mu \mathrm{L}$ DNA-free water and subjected to three freeze-thaw cycles) and extracts used for ARISA (see Smith et al. (2017)). P. australis identification was confirmed with scanning electron microscopy conducted on Lugol's preserved material (Bates et al., 2018).

\subsubsection{Particulate Domoic Acid}

For pDA analysis, $125-250 \mathrm{~mL}$ of seawater were filtered through a $0.45 \mu \mathrm{m}$ pore size nitrocellulose filter and frozen at $-20^{\circ} \mathrm{C}$ until analysis. Prior to analysis, extracts were

filtered through $0.22 \mu \mathrm{m}$ PVDF syringe filters. Extracts were analyzed using an Acquity UPLC system coupled to a Quattro Micro $^{T M}$ API triple quadrupole mass spectrometer 
operated in positive ionization mode (ESI + ) according to a method adapted from Wang et al., (2007). Separations were performed on an Acquity UPLC BEH C18 $1.7 \mu \mathrm{m}$ column $(2.1 \times 50 \mathrm{~mm})$. Mobile phase consisted of Nanopure water (A) and acetonitrile (B) in a binary system with $0.1 \%$ formic acid as an additive. The detection of DA was achieved by multiple reaction monitoring (MRM) using optimized instrument parameters. MRM transitions from the protonated DA ion were monitored for the following transitions: $\mathrm{m} / \mathrm{z} 312>248, \mathrm{~m} / \mathrm{z} 312>266$ and $\mathrm{m} / \mathrm{z} 312>193$. The transition $\mathrm{m} / \mathrm{z} 312>266$ was used for quantitation. A certified reference solution of domoic acid purchased from the National Research Council, Halifax, Canada was used to generate a 9-point standard curve from $0.78-200 \mathrm{ng} \mathrm{DA} \mathrm{mL}^{-1}$. The limit of detection was defined as the level yielding a signal to noise ratio of 3 . The limit of quantitation was defined as the lowest concentration on the standard curve $\left(0.78 \mathrm{ng} \mathrm{DA} \mathrm{mL}^{-1}\right)$ or the concentration that yielded a signal to noise ratio of 10 if that was greater than $0.78 \mathrm{ng} \mathrm{DA} \mathrm{mL}-1$.

\subsubsection{Biological Data - Mt. Desert Island Time Series}

From 2013 to 2016, weekly water samples were collected from Mt. Desert Island Biological Laboratory (MDIBL) and Bar Harbor on Mt. Desert Island, Maine as part of the Maine Department of Marine Resources' volunteer phytoplankton monitoring program. Ten-liter water samples were concentrated to $15 \mathrm{~mL}$ using a $15 \mu \mathrm{m}$ sieve, which may not have captured all (especially smaller) Pseudo-nitzschia cells. For cell counts via light microscopy, a $1 \mathrm{~mL}$ sample was added to a gridded Sedgewick Rafter slide, and cells $\mathrm{L}^{-1}$ were enumerated either by counting all cells or by estimating based on the grid number at which 500 cells were enumerated; cells were categorized as either "large" ( $>3 \mu \mathrm{m}$ in width) or "small" ( $<3 \mu \mathrm{m}$ in width). Species composition at Bar Harbor in 2013 was evaluated by ARISA (Section 2.2.2.1) and pDA was measured from whole seawater by LC-MS/MS (Section 2.2.3). Water temperature, salinity, and dissolved oxygen were measured with a handheld YSI (YSI Instruments, Yellow Springs, OH), and dissolved 
nutrient concentrations were measured from whole seawater samples according to the methods in Section 2.2.5.

\subsubsection{Physicochemical Data}

\section{Nutrients.}

Ship survey water samples from 1, 10, and $20 \mathrm{~m}$ and Mt. Desert Island surface samples were analyzed for nitrate+nitrite $\left(\mathrm{NO}_{\mathrm{x}}{ }^{-}\right)$, ammonium $\left(\mathrm{NH}_{4}{ }^{+}\right)$silicic acid $\left(\mathrm{Si}(\mathrm{OH})_{4}\right)$, and phosphate $\left(\mathrm{PO}_{4}{ }^{3-}\right)$. Samples were filtered through a $0.22 \mu \mathrm{m}$ acetate luer-lock syringe filter and frozen at $-20^{\circ} \mathrm{C}$ until analysis. Dissolved $\mathrm{NO}^{-}$, phosphate, and silicic acid concentrations were measured with a QuickChem 8500 Flow Injection Analysis system, and dissolved ammonium concentrations were measured on a TD-700 fluorometer.

Oceanographic, Atmospheric, and Riverine Measurements.

Buoys from the Northeastern Regional Association of Coastal Ocean Observing Systems (NERACOOS) have recorded temperature, salinity, conductivity, potential temperature, air temperature, air pressure, and wind speed at hourly intervals since 2001 (Morrison, 2019) (Figure 2-1B). Instruments were positioned at 1, 20, and $50+\mathrm{m}$ below the surface (site-depending), allowing for characterization of the vertical structure of the water column at high temporal resolution. Salinity and temperature data from buoys N, M, and I from 2001-2016 were used to characterize water mass characteristics and climatology. Wind speed and direction from station I were used to calculate the upwelling index from 2001 to 2016.

An upwelling index (UI) was calculated according to Schwing et al. (1996): $U I=\frac{\tau_{x}}{\rho f}$, where $\tau_{x}$ is the alongshore component of the wind stress as defined by Large and Pond (1981), $\rho$ is the surface water density in $\mathrm{kg} \mathrm{m}^{-3}$, and $f$ is the Coriolis parameter. According to this convention, a positive UI indicates upwelling, while a negative UI indicates downwelling. 
Cumulative UI (CUI) was calculated by integrating UI over time from April through December in each year from 2001 to 2016.

The U.S. Geological Survey (USGS, 2013) and Canadian Water Office (Canada, 2018) report daily mean river discharge $\left(\mathrm{m}^{3} \mathrm{~s}^{-1}\right)$ for the St. John, Penobscot, Kennebec, Androscoggin, and Merrimack rivers. Cumulative river discharge was calculated in 2012-2016 by integrating daily discharge in $\mathrm{m}^{3} \mathrm{~s}^{-1}$ over time to calculate $\mathrm{m}^{3}$.

Data used for this study are summarized in Table 2-1.
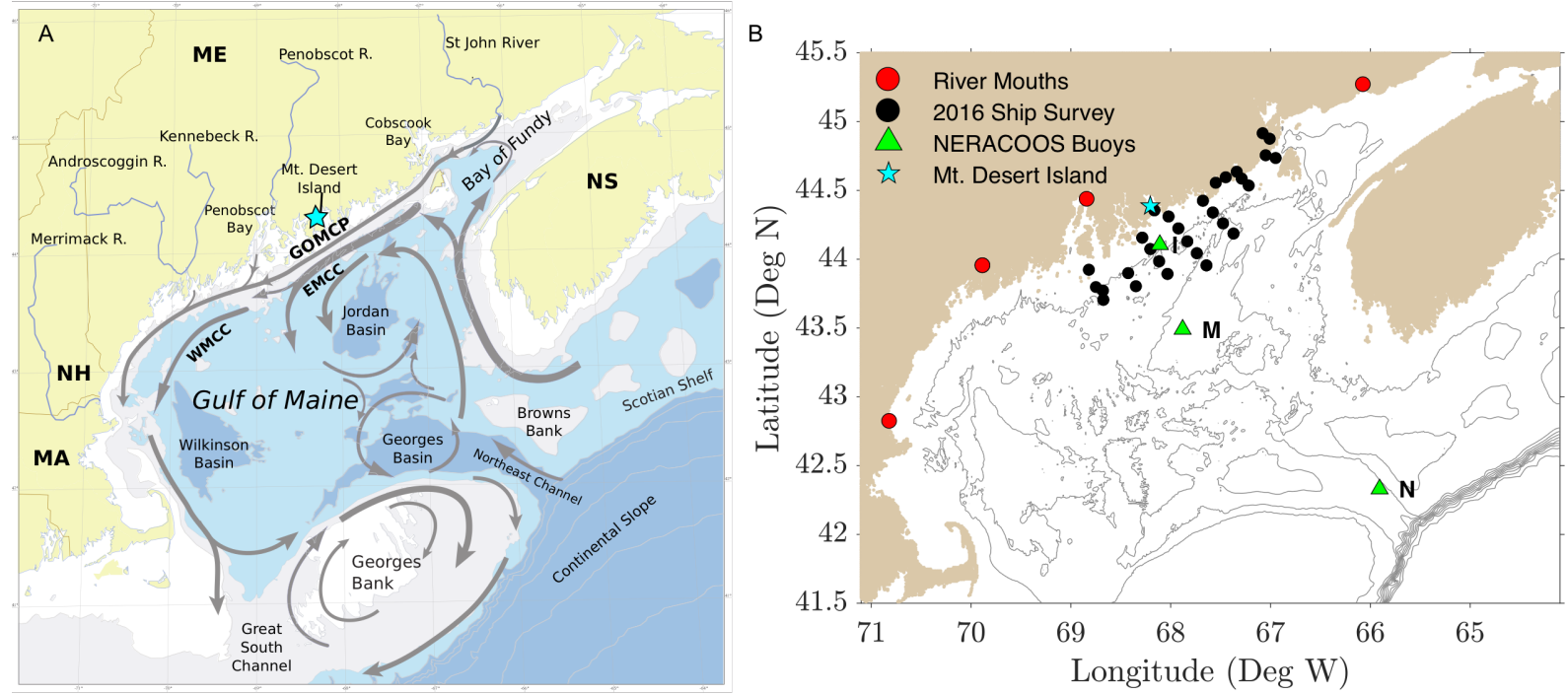

Figure 2-1 - (A) Climatological circulation of the GOM as described in Pettigrew et al., (2005) and adapted in Anderson et al., (2005)². (B) Locations of hydrographic instruments and the 2016 Pseudo-nitzschia ship survey in the GOM. "Mt Desert Island" is shown, where both MDIBL and Bar Harbor are located.

2 This figure was published in Deep-Sea Research II, Vol 52, Anderson, Donald M., Keafer, Bruce A., McGillicuddy, Dennis J., Mickelson, Michael J., Keay, Kenneth E., Libby, P. Scott, Manning, James P., Mayo, Charles A., Whittaker, David K., Hickey, J. Michael, He, Ruoying, Lynch, Daniel R., Smith, Keston W. "Initial observations of the 2005 Alexandrium fundyense bloom in southern New England: General patterns and mechanisms." p. 2858, Copyright Elsevier (2005) 
Table 2-1 - Summary of physical and biological time series and survey data.

$M D I B L=M t$. Desert Island Biological Laboratory; $\mathrm{NO}_{x}^{-}=$nitrate + nitrite; $\mathrm{NH}_{4}^{+}=$ammonium; $\mathrm{Si}(\mathrm{OH})_{4}=$ silicic acid; $\mathrm{PO}_{4}^{3-}=$ phosphate

\begin{tabular}{|c|c|c|}
\hline Data Source & Sample Dates & Parameters \\
\hline Survey Cruises & $\begin{array}{l}\text { Aug 2012, } \\
\text { Jul 2014, } \\
\text { Aug 2015, } \\
\text { Oct 2016 }\end{array}$ & $\begin{array}{l}\text { Temperature, Salinity, } \\
\mathrm{NO}_{\mathbf{x}}^{-}, \mathrm{NH}_{4}^{+}, \mathrm{Si}(\mathrm{OH})_{4}, \mathrm{PO}_{4}^{3-}, \\
\text { Pseudo-nitzschia cell counts, } \\
\text { Species Relative Abundance }\end{array}$ \\
\hline $\begin{array}{l}\text { MDIBL } \\
\text { time series }\end{array}$ & $\begin{array}{l}\text { Jul-Nov 2013, } \\
\text { Jun-Oct 2014, } \\
\text { Feb-Sep 2015, } \\
\text { Jun-Oct 2016 }\end{array}$ & $\begin{array}{l}\text { All years: Pseudo-nitzschia cell counts } \\
2013 \text { only: Temperature, Salinity, } \\
\mathrm{NO}_{\mathbf{x}}^{-}, \mathrm{NH}_{4}^{+}, \mathrm{Si}(\mathrm{OH})_{4}, \mathrm{PO}_{4}^{3-} \\
\text { Species Relative Abundance }\end{array}$ \\
\hline $\begin{array}{l}\text { NERAOCOS } \\
\text { moorings }\end{array}$ & $\begin{array}{l}\text { Continuous } \\
2002-2017\end{array}$ & $\begin{array}{c}\text { Temperature, Salinity, } \\
\text { Air temperature, Air Pressure, } \\
\text { Wind Speed }\end{array}$ \\
\hline River Gauges & Varied & Daily discharge \\
\hline
\end{tabular}

\subsubsection{Descriptive and Statistical Analyses}

Cell concentrations and species relative abundance were plotted at their sample locations to explore spatial variability. Each analysis described below was conducted on absolute cell abundance (cells $\mathrm{L}^{-1}$ ), relative species abundance, chlorophyll, pDA, temperature, salinity, and dissolved nutrient concentrations. Relative nutrient concentrations were also analyzed including the silicic acid-to-total nitrogen ratio $\left(\mathrm{Si}(\mathrm{OH})_{4}:\left(\mathrm{NO}_{\mathrm{x}}{ }^{-}+\mathrm{NH}_{4}{ }^{+}\right)\right.$or simply Si:N), silicic acid-to-phosphorous ratio $\left(\mathrm{Si}(\mathrm{OH})_{4}: \mathrm{PO}_{4}{ }^{3-}\right.$ or $\left.\mathrm{Si}: \mathrm{P}\right)$, total nitrogen-tophosphorous ratio $\left(\left(\mathrm{NO}_{\mathrm{x}}{ }^{-}+\mathrm{NH}_{4}{ }^{+}\right): \mathrm{PO}_{4}{ }^{3-}\right.$ or simply $\left.\mathrm{N}: \mathrm{P}\right)$, and residual silicic acid $\left(\mathrm{Si}^{*}=\left[\mathrm{Si}(\mathrm{OH})_{4}\right]-\left[\mathrm{NO}_{x}^{-}\right]\right)$. Each year was analyzed individually, with all depths combined, except where indicated otherwise. For all statistical tests, correlations with a p-value $<0.05$ were considered significant.

ARISA data were used in conjunction with pDA concentrations to estimate cellular DA (DA cell-1 or cDA), which varies widely among Pseudo-nitzschia species and is thus 
challenging to estimate from field data. Therefore, samples dominated by one species (relative abundance $>85 \%$ ) were selected, with exceptions made for samples as low as $70 \%$ relative abundance of the dominant species, as long as the other species were not associated with pDA in the dataset. Such allowances increased the number of samples to improve statistical robustness. If a sample had $>85 \%$ relative abundance from the dominant species, but $P$. australis was also detected by ARISA, then that sample was discarded because $P$. australis is known to produce pDA. PDA $\left(\mu \mathrm{g} \mathrm{L}^{-1}\right)$ was divided by the total cell concentration (cells $\left.\mathrm{L}^{-1}\right)$ to find an estimate of $\mathrm{cDA}\left(\mathrm{pg}\right.$ cell $\left.^{-1}\right)$. The cDA calculation accounted for the relative abundance of the dominant species by dividing by its fraction of the sample:

$$
\frac{D A}{\text { cell }}=\frac{p D A(\text { Water Volume })^{-1}}{(\text { relativeabundance }) *\left(\text { cells }(\text { Water Volume })^{-1}\right)}
$$

Correcting by the relative abundance makes the assumption that DNA prevalence is proportional to cell counts, which is not necessarily correct. However, the calculation was also performed without adjusting for relative abundance, and the results varied little. The calculation was also performed with a lower minimum cutoff for relative abundance of the dominant species of $60 \%$, and the main results did not change (Appendix A, Table 6-2).

Several statistical analyses were employed to quantify the relationships observed in the descriptive analysis. Linear least squares regression was used to explore correlations between species relative abundance, cell abundance, $\mathrm{pDA}$ and environmental parameters. Each species was tested against the environmental factors listed at the beginning of this section. Regression analysis was run for the cruise data and time series data, with each year individually, with all years combined, with all samples, and with only samples where $\mathrm{pDA}>\mathrm{LOQ}$.

Principal Component Analysis (PCA) was used to quantify variability in environmental factors and species relative abundance in the cruise data. Canonical Correspondence 
Analysis (CCA) was used to quantify correlations between environmental factors and community species composition in the cruise data. PCA and CCA were performed both on each year individually and on all years combined.

Lastly, the Wilcoxon signed rank test was used to test whether the measured environmental factors were statistically significantly different between years. This test was chosen because it does not assume normal sample distribution. Cruise data from 2016 were compared with other cruise data (2012, 2014, and 2015). Samples with pDA>LOQ were used, as the goal was to determine the effect of different environmental factors on DA concentrations when toxic species were already present.

\subsection{Results}

\subsubsection{Biogeography prior to 2016}

\subsubsection{Temporal Variability}

Pseudo-nitzschia dynamics in the GOM exhibited interannual and seasonal variability in bloom timing, cell abundance, and relative species abundance (Figure 2-2 and Figure 2-3). Notable patterns are summarized below.

\section{Interannual Variability}

Maximum cell abundance was 75,000 cells L ${ }^{-1}$ in 2012, 190,000 cells L ${ }^{-1}$ in 2013, 65,000 cells L $\mathrm{L}^{-1}$ in 2014, and 180,000 cells L $\mathrm{L}^{-1}$ in 2015. Ten Pseudo-nitzschia species were present in the GOM from 2012 to 2015, based on ARISA and sequencing data: P. pungens, P. plurisecta, P. seriata, and P. delicatissima were consistent members of the community, with varying degrees of relative abundance, while $P$. multiseries, $P$. heimii/americana, P. fraudulenta, P. cuspidata, P. caciantha, and P. obtusa were detected only in some years (Table 2-2). Before 2016, GOM interannual variability was characterized by shifts in dominance between four species, but not complete shifts in species assemblage. In 
addition, while some samples were dominated by one species, in none of the years prior to 2016 was a single species dominant in all samples for that year.

Table 2-2 - Presence/Absence of Pseudo-nitzschia species 2012-2016. An ' $X$ ' indicates that in at least one sample the ARISA measured $>0$ relative abundance for that species in that year.

\begin{tabular}{|c|c|c|c|c|c|c|c|c|c|c|}
\hline & 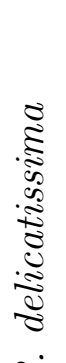 & 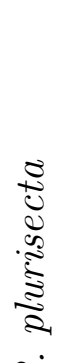 & 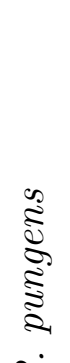 & 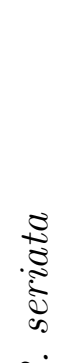 & 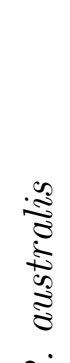 & 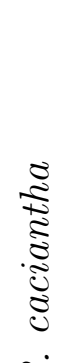 & 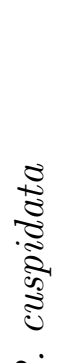 & 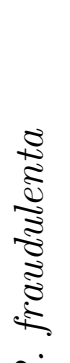 & 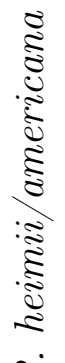 & 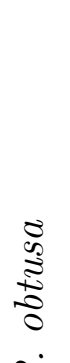 \\
\hline & $2 i$ & $R_{i}$ & $R_{i}$ & $R^{\circ}$ & $R_{i}$ & $R_{i}$ & 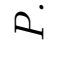 & $R_{i}$ & $R_{i}$ & $R_{i}$ \\
\hline 2012 & $\mathrm{X}$ & $\mathrm{X}$ & $\mathrm{X}$ & $\mathrm{X}$ & & & $\mathrm{X}$ & & $\mathrm{X}$ & $\mathrm{X}$ \\
\hline 2013 & $\mathrm{X}$ & $\mathrm{X}$ & $\mathrm{X}$ & $\mathrm{X}$ & & & $\mathrm{X}$ & $\mathrm{X}$ & $\mathrm{X}$ & $\mathrm{X}$ \\
\hline 2014 & $\mathrm{X}$ & $\mathrm{X}$ & $\mathrm{X}$ & X & & X & X & & & \\
\hline 2015 & $\mathrm{X}$ & $\mathrm{X}$ & $\mathrm{X}$ & $\mathrm{X}$ & & $\mathrm{X}$ & $\mathrm{X}$ & $\mathrm{X}$ & $\mathrm{X}$ & \\
\hline 2016 & $\mathrm{X}$ & $\mathrm{X}$ & $\mathrm{X}$ & $\mathrm{X}$ & $\mathrm{X}$ & & & $\mathrm{X}$ & $\mathrm{X}$ & \\
\hline
\end{tabular}

Seasonal Progression

Temporal variability also existed in the form of seasonal progression. Based on the monitoring time series from MDIBL, there were two Pseudo-nitzschia cell concentration peaks in 2013 with varying species composition. The first peak of 150,000 cells L ${ }^{-1}$ occurred in late-July/early-August and was comprised largely of P. plurisecta (Figure 2-3). The second peak of 190,000 cells $\mathrm{L}^{-1}$ occurred in mid-September and included mostly P. pungens. 


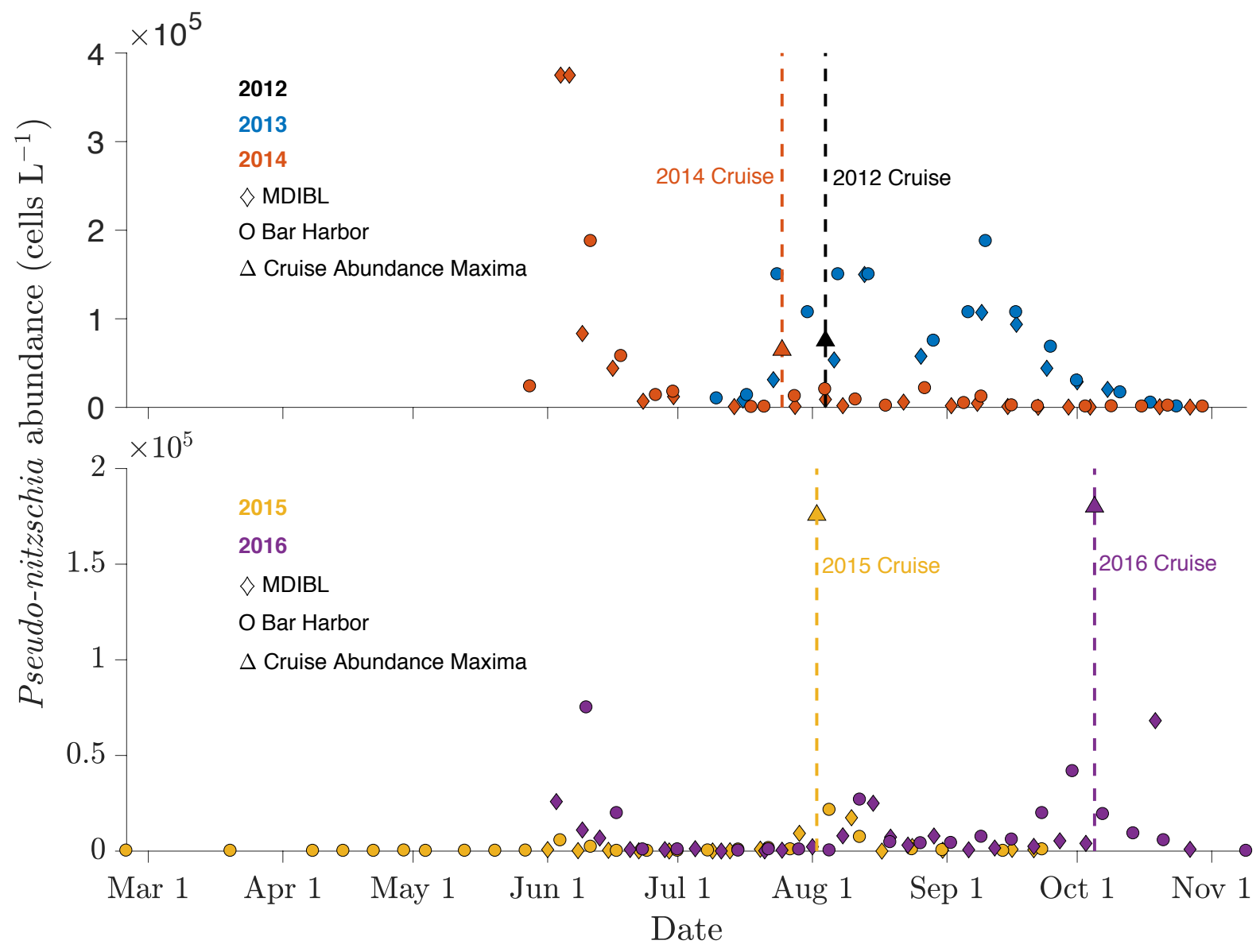

Figure 2-2 - From the MDIBL and Bar Harbor time series data, Pseudo-nitzschia spp. cell concentration versus time in 2013, 2014, 2015, and 2016. Timing of the 2014, 2015, and 2016 cruises are indicated with vertical lines. Maximum total cell abundance from each cruise is plotted as a single point. Note that the $y$ axis scales are different. 


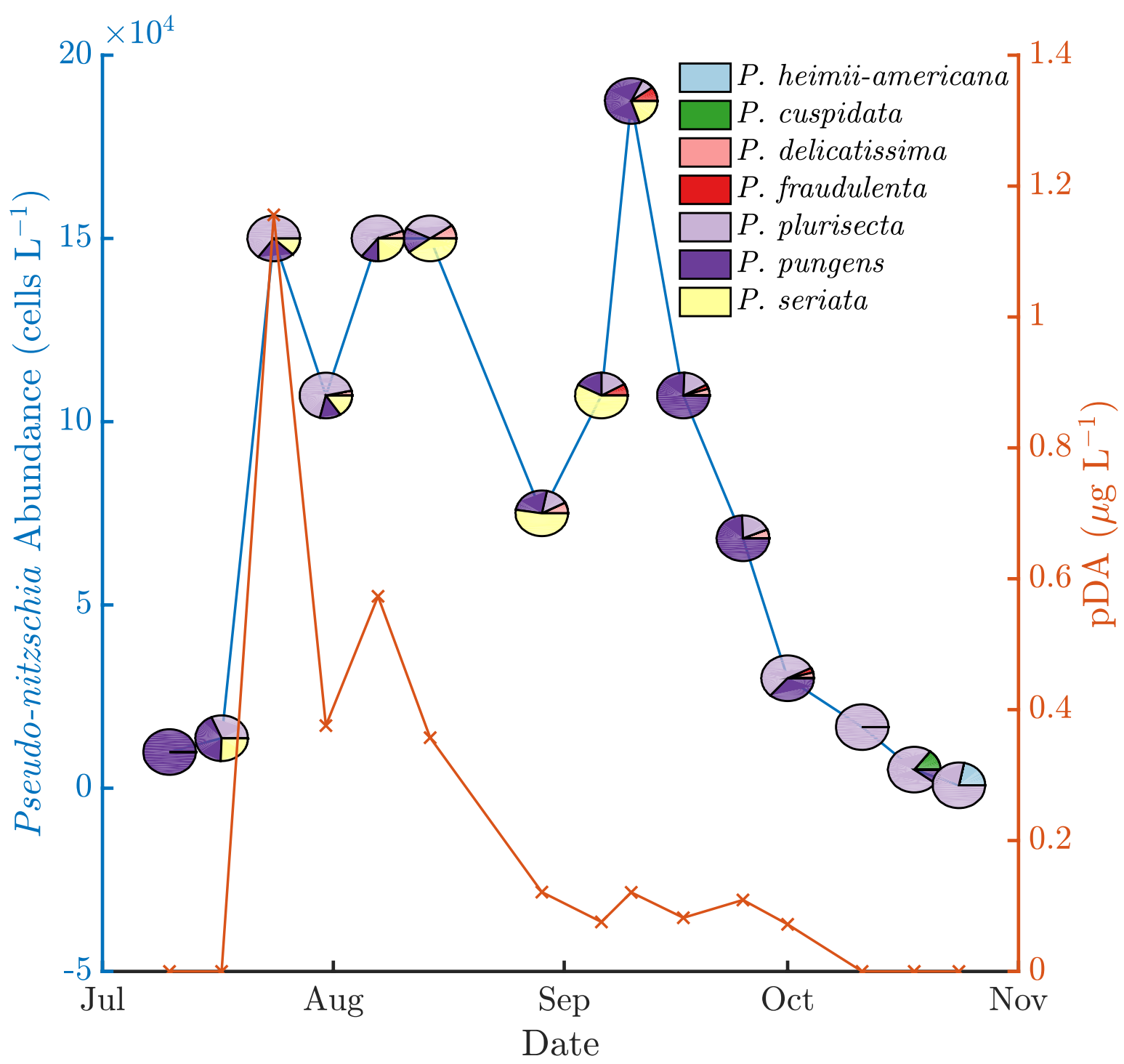

Figure 2-3 - From the Bar Harbor time series, Pseudo-nitzschia cell concentration (left axis; blue line) and $p D A$ (right axis; red Xs) versus time in 2013. Relative species abundance for each sample is indicated with pie charts.

\subsubsection{Spatial Variability}

In addition to temporal variability, spatial variability was observed in the cruise data (Figure 2-4, Figure 2-5, Figure 2-6, and Figure 2-7). Prior to 2016, the greatest cell concentrations were consistently inshore and at the surface. Because the inshore waters also had lower salinity, the samples in 2012 and 2015 could be categorized into two groups: one group at higher salinity and lower cell counts (offshore), and the second group at lower salinities and higher cell counts (inshore). 

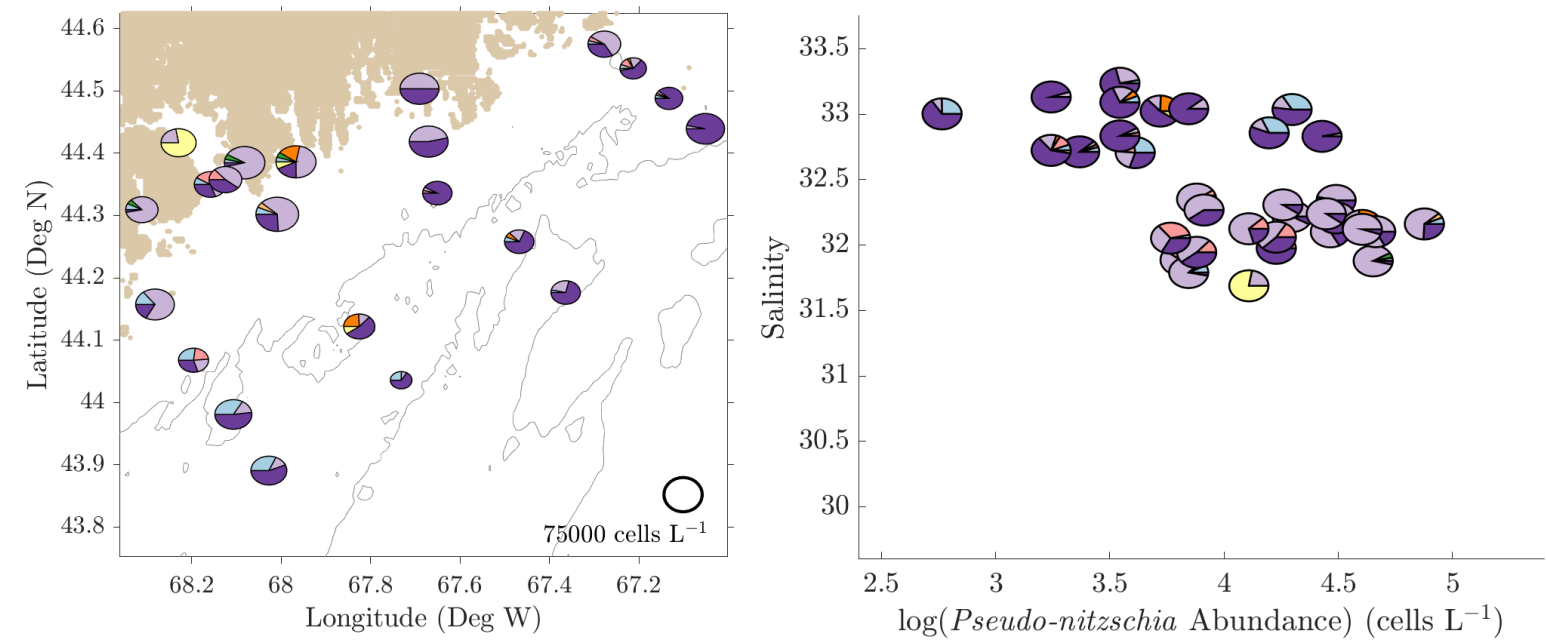

$\square$ P. heimii-americana $\square$ P. caciantha $\square$ P. delicatissima $\square$ P. multiseries $\square$. plurisecta $\square$ P. seriata
$\square$ P. australis $\quad \square$. cuspidata $\square$. fraudulenta $\square$. obtusa $\square$. pungens

Figure 2-4 - (Left) August 2012 species relative abundance of surface samples plotted on the sampling locations in the GOM. Pie chart size was determined by log(cell count) (scale shown at lower right). (Right) 2012 relative species abundance on a salinity vs. cell count diagram, with axes scaled to match Figure 2-5, Figure 2-6, and Figure 2-7.

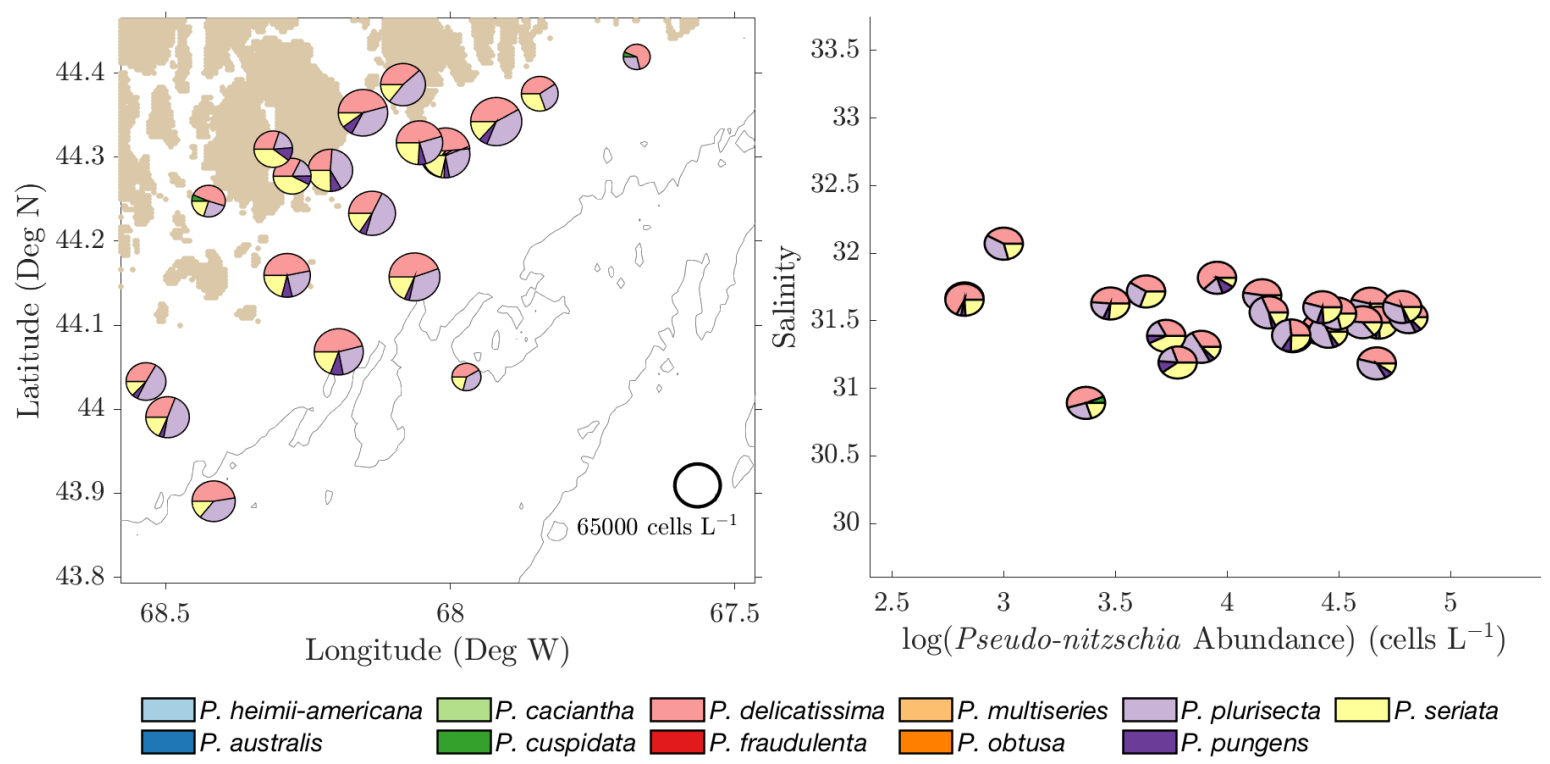

Figure 2-5 - (Left) July 2014 species relative abundance of surface samples plotted on the sampling locations in the GOM. Pie chart size was determined by log(cell count) (scale shown at lower right). (Right) 2014 relative species abundance on a salinity vs. cell count diagram, with axes scaled to match Figure 2-4, Figure 2-6, and Figure 2-7. 

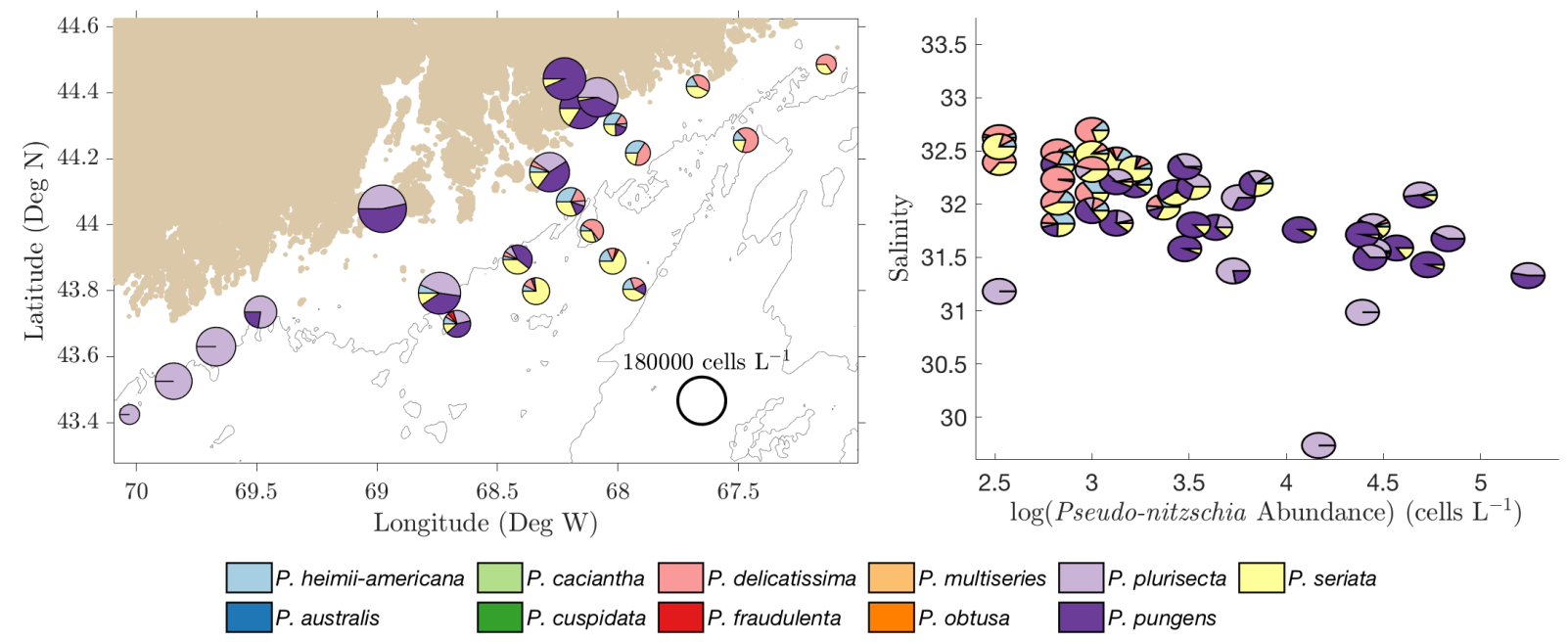

Figure 2-6 - (Left) August 2015 species relative abundance of surface samples plotted on the sampling locations in the GOM. Pie chart size was determined by log(cell count) (scale shown at lower right). (Right) 2015 relative species abundance on a salinity vs. cell count diagram, with axes scaled to match Figure 2-4, Figure 2-5, and Figure 2-7.

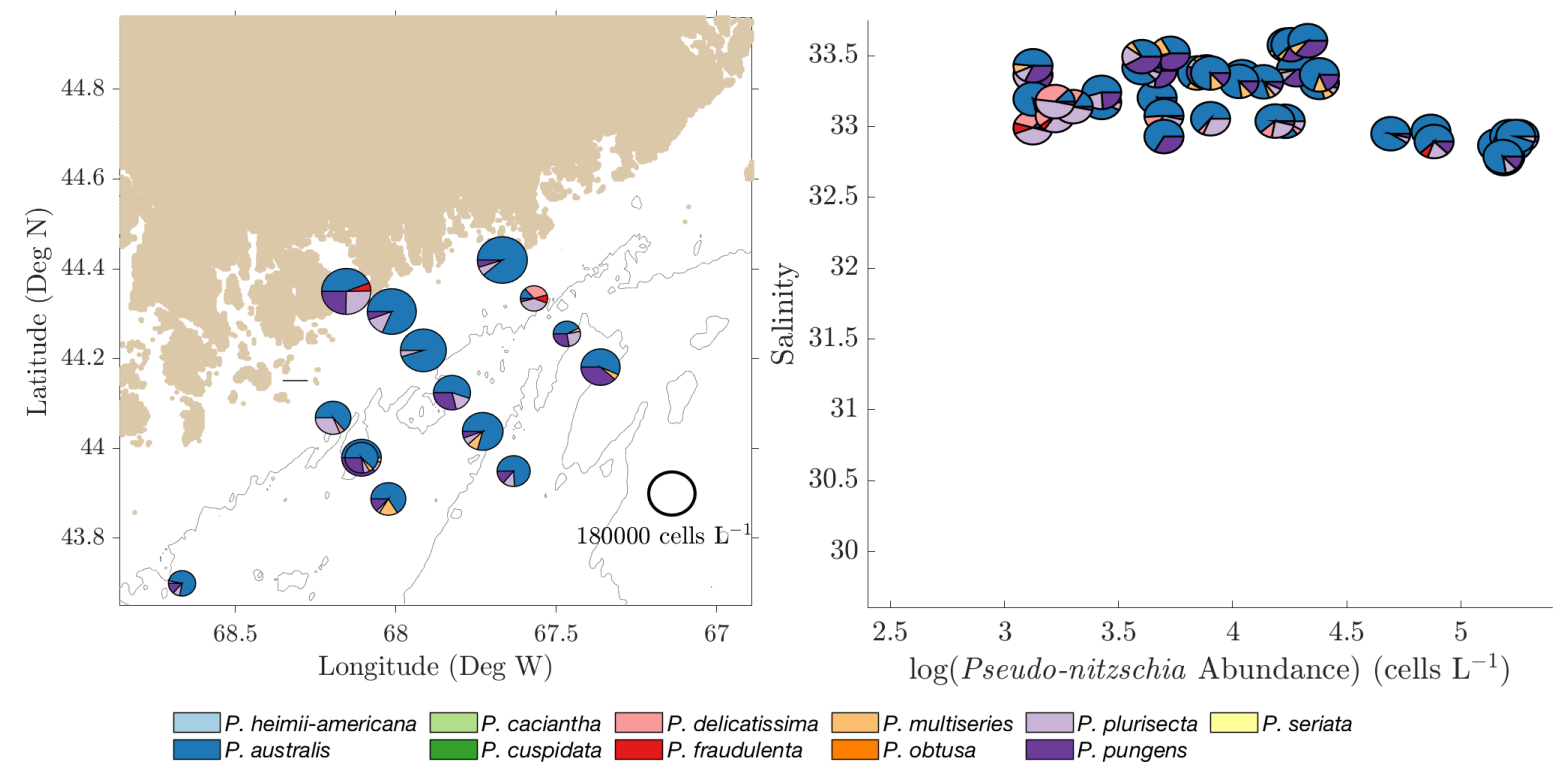

Figure 2-7 - (Left) October 2016 species relative abundance of surface samples plotted on the sampling locations in the GOM. Pie chart size was determined by log(cell count) (scale shown at lower right). (Right) 2016 relative species abundance on a salinity vs. cell count diagram, with axes scaled to match Figure 2-4, Figure 2-5, and Figure 2-6. 
In 2012, inshore salinity ranged from 31.5 to 32.5 while offshore salinity ranged from 32.5 to 33.5 (Figure 2-4). In 2015, inshore salinity ranged from 29 to 32.5, while offshore salinity ranged from 32 to 33 (Figure 2-6). P. plurisecta was consistently found at greater relative abundance in inshore samples, while $P$. seriata and $P$. delicatissima were consistently found in offshore samples (Figure 2-4 and Figure 2-6). P. pungens was found both inshore and offshore.

\subsubsection{6 event}

In 2016, shellfisheries were closed because shellfish DA concentrations exceeded the regulatory limit for the first time in the GOM (Bates et al., 2018). Particulate DA concentrations reached a maximum of $37.5 \mu \mathrm{g} \mathrm{L}-1$ at one site and were on average an order of magnitude larger than pDA measured in previous years (Figure 2-8). Shellfishery closures in the GOM were preceded by shellfishery closures in the Bay of Fundy, where shellfish DA concentrations exceeded $20 \mu \mathrm{g}$ of DA g-1 shellfish tissue at various locations from September 16 to 30 (Canadian Food Inspection Agency, 2016).

The 2016 bloom likely began in September in the Bay of Fundy, and samples containing up to 180,000 Pseudo-nitzschia cells $\mathrm{L}^{-1}$ were collected along the eastern Maine coast during the 2016 cruise from October 5 to October 7. The bloom was accompanied by greater salinity, greater ammonium, and lower $\mathrm{Si}^{*}$, all of which were significantly different from measurements in at least one previous year (Section 2.3.4).

During the 2016 bloom, P. australis was observed at all sample sites and depths (Figure 2-7), and therefore at varying nutrient ratios and the full range of temperatures $\left(12.23-14.20^{\circ} \mathrm{C}\right)$ and salinities $(32.77-33.61)$ recorded that year. The inshore-offshore biogeographic patterns in cell abundance and species composition that were observed in summer 2012 and 2015 (Section 2.3.1) were not present in fall 2016. Cell abundances and 
P. australis relative abundance were relatively uniform across the sample area from inshore to offshore.

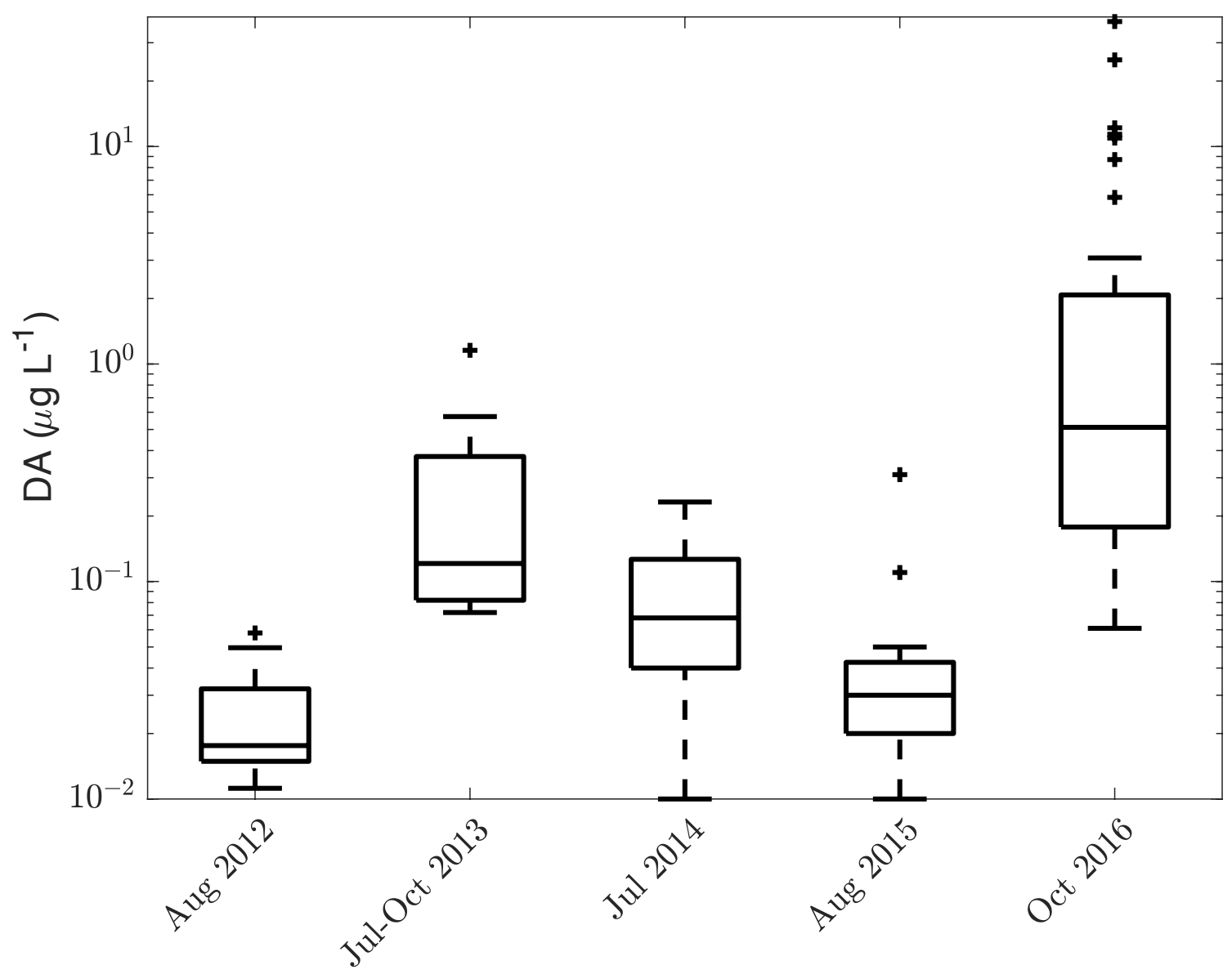

Figure 2-8- Box-and-Whisker plots of particulate DA measured during August 2012, June-October 2013, July 2014, August 2015, and October 2016. Note that the y axis is a log scale. The crosses are outliers, defined as points greater than (less than) Q3(Q1) +(-) 1.5*(Q3-Q1), where Q1 is the first quartile and Q3 is the third quartile.

\subsubsection{Domoic Acid}

DA concentrations varied spatially, seasonally, and interannually, in correlation with cell concentrations and with the relative abundance of known toxic species (Figure 2-9). In 2012, the highest pDA $\left(0.06 \mu \mathrm{g} \mathrm{L} \mathrm{L}^{-1}\right)$ was observed in samples with at least $10^{4}$ cells $\mathrm{L}^{-1}$ and $>50 \%$ P. plurisecta relative abundance. At Mt. Desert Island in 2013, the first peak in cell abundance, which was dominated by P. plurisecta, a known toxic species, coincided with a peak in pDA (Figure 2-3). The second peak, however, which was dominated by 
P. pungens, did not result in elevated DA concentrations. In 2014, relative species proportions were constant, but pDA concentrations increased as absolute cell concentrations increased: the maximum pDA $\left(0.23 \mu \mathrm{g} \mathrm{\textrm {L } ^ { - 1 }}\right)$ co-occurred with a cell concentration of 15,000 cells L ${ }^{-1}$, and most pDA concentrations over $0.1 \mu \mathrm{g} \mathrm{L}-1$ co-occurred with cell concentrations greater than $10^{4}$ cells L-1 ${ }^{-1}$ In 2015 , samples with P. plurisecta had higher $\mathrm{pDA}$ than those with $P$. delicatissima and $P$. seriata, and the greatest $\mathrm{pDA}$ concentration was $0.31 \mu \mathrm{g} \mathrm{L}{ }^{-1}$. In 2016 the greatest pDA concentration was $37.5 \mu \mathrm{g} \mathrm{L} \mathrm{L}^{-1}$, and samples that were nearly completely dominated by $P$. australis had the greatest pDA.

Estimated cDA varied widely in the survey and time series data. From samples dominated by one species, cDA estimates were possible for $P$. australis, P. pungens, P. seriata, P. delicatissima, and P. plurisecta. $\mathrm{PDA}$ was $<\mathrm{LOQ}$ in all samples dominated by P. delicatissima. Cellular DA estimates were $<\mathrm{LOQ}-11.1 \mathrm{pg}$ cell $^{-1}$ for $P$. seriata, 0.6-26.7 pg cell ${ }^{-1}$ for $P$. plurisecta, and $10.2-42.6 \mathrm{pg}^{\text {cell }}{ }^{-1}$ for $P$. australis (more information can be found in Appendix A, Table 6-2). P. pungens cDA estimates were only greater than zero when the analysis was run including samples with relative abundance as low as $60 \%$, and ranged from $<$ LOQ $-0.75 \mathrm{pg}^{\text {cell }}{ }^{-1}$. This approach was validated by previously published estimates for the observed species: $\mathrm{cDA}$ estimates for $P$. pungens and $P$. delicatissima are less than $1 \mathrm{pg}$ cell $^{-1}$, while cDA estimates for P. seriata range from 0.8-33.6 pg cell ${ }^{-1}$ (Trainer et al., 2012). P. plurisecta was previously identified and confirmed to produce DA in the GOM (Fernandes et al., 2014), and P. australis cDA has been shown to reach $>90 \mathrm{pg}^{\text {cell }}{ }^{-1}$ (Ryan et al., 2017). 

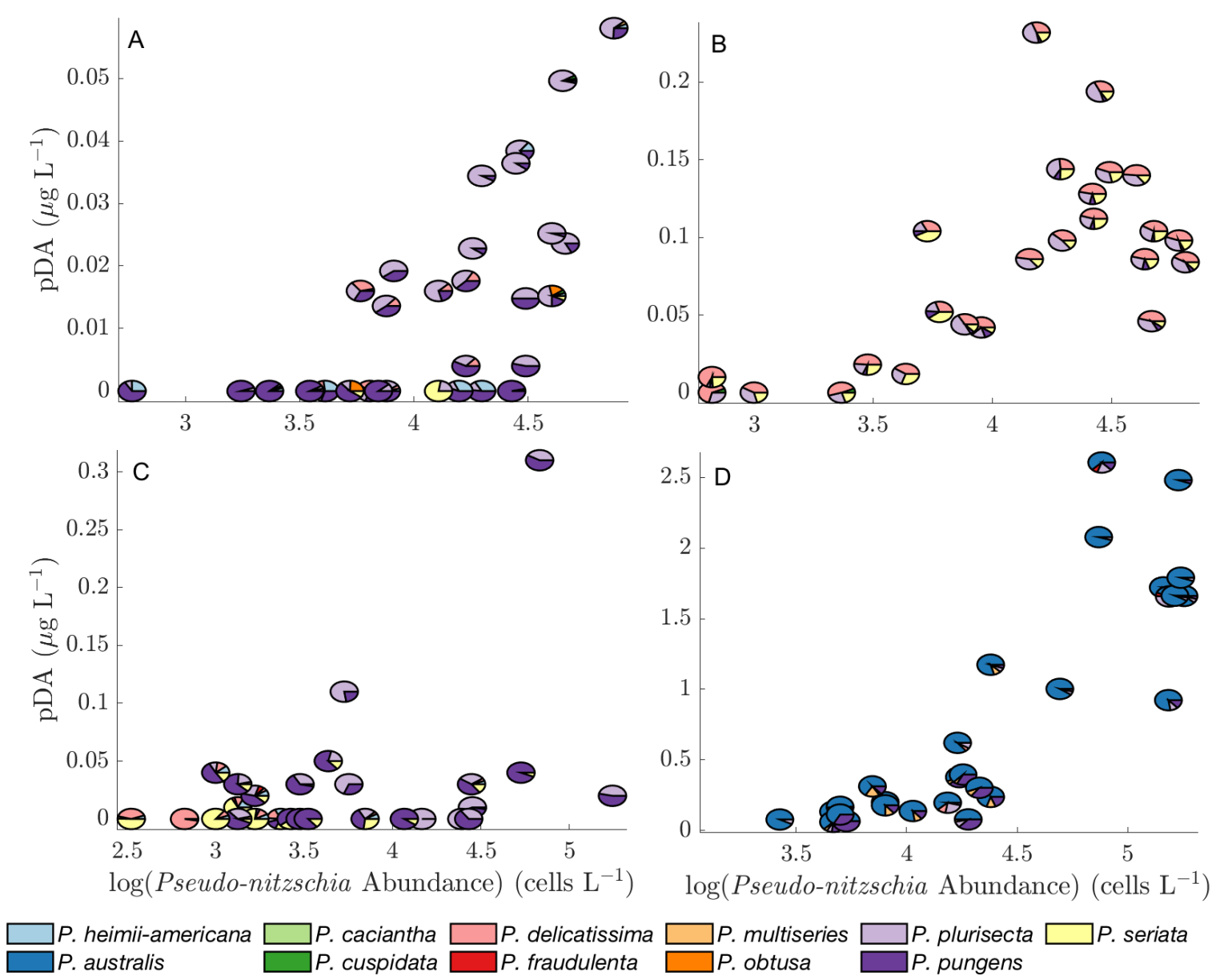

Figure 2-9 - Relative species abundance for each survey cruise on a particulate DA vs log(cell count) diagram: (A) 2012, (B) 2014, (C) 2015, (D) 2016. Note that the axes scales are different. 


\subsubsection{Statistical Analysis}

Statistics were used to quantify correlations from the descriptive analysis, beginning with correlations with environmental parameters. Linear regressions between pDA concentrations or relative species abundance and environmental parameters yielded statistically significant results $(\mathrm{p}$-value $<0.05)$, however the correlations were low $\left(\mathrm{R}^{2}<0.1\right)$. The exception is in linear regressions from 2013: P. pungens was negatively correlated with temperature $\left(\mathrm{R}^{2}=0.85\right), P$. seriata was negatively correlated with salinity $\left(\mathrm{R}^{2}=0.53\right)$, and $\mathrm{pDA}$ was negatively correlated with phosphate $\left(\mathrm{R}^{2}=0.57\right)$. Some correlations existed between relative species abundance and salinity, which are discussed in Section 2.3.1.2. When the analysis included only samples with pDA > LOQ (130 out of 372 total samples), pDA and species abundance were not consistently correlated with one environmental parameter across the years. Thus, variation in species composition and $\mathrm{pDA}$ concentrations were not functions of any one environmental parameter. (Refer to Appendix A for full tables of p-values and $\mathrm{R}^{2}$ values from regression analysis.)

Linear regressions between relative species abundance and pDA were similarly inconclusive: $\mathrm{R}^{2}$ values were less than 0.2 . Therefore, one species was not the sole producer of pDA across all years of the study. However, when the analysis included only samples with $\mathrm{pDA}>\mathrm{LOQ}$, there were consistent correlations between $\mathrm{pDA}$ and the abundance of P. plurisecta, P. pungens, P. australis, and total cell counts (Table 2-3).

CCA and PCA analyses were inconclusive: in neither of the analyses, whether each cruise individually or all cruises combined, were species clearly and consistently correlated with an environmental factor. From the analysis, nutrient and temperature variability dominated the system, but did not correlate with species variability. Despite a lack of direct correlations between environmental factors and species or pDA, interannual differences were observed. According to the Wilcoxon signed rank test, ammonium, N:P, and salinity were significantly higher in 2016 than in 2012 and 2015, while Si* and Si:N 
were significantly lower in 2016 compared to 2012 and 2015. 2016 was not significantly different from 2014 in any category except cDA.

Table 2-3 - Results of linear regressions between species abundance and $p D A$ concentrations of only samples where $p D A>L O Q$. Only statistically significant correlations of species with DA cell $^{-1}>0$ are shown.

\begin{tabular}{ccc}
\hline Year(s) & Species & $\mathbf{R}^{2}$ \\
\hline 2012 & P. plurisecta & 0.33 \\
\hline 2012 & Total cell count & 0.47 \\
\hline 2013 & P. plurisecta & 0.53 \\
\hline 2014 & P. plurisecta & 0.29 \\
\hline 2014 & Total cell count & 0.17 \\
\hline 2016 & P. australis & 0.22 \\
\hline 2016 & Total cell count & 0.66 \\
\hline $2012-2016$ & P. australis & 0.19 \\
\hline $2012-2016$ & Total cell count & 0.53 \\
\hline
\end{tabular}

\subsubsection{Physical Forcing and Hydrodynamics}

The CUI in 2016 was at a minimum in May and increased faster in summer 2016 than in summer 2012, 2013, 2014, or 2015 (Figure 2-10A). By late September 2016, the CUI was larger than in all previous years except 2013, and an abrupt shift to downwelling-favorable winds occurred from the $23^{\text {rd }}$ to the $27^{\text {th }}$ of September. Cumulative river discharge was lower than the average from the 2001-2015 climatology (Appendix A, Figure 6-4), and salinities during the 2016 cruise were higher and had a narrower range than in previous cruises (Figure 2-10). North Atlantic inflows in 2016 were also noteworthy: at 
NERACOOS Station M in 2016 there was a warm and salty anomaly at $250 \mathrm{~m}$ that caused salinity to increase from 34.25 to 34.8 and temperature to increase from 8.71 to $10.35^{\circ} \mathrm{C}$ in 6 days (Figure 2-11).
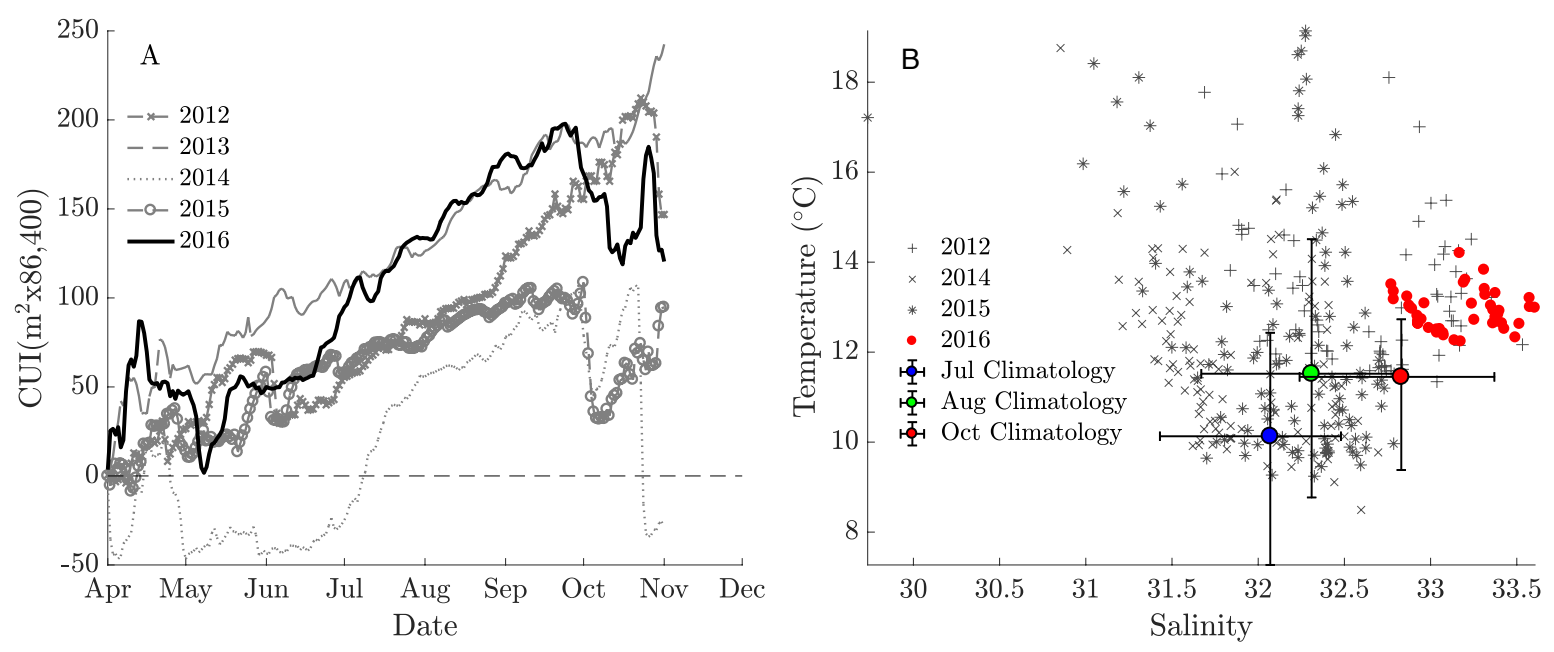

Figure 2-10- (A) Cumulative Upwelling Index vs time in 2012-2016, calculated with atmospheric data from NERACOOS Station I. (B) Temperature and salinity measurements from all ship surveys plotted on one temperature-salinity diagram. Climatological means (circles) and minima/maxima (error bars) of temperature and salinity for the months July, August, and October (the same months as the cruise surveys) are also shown from NERACOOS station I.

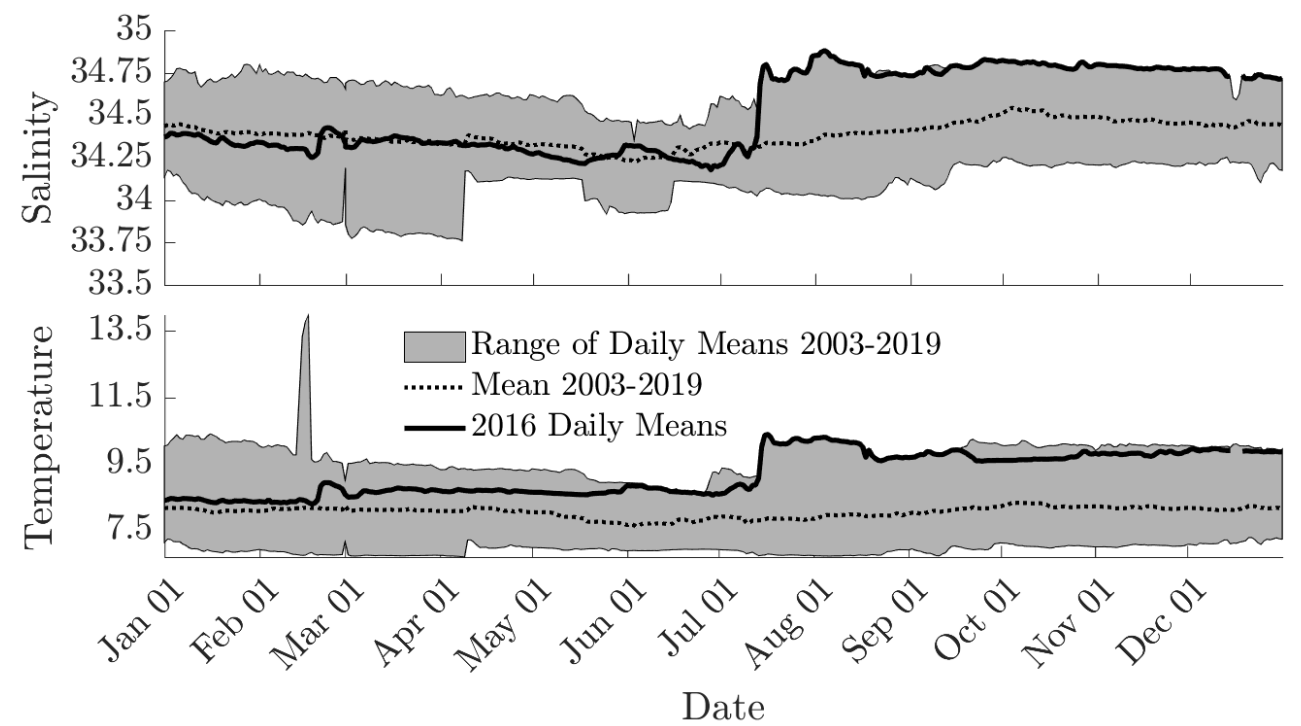

Figure 2-11 - Salinity (top) and temperature (bottom) climatology as measured by NERACOOS buoy station $M$ (Jordan Basin) at 250m. Climatology was calculated from data measured in 2003-2019, and 2016 daily means are overlain. 


\subsection{Discussion}

\subsubsection{Pseudo-nitzschia Biogeography}

Although inshore-offshore Pseudo-nitzschia biogeography correlated with salinity, it may not be due to differences in species' salinity preferences. In fact, the literature is inconsistent on salinity preferences for species in the dataset. For example, P. delicatissima and P. pungens were observed in salinities ranging from 20.8 to 38 in the western Mediterranean (Quijano-Scheggia et al., 2008), while a survey of the Bay of Seine (Thorel et al., 2017) found a trend that was the opposite: P. pungens was found in 32-33.5 salinity waters, while $P$. delicatissima was found in 31.6-32.8 salinity waters.

Cross-shore patterns could also be indicative of underlying water mass changes. For example, inshore-offshore patterns in species composition have been observed in Monterey Bay, where an upwelled cold tongue divided non-toxic inshore populations of P. fraudulenta from toxic offshore populations of $P$. australis (Bowers et al., 2018). In the GOM dataset, cross-shore patterns in species composition and salinity may reflect the

coastal river plume decreasing salinity in the nearshore, which was apparent in 2012 (Figure 2-4) and in 2015 (Figure 2-6). If variations in salinity are associated with different water masses, other factors likely varied simultaneously. Species' niche in salinity space was inconsistent from year to year in the GOM dataset, there are not currently enough data to tease apart the effects of only salinity from other factors, and seemingly contradictory findings in the literature may indicate intraspecific diversity. It is therefore not possible to define salinity niches in the GOM dataset.

\subsubsection{Cruise Results in the Context of Temporal Variability}

It may be tempting to draw conclusions about species' environmental preferences by comparing cruise data, but in each year the cruise data captured only a snapshot of a spatially and temporally variable process. It is therefore difficult to say what conditions 
preceded a bloom and how the bloom itself may have altered its environment. In addition, seasonal progression in species relative abundance (e.g. 2013, Figure 2-3) combined with interannual variability in the timing of peak cell abundance (Figure 2-2), make it unlikely that four different cruises conducted at different times captured the same point in the blooms' progression. Variations among years therefore cannot be used to draw conclusions about factors regulating species distribution.

In 2014, inshore-offshore patterns were less pronounced than in 2012 and 2015. One explanation for this is interannual variability in species dominance, which has also been observed in the Bay of Seine: a 2012 bloom was a composite of P. australis, P. pungens, and P. fraudulenta, but a 2013 bloom was dominated by P. delicatissima (Thorel et al., 2017). However, because the same species were present in the GOM in 2012, 2014, and 2015, but at varying relative abundances, it is more likely that the difference in biogeography is due to differences in cruise timing relative to bloom timing and seasonal cycles in environmental conditions. The 2014 survey occurred when Bar Harbor and MDIBL cell concentrations were low, and $P$. plurisecta was observed in similar proportions across most sample sites. The 2012 and 2015 cruises, meanwhile, occurred when cell concentrations were at a maximum, and P. plurisecta dominated inshore (Figure 2-2, Figure 2-4, Figure 2-6). In 2013, species assemblage shifted from a more even distribution early in the season to dominance by $P$. plurisecta later in the season (Figure 2-3). Similar seasonal transitions have been observed in the English Channel (Downes-Tettmar et al., 2013) and western Scottish waters (Fehling et al., 2006): multiple species existed at one location, but they bloomed at different times of the year. Assuming the temporal pattern observed in the 2013 time series was consistent for the years preceding 2016, the cruises likely captured inshore summertime P. plurisecta dominance in 2012 and 2015 but not in 2014. 


\subsubsection{Domoic Acid}

The production of DA in the ocean depends both on the presence/abundance of a toxic species and on conditions that lead to DA synthesis. Genetic analysis confirmed the presence of certain species and $\mathrm{pDA}$ in each of the sampling years: P. plurisecta and P. seriata from 2012-2015, and P. plurisecta, P. seriata, and P. australis in 2016. In the cruise samples and MDIBL time series pDA typically increased with increasing relative abundance of $P$. plurisecta and P. australis, known DA-producers (Figure 2-3 and Figure 2-9). In 2016, when the species assemblage was dominated by the putatively toxic P. australis, $\mathrm{pDA}$ levels were an order of magnitude higher than previous years. In samples where $\mathrm{pDA}>\mathrm{LOQ}, \mathrm{pDA}$ was correlated with $P$. pungens, $P$. plurisecta, $P$. australis and total cell counts. Cellular DA calculations varied between species (Section 2.3.3), with highest cDA estimates for $P$. australis cells, followed by $P$. plurisecta, and finally $P$. seriata and P. pungens. Particulate DA concentrations were correspondingly highest in P. australis-dominated samples, followed by P. plurisecta samples, and P. seriata samples.

The effect of species composition on DA concentrations is supported by studies in both the field and the lab. In the Bay of Seine, Thorel et al., (2017) observed that blooms dominated by $P$. delicatissima were non-toxic, while blooms dominated by $P$. australis were toxic. That study reported variability in species composition, nutrient concentrations, nutrient ratios, salinity, temperature, and irradiance, but concluded that, of all these, species composition had the largest effect on DA. Similarly, Downes-Tettmar et al. (2013) observed seasonal variations in DA and species composition in the Western English Channel and concluded that DA concentrations correlated with cells from the $P$. seriata group (of which $P$. australis is part) and $P$. pungens/multiseries group. Lab studies have led to similar conclusions. Lema et al. (2017) measured the effects of varying phosphorus concentrations and changing species composition on DA production and concluded that species was the leading order factor to DA production. Based on cDA 
analysis, linear regressions, and evidence from the literature, species composition was likely the leading factor affecting pDA concentrations in the GOM.

The presence of toxic Pseudo-nitzschia spp. is not the only factor to pDA concentrations, as production of DA can vary depending on life stage (Auro and Cochlan, 2013), light availability (Auro and Cochlan, 2013; Terseleer et al., 2013), macronutrients (Lema et al., 2017), nutrient ratios (Lema et al., 2017), trace metals (Wells et al., 2005), or even the presence/absence of predatory zooplankton (Lundholm et al., 2018; Tammilehto et al., 2015). The Wilcoxon signed-rank test indicated that Si:N of positive DA samples was significantly lower in 2016 than in 2012 and 2015, and that N:P was significantly higher in 2016 than in 2012 or 2015 . This may be the result of the significantly higher ammonium concentrations that were measured in 2016 , because, in the ratios, $\mathrm{N}$ was the sum of $\mathrm{NO}_{\mathrm{x}}{ }^{-}$ and $\mathrm{NH}_{4}{ }^{+}$. However, $\mathrm{Si}^{*}$ was also significantly lower in 2016, and that measurement is only a comparison between $\mathrm{Si}(\mathrm{OH})_{4}$ and $\mathrm{NO}_{\mathrm{x}}{ }^{-}$. Several lab studies have found $\mathrm{DA}$ production to increase under silicic acid-limiting conditions when nitrogen was abundant (Lema et al., 2017; Tatters et al., 2012; Terseleer et al., 2013). One field study also observed that maximum pDA concentrations occurred when both silicate and phosphate were limiting (Thorel et al., 2017). Although this ratio was not directly correlated with pDA concentrations in the present study, its role in triggering and enhancing DA production by $P$. australis and other species cannot be ignored.

Despite the laboratory evidence of the role of environmental factors in DA production, it is difficult to translate lab results to the field. Communities in the lab are often monospecific, and all other factors besides the parameter in question are carefully controlled. In the field, there are typically many Pseudo-nitzschia species present as well as other plankton that interact with Pseudo-nitzschia and utilize nutrients. For example, grazer interactions have recently been shown to dramatically enhance DA production in Pseudo-nitzschia (Lundholm et al., 2018). As in this study, studies along the Washington 
and California coasts were unable to attribute DA concentrations or species abundance to a single environmental parameter (Smith et al., 2017; Trainer et al., 2009a). The lack of simple correlations between environmental factors and $\mathrm{pDA}$ does not indicate that environmental factors are unimportant, but rather that pDA concentrations in the field likely depend on a combination of many different factors.

\subsubsection{The 2016 Event}

The DA event in 2016 was unique from previous years in three ways. First, P. australis was identified for the first time in the GOM (Bates et al., 2018). Second, the bloom occurred in September and October, whereas in previous years Pseudo-nitzschia cell concentrations peaked in the spring or summer (Figure 2-2 and Figure 2-3) and the bloom season had been assumed to end in fall. Third, the species assemblage during the 2016 bloom was not a mix of $P$. delicatissima, $P$. seriata, P. plurisecta, and P. pungens, but rather dominated by one species. P. australis was present in every sample, and in many samples its relative abundance was more than $50 \%$ by ARISA estimates.

\subsubsection{What caused the abnormally high pDA levels in 2016?}

The historic shellfish closures in the GOM in 2016 prompt the question: why was pDA so high? PDA values in 2016 were likely the result of high $P$. australis relative abundance in combination with limiting silicic acid concentrations, but, of these, P. australis was the leading order factor in high pDA levels.

P. australis is one of the most toxic Pseudo-nitzschia species, both in this dataset and in the literature (Section 2.4.3). The presence of $P$. australis alone might be enough to explain the high pDA levels in 2016, because cDA was significantly higher in 2016 despite similar total cell counts. However, significantly lower $\mathrm{Si}^{*}$ co-occurred with the $P$. australis cells in 2016, and DA production has been linked to silica stress in both the laboratory (Doucette et al., 2008; Terseleer et al., 2013), and the field (Marchetti et al., 2004; Ryan 
et al., 2017). Low Si* may have enhanced DA production by P. australis cells to create higher pDA concentrations. Because 2014 had equally low Si* to 2016 but pDA concentrations in line with 2012, 2013, and 2015, and since P. australis was not present in 2014, P. australis was probably the leading factor for the high pDA concentrations in 2016.

\subsubsection{Where did P. australis originate?}

The first hypothesis for the origin of $P$. australis is that it was present in undetectable amounts prior to 2016 and grew in 2016 because of altered environmental conditions. This hypothesis cannot be ruled out, but it seems unlikely, because there is little evidence to suggest that there were sufficient changes to growth conditions to favor a $P$. australis bloom. Nutrient concentrations and ratios were not significantly different in 2016 compared to all prior years. Si* was significantly lower in 2016 compared to 2012 and 2015, but this is expected to stress Pseudo-nitzschia cells, not improve their growth (Terseleer et al., 2013). There is no evidence in the literature to suggest that $P$. australis growth in particular improves with low silicic acid, so it is unknown whether low $\mathrm{Si}^{*}$ might have enhanced $P$. australis growth over other Pseudo-nitzschia species. $\mathrm{NH}_{4}{ }^{+}$was significantly higher in 2016 compared to 2012 and 2015, and in Puget Sound P. australis and P. seriata relative abundance were found to correlate with $\mathrm{NH}_{4}{ }^{+}$(Hubbard et al., 2014), but growth experiments have not found significantly improved $P$. australis growth when nitrogen was in the $\mathrm{NH}_{4}{ }^{+}$form (Howard et al., 2007; Martin-Jézéquel et al., 2015). As previously discussed, it is difficult to draw conclusions about the conditions preceding a bloom from survey data alone. Thus, the differences in nutrients in 2016 do not conclusively point to improved conditions for P. australis growth.

Salinity was significantly higher in 2016 than in three previous years, suggesting a possible factor in the emergence of $P$. australis. It is possible for salinity to favor $P$. australis growth, because $P$. australis has been shown to prefer a more limited range of salinity 
relative to other species (Ayache et al., 2018), but the 2016 cruise data are insufficient to fully explore correlations between $P$. australis and salinity. The greater salinity values in 2016 compared to those in previous years (Figure 2-10) could be explained in a number of ways, some of which point to other explanations for the P. australis bloom. The 2016 cruise occurred later in the year than previous years, and salinity typically increases through the summer and fall in the GOM. Salinity during the 2016 cruise was only slightly higher than regional climatology for that time of year (Figure 2-10). Relatively low river discharge in 2016 also may have led to greater than average salinities inshore.

The high salinity values may also indicate an anomalous water mass, which relates to a hypothesis that P. australis was introduced into the GOM in 2016. Inflows from the Scotian Shelf and Northeast Channel vary in strength interannually (Townsend et al., 2014), and may provide a potential pathway for introducing $P$. australis cells. In particular, climatology from NERACOOS station $M$ in Jordan Basin showed a rapid increase in salinity and temperature values in summer 2016 at $250 \mathrm{~m}$ (Figure 2-11) that may have been associated with anomalously warm/salty eddies propagating from the Grand Banks near Novia Scotia (Brickman et al., 2018) or with Gulf Stream Ring water (GSRW). Townsend et al., (2015) showed evidence of GSRW, or a mixture containing a significant fraction of GSRW, that had penetrated at intermediate and bottom depths into Jordan Basin in the interior GOM in fall 2013. They analyzed a time series of temperature and salinity at Buoy $\mathrm{M}$ in Jordan Basin, as augmented by in situ nitrate data collected at $100 \mathrm{~m}$ with a Satlantic optical nitrate sensor (Twardowski et al., 2015). Nitrate served as a third semiconservative water mass tracer to identify an intrusion of anomalously warm and salty, but low nitrate, GSRW. Unlike low-nitrate GSRW, an intrusion of Warm Slope Water with similar T/S properties would have exhibited elevated nitrate concentrations (typically $16-17 \mu \mathrm{M}$; Townsend et al. 2006), not the drop from $12 \mu \mathrm{M}$ to $8 \mu \mathrm{M}$ that was observed (Townsend et al., 2015). 
Similarly timed signals were observed at buoy station M in Jordan Basin in 2016 and in the late summer and fall in 2017 and 2018. Deep waters (at $200 \mathrm{~m}$ and $250 \mathrm{~m}$ ) during those events exhibited the warmest and saltiest values of the time series in Jordan Basin (2003 to present) and were accompanied by lowered nitrate concentrations (Townsend, unpublished), characteristic of GSRW (Townsend et al., 2010). Warm Core Rings can encompass $1500 \mathrm{~m}$ in the vertical (Joyce, 1984) which suggests that the signals observed at $250 \mathrm{~m}$ in 2016 and $100 \mathrm{~m}$ in 2013 (Townsend et al., 2015) could both have been caused by GSRW.

From GOM hydrodynamics, bloom timing, and experiments in Pseudo-nitzschia physiology, it is plausible that the $P$. australis cells observed in the Bay of Fundy and near eastern Maine in 2016 were carried in with a GSRW intrusion. The intrusion was observed in Jordan Basin in July. Assuming an average current speed of $10 \mathrm{~cm} \mathrm{~s}^{-1}$, it would have taken one to two months for this water to circulate the basin and transit to the Bay of Fundy, where elevated DA concentrations led to shellfishery closures in early September 2016. Therefore, there was more than enough time for the water mass to advect to the bloom region, where it would be mixed into the upper water column by strong tidal pumping in those areas. Notably, this would also require a departure from the climatological circulation pictured in Figure 2-1, which is possible in the event of an anomalous water mass intrusion. Because the anomaly in Jordan Basin was observed at 250m, any Pseudo-nitzschia cells associated with this water mass would have been deep in the water column, and the question remains whether the cells can survive at depth for an extended period of time. In a recent experiment, Pseudo-nitzschia spp. cultures (species not specified) were able to survive more than 6 weeks of complete darkness and resume growth with no lasting effects (Fang and Sommer, 2017).

Continuous plankton recorder (CPR) data from offshore and from on the Scotian Shelf in 2016 were examined to look for offshore peaks in large Pseudo-nitzschia cell 
concentrations, but none were found (refer to Appendix A for plots of CPR data). This does not completely rule out the North Atlantic as a source, however, because the CPR data had coarse temporal resolution and samples were only taken from the surface, so sub-surface populations would not have been detected. The intrusion hypothesis can therefore be neither refuted nor confirmed, and remains a possibility.

\subsubsection{Hydrodynamics as drivers of the 2016 bloom}

The cumulative upwelling index (CUI) gave important clues to the timing of the 2016 $P$. australis bloom. Wind direction has been shown to influence alongshore transport in the GOM: in 2010, strong upwelling-favorable winds in combination with a weak dynamic height gradient led to weak alongshore flow, reducing the alongshore extent of an A. catenella bloom (D. J. McGillicuddy et al., 2011). In 2016 the CUI began at a minimum in May and rapidly climbed to outpace every other year except 2013 (Section 2.3.5). Upwelling-favorable winds in 2016 may have reduced alongshore transport and led to Pseudo-nitzschia retention in the Bay of Fundy, where DA in excess of $20 \mu \mathrm{g} \mathrm{g}^{-1}$ of shellfish tissue was recorded from September 16-30 (Canadian Food Inspection Agency).

A rapid switch from upwelling-favorable to downwelling-favorable winds occurred from September $23^{\text {rd }}$ to $27^{\text {th }}$, potentially accelerating alongshore flow and cell transport (Franks and Anderson, 1992). Shellfish closure timing aligned with alongshore transport time: shellfisheries in Cobscook Bay on the Canadian border were closed on September $27^{\text {th }}$, 2016, and shellfisheries at Mt. Desert Island 95km away were closed 3 days later, on September 30 ${ }^{\text {th }}, 2016$ (Rappaport, 2016). In addition, there were recalls of mussels and mahogany quahogs harvested near Jonesport, ME between September 25 and 30 and clams harvested near Corea, ME between September 28 and 30. From NERACOOS buoy I, the average surface current speed in 2016 was $0.3 \mathrm{~m} \mathrm{~s}^{-1}$. Assuming this average, it would take less than a day for alongshore currents to transport cells from the Bay of Fundy to Cobscook Bay, and about 4 days for them to transport cells to Mt. Desert Island. These 
timelines and calculations are estimates, but they suggest that the shift from upwellingfavorable to downwelling-favorable winds on September $23^{\text {rd }}-27^{\text {th }}$ was a factor in bloom timing on the coast of Maine.

\subsection{Conclusion}

This paper (published in Harmful Algae, Clark et al. 2019) builds on the work of Fernandes et al. (2014) by analyzing the spatial and temporal patterns in Pseudo-nitzschia species composition in the GOM. ARISA was used to identify 11 species from ship survey and time series samples in 2012, 2013, 2014, 2015, and 2016. Pre-2016, observed Pseudonitzschia blooms followed consistent biogeography in the GOM, with P. plurisecta inshore and $P$. seriata and $P$. delicatissima offshore. In addition, pDA concentrations increased with cell concentrations, toxic species relative abundance, and as a result of inter-species variation in cellular DA quotas.

Spatial, seasonal, and interannual variability in species composition and absolute cell abundance may have been influenced by seasonal and interannual variations in upwelling winds, North Atlantic inflows, cumulative river discharge, and alongshore transport. The effects of these regional patterns may have been modified by local variations in temperature, salinity, nutrient concentrations, and nutrient ratios, but in contrast to several other studies (e.g., Kaczmarska et al. 2007) no significant correlations between individual species and environmental factors, individual species and pDA, or environmental factors and pDA were found. Increased relative abundance of toxic species led to increased pDA, but DA concentrations were likely caused by a combination of species composition and environmental factors.

Of particular interest was the 2016 P. australis bloom. This was the first known observation of $P$. australis in the GOM, and it was the first time in GOM history that shellfisheries were closed because DA concentrations exceeded the regulatory limit (Bates 
et al., 2018). Particulate DA concentrations reached $37.5 \mu \mathrm{g} \mathrm{\textrm {L } ^ { - 1 }}$ in 2016, which is comparable in magnitude to DA that has been measured on the west coast of the U.S. during Pseudo-nitzschia blooms. The high pDA in 2016 is attributed to the presence of $P$. australis in combination with low $\mathrm{Si}^{*}$. The source of $P$. australis is still unclear; we hypothesize that the species was carried in on an anomalous water mass in 2016, but more investigation is needed to determine the origin of these toxic cells, as well as the extent to which they persist within the GOM. Continued monitoring is essential both to improve the understanding of Pseudo-nitzschia bloom dynamics in the GOM and for the protection of public health. 
This page intentionally left blank. 


\section{Investigating Pseudo-nitzschia australis introduction to the Gulf of Maine with observations and models}

\subsection{Introduction}

The harmful algal genus Pseudo-nitzschia is a lightly-silicified diatom of growing global presence and increasing concern (Bates et al., 2018; Trainer et al., 2012). Species of the genus are often described as "cosmopolitan" because they can persist in a wide range of temperature conditions (Hasle, 2002), and because their distributions span estuaries, coastal environments, and the open ocean (Bates et al., 2018). Some Pseudo-nitzschia species produce domoic acid (DA), a neurotoxin responsible for Amnesic Shellfish Poisoning. More than 52 Pseudo-nitzschia species have been identified worldwide, and at least half are confirmed DA producers (Bates et al., 2018).

In 2016 in the Gulf of Maine (GOM), DA concentrations exceeded the regulatory limit of $20 \mu g$ DA $g^{-1}$ of shellfish tissue, leading to the first regional DA-induced shellfishery closures (Bates et al., 2018; Clark et al., 2019; Hubbard et al., 2017; Lewis et al., 2017). The bloom began in the Bay of Fundy in late September, 2016, and progressed along the coast of Maine, continuing into the second week of October. Fourteen Pseudo-nitzschia species had been identified in the region prior to the DA event (Fernandes et al., 2014), but the record DA concentrations were caused primarily by the novel appearance of P. australis (Clark et al., 2019).

In observations from the 2016 DA event, neither cell concentrations nor relative species abundance correlated with various environmental parameters (temperature, salinity, nitrate, ammonium, silicic acid, phosphate, or nutrient ratios). In addition, except for 
salinity, environmental parameters were not significantly different in 2016 compared to previous years (2012-2015) (Clark et al., 2019). Salinity was significantly higher in 2016 compared to the four previous years (0.4-1.5 PSU greater), but the salinity difference was not enough to result in improved growth conditions based on the literature for P. australis. An alternative explanation to changing environmental conditions for the novel bloom in 2016 is that $P$. australis was introduced to the region in a process linked to the anomalously saline conditions in the GOM (Clark et al., 2019). Of the primary source waters flowing into the GOM, Gulf Stream Ring water (GSRW) is saltier than Slope Water or Scotian Shelf Water (Townsend et al., 2015). Previous studies have shown that GSRW can contribute to or modify Northeast Channel inflows (Brooks, 1987), and measurements at NERACOOS Buoy M suggested the presence of GSRW in the GOM interior in July 2013 (Townsend et al., 2015) and again in July 2016 (Clark et al., 2019). GSRW is not the only potential source for anomalously saline water, however. From 1990 to 2015, Brickman et al. (2018) observed near-bottom anomalies upstream on the Scotian Shelf that alternate between warm and saline or fresh and cool. With a model they showed that such anomalies form due to interactions between the Gulf Stream and Labrador Current off of the Grand Banks in the North Atlantic Ocean, propagate toward the southwest, and can penetrate into the GOM via the Northeast Channel. Based on both observations and model results, Brickman, et al. argued that warm/saline anomalies increased in frequency and magnitude from 2006 to 2015.

The correspondence of $P$. australis and an anomalous water mass is not without precedence. In 2015, a P. australis bloom on the West Coast of the United States led to record-breaking DA concentrations in Monterey Bay, CA (Ryan et al., 2017). The bloom occurred during the North Pacific Ocean Warm Anomaly, during which sea surface temperatures were more than $2.5^{\circ} \mathrm{C}$ higher than the long-term average (McCabe et al., 2016). The anomalously warm water is thought to have contributed to the bloom, either as a primary factor (McCabe et al., 2016) or as a contributing factor along with 
intermittent upwelling (Ryan et al., 2017). Thus, the anomalies observed in recent years in the GOM region (increased salinity along the coast of Maine and in Jordan Basin (Clark et al. 2019), and warm, saline anomalies on the Scotian Shelf (Brickman et al. 2018)) may relate to the introduction of $P$. australis.

This study (submitted to Continental Shelf Research) uses field data, a hydrodynamic model, and a Lagrangian particle tracking model to address the following questions:

- What are the most likely sources of $P$. australis to the Gulf of Maine?

- Was the connectivity from potential source regions to the Gulf of Maine different in 2016 compared to previous and subsequent years?

- Do model results indicate differences in hydrographic conditions in the Gulf of Maine that may have affected $P$. australis bloom timing, location, or distribution?

The following sections describe the study site, field data, hydrodynamic model, and particle tracking model and analysis. Simulations of the hydrodynamics and Lagrangian transport are compared for the years 2012-2019, with a focus on 2016. We evaluate hypotheses for $P$. australis introduction, effects of changing hydrodynamics on the 2016 bloom, influences of Scotian Shelf processes on the GOM in 2016, potential links to other P. australis populations in the North Atlantic, and implications of this research for future studies and monitoring practices.

\subsection{Methods}

\subsubsection{Study Site - The Gulf of Maine}

The GOM lies between Cape Cod, MA, USA at $42^{\circ} \mathrm{N}$ and the Bay of Fundy, Canada at $44.5^{\circ} \mathrm{N}$ (Figure $3-1$ ). Sea surface temperatures range from $6^{\circ} \mathrm{C}$ in the winter to $22.5^{\circ} \mathrm{C}$ in the summer, and salinity ranges from 29 near the coast to 33.5 offshore ( $\mathrm{Li}$ and $\mathrm{He}, 2014$ ). It is considered a gulf because its offshore boundaries, Georges Bank and Browns Bank, are shallower than 100m, while its three major basins - Georges Basin, Jordan Basin, and 
Wilkinson Basin - are deeper than 200m (Townsend et al., 2006). Gulf inflows occur via the Northeast Channel and south of Nova Scotia. The general circulation around the GOM is cyclonic, and outflows occur via the Great South Channel and the Northeast Channel (Brooks, 1985; Lynch et al., 1997; Pettigrew et al., 2005; Xue et al., 2000). Water properties in the GOM interior are set by the water mass properties at the inflow locations: Northeast Channel deep inflows are a mix of relatively warm and salty Warm Slope Water and slightly cooler and fresher Labrador Slope Water, while Nova Scotia surface inflows are made up of cool, fresh Scotian Shelf Water (Smith et al., 2012; Townsend et al., 2015).

\subsubsection{Field Data}

The Department of Fisheries and Oceans Canada (DFO) has conducted annual summer surveys of the Scotian Shelf since 1970. In 2016, the survey was conducted from June 28 to Aug 15, and a total of 250 stations were sampled with Conductivity-TemperatureDepth (CTD) profiles (Figure 3-1). At the surface, 50m, 100m, and the bottom, temperature and salinity values were interpolated onto a 0.2 -by-0.2 degree grid via optimal interpolation (Hebert et al., 2018).

Buoys from the Northeastern Regional Association of Coastal Ocean Observing Systems (NERACOOS) have recorded temperature, salinity, conductivity, potential temperature, air temperature, air pressure, and wind speed at hourly intervals since 2001 (Morrison, 2019) (Figure 3-1). Instruments were positioned at 1, 20, and 50+ $\mathrm{m}$ below the surface (site-depending), allowing for characterization of the vertical structure of the water column at high temporal resolution. Salinity and temperature data from buoys N, M, and I from 2001-2019 were used to characterize water mass characteristics and climatology. 

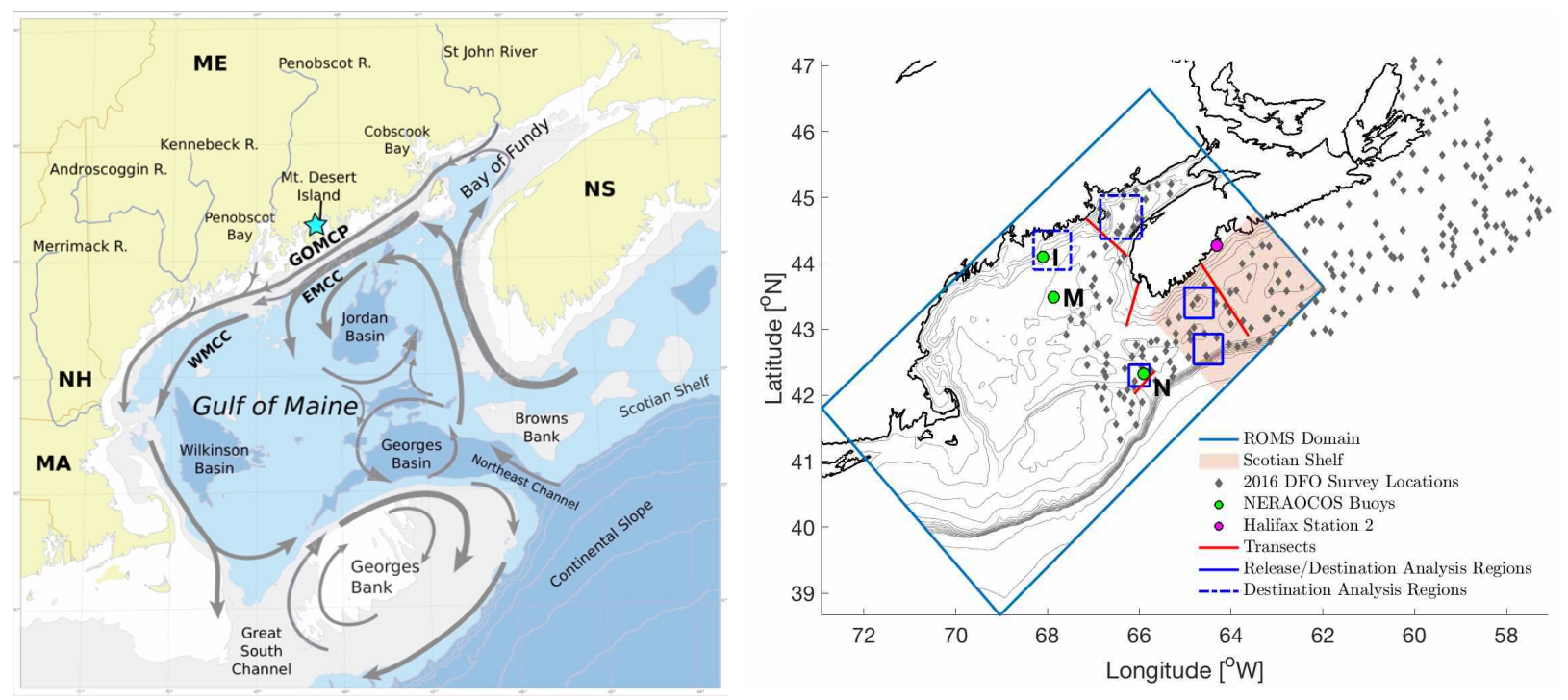

Figure 3-1 - (left) Climatological circulation of the GOM as described in Pettigrew et al. (2005) and adapted in Anderson et al., (2005)3. GOMCP stands for Gulf of Maine Coastal Plume, WMCC stands for Western Maine Coastal Current, and EMCC stands for Eastern Maine Coastal Current. Two-letter abbreviations are for Massachusetts (MA), New Hampshire (NH), and Nova Scotia (NS). (right) Map of the Gulf of Maine showing the ROMS domain (blue box), the Scotian Shelf portion of the ROMS domain (red shaded box), NERACOOS buoys (green circles), Halifax Station 2 (magenta circle), 2016 DFO survey locations (grey diamonds), transects for analysis (red lines), and particle analysis regions (solid blue boxes are sources and destinations, while dashed blue boxes are destinations only). The contour lines inside the ROMS domain are drawn at $25 \mathrm{~m}, 50 \mathrm{~m}, 75 \mathrm{~m}$, every $100 \mathrm{~m}$ to $1000 \mathrm{~m}$, and $2000 \mathrm{~m}$.

\subsubsection{Models}

\subsubsection{Hydrodynamic Model}

The Regional Ocean Modeling System (ROMS) is a free-surface, hydrostatic, primitive equation circulation model with split-explicit time-stepping for the baroclinic and barotropic modes (Shchepetkin and McWilliams, 2005). It has been applied to the GOM, where it is used annually to forecast A. catenella blooms (He et al., 2008). The GOM ROMS configuration includes 36 terrain-following sigma layers, 1-km resolution inshore, and 3-km resolution offshore. The model domain stretches from Georges Bank and Cape

\footnotetext{
${ }^{3}$ This figure was published in Deep-Sea Research II, Vol 52, Anderson, Donald M., Keafer, Bruce A., McGillicuddy, Dennis J., Mickelson, Michael J., Keay, Kenneth E., Libby, P. Scott, Manning, James P., Mayo, Charles A., Whittaker, David K., Hickey, J. Michael, He, Ruoying, Lynch, Daniel R., Smith, Keston W. "Initial observations of the 2005 Alexandrium fundyense bloom in southern New England: General patterns and mechanisms." p. 2858, Copyright Elsevier (2005)
} 
Cod in the Southwest to the Bay of Fundy and Halifax in the Northeast (Figure 3-1), encompassing 38 to $47^{\circ} \mathrm{N}$ and 61 to $73^{\circ} \mathrm{W}$.

Three-dimensional temperature, salinity, and velocity, and two-dimensional sea surface height from HYCOM (HYbrid Coordinate Ocean Model) ${ }^{4}$ were interpolated to the ROMS grid to create initial and boundary condition files. HYCOM experiment GOFS3.0, with 33 vertical layers and $1 / 12^{\circ}$ horizontal resolution, was used for 2012-2018, while GOFS3.1, with 41 vertical layers and $1 / 12^{\circ}$ horizontal resolution, was used for 2019, because GOFS3.0 was only available through November 2018. HYCOM utilizes hybrid vertical coordinates, with isopycnal vertical layers in the open stratified ocean, terrain-following sigma layers in the coastal ocean, and z-coordinates in unstratified areas. HYCOM also assimilates data from the Navy Coupled Ocean Data Assimilation (Cummings, 2005) and estimates surface fluxes with bulk parameterization and data from the Navy Operational Global Atmospheric Prediction System (NOGAPS).

Atmospheric forcing in the GOM ROMS was parameterized via bulk formulation with data from the North American Regional Reanalysis (NARR) ${ }^{5}$, which assimilates data from various sources to calculate air temperature, air pressure, wind speed, cloud fraction, longand shortwave radiation, relative humidity, and precipitation. Output resolution was 6 hours and $1 / 6^{\circ}$. Five rivers are included in the GOM ROMS forcing files as volumetric transport $\left(\mathrm{m}^{3} \mathrm{~s}^{-1}\right)$ as measured by the U.S. Geological Survey' (in order of decreasing transport) St. John River, Penobscot River, Kennebeck River, Androscoggin River, and Merrimack River. A volumetric adjustment was added during forcing file generation to account for drainage area downstream of the gauge.

\footnotetext{
4 https://www.hycom.org/

${ }^{5}$ https://www.ncdc.noaa.gov/data-access/model-data/model-datasets/north-american-regional-reanalysisnarr

${ }^{6}$ http://waterdata.usgs.gov
} 
For each year from 2012 to 2019, GOM ROMS was initialized in February and run through December. These years were chosen to compare four non- $P$. australis years (2012-2015) with the four years after P. australis' first appearance (2016-2019). Each year was initialized with HYCOM output to reduce potential error caused by model drift over time. Because of strong tidal variability in the region, model results were saved hourly for use with the particle tracking model.

\subsubsection{Particle Tracking Model}

The Lagrangian TRANSport Model (LTRANS) is an offline, three-dimensional particle tracking model (North et al., 2008, 2006; Schlag and North, 2012; Hunter 2020). It reads in the output from ROMS and calculates particle trajectories through a combination of advection (4 $4^{\text {th }}$ Order Runge-Kutta advection scheme), turbulence, and particle behavior. Turbulence was parameterized with a random walk model in the horizontal and a random displacement model in the vertical, with horizontal diffusivity set to $2 \mathrm{~m}^{2} \mathrm{~s}^{-1}$ and vertical diffusivity taken directly from ROMS. Particles in these simulations were passive and neutrally buoyant. LTRANS operates on the native ROMS grid, using bilinear interpolation in the horizontal and spline interpolation in the vertical to interpolate velocities, temperature, and salinity to sub-grid scales. Land-ocean boundaries are reflective, as is the surface boundary, and open ocean boundaries allow particles to escape the domain, but not reenter. For all experiments listed below, the internal time step for particle movement was two minutes, the external time step (from GOM ROMS) was one hour, and particle tracking results were saved every 6 hours.

\subsubsection{Particle Tracking Experiments}

A series of reverse and forward particle tracking experiments were designed to explore three related questions: (1) what are the most likely source regions for $P$. australis, (2) which of the source regions had the strongest connectivity to locations where contaminated shellfish and $P$. australis were observed, and (3) was the connectivity from source regions to the GOM different in 2016 compared to previous and subsequent years? 
LTRANS was run "in reverse" by multiplying the velocities by -1 and reversing model fields (salinity, temperature, and velocity) with respect to time. The accuracy of this method was checked by plotting individual particle tracks without turbulence in the reverse and forward runs and ensuring that they matched. Particles were seeded at each of the 2016 ship survey sample locations in Clark et al., (2019) at 1m, 10m, and 20m, in accordance with sample depths. 2,000 particles total were released at each unique (x,y,z) location, according to the method outlined in Simons et al. (2013). The particles were distributed evenly with one release at each location every 6 hours during the period of shipboard observations (Oct 5 00:00 to Oct 7 18:00) for a total of 420,000 particles. In addition to focusing on the timing of the 2016 ship survey, this release time period was sufficient for capturing the stochasticity of reverse connectivity, as the particle tracks fully sampled the known inflow pathways in the region (Section 3.3.2.1). The experiment was repeated in each year from 2012 to 2019 and run backward to the beginning of June (120 days).

The forward experiments were designed to complement, and were guided by, the reverse experiments. A preliminary analysis of the reverse experiment pointed to the inner Scotian Shelf and Northeast Channel as the two most likely source regions for $P$. australis. For each forward experiment, a latitude-longitude point was made the center of a square with side lengths that were chosen to encompass the region of interest (see Figure 3-1). Particles were randomly distributed horizontally within the square at a density of 3 particles $\mathrm{km}^{-2}$, which was informed by the methods in Simons et al. (2013). At each (x,y) point, particles were released at the bottom, at mid-depth, and at $50 \mathrm{~m}, 25 \mathrm{~m}$, and $1 \mathrm{~m}$. Particles were released every six hours for 3 days starting at midnight on July 15, August 1, and September 1 of each year and experiments were run through October 5. A six-hour release interval was chosen to avoid aliasing the tidal signal, and the three months were chosen to include mesoscale and other low-frequency variability. At the Northeast Channel (NEC) 9,375 particles were released at one time, and on the inner Scotian Shelf (SS) 
15,360 particles were released at one time. This totals 121,875 (NEC) or 199,680 (SS) particles per location-release, 365,625 (NEC) and 599,040 (SS) particles per location (July, August, and September combined), 964,665 particles per year (2 locations and 3 release times), and 7,717,320 particles in all.

Table 3-1 - Locations of particle releases for the forward experiments.

\begin{tabular}{lll}
\hline Release Location & Center latitude/longitude & Region Side length $(\mathrm{km})$ \\
\hline Inner Scotian Shelf & $43.4,-64.7$ & 32 \\
\hline Northeast Channel & $42.3,-66.0$ & 25
\end{tabular}

\subsubsection{Data Analysis}

\subsubsection{Field Data and ROMS}

To see if the hydrographic conditions or transport pathways were distinct in 2016, both model output and observations were used to plot water mass properties, velocity, transport, and vertical water column structure. For all analyses, ROMS output was extracted from the nearest grid cell to the location, rather than interpolated.

On the Scotian Shelf, ROMS surface and bottom salinity and temperature were averaged over the region between $42.55^{\circ} \mathrm{N}$ and $44.64^{\circ} \mathrm{N}$ and $65.53^{\circ} \mathrm{W}$ and $62.01^{\circ} \mathrm{W}$ (Figure $3-1$ ). Stratification was defined as the difference in average potential density between the bottom and the surface.

ROMS results were further analyzed as transects. Four transects were chosen to capture various upstream locations from the 2016 sample site, where "upstream" was determined by knowledge of the climatological circulation and the results from the reverse particle tracking simulations. The four transects were on the Scotian Shelf $\left(64.66^{\circ} \mathrm{W}, 44.00^{\circ} \mathrm{N}\right.$ to $\left.63.62^{\circ} \mathrm{W}, 42.9^{\circ} \mathrm{N}\right)$, south of Nova Scotia $\left(66.57^{\circ} \mathrm{W}, 42.62^{\circ} \mathrm{N}\right.$ to $66.02^{\circ} \mathrm{W}$ to $\left.43.69^{\circ} \mathrm{N}\right)$, across the Northeast Channel $\left(66.11^{\circ} \mathrm{W}, 42.02^{\circ} \mathrm{N}\right.$ to $\left.65.66^{\circ} \mathrm{W}, 42.37^{\circ} \mathrm{N}\right)$, and across the mouth of the Bay of Fundy $\left(67.16^{\circ} \mathrm{W}, 44.68^{\circ} \mathrm{N}\right.$ to $\left.66.26^{\circ} \mathrm{W}, 44.11^{\circ} \mathrm{N}\right)$ (Figure $\left.3-1\right)$. ROMS $u$ and $v$ 
velocities were projected in the alongshore direction according to the angle of the coast relative to East such that $u>0$ was toward the GOM. In the Northeast Channel, velocities were projected parallel to the channel walls. Transport toward (away from) the GOM was calculated via

$$
\text { Transport }=\sum_{i=1}^{N} u_{i} * A_{i}
$$

where $i$ is each grid cell where $u>0(u<0), u$ is the alongshore component of the velocity in grid cell $i, A_{i}$ is the grid cell cross-sectional area, and $N$ is the total number of grid cells where $u>0(u<0)$.

Salt transport was calculated via

$$
\text { Salt Transport }=\sum_{i=1}^{N} S_{i} * u_{i} * A_{i}
$$

where $S_{i}$ is the salinity in grid cell $i$. Transport estimates were filtered with a weekly running mean before plotting to reduce the tidal signals.

\subsubsection{LTRANS}

\section{Particle Density and Particle Probability}

To compare connectivity between one source region and multiple destination regions, particle density was calculated by dividing the sum of all particles in the destination region by the region area $\left(l^{2}\right.$, where $l$ is the side length defined in Table $\left.3-1\right)$. This method was chosen to enable comparisons between regions of different sizes. The destinations for the reverse run, the inner Scotian Shelf $\left(43.4^{\circ} \mathrm{N}, 64.7^{\circ} \mathrm{W}, l=32 \mathrm{~km}\right)$ and Northeast Channel $\left(42.3^{\circ} \mathrm{N}, 66.0^{\circ} \mathrm{W}, \quad l=25 \mathrm{~km}\right)$, were the same as the forward release locations (Table 3-1). 
For intra- and interannual comparisons in connectivity, particle probability was calculated according to

$$
\text { probability }=\frac{\sum \text { particles within region }}{P_{i}} \times 100 \%
$$

where $P_{i}$ is the total number of particles initially released from the source region. The destination regions were the Bay of Fundy, centered on $44.7^{\circ} \mathrm{N}, 66.4^{\circ} \mathrm{W}$, with a side length of $50 \mathrm{~km}$, and the eastern Maine coast, centered on $44.2^{\circ} \mathrm{N}, 67.9^{\circ} \mathrm{W}$, with a side length of $45 \mathrm{~km}$ (Figure 3-1). The Bay of Fundy was chosen because it was where the 2016 bloom was first observed. The location along the eastern Maine coast was based on the 2016 ship survey location in Clark et al. (2019) and subsequent reports of shellfishery closures in eastern Maine.

\section{Growth Delivery Potential}

An estimate of potential growth for $P$. australis as a function of temperature was calculated for those particles that were in the Bay of Fundy at any point between September 5 and September 19, the two weeks leading up to when shellfish toxicity exceeded the regulatory limit (Canadian Food Inspection Agency, 2016). Growth rates were also estimated for particles in the Bay of Fundy between September 12 and 19, and results were similar to the two-week time period.

Temperature-based laboratory growth rates were measured for a Gulf of Maine P. australis isolate obtained from the 2016 toxic bloom. The isolate was maintained with batch cultures in sterile GOM seawater (salinity 33) amended with $\mathrm{f} / 4$ nutrients at $13^{\circ} \mathrm{C}$ under a 12:12-hour light:dark cycle with cool-white light at $\sim 150 \mu \mathrm{mol}$ photons $\mathrm{m}^{-2} \mathrm{~s}^{-1}$. For acclimatized growth rates, cultures were transferred to a thermal-gradient device (Blankley and Lewin, 1976) while keeping other growth conditions the same. Growth was monitored by measuring in vivo fluorescence daily with a Turner AU-10 Fluorometer (Turner Designs, San Jose, CA). After reaching steady state growth (i.e., for 3 generations) at $13^{\circ} \mathrm{C}$, cultures were similarly acclimatized to additional temperatures 
$\left(7,9,11,13\right.$, and $\left.15^{\circ} \mathrm{C}\right)$ using a stepwise increase or decrease of $2^{\circ} \mathrm{C}$. If positive growth was achieved for a given temperature, cultures were transferred to a new temperature after three generations, even if they were not in steady state.

To calculate per-particle potential daily growth, each particle's along-track temperature was extracted on days when it was entirely in the euphotic zone (defined as $100 \mathrm{~m}$ according to the data on NASA's Earth Color Website`) and averaged over the entire day. Euphotic zone depths of 50 and $75 \mathrm{~m}$ were also tested with no discernible changes to the results. Growth rate at each daily temperature was assigned via linear interpolation of the growth curve. On days when the particle exited the euphotic zone, the growth rate was set to zero.

Per-particle average potential daily growth rate was calculated over each particle's trajectory by dividing the sum of daily potential growth rates by the number of days in the experiment. Interannual comparisons of the distributions of average potential daily growth rate were done with the Kolmogorov-Smirnov test. This pair-wise test compares the maximum difference between two empirical distributions to a theoretical maximum difference to determine the likelihood that the two samples are from the same distribution. It does not assume normal distribution.

\subsubsection{Model Validation}

ROMS has been used for many years to study circulation and A. catenella (formerly A. fundyense) blooms in the Gulf of Maine (Fennel and Wilkin, 2009; He et al., 2008; Li et al., 2015, 2009; López et al., 2020; McGillicuddy et al., 2011). From a comparison between ROMS data and coastal CTD casts and NERACOOS moorings, Li et al. (2009) found that the model accurately captured surface and sub-surface temperature, salinity, and velocity to reproduce the general hydrodynamics along the coast on monthly and

\footnotetext{
${ }^{7}$ https://oceancolor.gsfc.nasa.gov/atbd/kd_490/
} 
seasonal time scales, but that it missed processes on an event-by-event basis and at local scales. Our analysis agrees with this assessment.

ROMS accurately depicted the GOM's climatic circulation, with cyclonic circulation in the gulf interior, anticyclonic circulation around Georges Bank, inflows via Nova Scotia and the Northeast Channel, and outflows via the Northeast Channel and Great South Channel (Figure 3-2, compare with Figure 3-1). The model also depicts the episodic nature of Northeast Channel inflows: at depth $(>100 \mathrm{~m})$ near NERACOOS buoy N, both ROMS and the observations show changes in salinity up to $2 \mathrm{PSU}$ and changes in temperature up to $6^{\circ} \mathrm{C}$ in as little as a week (Figure 7-1 in Appendix B). The model also captures seasonal and spatial patterns in sea surface temperature: time series of model output vs NERACOOS Buoy measurements and Halifax Station 2 are in good agreement (Li et al., 2009). On the Scotian Shelf, ROMS estimates of water mass properties were in general agreement with observations from the 2016 DFO Summer Survey (Figure 3-3).

ROMS captures key features that are relevant to the research questions in this study. Because the model captures the alongshore flow along the coast of Maine, bloom progression and $P$. australis connectivity in the gulf interior can be addressed. With the model's representation of Northeast Channel and Nova Scotia inflows, the P. australis gulf introduction hypothesis can be tested. Third, because the model captures both high salinity pulses at the Northeast Channel and the location and magnitude of the observed near-bottom salinity on the Scotian Shelf in 2016 (Figure 3-4), potential origins of the high salinity signal near the coast of Maine in 2016 (Clark et al. 2019) can be explored.

Point comparisons between the observations and ROMS output revealed local inaccuracies in model predictions, which emphasize the need to focus on long-term, low-frequency processes. In some instances, ROMS inaccurately simulated salinity: at Halifax Station 2, surface salinity in the model was more saline than observations by 1 PSU on average (up to 1.8 PSU, Appendix B Figure 7-3), while salinity at depth was fresher than the DFO observations (Figure 3-4). The disagreement at depth could be partly due to the scarcity 
of nearshore observations in the survey, but inshore salinity values in ROMS were often fresher than observations. However, ROMS represented the key spatial gradients in the salinity distribution: increasing salinity with depth and with distance from shore. At NERACOOS buoy I, 50m modeled salinity was fresher than observations by up to 1.3 PSU, but $1 \mathrm{~m}$ modeled salinity agreed with the observations (Appendix B Figure 7-4). Finally, ROMS did not capture the rapid increase in salinity ( $\sim .5$ PSU over 6 days) observed at 250m at NERACOOS Buoy M in July 2016 (Clark et al., 2019). However, as mentioned above, ROMS did have rapid changes in salinity at the Northeast Channel and episodic salinity inflows, which are the processes thought to drive the rapid salinity increase at Buoy M.

For the purposes of this paper, ROMS is used to draw relative comparisons between years and locations, because large-scale, low-frequency flow is accurate in spite of local disagreements. In addition, large-scale patterns in salinity allow for analysis of nearshore vs. offshore inflow routes and water mass changes with depth. The model is also used to assess interannual variations in connectivity, inflows through the Northeast Channel, and water mass properties on the Scotian Shelf, to compare 2016 to the other years from 2012 to 2019, and to evaluate $P$. australis introduction hypotheses. 

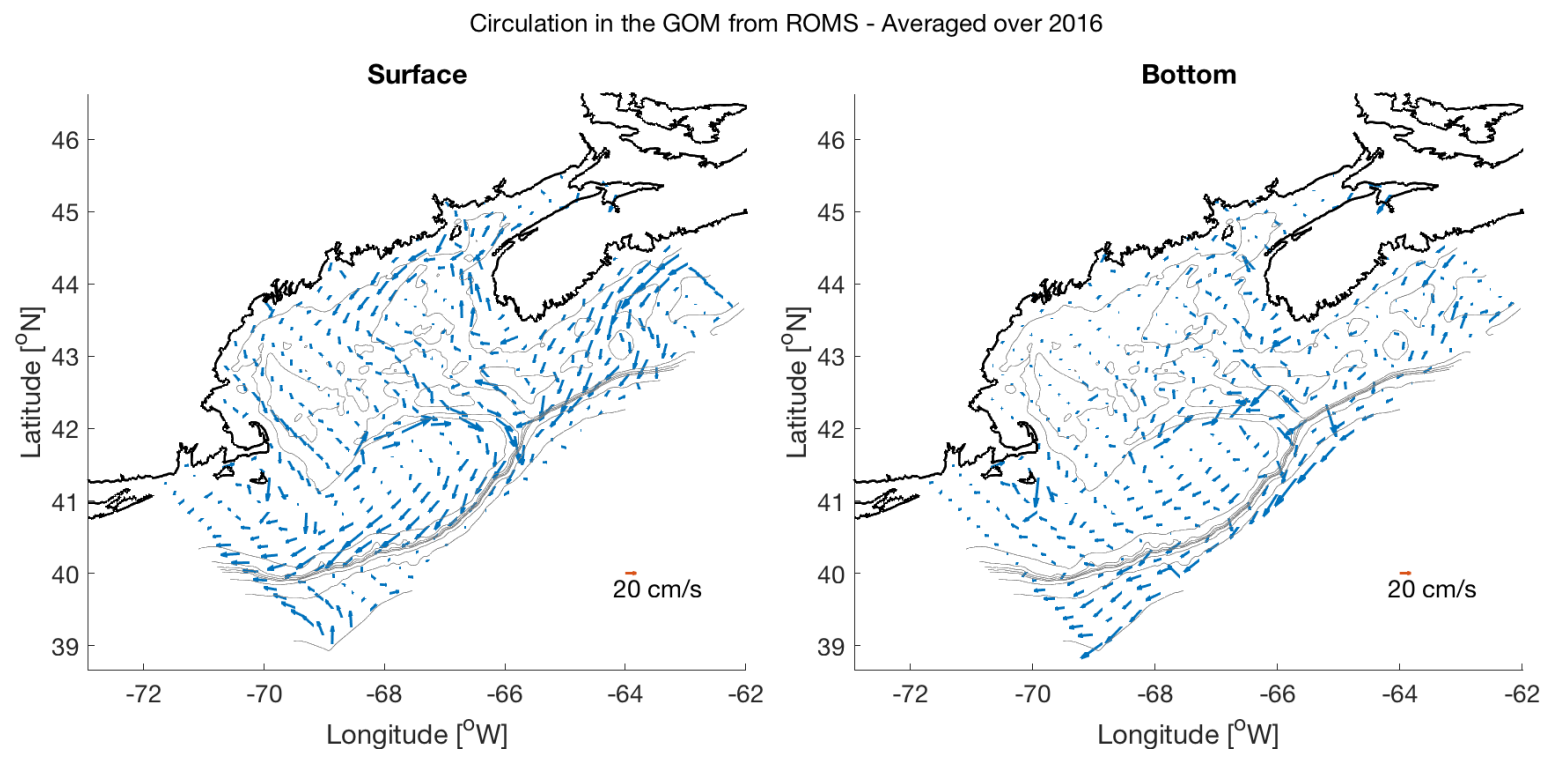

Figure 3-2 - Year-long averaged (left) surface and (right) bottom circulation in the Gulf of Maine in 2016 as simulated by ROMS. The output grid was decimated by a factor of ten before plotting. The scale of the velocity arrows is given in the bottom right.

ROMS-DFO Data Comparison in T-S Space
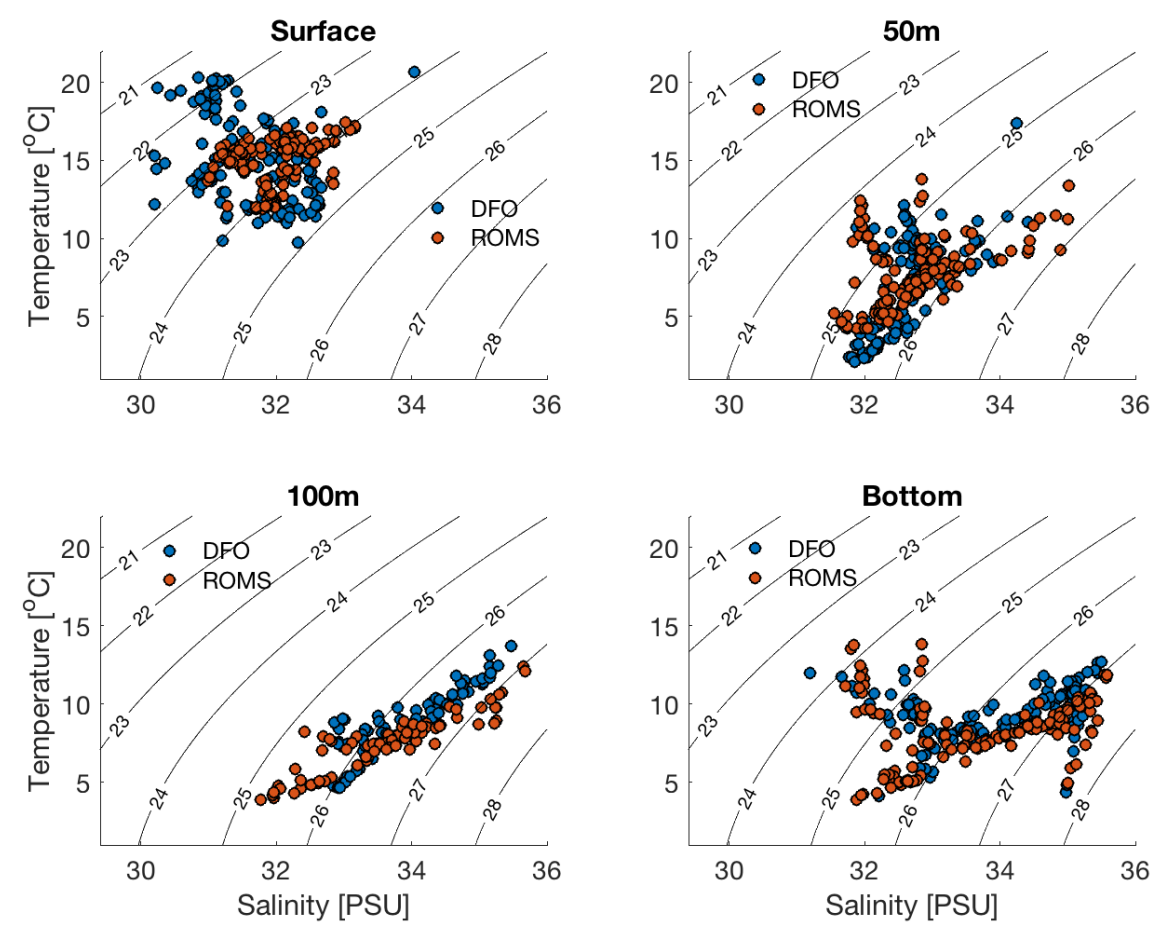

Figure 3-3 - ROMS (red) and DFO (blue) temperature vs. salinity on the Scotian Shelf at (clockwise from top left) the surface, $50 \mathrm{~m}$, the bottom, and $100 \mathrm{~m}$. ROMS data were extracted from the nearest grid point to the DFO sample location. 

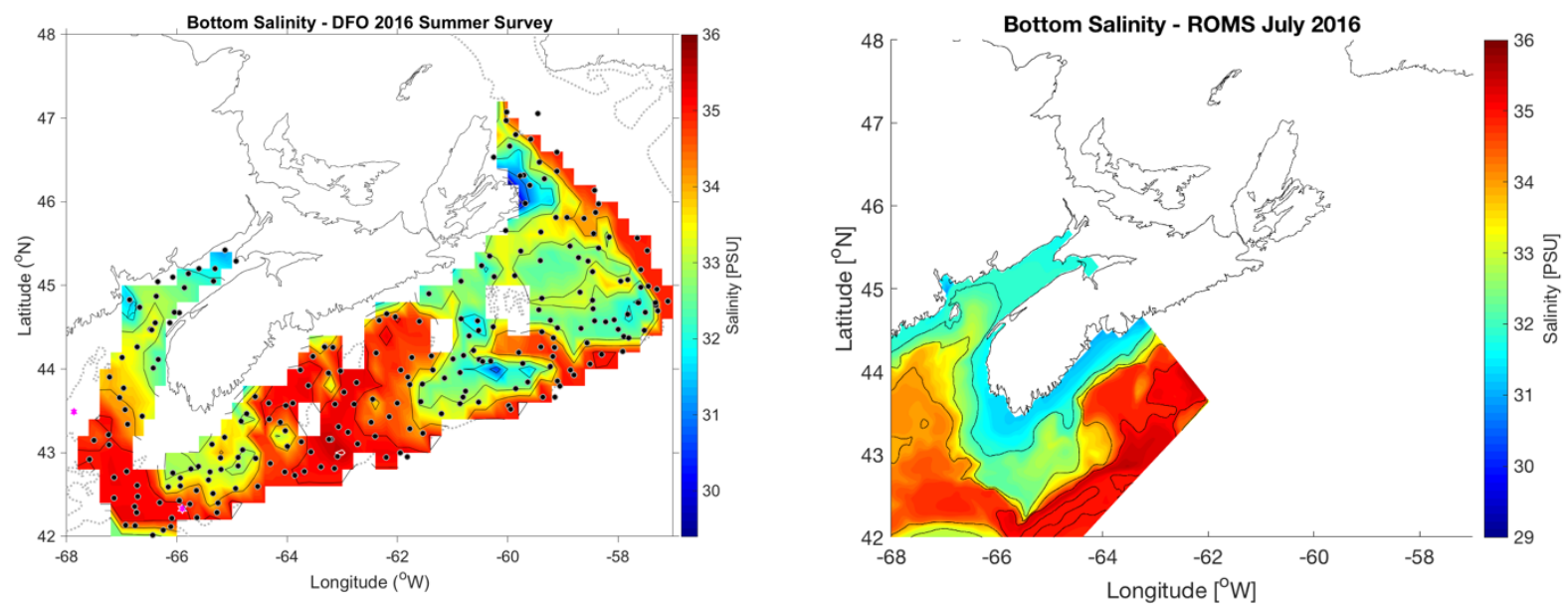

Figure 3-4-(left) Scotian Shelf bottom salinity as measured during the DFO Summer Survey in July, 2016. Black points indicate sample locations, and values are indicated by the color bar on the right. Spaces between sample locations were filled via optimal interpolation; (right) Bottom salinity as simulated by ROMS on July 15, 2016. The color bar limits are the same as on the left. 


\subsection{Results}

\subsubsection{Hydrodynamics from ROMS Output and Observations}

\subsubsection{Water Mass Properties}

From the DFO survey in July 2016, bottom waters on the Scotian Shelf were anomalously warm (up to $4^{\circ} \mathrm{C}$ ) and saline (up to 0.7 PSU) relative to the 1981-2010 climatology (Figure 3-5). Summer water mass properties are relevant to the fall bloom because of transport time scales (Section 3.3.2.1). Although ROMS did not capture the exact location of the anomalies, the model had relatively high saline water (36 PSU) at a similar location to the observations (south of Halifax), as shown in Figure 3-4. Along with the increased salinity at depth, modeled sea surface salinity decreased on the Scotian Shelf in 2016 compared to previous years (Figure 3-6): the annual average was lowest in 2017 and second-lowest in 2016 during the 8-year time period, with yearly minima in August 2016 and July 2017. Similarly, at Halifax Station 2, surface salinity (5-20m) in 2016 decreased below any other year in the 8-year time period besides 2013, and mid-depth salinity (50-100m) in 2016 and 2017 was less variable than in the other 6 years studied (Appendix B Figure 7-8). However, given that the temporal resolution of the 2016 observations was coarser than in the other years from 2012 to 2019, it is difficult to assess the significance of these changes.

\subsubsection{Transport}

At the same time and location that positive salinity anomalies were observed on the Scotian Shelf in July 2016, modeled volume and salt transport toward the GOM increased as a result of increased velocities and increased salinity (Appendix B Figure 7-9). When the salt transport was calculated with just data from offshore $(>80 \mathrm{~km}$ from the coast), the results were qualitatively similar to the full transect. This occurred simultaneously with the decreased sea surface salinity (Figure 3-6), so the overall increase in salinity transport suggests that the offshore, deep salinity anomalies (Figure 3-5) dominated the transport signal. (The potential relationship between increased bottom salinity yet 
decreased nearshore surface salinity in July 2016 is discussed more in Section 3.4.3.) In addition, salt transport was calculated at additional transects downstream of the Scotian Shelf transect (not pictured in Figure 3-1), and increased velocity and salt transport were consistent features along the shelf in mid-July 2016 (not shown). This suggests an anomaly that propagated along the outer shelf.
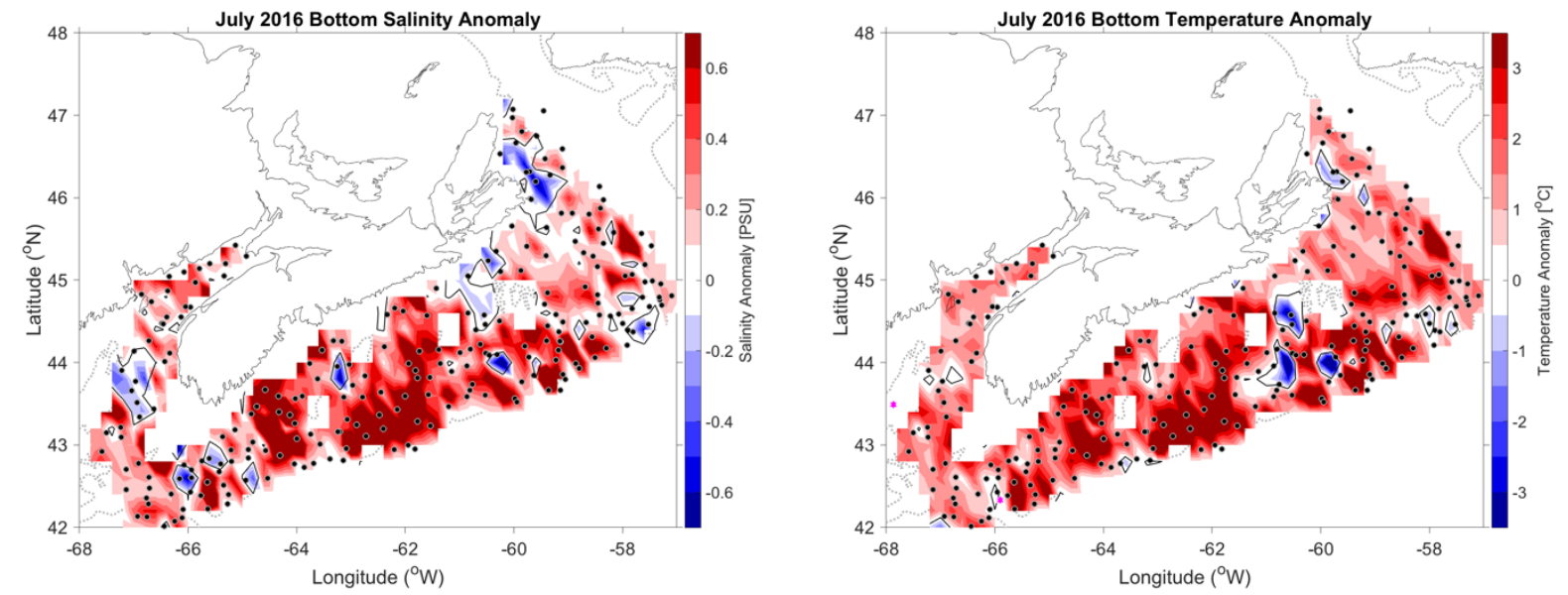

Figure 3-5 - Anomalies relative to the 1981-2010 climatology for (left) salinity and (right) temperature on the bottom of the Scotian Shelf in July 2016 as measured by the annual DFO Summer Survey. Color values are given by the color bars on the right of each plot.

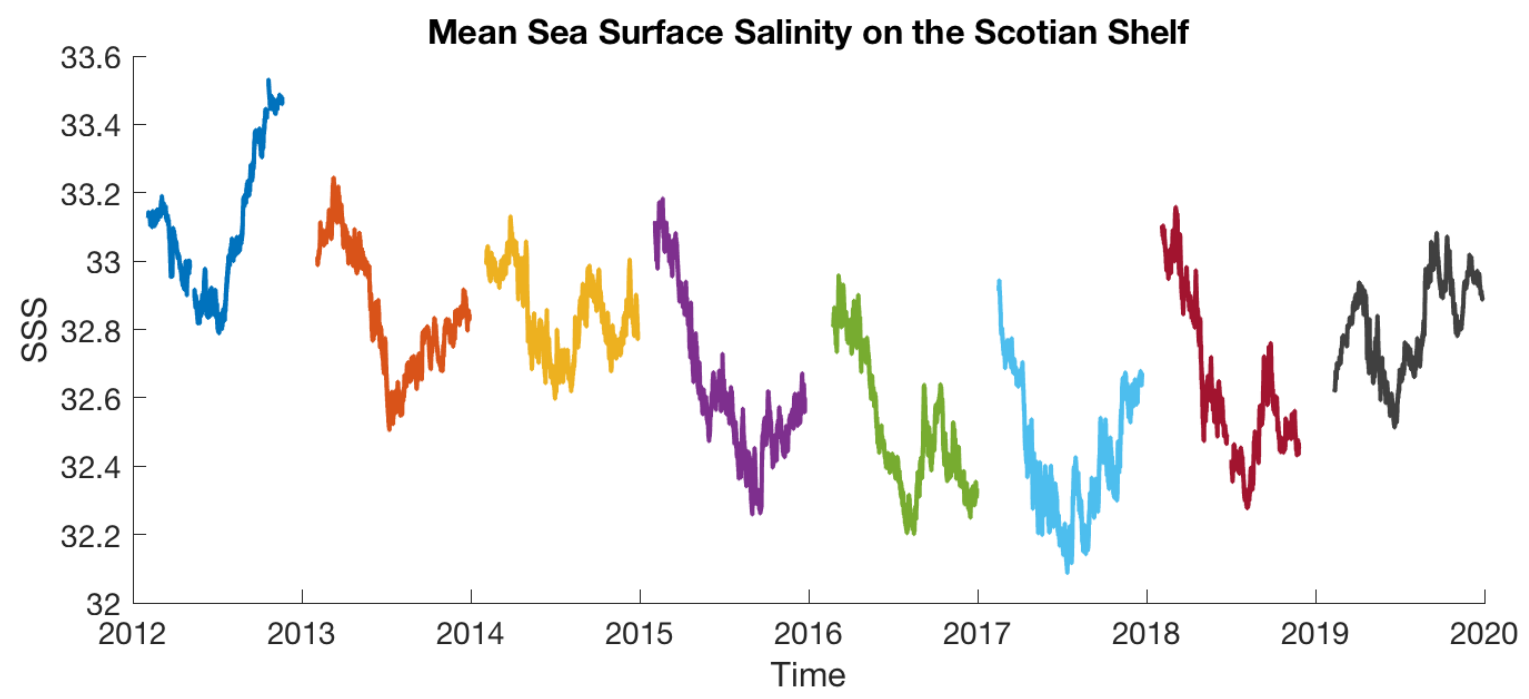

Figure 3-6 - Mean sea surface salinity (SSS) on the Scotian Shelf (as simulated by ROMS) vs time, from 2012-2019. 


\subsubsection{LTRANS}

The next section focuses on connectivity and potential growth estimates from the particle tracking experiments, with an emphasis on the August release. August was chosen as an illustrative release date, because the connectivity time scale from the October 2016 sample region to the inner Scotian Shelf and Northeast Channel in the reverse simulation was 30-60 days (see below), or early August.

\subsubsection{Connectivity}

The 2016 LTRANS reverse simulation indicates connectivity from the 2016 sample region to the Northeast Channel and the inner Scotian Shelf (Figure 3-7). Connectivity was quickest to the Northeast Channel, rising at about 20 days post release in early/midSeptember, while connectivity to the inner Scotian Shelf increased about 30 days post release, or late August/early September (Figure 3-7). Coastal connectivity to the inner Scotian Shelf was roughly consistent once established. Meanwhile, connectivity to the Northeast Channel was more episodic, with peaks near 20,30,45, and 65 days, possibly due to the highly variable nature of Northeast Channel inflows. Connectivity to the Northeast Channel was greater than to the inner Scotian Shelf via the coast, but the majority of particles that initially passed through the Northeast Channel ultimately continued upstream onto the outer Scotian Shelf (Figure 3-7). Therefore, regardless of inflow pathway, the most likely source region for P. australis was the Scotian Shelf. 

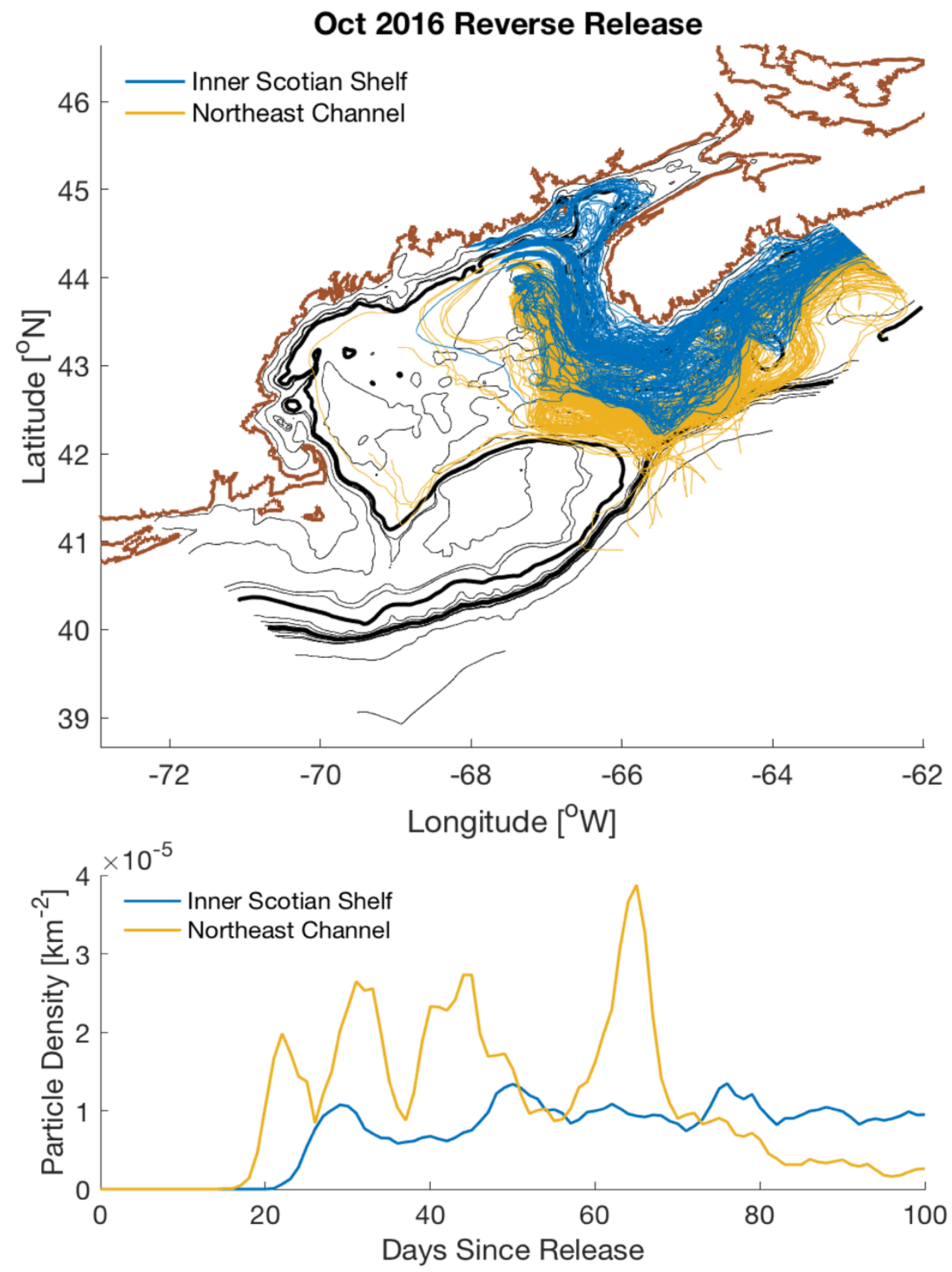

Figure 3-7 - (top) Particle tracks from the 2016 reverse simulation on a planar map of the Gulf of Maine. Tracks are color-coded by the first origin region the particle passed through: (blue) inner Scotian Shelf or (yellow) Northeast Channel. The thick brown contour indicates the shoreline, the thick black contours indicate $100 \mathrm{~m}$ and $500 \mathrm{~m}$, and the thin black contours indicate $25 \mathrm{~m}, 50 \mathrm{~m}$, $75 \mathrm{~m}$, every $100 \mathrm{~m}$ to $1000 \mathrm{~m}$, 2000m, and 3000m. (bottom) Particle density for each of the potential transit regions (blue =inner Scotian Shelf; yellow $=$ Northeast Channel) vs day since release from the 2016 reverse simulation. Particle densities are shown, rather than probabilities, because the Northeast Channel area is smaller than the inner Scotian Shelf area. 
The forward simulations complement the reverse simulations by illustrating connectivity between each source region and the Bay of Fundy, where toxicity was first observed in 2016, and the eastern Maine coast, where P. australis was observed in water samples (Bates et al., 2018; Clark et al., 2019). Regardless of release time, particles were more likely to pass through the Bay of Fundy if released from the inner Scotian Shelf than the Northeast Channel. In 2016 this difference was up to an order of magnitude (Figure 3-8), and for all 8 years it ranged from a factor of 2 to a factor of 8 (Figure 3-9). In contrast, the likelihood of reaching the eastern Maine coast was within the same envelope of variability for particles released on the inner Scotian Shelf and in the Northeast Channel in all years (Figure 3-8, Figure 3-9). On average, about $70 \%$ of the particles released on the inner Scotian Shelf that passed through the Bay of Fundy also passed along the eastern Maine coast. Connectivity varied interannually (Figure 3-9), but from neither the inner Scotian Shelf nor the Northeast Channel did particles in 2016 have an increased probability of reaching either the Bay of Fundy or the eastern Maine coast relative to other years from 2012 to 2019. In addition, weekly variability in connectivity was as large as interannual variability: in a series of tests for 2016, connectivity differences between release dates August $1^{\text {st }}, 7^{\text {th }}, 14^{\text {th }}$, and $21^{\text {st }}$ were as large as connectivity differences among the August $1^{\text {st }}$ releases in all 8 years (not shown). Interannual differences are therefore considered insignificant in this context. 

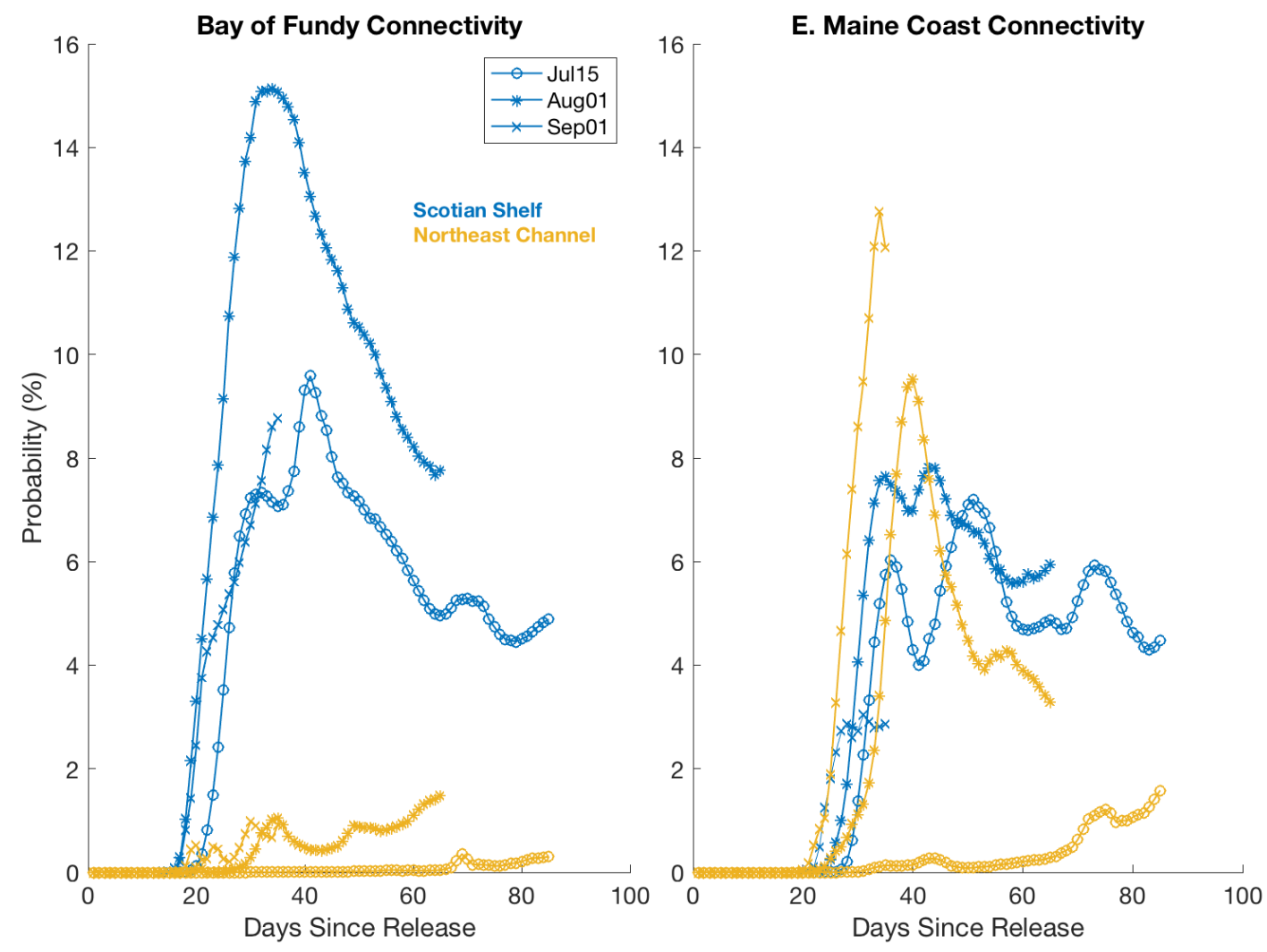

Figure 3-8 - Probability of a particle being in the Bay of Fundy (left) or E. Maine (right) vs. days since release as a function of release location (blue $=$ inner Scotian Shelf; yellow $=$ Northeast Channel) and release time (o = July 15; $*$ August 01; $x=$ September 01) in 2016. 

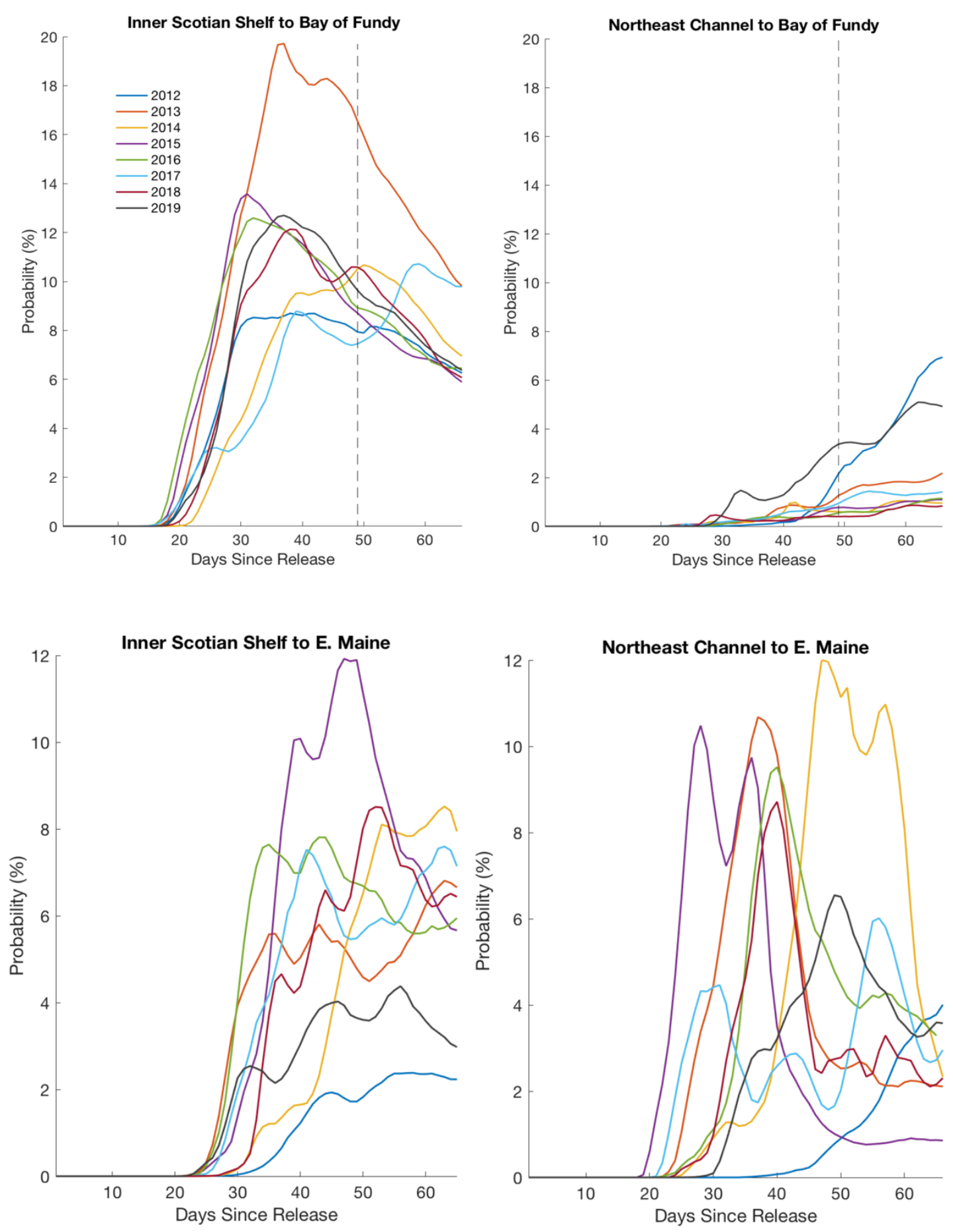

Figure 3-9 - Probability of being in the (top) Bay of Fundy or (bottom) E. Maine coast vs. days since release for particles released on August 1 on the inner Scotian Shelf (left) and in the Northeast Channel (right). Each year is represented by a different color, which is the same in all four plots. The vertical dashed line in the top plots indicates September 19, the time when toxic shellfish were first observed in the Bay of Fundy. 
Because of their proximity to the coast, particles released from the inner Scotian Shelf were associated with warmer and fresher water than particles released in the Northeast Channel (Figure 3-10). On average, the particles released in August on the inner Scotian Shelf that passed along the eastern Maine coast were $0.8^{\circ} \mathrm{C}$ warmer, $1.2 \mathrm{PSU}$ fresher, and $7 \mathrm{~m}$ shallower than those released in the Northeast Channel that passed along the eastern Maine coast Table 3-2. In 2016, particles released on the inner Scotian Shelf that passed along the eastern Maine coast were typically $2^{\circ} \mathrm{C}$ warmer, $0.6 \mathrm{PSU}$ fresher, and $14 \mathrm{~m}$ shallower than particles released in the Northeast Channel that passed along the eastern Maine coast (Table 3-2).

Table 3-2 - Summary of average temperature, salinity, and depth (2016 mean and overall mean) for particles released from either the inner Scotian Shelf or the Northeast Channel that passed through the 2016 ship survey region.

\begin{tabular}{llllllll}
\hline & \multicolumn{2}{c}{ Temperature Mean } & \multicolumn{2}{c}{ Salinity Mean } & \multicolumn{2}{c}{ Depth Mean } \\
\hline Release Location & $\underline{\text { Overall }}$ & $\underline{2016}$ & $\underline{\text { Overall }}$ & $\underline{2016}$ & & $\underline{\text { Overall }}$ & $\underline{2016}$ \\
\hline Inner Scotian Shelf & $11.3^{\circ} \mathrm{C}$ & $11.5^{\circ} \mathrm{C}$ & 32.1 & 31.8 & $33 \mathrm{~m}$ & $30 \mathrm{~m}$ \\
\hline Northeast Channel & $10.1^{\circ} \mathrm{C}$ & $9.5^{\circ} \mathrm{C}$ & 33.3 & 32.4 & $40 \mathrm{~m}$ & $44 \mathrm{~m}$ \\
\hline
\end{tabular}



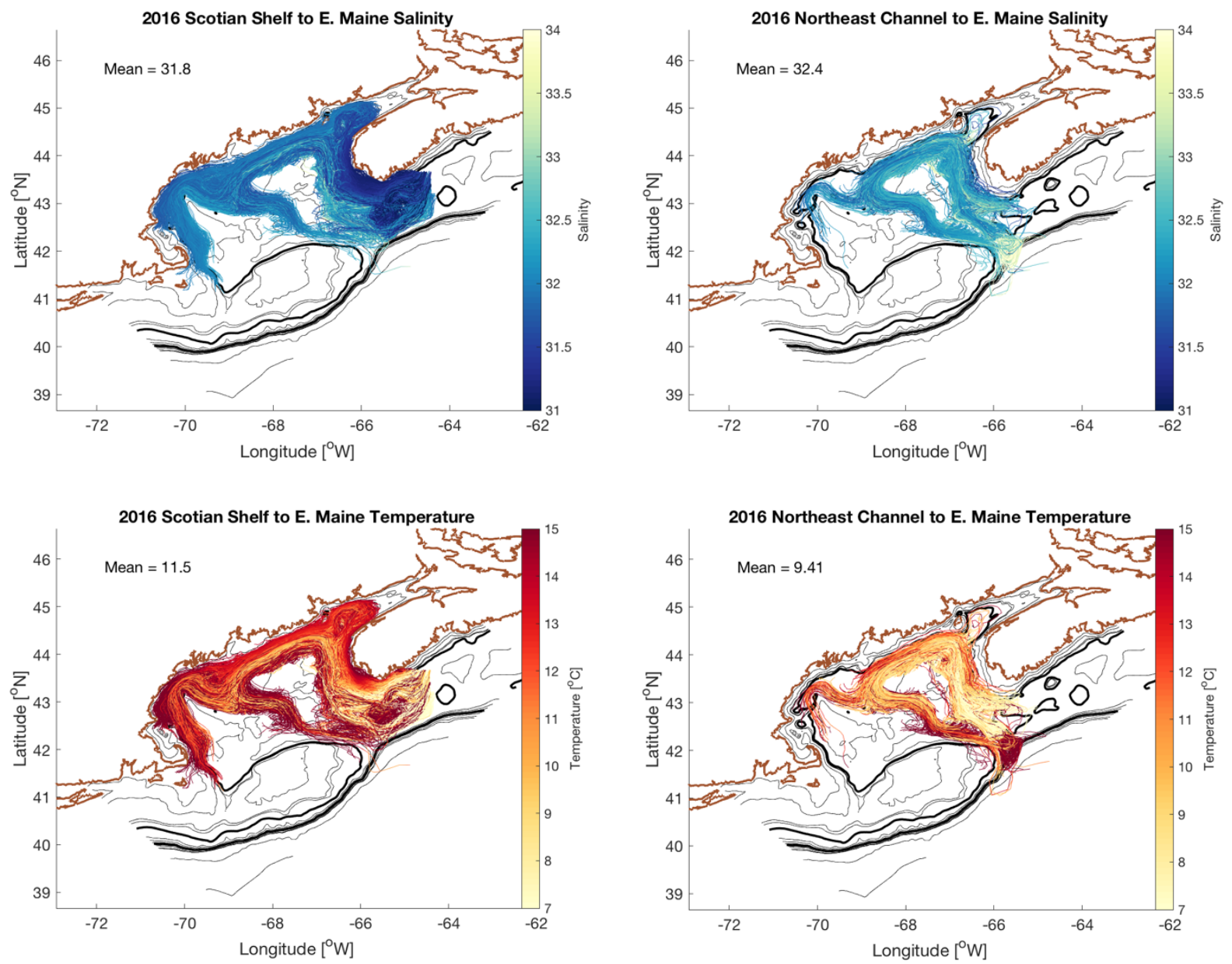

Figure 3-10 - Planar view of particle tracks in 2016 for particles released on August 1 from (left) the Scotian Shelf and (right) the Northeast Channel. Particle tracks are color-coded by (top) Salinity, or (bottom) Temperature, with the scale given by the color bars on the right. 


\subsubsection{Potential Growth}

Growth rates were measured in laboratory experiments for $7,9,11,13$, and $15^{\circ} \mathrm{C}$ (Figure $3-11$ ). As evident by high standard error, cultures at 7 and $9^{\circ} \mathrm{C}$ did not achieve steady growth. Nevertheless, they maintained positive growth at both temperatures for multiple transfers and thus mean - rather than acclimated - growth rates were calculated. Growth rates were extrapolated beyond the $7-15^{\circ} \mathrm{C}$ range using the rate of change of growth with temperature $\left(0.02 \mathrm{~d}^{-1{ }^{\circ}} \mathrm{C}^{-1}\right.$ if $T<7^{\circ} \mathrm{C}$ and $-0.03 \mathrm{~d}^{-1{ }^{\circ}} \mathrm{C}^{-1}$ if $\left.T>15^{\circ} \mathrm{C}\right)$. These rates were derived from the growth response of $P$. australis maintained at $13^{\circ} \mathrm{C}$ following short-term exposure to temperatures $<7^{\circ} \mathrm{C}$ and $>15^{\circ} \mathrm{C}$. To account for the variability across temperatures as well as the uncertainty associated with testing a single $P$. australis isolate, a growth curve was fit to the growth rates at $4,7,9,11,13,15$, and $18^{\circ} \mathrm{C}$ according to the function given in Thomas et al. (2012):

$$
\mu(T)=a e^{b T}\left[1-\left(\frac{T-z}{w / 2}\right)^{2}\right]
$$

$T$ is the temperature in degrees Celsius, $w$ is the thermal niche width, and $z$ is the location of the maximum of the quadratic portion of the function, or the temperature at which the growth curve is tangent to the Eppley Curve (Eppley, 1972). Parameter $a$ is the growth rate estimate at $0^{\circ} \mathrm{C}$, and $b$ is the Eppley coefficient, or the slope of the growth curve where growth rate rises as a function of temperature. Parameters $a, b, z$, and $w$ were fit within defined bounds. The bounds for $a$ and $b$ were [0,1], which was informed by the values given in (Norberg, 2004). The bounds for $z$ were $[7,15]$ and the bounds for $w$ were $[10,20]$, which were based on the range of temperatures at which growth rates were measured. The best fit by nonlinear least-squares was achieved when $a=0.198, b=0.0746$, $z=7$, and $w=15.75$. These $a$ and $b$ values are the same order of magnitude as in Norberg (2004), and these $z$ and $w$ values are reasonable given the temperature values measured in laboratory experiments. The sum of squared errors from this fit was 0.0026 . The full 
growth curve is given in Figure 3-11 and the measured growth values are given with corresponding standard errors in Appendix B, Table 7-1.

Because particles released from the inner Scotian Shelf were in warmer water, they had higher average potential growth rates than those released from the Northeast Channel (Figure 3-12). The largest potential growth rates generally occurred nearshore and in the Bay of Fundy, with occasional elevated growth rates farther offshore (not shown). The exception to this is the year 2012, the year of a marine heat wave (Pershing et al., 2015), when potential growth rates were higher at all locations and there was no cross-shore gradient (not shown).

The Kolmogorov-Smirnov test indicated that potential growth rates from the inner Scotian Shelf were significantly higher than from the Northeast Channel, whether the growth rates were from all years combined or from 2016 individually. However, potential daily growth rates were neither significantly higher nor significantly lower in 2016 compared to other years from 2012 to 2019, regardless of release location.

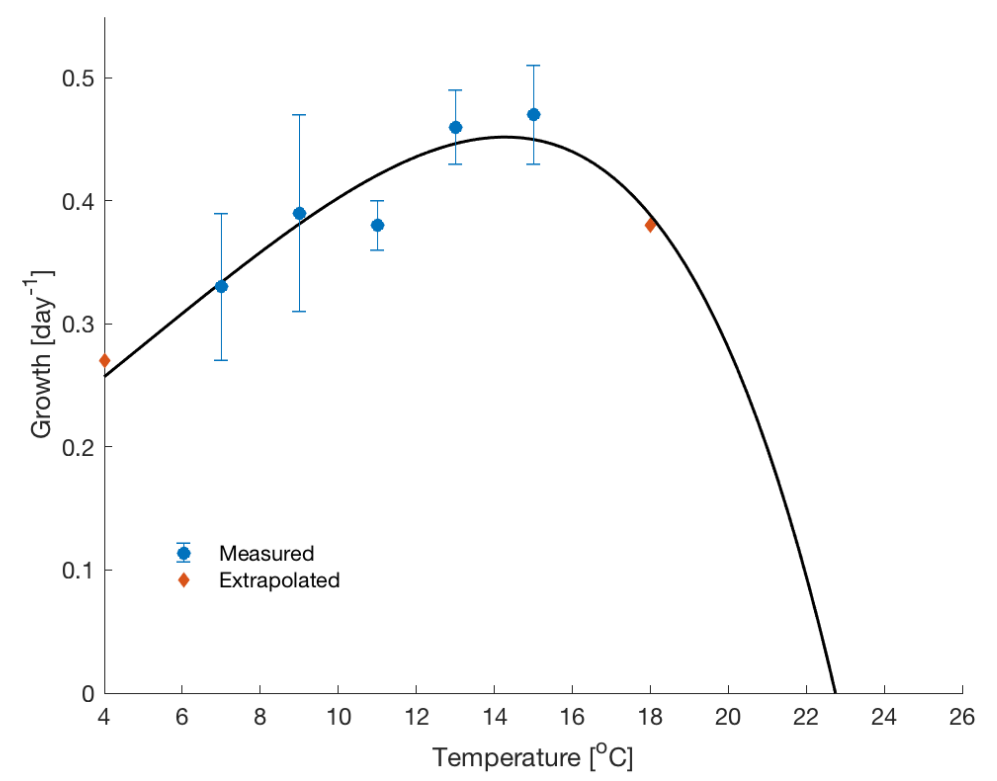

Figure 3-11 - Growth rate as a function of temperature as measured in lab cultures. The blue points indicate values that were measured, and the error bars show standard error. The orange diamonds were estimated using a rate of change of growth rate with temperature as measured during short-term exposure experiments. The black line shows the theoretical curve as estimated from equation S.1 in Thomas et al. (2012). 
Per-particle Average Growth Rates: 2016
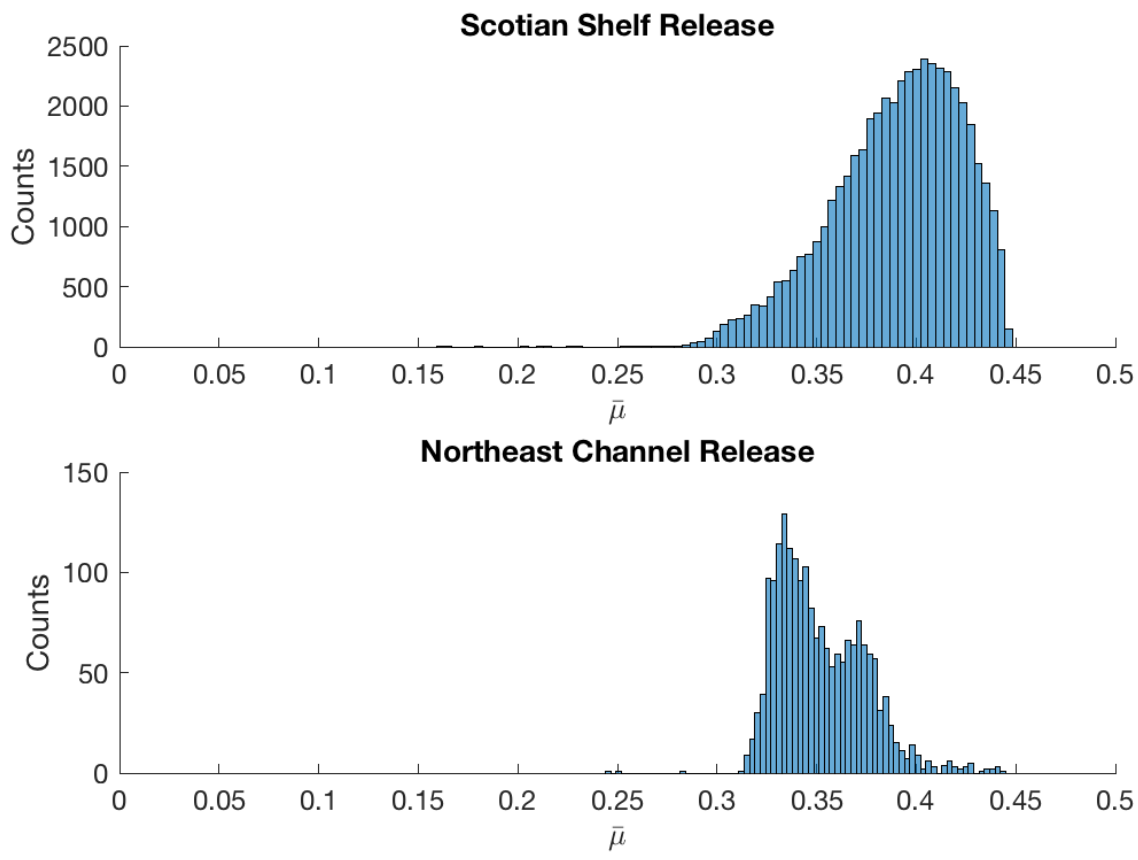

Figure 3-12 - Histograms of particle-averaged potential growth rates in 2016 for particles released on the inner Scotian Shelf (top) and in the Northeast Channel (bottom) that were in the Bay of Fundy between September 5 and September 19, 2016. Note that the y-axis scales are different. 


\subsection{Discussion}

\subsubsection{Likely $P$. australis Introduction Pathway}

The LTRANS reverse results indicate a $P$. australis source region on the Scotian Shelf, and inflow routes via either the Northeast Channel or around the southern tip of Nova Scotia. The current along the latter inflow route is not well defined in the literature, having been referred to as both "an extension of the Nova Scotia Current" (Townsend et al., 2015) and the beginning of the Gulf of Maine Coastal Current (Pettigrew et al., 2005). This route will therefore be called the coastal route for simplicity. In 2016, particles released in the Northeast Channel were as likely to reach the eastern Maine coast as those released on the inner Scotian Shelf, the majority of which were transported along the coastal route (Figure 3-8). From this alone, both the Northeast Channel and the coastal route were equally likely inflow routes for P. australis cells in 2016. However, particles released from the Northeast Channel had a low probability of reaching the Bay of Fundy compared to those released from the inner Scotian Shelf (Figure 3-8). An additional reverse experiment was run with particles released just below the surface in the Bay of Fundy from September 12 to September 19, which was the period of shellfish closures in that region. It confirmed that particles in the Bay of Fundy were connected to the inner Scotian Shelf via the coastal route, but were not connected to the Northeast Channel (Appendix B Figure 7-12).

In addition to connectivity, along-path temperature and salinity provide important context. Particles that entered the gulf via the Northeast Channel were generally in a higher salinity range (Figure 3-10) than those that entered via the coastal route. Although the salinity average was not as high as the coastal observations in Clark et al. (2019), it was closer to the 2016 observations than the average salinity of particles from the inner Scotian Shelf that followed the coastal inflow route. However, particles that entered via the coastal route were more likely to be between 7 and $15^{\circ} \mathrm{C}$, the range in which the GOM strain of $P$. australis can sustain growth, than particles that entered via the Northeast 
Channel. The highest potential growth values occurred near the coast and in the Bay of Fundy, where water is shallower and warmer. As a result, potential growth rates were higher for particles coming in via the coastal route than for those coming in via the Northeast Channel.

Thus, there are arguments for and against both inflow routes, and particles entering both via the coastal route and the Northeast Channel connected to the eastern Maine coast. Northeast Channel particles were in a salinity range closer to the 2016 observations, but they lacked connectivity to the Bay of Fundy and were in relatively cool water. Meanwhile, coastal route particles had the strongest connectivity to the Bay of Fundy and were in a temperature range that promoted growth, but were in relatively fresh water. Despite the fact that the modeled salinity did not agree with the 2016 coastal observations, the warmer temperatures and connectivity to the Bay of Fundy mean that inflows via the coastal route were more likely to introduce $P$. australis than inflows via the Northeast

Channel. In order for the cells to have been introduced to the Bay of Fundy before the first observation of toxic shellfish in mid-September 2016, they would have had to come from the Scotian Shelf sometime on or before early August 2016 and entered the Gulf of Maine near the coast of Nova Scotia.

\subsubsection{6 in an Interannual Context}

A distinct aspect of the 2016 P. australis bloom compared to previous Pseudo-nitzschia blooms of other species in the Gulf of Maine is that it occurred in late September to October, while previous blooms associated with DA had occurred from July to early September (Clark et al., 2019; Fernandes et al., 2014). The September bloom could be related to a "marine heat wave" that took place in 2016 across the GOM and Scotian Shelf (Pershing et al., 2018). From ship observations in 2016 (Clark et al., 2019, Figure 10B), sea surface temperatures along the coast of Maine in early October 2016 were warmer than the 2001-2016 October mean as measured at NERACOOS Buoy I, and as many as half of the measurements were more than one standard deviation warmer than the 
2001-2016 October mean. The average water temperature from the ship observations was $13.5^{\circ} \mathrm{C}$, which is near the optimal temperature for the tested strain of $P$. australis (Section 3.3.2.2, Figure 3-11). Increased temperatures have also been associated with increased DA production on the U.S. West Coast (Trainer et al., 2020). Temperature has also been found to contribute to regime shifts between species of Pseudo-nitzschia near Denmark (Lundholm et al., 2010), and between zooplankton communities along the United States East Coast (Morse et al., 2017), although the shifts occurred over decades, not years. Therefore, increased temperatures may have been important for both growth and DA production in the GOM in 2016. The 2016 marine heat wave might also have selected against other organisms, whether competitive or predatory, to allow $P$. australis a greater chance to survive and grow. Water temperature effects on inter-community competition and long-term trends in the GOM are speculative and warrant further research.

Warmer temperatures may have supported a later bloom and more particles with relatively high growth potential in 2016, but the connectivity and potential growth rates that year were not significantly different from the other years between 2012 and 2019. Although the warm temperatures could have provided favorable growth conditions at other locations within the Gulf of Maine, they did not correspond with improved growth delivery potential along the inflow routes. It should be noted that the growth model used here incorporated only temperature-dependent growth rates. Although growth rates as a function of salinity have been reported for other strains of $P$. australis (Ayache et al., 2020), they are not currently available for this strain. In addition, other factors to growth, such as light availability, nutrients, and predation, have not been considered. This growth model is based only on temperature and on a single strain of $P$. australis. To improve our understanding of bloom dynamics in the region, growth rate estimates as a function of salinity, irradiance, and nutrients should be explored, as well as growth rates from different $P$. australis strains. Expanding the model, however, is beyond the scope of this study. 


\subsubsection{Changes Upstream}

\subsubsection{Increased Bottom Salinity on the Scotian Shelf}

A notable change on the Scotian Shelf in 2016 was the increased bottom salinity in the summer, which was captured both by ROMS and by the DFO summer survey. Brickman et al. (2018) observed and modeled these anomalies from 1990 to 2015 and argued that they occur as a result of warm, saline Gulf Stream water cutting off cool, fresh Labrador Current water near the Grand Banks off the coast of Newfoundland, Canada. Positive anomalies increased in frequency from 2006 to 2015, leading to more positive temperature and salinity anomalies at depth on the Scotian Shelf, but this might be the result of interdecadal variability in the region, rather than an indicator of a long-term trend (Brickman et al., 2018).

The timing of the increased salinity on the Scotian Shelf (Figure 3-4) and the connectivity from the Northeast Channel to the eastern Maine coast support the hypothesis that a salinity anomaly entered via the Northeast Channel. Brickman et al. (2018) estimated that salinity anomalies on the Scotian Shelf propagate southwest at about 150 $\mathrm{km}$ month $^{-1}$. The distance from the Scotian Shelf transect (where the increased salt transport was observed) to the Northeast Channel is about $230 \mathrm{~km}$, which means that the observed pulse would have taken about 1.5 months ( 45 days) to travel from the transect to the Northeast Channel, arriving at the Northeast Channel in mid-to-late August. From the model output, salt transport toward the Gulf of Maine across the Northeast Channel in mid-August increased more than one standard deviation above the interannual mean (as it did on the Scotian Shelf) and remained elevated for about 5 days. This salt transport was not larger than all other years from 2012 to 2019, and some years besides 2016 had summer salt transports of similar magnitude, but 2016 was the only year with elevated summer transport on both the Scotian Shelf and the Northeast Channel. Meanwhile, connectivity between the coast and the Northeast Channel in the reverse experiment in 2016 had a peak near 45 days post-release, or mid-August. This suggests that a water 
mass that was present on the Scotian Shelf in July and entered via the Northeast Channel in August could have arrived at the coast of Maine by early October, in time to be observed during the 2016 ship survey.

This discussion has focused on the timing of a particular anomaly observed in mid-July 2016, but as described by Brickman, et al. (2018), multiple anomalies can form on the Scotian Shelf in a summer. Perfect timing is therefore not necessary for this introduction route to be plausible. Transport time varies with depth as a function of velocity shear: transport time scales from the Northeast Channel to the eastern Maine coast were calculated as a function of particles' initial depth and found to range from 45 days (surface to $50 \mathrm{~m}$ release) to 90 days (bottom release). From the DFO survey data, anomalous salinity signals were present from 50 to $125 \mathrm{~m}$. Considering the range of possible depths and associated transport time scales, an anomaly passing through the Northeast Channel any time between early June and mid-August 2016 could explain the elevated salinity values at the coast.

Brickman et al. also hypothesized that repeated salinity anomalies would, through an integrative effect, result in deeper on-shelf penetration via channels such as the Northeast Channel. Considering that 2016 followed several years of increased bottom salinity anomalies on the Scotian Shelf (Brickman et al., 2018), it is not unreasonable that an anomaly would have reached the coast of Maine in 2016, causing the high salinity values observed in Clark et al. (2019). Given these lines of evidence, the saline water mass that was observed on the coast of Maine in 2016 likely came from the Gulf Stream, propagated along the outer Scotian Shelf, and entered the GOM through the Northeast Channel.

\subsubsection{Decreased Sea Surface Salinity on the Scotian Shelf}

As the bottom salinity on the Scotian Shelf increased in 2016, the surface salinity decreased by up to 0.6 PSU. Although the increased bottom salinity and decreased surface salinity occurred simultaneously in summer 2016 (Figure 3-5, Figure 3-6), bottom salinity and surface salinity on the Scotian Shelf were not consistently correlated across the 
8 years studied. For each year, linear regressions were calculated between surface nearshore salinity and bottom offshore salinity at the ROMS eastern boundary (on the Scotian Shelf), and $\mathrm{R}^{2}$ values ranged from 0.01 to 0.67 , with an average of 0.16 . Therefore, the surface and bottom salinity anomalies appear to be largely unrelated.

The modeled decrease in sea surface salinity on the Scotian Shelf in 2016 and 2017 (Figure 3-6) might suggest increased outflow from the St. Lawrence River via the HYCOM boundary conditions, because upper layer salinity $(30-50 \mathrm{~m})$ on the Scotian Shelf is comprised of St. Lawrence River discharge (Dever, et al., 2016). However, St. Lawrence River discharge was at an 8-year minimum in the 12 months prior to summer $2016^{8}$, and it has been shown that the salinity signal from the St. Lawrence River decreases to +/- 0.1 PSU by the time it reaches the Halifax Line (Ohashi and Sheng, 2013). It is therefore unlikely that changes in the St. Lawrence River caused the sea surface salinity changes on the Scotian Shelf. Townsend, et al. (2015) argued that there had been an increase in the frequency of strong Scotian Shelf Water inflows via Nova Scotia in the early 2010s, and presented evidence of increasing freshwater fluxes from the Labrador Sea via the Labrador Current. It is possible that the surface freshening modeled on the Scotian Shelf in 2016 and 2017 is indicative of these episodic changes. This is in contrast to the findings of Brickman et al. (2018), which outlined how the Gulf Stream effectively cuts off the Labrador Current near the Grand Banks, but this difference could be because the processes Townsend et al. described occur at the surface, while those described by Brickman et al. occur at depth.

Intermediate layer water on the Scotian Shelf (50-100m, also known as the Cold Intermediate Layer, or CIL) is composed of either the inshore branch of the Labrador Current or CIL water formed in the Gulf of St Lawrence, which is distinct from St. Lawrence River outflow (Dever et al., 2016). In the intermediate layer at

\footnotetext{
${ }^{8}$ https://waterdata.usgs.gov/nwis/dv?referred_module=sw\&site_no=04264331
} 
Halifax Station 2, observed salinity and temperature were both lower and less variable in 2016 than in the 7 other years in this study, with a water mass signature that was a mixture of Labrador Slope Water, Cabot Strait-Cold Intermediate Layer water, and Cabot Strait Subsurface water, as described in Dever, et al. (2016) (Figure 3-13). This suggests that changes on the Scotian Shelf are driven by changes in the Labrador Current or Gulf of St. Lawrence, either of which could be a link to the upstream source of P. australis. More work is necessary - either via an expanded model domain or ship surveys - to determine the relative likelihood of each source.

To summarize the introduction routes, $P$. australis likely entered the Gulf of Maine via the inner Scotian Shelf and coastal route around southern Nova Scotia, was concurrent with decreased sea surface salinity on the Scotian Shelf, and had an upstream source in either the Labrador Current or Gulf of St. Lawrence. In contrast, the observed positive salinity anomalies on the Maine Coast likely originated in the Gulf Stream and entered the GOM via the Northeast Channel. Particle tracking experiments suggest that these two phenomena met along the upper coast of Maine and were mixed through strong tidal mixing, which is not unreasonable according to the data. If the positive salinity anomaly at the bottom $($ mean $=35)$ and negative salinity anomaly at the surface $($ mean $=32.5)$ were to mix, the required mixing ratio to achieve the salinity observed in Clark et al. (2019) $($ mean $=33.25)$ would be $30 / 70($ bottom/surface $)$. The mixed water could have then flowed southwest where it was observed during the 2016 ship survey.

Changing upstream water masses could also have affected nutrient concentrations in the GOM, and, in turn, the 2016 bloom. The surface and mid-depth salinity changes suggest increasing influence from the Labrador Current, which typically has a silica-to-nitrate ratio greater than 1 (Townsend et al., 2010). The bottom salinity anomalies, meanwhile, are thought to have originated in the Gulf Stream, which has a silica-to-nitrogen ratio less than 1 (Townsend et al., 2010). It is logical from a nutrient perspective that $P$. australis were carried in with the surface Scotian Shelf inflows: an increased silica-to-nitrogen ratio 
could have supported a healthy diatom population. In the 2016 ship survey, however, the silica-to-nitrogen ratio was significantly lower compared to two of the previous years' ship survey samples, and was thought to exacerbate DA production (Clark et al., 2019). The low ratio in the observations could be the result of Gulf Stream water mixing with Scotian Shelf water at the mouth of the Bay of Fundy, as hypothesized above. Thus, the twopronged introduction hypothesis, in combination with the nutrient characteristics of the source water masses, suggest that a healthy population of $P$. australis was advected into the Bay of Fundy and eastern Maine, where it met waters with low silica, leading to enhanced DA production.

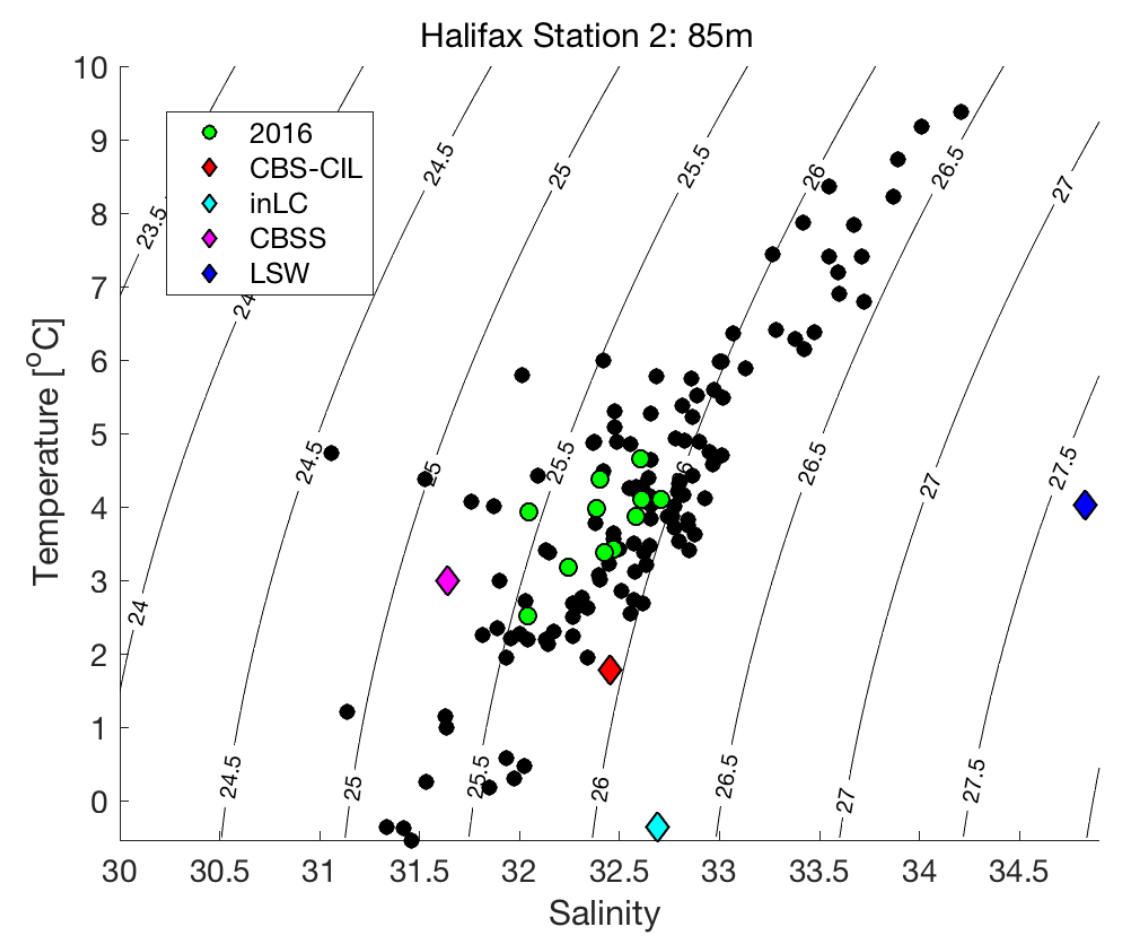

Figure 3-13 - Year-round temperature vs salinity as measured at Halifax Station 2 at 85m. 2016 is highlighted in green, while 2012-2018 are plotted in black. For comparison, the endmembers of CBS-CIL (Cabot Straight-Cold Intermediate Layer), inLC (Inshore Labrador Current), CBSS (Cabot Straight Subsurface Water), and LSW (Labrador Slope Water), as defined in Dever et al., (2016), are plotted. 


\subsubsection{P. australis Distribution in the North Atlantic}

Evidence suggests that $P$. australis originated outside the GOM, which necessitates a look at $P$. australis distributions in the North Atlantic. P. australis has been observed near the United Kingdom and Ireland (Bresnan et al., 2017, 2015; Cusack et al., 2002; Fehling et al., 2006; Hasle, 2002; Thorel et al., 2014), France (Ayache et al., 2020; Husson et al., 2016; Klein et al., 2010; Lema et al., 2017; Thorel et al., 2017), the Iberian Peninsula (Churro et al., 2009; Palma et al., 2010; Zapata et al., 2011), and Morocco (Ennaffah et al., 2012). The question remains how the cells could have been transported from these regions in the eastern Atlantic to the Scotian Shelf and Gulf of Maine.

The two likely transport routes are via the subtropical gyre and the Gulf Stream, or via the subpolar gyre and the Labrador Current, which meet near the Grand Banks of Newfoundland (Townsend et al., 2006). Introduction via the subtropical gyre would indicate a more southern origin of the species, possibly from Morocco or the Iberian Peninsula. To have been introduced along this route, the cells would have been carried west across the subtropical Atlantic and then northward by the Gulf Stream. However, growth rates of the 2016 GOM strain of $P$. australis declined rapidly at temperatures above $18^{\circ} \mathrm{C}$ (Figure $3-11$ ), which is regularly exceeded along this route. In addition, we have argued that the source of $P$. australis was likely either the Labrador Current or Gulf of St. Lawrence. The strong connectivity from the inner Scotian Shelf to the Bay of Fundy and the decreased surface salinity on the Scotian Shelf in 2016 align with introduction via the subpolar gyre and Labrador Current. This suggests a cooler origin, which better aligns with the temperature growth curve for the GOM P. australis isolate. For comparison, P. australis from the English Channel grew best at $13.5-18.6^{\circ} \mathrm{C}$, with growth rates from 0.47 to 0.83 day $^{-1}$ (Thorel et al., 2014). This temperature range overlaps with the range of peak growth for the GOM strain of $P$. australis, but it is slightly warmer and the growth rates are slightly higher. This could be due to population variability in the GOM that was not represented by examining a single GOM strain under the chosen laboratory conditions. 
Alternatively, selection may have occurred en route to the GOM. A subpolar introduction route seems more likely, but this hypothesis can be neither proven nor refuted without additional data. The best way to test this hypothesis is via targeted sampling, further modeling, and a genetic comparison between the GOM $P$. australis strain and other strains across the Atlantic, which could be the subject of future research.

\subsubsection{Looking to the Future: Persistence vs. Persistent Introduction}

An important question for scientists, managers, and state officials is whether the P. australis bloom in 2016 was anomalous or if it indicates a growing DA concern for the region. The 2016 event was likely due to the import of $P$. australis from the Scotian Shelf, but future blooms could be seeded by cells retained in the GOM, recurring introductions of cells from outside the GOM, or some combination of both. In other words, do we expect introduction plus persistence, or persistent introduction?

P. australis cells and DA-related shellfish harvest area closures have occurred in Maine every year since 2016 (Chadwick, 2021). In addition, concentrations of large Pseudonitzschia cells at the Bar Harbor monitoring station exceeded 100,000 cells L-1 in 2017, 2019, and 2020. Low cell concentrations in 2018 could be the result of a spatially heterogeneous bloom in which cell concentrations were higher elsewhere, because data post-2016 are from a single-point time series.

However, despite observations of $P$. australis since 2016, the model output in this study did not point to any shifts that could explain why there were no DA events pre-2016 but annual DA events post-2016. Surface salinity was low in 2016 and 2017 and this corresponded with the original P. australis bloom in 2016 (Section 3.4.3.2), but the signal did not persist past 2017. In addition, model output did not indicate lasting changes in connectivity strength, connectivity timing, or growth potential. Evidence from the literature does point to long-term trends of increased inflows of Scotian Shelf Water (Townsend et al. 2015) and increasingly warm/saline near-bottom water on the Scotian Shelf (Brickman et al. 2018). This study did not identify any regime shift in water mass 
characteristics associated with the 2016 bloom, but other studies suggest changes in GOM inflows.

The evidence post-2016 indicates that $P$. australis blooms have continued in the GOM, but the available data are insufficient to determine whether the blooms are due to persistence or persistent introduction. Continued and expanded time series monitoring is recommended to map future blooms as they occur and to better understand interannual variability in the timing, extent, and severity of DA events in the region. Ideally this expanded effort would include sample collection on the Scotian Shelf and regions further upstream to better understand connectivity with established $P$. australis populations.

\subsection{Conclusions}

This study (submitted to Continental Shelf Research, 2021) used a physical model, particle tracking model, and observations to explore introduction and connectivity pathways to the Gulf of Maine in 2016, the year of a regionally historic DA event. Results from the particle tracking simulations revealed that $P$. australis cells likely originated on the Scotian Shelf and were carried into the GOM via inflows south of Nova Scotia, because only this pathway explains the $P$. australis cells and observed toxicity in the Bay of Fundy. Anomalously saline water originated near the bottom on the Scotian Shelf, entered the GOM via the Northeast Channel, and mixed with lower salinity surface water near the mouth of the Bay of Fundy. Regional connectivity and potential growth rates in 2016 were not larger than in the other modeled years between 2012 and 2019, but surface salinity on the Scotian Shelf was up to 0.6 PSU lower than the 7 other years in this study, and bottom salinity on the Scotian Shelf was 0.7 PSU greater than the 1981-2010 climatology. This suggests that the bloom was controlled by large-scale processes, not local-scale ones, and we propose that $P$. australis arrived at the Scotian Shelf and GOM via either the Gulf of St. Lawrence or the Labrador Current. Future studies should consider adding nutrient-, light-, or salinity-dependency to the growth model, exploring mechanisms underlying DA production in the GOM, expanding the hydrodynamic model 
domain to include offshore dynamics, and running the model continuously over more years to test the question of interannual persistence. Ocean sampling is recommended on and beyond the Scotian Shelf to determine if there is an upstream source of P. australis. Finally, $P$. australis blooms are likely to remain a concern in the GOM, and continued monitoring is warranted. 


\section{Potential effects of climate change on Pseudo-nitzschia bloom dynamics in the Gulf of Maine}

\subsection{Introduction}

Pseudo-nitzschia is a lightly silicified, pennate diatom genus with at least 52 confirmed species (Bates et al., 2018). Pseudo-nitzschia can produce domoic acid (DA), a neurotoxin that can lead to Amnesic Shellfish Poisoning, the side effects of which include stomach pain, short-term memory loss, and even death (Bates et al., 2018, 1989). There are at least 26 confirmed DA-producing Pseudo-nitzschia species (Bates et al., 2018), but DA production is not constitutive; it can vary between species, between species strains, or depending on environmental conditions or cell growth stage (e.g. Bates et al., 1991; Lundholm et al., 2004; Maldonado et al., 2002; Thessen et al., 2009; Thorel et al., 2014). Pseudo-nitzschia have been described as "cosmopolitan" (Hasle, 2002) because they are able to tolerate a wide range of temperature and salinity conditions, and as a result they have been observed around the globe (Bates et al., 2018). The severity and range of Harmful Algal Blooms (HABs) caused by Pseudo-nitzschia have been increasing in recent years, with large-scale blooms leading to millions of dollars in economic losses (Moore et al., 2020), and new species blooming in previously unaffected regions (e.g. Bates et al., 2018; Clark et al., 2019; Park et al., 2018).

One example of the increasing abundance and extent of Pseudo-nitzschia HABs is an unprecedented DA event and subsequent shellfishery closures in the Gulf of Maine (GOM) in 2016 (Bates et al., 2018; Clark et al., 2019). Prior to 2016, 14 Pseudo-nitzschia species had been identified in the region (Fernandes et al., 2014), including some DA producers, but the 2016 bloom was caused primarily by $P$. australis, which had never before been 
observed in the GOM (Clark et al., 2019). P. australis blooms have occurred every year since 2016, reflecting a possible "regime shift" in Pseudo-nitzschia bloom dynamics.

The DA event in 2016 is but one example of recent changes in the GOM. In 2012, an ocean heat wave led to reduced Atlantic Cod recruitment, which, combined with overfishing, caused a collapse of the GOM cod fishery (Pershing et al., 2015). Another heat wave in the GOM-Scotian Shelf region was observed in 2016 (Pershing et al., 2018). Although the rate of warming in the GOM and its effect on the ecosystems is under debate (Palmer et al., 2016; Pershing et al., 2016, 2015), there is no question that sea surface temperatures are warming, and that the warming is strongest in the summer and autumn (Thomas et al., 2017), the time of year when previous Pseudo-nitzschia blooms - including P. australis - have occurred. In addition, the relative importance of different source waters to the GOM may have changed in recent decades: Townsend et al. (2015) provided evidence that in recent decades the proportion of Scotian Shelf Water flowing into the region has increased relative to Slope Water, although it is unclear whether this is a longterm trend. Farther upstream, the Gulf of St. Lawrence is predicted to change as a result of climate change, with less ice coverage in the winter, warmer and fresher sea surface waters in the summer, and weaker cold water formation (Long et al., 2016). These changes are likely to affect inflows to the GOM and water mass properties in the interior.

Changes to the GOM and its source waters might affect the existing assemblage of Pseudonitzschia, or alter environmental conditions to change the assemblage. Studies in other regions have explored how climatic factors affect Pseudo-nitzschia growth, competitiveness, and DA production. Changing temperatures might affect Pseudonitzschia abundance by increasing growth rates (Thorel et al., 2014), or by favoring Pseudo-nitzschia over other phytoplankton (Zhu et al., 2017). Higher temperatures have also been shown to increase DA production, particularly in P. australis (McKibben et al., 2017; Thorel et al., 2014; Zhu et al., 2017). Indeed, some changes to Pseudo-nitzschia abundance worldwide have already occurred as a result of warming oceans. 
A record-breaking $P$. australis bloom on the U.S. West Coast, which was preceded by a "Warm Blob" and intermittent upwelling (McCabe et al., 2016), is an example of what might be expected with climate change (Trainer et al., 2020). Farther down the coast in the Santa Barbara Bight, warming ocean temperatures were correlated with a decline in diatoms of the genera Chaetoceros and Rhizosolenia, but an increase in Pseudo-nitzschia species broadly and P. australis specifically (Barron et al., 2013). In the North Atlantic, data from the Continuous Plankton Recorder showed an increase in the abundance of diatoms from 1960 to 2009 (Hinder et al., 2012), and in Danish sill-fjords Pseudo-nitzschia species assemblages have shifted as a result of increased nitrogen loading and temperature (Lundholm et al., 2010).

In the context of these global changes and the initiation of annual $P$. australis blooms in the GOM starting in 2016, it is important to understand how Pseudo-nitzschia blooms in the GOM might change as a result of climate change. Models offer an ideal tool for such investigations, but a typical Global Climate Model is too coarse (about 1-degree resolution) to accurately capture the nearshore processes and complex bathymetry that are important to regional hydrodynamics. One recommended solution is to downscale a coarse circulation model to a GOM regional model (Ralston and Moore, 2020). This approach was used to model the Northwest Atlantic from the Gulf of Mexico to the Gulf of St. Lawrence (Alexander et al., 2020): climate simulation results from the Geophysical Fluid Dynamics Laboratory Earth System Model (GFDL-ESM2M) were used to force a Regional Ocean Modeling System (ROMS) with $7 \mathrm{~km}$ horizontal resolution. The higher resolution model predicted enhanced bottom warming in the GOM relative to the climate model, because its finer resolution better captured ocean circulation, deep inflows in the Northeast Channel, and altered upstream water mass properties (Shin and Alexander, 2020a).

This study will further downscale the $7 \mathrm{~km}$ resolution ROMS (Alexander et al., 2020) to a 1-3km resolution Gulf of Maine ROMS (He et al., 2008; Li et al., 2009; McGillicuddy 
et al., 2011) to investigate the effects of climate change on Pseudo-nitzschia bloom dynamics in the GOM. To our knowledge, this is the first downscaled climate model to be applied to the GOM at such a high resolution, and the first study to investigate the effects of climate change on Pseudo-nitzschia with a physical circulation model. The following methods section describes the study region, the two ROMS configurations, the "Delta Method", and relevant analysis. The results and discussion section will focus on changes to hydrodynamics, the mechanics thereof, and their consequences for Pseudonitzschia blooms. Particular attention is given to how P. australis bloom dynamics might change in the eastern GOM as a result of changing hydrodynamics and growth potential.

\subsection{Methods}

\subsubsection{Region of Study}

\subsubsection{Gulf of Maine}

The Gulf of Maine is a shelf sea off the coast of the northeast United States and Canada, stretching from 42 to $44.5^{\circ} \mathrm{N}$ and from 66 to $71^{\circ} \mathrm{W}$ (Figure $4-1$ ). Mean sea surface temperatures range from $4^{\circ} \mathrm{C}$ in February to $22.5^{\circ} \mathrm{C}$ in August, and historical salinity values range from 29 nearshore to 33.5 offshore (Li et al., 2014). Interior water mass properties are largely driven by inflows, which enter the gulf along the coastal region south of Nova Scotia and at depth in the Northeast Channel (Townsend et al., 2015). Nova Scotian inflows are made up of relatively fresh, cool Scotian Shelf Water $\left(5-7^{\circ} \mathrm{C}, 32.5-33.4\right)$, while Northeast Channel inflows are a mixture of Warm Slope Water (WSW; $11^{\circ} \mathrm{C}, 35$ ), and Labrador Slope Water (LSW; $6.5^{\circ} \mathrm{C}, 34.5$ ) (Townsend et al., 2015, 2014). Nutrients that are carried in with dense slope waters are brought to the surface via tidal mixing in the Bay of Fundy (Brooks and Townsend, 1989) and via deep convection in the winter. The Bay of Fundy, Georges Bank, and northeastern GOM remain well-mixed year-round because of the energy imparted by the tides (Townsend et al., 2014). 
The interior GOM is comprised of three basins with depths greater than 200m - Georges Basin, Wilkinson Basin, and Jordan Basin - and is separated from the open North Atlantic via offshore banks shallower than 100m - Georges Bank and Browns Bank. The general circulation in the GOM is cyclonic, with anticyclonic circulation around Georges Bank (Bigelow, 1927; Brooks, 1994; Xue et al., 2000). Alongshore flow on the coast of Maine is divided into the buoyancy-driven Maine Coastal Current, and the GOM Coastal Plume (Bisagni et al., 1996; Keafer et al., 2005; Pettigrew et al., 2005), which is fed by the region's five largest rivers, the St. John, Penobscot, Merrimack, Kennebec, and Androscoggin. The cyclonic circulation around Jordan Basin (sometimes referred to as the Jordan Basin Gyre) is baroclinically driven and strengthens when there is more dense slope water in the basin (Brooks and Townsend, 1989). Stronger circulation of the Jordan Basin Gyre increases the strength of offshore veering of the Maine Coastal Current that occurs just upstream of Penobscot Bay (Bisagni et al., 1996; Pettigrew et al., 1998). This offshore-directed current also intensifies during periods of stronger river outflow and upwelling-favorable winds and varies interannually, affecting the degree to which the Eastern Maine Coastal Current connects with the Western Maine Coastal Current (Luerssen et al., 2005; Pettigrew et al., 2005).

\subsubsection{Scotian Shelf}

Upstream of the GOM is the Scotian Shelf, a shelf sea that stretches from the Northeast Channel in the Southwest to the Laurentian Channel in the Northeast, from 42.5 to $45.5^{\circ} \mathrm{N}$ and from 57 to $65.5^{\circ} \mathrm{W}$. The 30-year (1981-2010) climatological annual mean sea surface temperature is $8.1^{\circ} \mathrm{C}$ on the Western Scotian Shelf, $8.5^{\circ} \mathrm{C}$ on the Central Scotian Shelf, and $7.1^{\circ} \mathrm{C}$ on the Eastern Scotian Shelf. Water temperatures have been warming rapidly in all three regions on the shelf, at rates of $0.5^{\circ} \mathrm{C}$ decade $^{-1}, 0.6^{\circ} \mathrm{C}$ decade $^{-1}$, and $0.4^{\circ} \mathrm{C}$ decade ${ }^{-1}$, respectively (Hebert et al., 2018). As a shelf sea, the Scotian Shelf is relatively shallow, with depths ranging from $0-200 \mathrm{~m}$ and several banks shallower than 100m (Hebert et al., 2018). The two main currents, the Nova Scotia Current and the 
Labrador Current, both flow from the northeast to the southwest, with the Nova Scotia Current along the coast and the Labrador Current along the shelf break (Townsend et al., 2006). The main upstream sources of Scotian Shelf water are the Gulf of St. Lawrence and the Labrador Current. Like the GOM, the Scotian Shelf is influenced by Slope Water intrusions, particularly offshore. Both WSW and LSW have been observed at depth during annual ship surveys conducted by the Department of Fisheries and Oceans Canada (Hebert et al., 2018). The relative proportion of WSW and LSW has been attributed to interdecadal variability in remote forcing from the North Atlantic Oscillation (Greene et al., 2013), and to interannual variability in Gulf Stream - Labrador Current interactions near the Grand Banks (Brickman et al., 2018). 


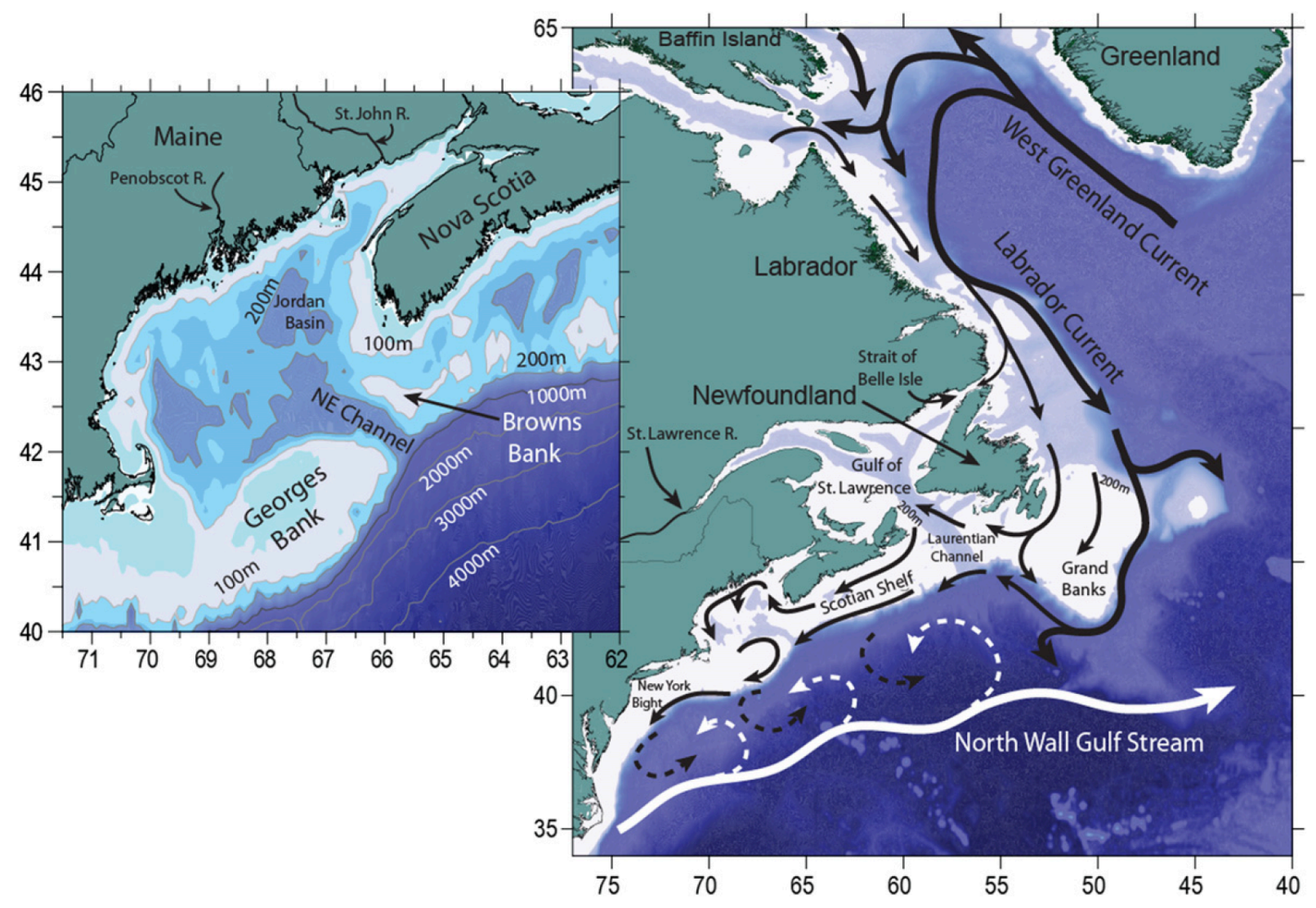

Figure 4-1 - From Townsend et al. (2010)": "Map of the NW Atlantic Ocean, Labrador Sea and Gulf of Maine, showing the major current systems (after Chapman and Beardsley, 1989; Loder et al., 1998) ... Dashed arrows indicate mixing of waters (not currents) in the slope sea (Csanady and Hamilton, 1988). Inset shows location of the Northeast Channel (sill depth ca. $220 \mathrm{~m}$ ) and the channel between Browns Bank and Nova Scotia (depth ca. $150 \mathrm{~m}$ )."

${ }^{9}$ This figure was published in Continental Shelf Research, Vol 30; Townsend, David W., Rebuck, Nathan D., Thomas, Maura A., Karp-Boss, Lee, Gettings, Rachel M., "A changing nutrient regime in the Gulf of Maine", p. 820-832, Copyright Elsevier (2010). 


\subsubsection{Models}

A series of nested models were used to simulate climate change in the Gulf of Maine (in order of increasing resolution): the Geophysical Fluid Dynamics Laboratory's Earth System Model (GFDL-ESM2M), the Northwest Atlantic ROMS, and the Gulf of Maine ROMS.

\subsubsection{Climate Model}

The GFDL-ESM2M, although not used directly in this study, plays an important role as its output was used to force the Northwest Atlantic ROMS in Alexander et al. (2020). Atmospheric resolution in the GFDL-ESM2M is $2^{\circ}$ (lat) $\times 2.5^{\circ}$ (lon) with 24 vertical levels, and the oceanographic resolution is approximately $1^{\circ} \times 1^{\circ}$, with 50 vertical levels (Alexander et al., 2020). The climate simulations that were used in Alexander et al. (2020) were projected with the RCP8.5 emissions pathway, the highest Representative Concentration Pathway defined by the Intergovernmental Panel for Climate Change $(\mathrm{IPCC})^{10}$. Under this scenario, radiative forcing exceeds $8.5 \mathrm{~W} \mathrm{~m}^{-2}$ by 2100 . Refer to Dunne et al. $(2012,2013)$ for more details about the GFDL-ESM2M configuration and Alexander et al. (2020) for comparisons between this and other climate models.

\subsubsection{Regional Ocean Modeling System}

The Regional Ocean Modeling System (ROMS) is a hydrostatic, free surface, split-explicit, terrain-following primitive equation model (Shchepetkin and McWilliams, 2003, 2005). Two different configurations are relevant to this study, the Northwest Atlantic ROMS and the GOM ROMS.

\section{Northwest Atlantic ROMS}

The Northwest Atlantic ROMS (NWA ROMS) covers the shelf sea on the east coast of North America from the Gulf of Mexico to the Gulf of St. Lawrence, from $10^{\circ} \mathrm{N}$ to $50^{\circ} \mathrm{N}$

\footnotetext{
${ }^{10}$ https://www.ipcc-data.org/guidelines/pages/glossary/glossary_r.html
} 
(Kang and Curchitser, 2013) (Figure 4-2). Its resolution is 7km in the horizontal and 40 layers in the vertical, with higher resolution near the surface. The boundary and initial conditions were extracted from the Simple Ocean Data Assimilation (SODA v2.1.6) (Carton and Giese, 2008), which has $0.5^{\circ}$ horizontal resolution and 40 vertical layers. Surface forcing was taken from the Coordinated Ocean-Ice Reference Experiments (CORE v2), which has a 6 -hour temporal resolution and $1.9^{\circ}$ spatial resolution (Large and Yeager, 2009). River discharge from the continental discharge database (Dai et al., 2009) was used to implement freshwater fluxes directly into the model's surface grid cells. Results from the control simulation (1976-2005) and the forecast (2070-2099) were saved as 5-day averages. The reader is referred to Kang and Curchitser (2013) for more details about the model setup and to Alexander et al. (2020) for specifics about the climate simulations.

\section{Gulf of Maine ROMS}

The Gulf of Maine ROMS (GOM ROMS) includes the GOM from Georges Bank in the South to the Bay of Fundy in the North $\left(38.7^{\circ} \mathrm{N}\right.$ to $\left.46.6^{\circ} \mathrm{N}\right)$, and from Coastal New England in the West to the Scotian Shelf in the East $\left(72.9^{\circ} \mathrm{W}\right.$ to $62.0^{\circ} \mathrm{W}$ ) (Figure 4-2). The horizontal resolution ranges from $1 \mathrm{~km}$ nearshore to $3 \mathrm{~km}$ offshore, and there are 36 vertical terrain-following layers.

Boundary conditions for temperature, salinity, velocity, and sea surface height for the GOM ROMS were extracted from HYCOM (Hybrid Coordinate Ocean Model) experiment GOFS3.0, which was interpolated to the GOM ROMS grid. HYCOM has a $1 / 12^{\circ}$ resolution in the horizontal and 40 layers in the vertical, and simulations from GOFS3.0 are available from 1994-2018. HYCOM utilizes hybrid vertical coordinates, with isopycnal vertical layers in the open stratified ocean, terrain-following sigma layers in the coastal ocean, and z-coordinates in unstratified areas. 
Atmospheric forcing in the GOM ROMS was specified via bulk formulation with data from the North American Regional Reanalysis (NARR) ${ }^{11}$, which has 6-hour temporal resolution and $1 / 6^{\circ}$ spatial resolution. The five largest rivers in the GOM (St. John, Penobscot, Kennebec, Androscoggin, and Merrimack) are included in the GOM ROMS forcing files as volume transport $\left(\mathrm{m}^{3} \mathrm{~s}^{-1}\right)$ as measured by U.S. Geological Survey ${ }^{12}$ river gauges. A volumetric adjustment was added to each river to account for drainage area downstream of the gauge. Multi-scale Ultra-High-Resolution Temperature (MUR4.13) from satellites was used for a surface heat flux correction. For more information about the GOM ROMS configuration, the reader is referred to He and McGillicuddy (2008), Li et al. (2009), and McGillicuddy et al. (2011).
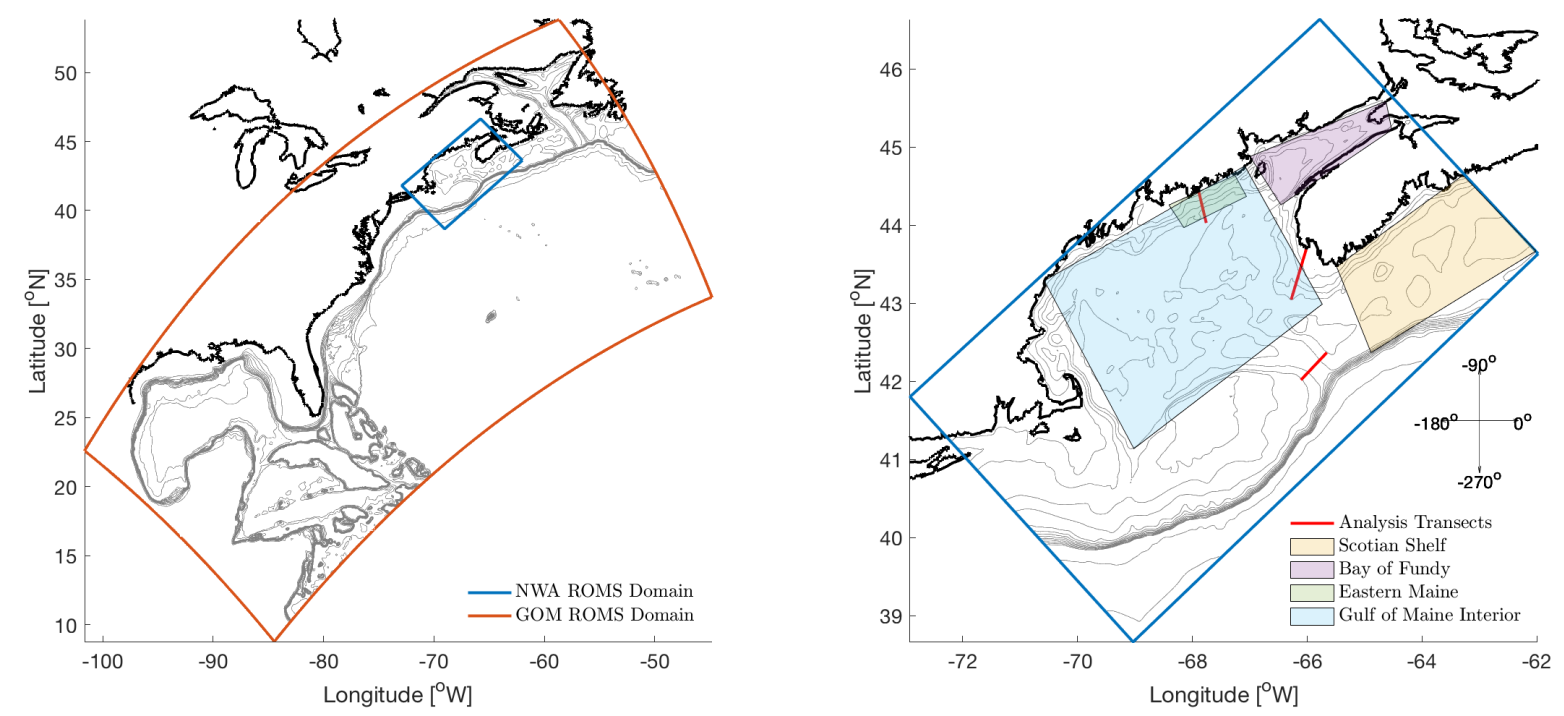

Figure 4-2 - (left) The Northwest Atlantic (NWA) ROMS Domain (red outline) and Gulf of Maine (GOM) ROMS Domain (blue outline). Bathymetry is drawn every $100 \mathrm{~m}$ from 0 to $1000 \mathrm{~m}$, at $2000 \mathrm{~m}$, and at $3000 \mathrm{~m}$ according to the bathymetry of the NWA ROMS. The bold black line indicates the coastline. (right) The GOM ROMS domain (blue outline) with transect locations indicated with red lines and important subregions indicated with shaded boxes. Bathymetry is drawn every $25 \mathrm{~m}$ from the surface to $100 \mathrm{~m}$, every $100 \mathrm{~m}$ to $1000 \mathrm{~m}$, and at $2000 \mathrm{~m}$ and $3000 \mathrm{~m}$. The bold black line indicates the coastline.

\footnotetext{
11 https://www.ncdc.noaa.gov/data-access/model-data/model-datasets/north-american-regionalreanalysis-narr

12 http://waterdata.usgs.gov

${ }^{13}$ https://thredds1.pfeg.noaa.gov/thredds/Satellite/MUR41/catalog.html?dataset=satellite/MUR41/ssta/ 1 day
} 


\subsubsection{Experimental Setup}

The GOM ROMS was run for 25 consecutive years as a hindcast (1994-2018) and forecast (2073-2097). Boundary and initial conditions for the hindcast runs were created from the sources detailed in Section 4.2.2.2, while the forecast runs were forced with the Delta Method, detailed below.

\subsubsection{Delta Method}

The NWA ROMS climate projections were downscaled to the GOM ROMS region via the Delta Method, as described in Alexander et al. (2020) and Shin and Alexander (2020). This method calculates the long-term differences in oceanic and atmospheric conditions between a climate simulation and hindcast simulation of a coarse model (in this case, the NWA ROMS) and applies the difference to the observed initial and boundary conditions and atmospheric forcing of a higher resolution model (the GOM ROMS). The method has been called a "seasonally varying delta method" (Shin and Alexander, 2020), because it calculates Delta values for each month, rather than one Delta for the entire year, with the understanding that climate change impacts are likely to have seasonal variation. This method incorporates the temporal and spatial variability of the present-day regional model into the forecast, but does not represent any potential changes in variability. The sources from which Deltas were calculated and the fields to which they were added are detailed in Table 4-1. 
Table 4-1 - Model fields to which Deltas were added, and the source from which Deltas were calculated. Note that ROMS can read humidity as either relative humidity (\%) or specific humidity ( $\mathrm{g} \mathrm{kg^{-1 } )}$

\begin{tabular}{|c|c|c|c|}
\hline Description & ROMS Variable & Units & Source \\
\hline 3D salinity & salt & PSU & \multirow{4}{*}{ NWA ROMS output } \\
\hline 3D temperature & temp & ${ }^{\circ} \mathrm{C}$ & \\
\hline $3 \mathrm{D}$ velocity & $\mathrm{u} / \mathrm{v}$ & $\mathrm{m} / \mathrm{s}$ & \\
\hline 2D sea surface height & zeta & $\mathrm{m}$ & \\
\hline Sea level air pressure & $\mathrm{P}_{\text {air }}$ & mbar & \multirow{7}{*}{ CORE2 } \\
\hline Surface relative humidity & $Q_{\text {air }}$ & $\%$ & \\
\hline Surface air temperature & $\mathrm{T}_{\text {air }}$ & ${ }^{\circ} \mathrm{C}$ & \\
\hline $10 \mathrm{~m}$ wind velocity & $\mathrm{u}_{\text {wind }} / \mathrm{v}_{\text {wind }}$ & $\mathrm{m} \mathrm{s}^{-1}$ & \\
\hline Rainfall rate & rain & $\mathrm{kg}\left(\mathrm{m}^{-2} \mathrm{~s}^{-1}\right)$ & \\
\hline $\begin{array}{l}\text { Downwelling longwave } \\
\text { radiation }\end{array}$ & lwrad & $\mathrm{W} \mathrm{m} \mathrm{m}^{-2}$ & \\
\hline $\begin{array}{l}\text { Downwelling shortwave } \\
\text { radiation }\end{array}$ & swrad & ${ }^{\circ} \mathrm{C}$ & \\
\hline River runoff & River transport & $\mathrm{m}^{3} \mathrm{~s}^{-1}$ & Dai et al. (2009) \\
\hline
\end{tabular}


The Delta Method was implemented as follows:

1. A 30-year monthly mean for each forcing field in the forecast and hindcast time periods was calculated from the sources in Table 4-1. Note that atmospheric Deltas were calculated from the CORE2 dataset that was used to force the NWA ROMS.

2. Twelve Deltas (one for each month) were calculated by subtracting the hindcast means from the forecast means.

3. The hindcast time periods for the NWA ROMS (1976-2005) and the GOM ROMS (1994-2018) were not the same because of the availability of the HYCOM simulations used to provide boundary conditions for the GOM ROMS. As a result, the average time difference between forecast and hindcast in the NWA ROMS simulations was 94 years, while the average difference between the forecast and hindcast in the GOM ROMS simulations was only 78 years. Deltas were multiplied by 78/94 to account for the difference, creating a "Fractional Delta". This assumes that the Deltas increase linearly with time, which is a simplifying assumption.

4. Fractional Deltas were spatially and temporally interpolated to the required resolution for the GOM ROMS initial and boundary conditions. In this study, this meant that oceanographic Deltas were interpolated to the HYCOM grid, atmospheric Deltas were interpolated to the NARR grid, and sea surface temperature Deltas were interpolated to the satellite grid.

5. Interpolated fractional Deltas were added to the appropriate forcing files for the forecast GOM ROMS.

6. The GOM ROMS was run consecutively for 25 years representing 2073-2097 with the new forcing files.

River inputs are implemented differently in the NWA ROMS and GOM ROMS configurations, so the river Deltas were relative: the monthly average percent change between hindcast and forecast in the river inputs was calculated from the NWA ROMS 
input files, and that percent change was applied to the river discharge in the GOM ROMS input files.

\subsubsection{Analysis}

\subsubsection{Hydrodynamic Analyses}

Data were extracted from three transects for transport analysis: across the Northeast Channel $\left(42.02^{\circ} \mathrm{N}, 66.11^{\circ} \mathrm{W}\right.$ to $\left.42.37^{\circ} \mathrm{N}, 65.66^{\circ} \mathrm{W}\right)$, perpendicular to the Nova Scotia coast $\left(42.62^{\circ} \mathrm{N}, 66.57^{\circ} \mathrm{W}\right.$ to $\left.43.69^{\circ} \mathrm{N}, 66.02^{\circ} \mathrm{W}\right)$, and cross-shore from Mt. Desert Island across the Eastern Maine Coastal Current (EMCC) $\left(44.43^{\circ} \mathrm{N}, 67.89^{\circ} \mathrm{W}\right.$ to $\left.44.03^{\circ} \mathrm{N}, 67.76^{\circ} \mathrm{W}\right)$ (Figure 4-2). At each transect, data were extracted from the nearest grid cell, rather than interpolated to a straight line. Velocities were projected in the alongshore direction according to the angle of the coastline with respect to east (Figure 4-2) such that velocities greater than zero were toward the GOM. The exception is the EMCC, where velocities were projected such that velocities greater than zero were toward the southwest, the predominant flow direction. Transport toward the GOM was calculated via

$$
\text { Transport }=\sum_{i=1}^{N} u_{i} * A_{i}
$$

where $i$ is each grid cell where $u>0, u$ is the alongshore component of the velocity in grid cell $i, A_{i}$ is the grid cell cross-sectional area, and $N$ is the total number of grid cells where $u>0$. In the Northeast Channel, "alongshore" refers to flow parallel to the channel walls. The GOM inflow ratio, which describes the relative strength of inflows around Nova Scotia and through the Northeast Channel, was calculated according to the equation given in Hebert et al. (2018):

$$
\text { Inflow Ratio }=\frac{\text { Nova Scotia transport }}{\text { Northeast Channel transport }+ \text { Nova Scotia transport }}
$$


Stratification was defined as the difference in potential density between the bottom and the surface, and mixed layer depth was defined as the depth below the surface at which $T-T_{s f c} \geq 0.5^{\circ} \mathrm{C}$ (Price et al., 1986).

\subsubsection{Biological Analyses}

Growth potential for $P$. australis was estimated according to the methods and growth curve in Clark et al. (submitted). In short, a theoretical growth curve was fit to measured growth rates of a $P$. australis isolate from the 2016 GOM bloom. Growth rates were measured at $7,9,11,13$, and $15^{\circ} \mathrm{C}$. Growth rates were extrapolated beyond the $7-15^{\circ} \mathrm{C}$ temperature range according to a rate of change of growth rate with temperature that

was determined by short-term exposure experiments $\left(d \mu / d T=-0.02 \mathrm{~d}^{-1{ }^{\circ} \mathrm{C}-1}\right.$ if $T<7^{\circ} \mathrm{C}$ and $-0.03 \mathrm{~d}^{-10} \mathrm{C}^{-1}$ if $\left.T>15^{\circ} \mathrm{C}\right)$. A theoretical curve was fit to the measured and estimated data points according to equation S.1 in Thomas et al. (2012). The growth curve is given in Figure 4-3, and the reader is referred to Clark et al. (submitted) for more details. Growth potential was calculated based on simulated temperatures and the growth curve for each grid cell at each time step before spatial or temporal averaging. It was calculated both for sea surface temperatures and for $10 \mathrm{~m}$ temperatures, because $P$. australis was observed at the surface, 10m, and 20m (Clark et al., 2019). 


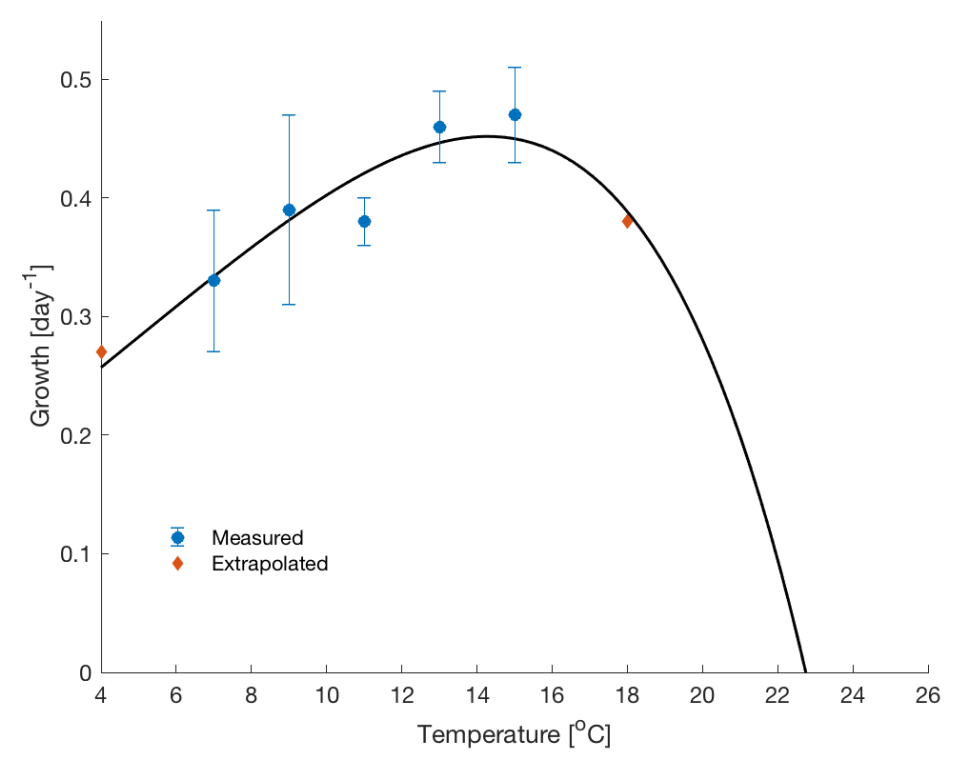

Figure 4-3 - P. australis growth vs. temperature as measured in Clark et al. (2021, submitted). Values measured in laboratory experiments are marked with blue circles (error bars indicate standard error), while values that were extrapolated are indicated with orange diamonds. The black line indicates the growth curve that was fit according to equation $S .1$ in Thomas et al. (2012). The growth curve is interpolated only as low as $4^{\circ} \mathrm{C}$ because laboratory equipment did not allow for measurement of growth rates below that temperature.

For estimates of bloom timing and growing season, surface noon-time growth rates were smoothed over a weekly time period, because week-to-week changes in growth rate are more ecologically relevant than day-to-day changes. Bloom timing was estimated by finding the day of maximum mean growth rate, according to the metric in Record et al. (2019). Bloom timing was estimated for the first half of the year, representing spring, and the second half of the year, denoting fall, because bimodal phytoplankton peaks are common in the GOM (Record et al., 2019). The growing season was estimated as the number of days when average noon-time growth rates were greater than $75 \%$ of the maximum growth rate $\left(0.47\right.$ day $\left.^{-1}\right)$, according to the metric defined in Gobler et al. (2017). An alternative approach for representing shifts in bloom timing is the HAB Window of Opportunity for A. catenella in Puget Sound (Moore et al., 2011), but this was deemed inappropriate for Pseudo-nitzschia because there are multiple species and the same species can adapt to different temperature ranges depending on the environment (e.g. P. australis 
in Clark et al. 2019; McCabe et al. 2016; Santiago-Morales and García-Mendoza, 2011; Thorel et al. 2014).

\subsubsection{Averaging Data Spatially and Temporally}

Model output was averaged both spatially and temporally to focus the analysis on regions and time periods of interest. The following calculations could be applied either separately or together, and this section serves only to clarify how averaging was done, not to specify all of the specific combinations that are included in the results.

A "composite year" is a year in which data were averaged across all 25 years from each simulation to represent the average hindcast or forecast. Years could also be further divided into seasonal averages, where winter is from December through February, spring is from March to May, summer is from June to August, and fall is from September to November. Regardless of whether data were averaged across the seasons, across the entire year, or averaged into composite years, a "change" in some parameter indicates the forecast value minus the hindcast value (not to be confused with "Deltas").

To quantify interregional variability within the GOM ROMS domain, four sub-regions were selected. The Scotian Shelf was chosen because of its influence on the GOM interior via Scotian Shelf Water inflows, the Bay of Fundy was selected because it is where the first P. australis bloom began in 2016 (Clark et al., 2019), the eastern Maine coast was selected because DA-induced shellfishery closures have occurred here since 2016, and the GOM interior was chosen to assess internal dynamics over the deep basins. The subregions are shown in Figure 4-2.

\subsection{Comparison Between ROMS Configurations}

The analyses described in the previous section focus on transport estimates, vertical water column structure, and growth potential as a function of temperature. To properly assess changes as predicted by the GOM ROMS, it is valuable to understand the GOM ROMS in the context of the NWA ROMS, and to briefly compare their simulations. 
Average sea surface temperatures in the two models agreed well in terms of magnitude and seasonal variability (Appendix C, Figure 8-1). On average the NWA ROMS average surface temperature was lower than the GOM ROMS surface temperature by $0.6^{\circ} \mathrm{C}$. This is perhaps due to the fact that the GOM ROMS applies a heat flux correction term based on satellite measurements, while the NWA ROMS does not. When the surface net heat flux correction is activated, the following equation applies:

$$
Q=Q+\alpha(T-S S T)
$$

in which $Q$ is the sum of shortwave, longwave, latent, and sensible heat fluxes, $\alpha$ is an adjustment term, $T$ is the ocean surface temperature as simulated by the model, and SST is the ocean surface temperature as measured by satellites. With a Delta applied to the sea surface temperature, the equation becomes

$$
Q^{\prime}=Q^{\prime}+\alpha\left(T^{\prime}-(S S T+\Delta)\right)
$$

where $Q^{\prime}$ is the new net heat flux as a result of changing atmospheric conditions and ocean temperatures, $T^{\prime}$ is the new ocean temperatures as simulated by the model, SST is the original satellite data, and $\Delta$ is the Delta of the sea surface temperature as calculated from the NWA ROMS output. The reference to observational data gives a degree of confidence to the GOM ROMS temperature values and resulting estimates of $P$. australis growth potential.

Both models forecast an increase in the GOM inflow ratio (Appendix C, Figure 8-2), which is a focal point for the analysis (see Section 4.4.1.4). The mean increase in the GOM ROMS was larger than the mean increase in the NWA ROMS, the likely cause of which is discussed below. The qualitative change is in agreement between the two models, however, suggesting that this is not an aberration in one model.

The most notable disagreement between the two models is their simulated change in surface salinity. Vertical salinity gradients affect stratification, while horizontal salinity gradients affect baroclinic circulation, so it is important to understand the accuracy of 
and the mechanisms behind the models' simulated salinity. Surface salinity decreased by 0.3 PSU on average in the NWA ROMS forecast within the GOM ROMS domain, but by 0.9 PSU on average in the GOM ROMS forecast (Appendix C, Figure 8-5). The change in total freshwater volume in the GOM was calculated from the two models, and it was found that the GOM ROMS freshwater volume increased in the forecast, whereas the NWA ROMS freshwater volume in the GOM decreased, despite freshening at the surface (Appendix C, Figure 8-4). This difference in change in freshwater volume might partly explain the difference in surface salinity change, because the NWA ROMS did not have as much freshwater to redistribute, but it is important to understand why the change in freshwater volume differed between the two models.

One potential cause of the difference in freshwater volume change is the differential implementation of rivers and the use of a relative river Delta. As mentioned above, the NWA ROMS implements river outflow as a freshwater flux at the surface of coastal grid cells, while the GOM ROMS implements river outflow as a volumetric transport at the land-sea boundary. NWA ROMS river outflow was converted to the same units $\left(\mathrm{m}^{3} \mathrm{~s}^{-1}\right)$ as in the GOM ROMS for comparison. Although the two models agreed on the order of magnitude and seasonality of total river outflow in the GOM (Appendix C, Figure 8-3), the NWA ROMS total river outflow was not as low during the dry season as the GOM ROMS outflow, and the NWA ROMS total river outflow was larger on average than the GOM ROMS river outflow. As a result, the fractional river Delta resulted in a larger change (in absolute value) in river outflow in the NWA ROMS than the GOM ROMS. The estimated change in river outflow was, on average, $134 \mathrm{~m}^{3} \mathrm{~s}^{-1}$ greater in the NWA ROMS than in the GOM ROMS. Assuming a residence time anywhere from 2 months to 10 months (transit time from the Bay of Fundy to the Great South Channel was estimated to be 2 months on average in Manning et al. (2009)) this discrepancy integrated over the residence time could lead to a disagreement in change in freshwater volume on the order of $10^{9} \mathrm{~m}^{3}$. This is 2 orders of magnitude smaller than the models' disagreement in change 
in total freshwater in the domain (order $10^{11} \mathrm{~m}^{3}$, see Appendix C, Figure 8-4). It is also in the opposite direction of the disagreement, because the NWA ROMS had a larger increase in river outflow but the GOM ROMS became fresher in the forecast. The difference in river outflow change therefore likely does not have a significant impact on overall freshwater or salinity estimates or changes thereof.

The discrepancy in freshwater volume change and surface salinity change was found to be largely a result of how the two models resolve alongshore transport on the Scotian Shelf, at the location of the eastern boundary in the GOM ROMS. At this boundary, the average salinity Delta was negative, with stronger freshening nearshore (Figure 4-4), and the average alongshore velocity delta was either zero or positive (toward the GOM), with a maximum increase of $5 \mathrm{~cm} \mathrm{~s}^{-1}$ nearshore (Figure 4-4). At the same boundary, the nearshore velocities toward the GOM were, on average, $10 \mathrm{~cm} \mathrm{~s}^{-1}$ faster in the GOM ROMS hindcast than in the NWA ROMS hindcast (Figure 4-4). The freshwater transport toward the GOM was therefore larger in the GOM ROMS than the NWA ROMS. After applying the Deltas, the increase in freshwater transport in the forecast run was larger still in the GOM ROMS $(+350 \%)$ than in the NWA ROMS $(+100 \%)$, which caused the greater increase in freshwater volume in the GOM ROMS. This discrepancy could have cascading effects downstream that must be considered when analyzing the GOM ROMS output. It could cause the larger increase in the GOM inflow ratio in the GOM ROMS than the NWA ROMS, because nearshore freshwater inflows at the eastern boundary continue southwest on the Scotian Shelf and enter the GOM around the tip of Nova Scotia. It could affect EMCC transport estimates, because the EMCC is partially driven by Scotian Shelf inflows (Brooks, 1994; Lynch et al., 1997). It could also affect estimates of salinity in the GOM interior.

Any analysis of changes to salinity or transport pathways in the GOM ROMS must keep this discrepancy at the eastern boundary in mind. It is still unclear whether the enhanced freshwater flux in the GOM ROMS forecast is realistic or a model artifact. To assess the 
accuracy of the GOM ROMS simulated velocity on the Scotian Shelf, net transport toward the GOM on the Scotian Shelf was calculated between the coast and the $100 \mathrm{~m}$ isobath at Halifax Line 2 and compared to observations (Hebert et al., 2018). Net transport from the GOM ROMS was the same order of magnitude (0.2-0.8 Sverdrups) as calculated from field data (Hebert et al., 2018). The agreement between the GOM ROMS transport estimates and the observations lends a degree of confidence to the GOM ROMS simulations and provides evidence that it might be more accurate than the NWA ROMS. This only applies to the hindcast, however, and cannot necessarily speak to the accuracy of the forecast. Regardless, the two models both predicted an increase in freshwater flux at the eastern boundary, an increasing GOM inflow ratio, and a decrease in surface salinity. So, the results are qualitatively in agreement, but the exact numbers should be assessed with a degree of caution.
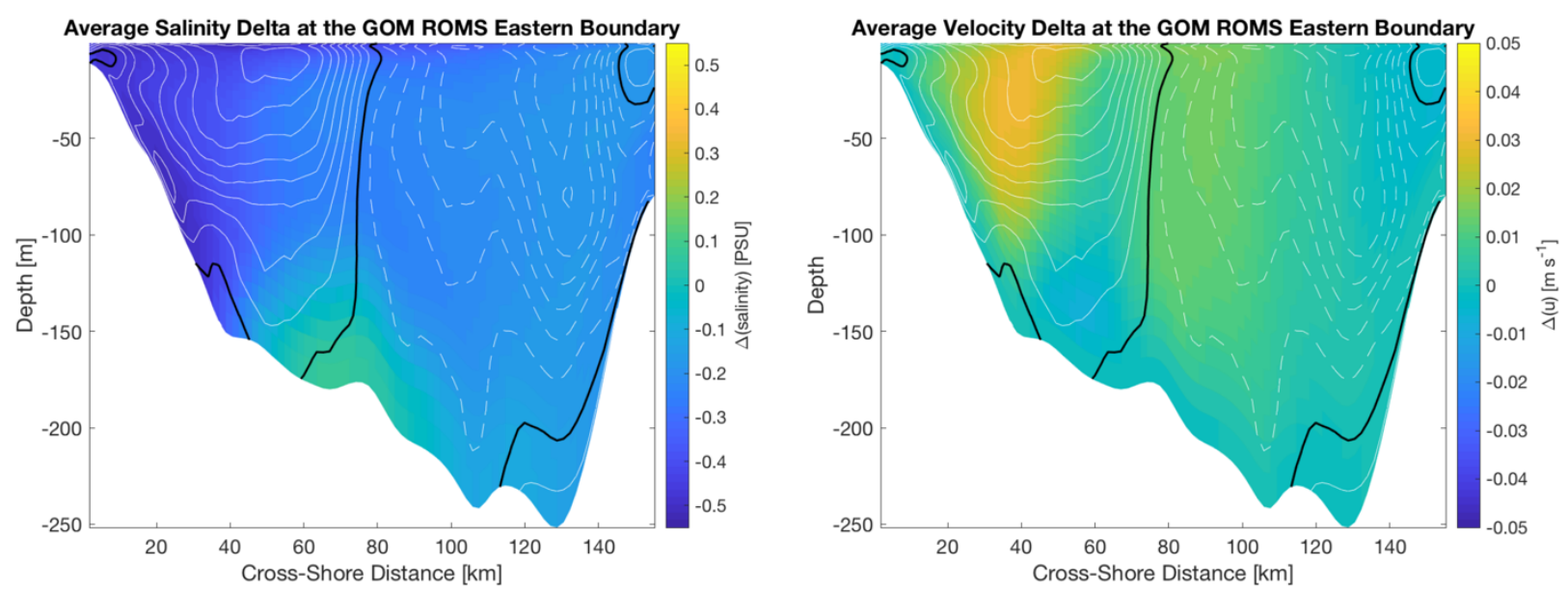

Figure 4-4-Contours of the average (left) salinity Delta and (right) velocity Delta at the GOM ROMS eastern boundary. Depth in meters is shown on the $y$ axis, and cross-shore distance in $\mathrm{km}$ is shown on the $x$ axis, with the coastline to the left. Corresponding color values are given in the color bars on the right. A positive velocity indicates flow toward the GOM. In both plots, contours of the average difference in hindcast velocity between the GOM ROMS and NWA ROMS are overlain in white. Solid contours indicate $u_{\text {GOM Roms }}-u_{\text {NWA ROMS }}>0$ (i.e. GOM ROMS transport toward the GOM is stronger), while dashed contours indicate $u_{\text {GOM ROMS }}-u_{\text {NWA Roms }}<0$ (i.e. NWA ROMS transport toward the GOM is stronger). Contours are drawn every $0.02 \mathrm{~m} \mathrm{~s}^{-1}$, and the zero contour is drawn in black. 


\subsection{Results}

\subsubsection{Hydrodynamics}

\subsubsection{Sea Surface Temperature}

In the forecast, across the GOM ROMS domain, sea surface temperature increased by $2^{\circ} \mathrm{C}$ on average, with the maximum increase in August and September. The seasonal signal and overall increased temperatures were consistent regardless of sub-region, but the degree of warming varied between regions. Of the sub-regions tested, the Scotian Shelf saw the greatest warming (up to $2.7^{\circ} \mathrm{C}$ in August), while the Bay of Fundy had the least warming (maximum $\left.1.9^{\circ} \mathrm{C}\right)($ Figure $4-5)$.

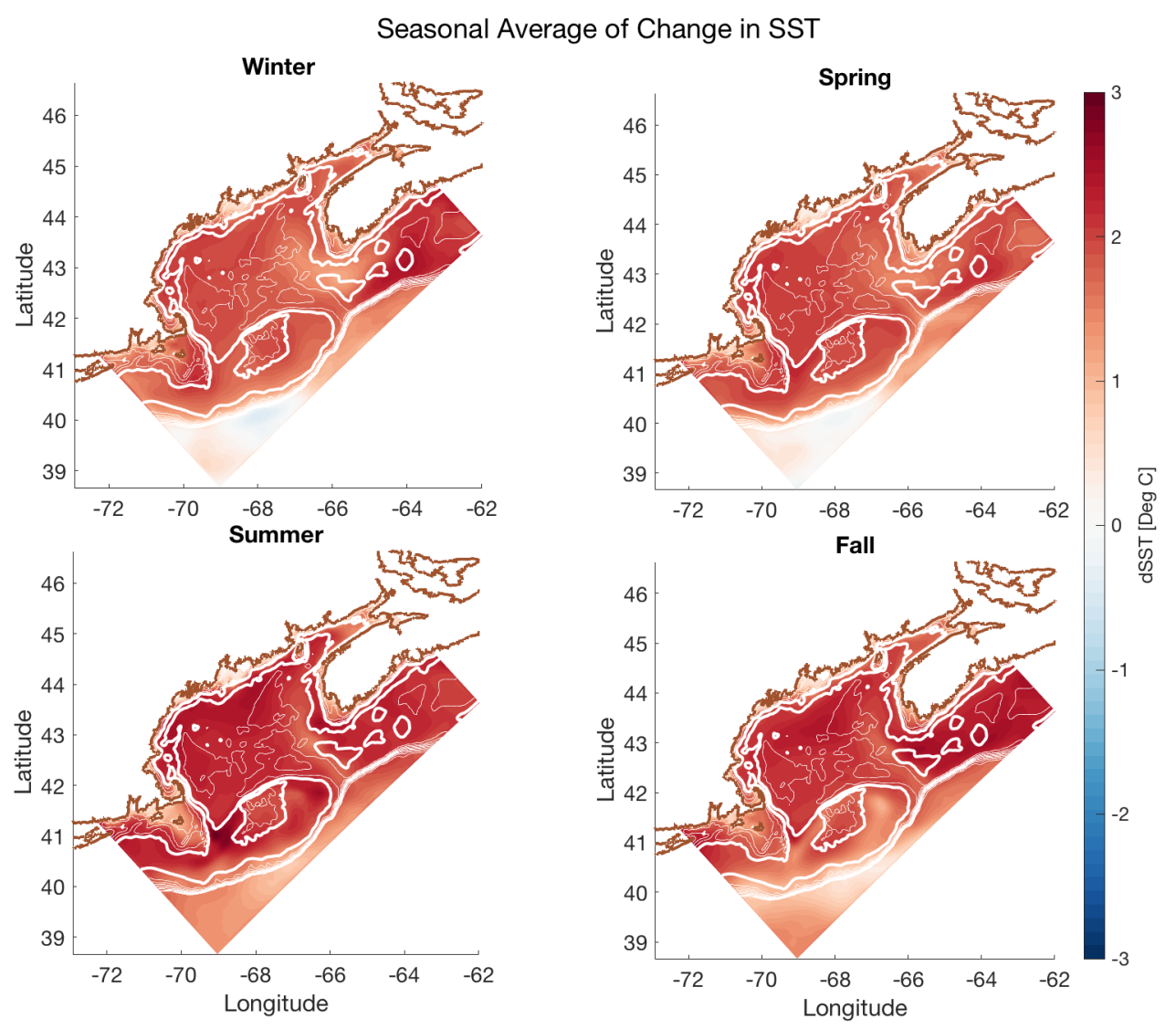

Figure 4-5 - Seasonally-averaged change in sea surface temperature (SST) in the (clockwise from top left) winter, spring, fall, and summer. Color values are defined by the color bar on the right. Bathymetry is drawn every $25 \mathrm{~m}$ to $100 \mathrm{~m}$, every $100 \mathrm{~m}$ to $1000 \mathrm{~m}$, and at $2000 \mathrm{~m}$ and $3000 \mathrm{~m}$. 


\subsubsection{Surface Salinity}

Surface salinity decreased throughout the GOM ROMS domain by 0.9 PSU on average (Figure 4-6). As with sea surface temperature, although the seasonal signal was largely consistent between sub-regions, the degree of freshening varied. Salinity decreased between 0.8 and 1.1 PSU in the Bay of Fundy, GOM, and eastern Maine sub-regions, with the largest decrease occurring in the fall. On the Scotian Shelf, meanwhile, surface salinity decreased between 0.2 and 0.7 PSU, with the largest decrease in August.

Seasonal Average of Change in Surface Salinity
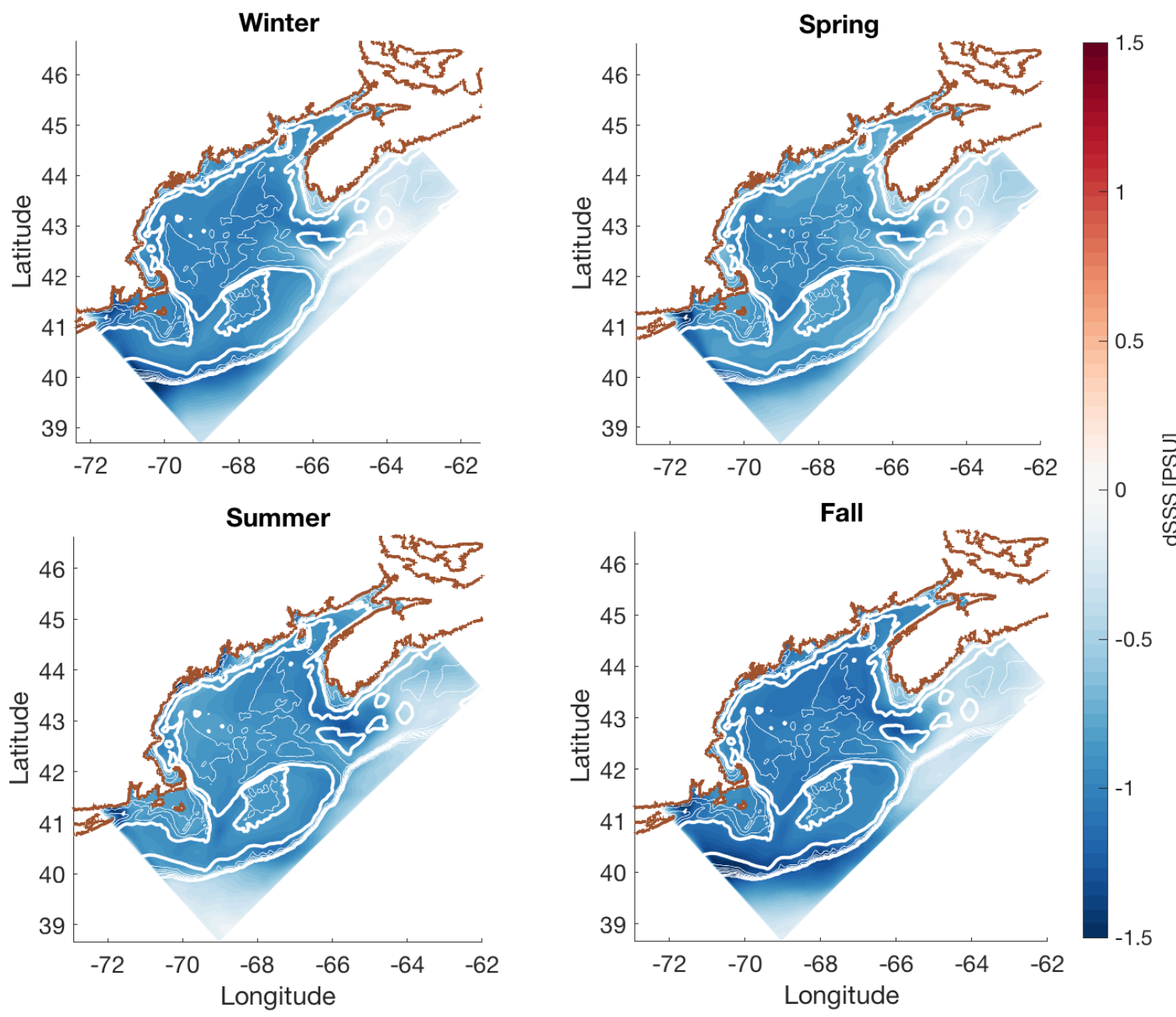

Figure 4-6 - Seasonally-averaged change in surface salinity in the (clockwise from top left) Winter, Spring, Fall, and Summer. Color values are defined by the color bar on the right. Bathymetry is drawn every $25 \mathrm{~m}$ to $100 \mathrm{~m}$, every $100 \mathrm{~m}$ to $1000 \mathrm{~m}$, and at $2000 \mathrm{~m}$ and $3000 \mathrm{~m}$. 


\subsubsection{Stratification}

Stratification largely increased in the forecast throughout the domain, with notable exceptions. Near the coast, in the Bay of Fundy, and at the crest of Georges Bank, stratification did not increase in the forecast, even in the summer. Stratification increased at the edges of Georges Bank, however, in the summer and fall. On the Scotian Shelf, stratification decreased in the winter and spring but increased in the summer and fall. In the GOM interior and on Browns Bank, stratification increased year-round. Regardless of interregional variability, the largest stratification increases occurred in the summer and fall (Figure 4-7).
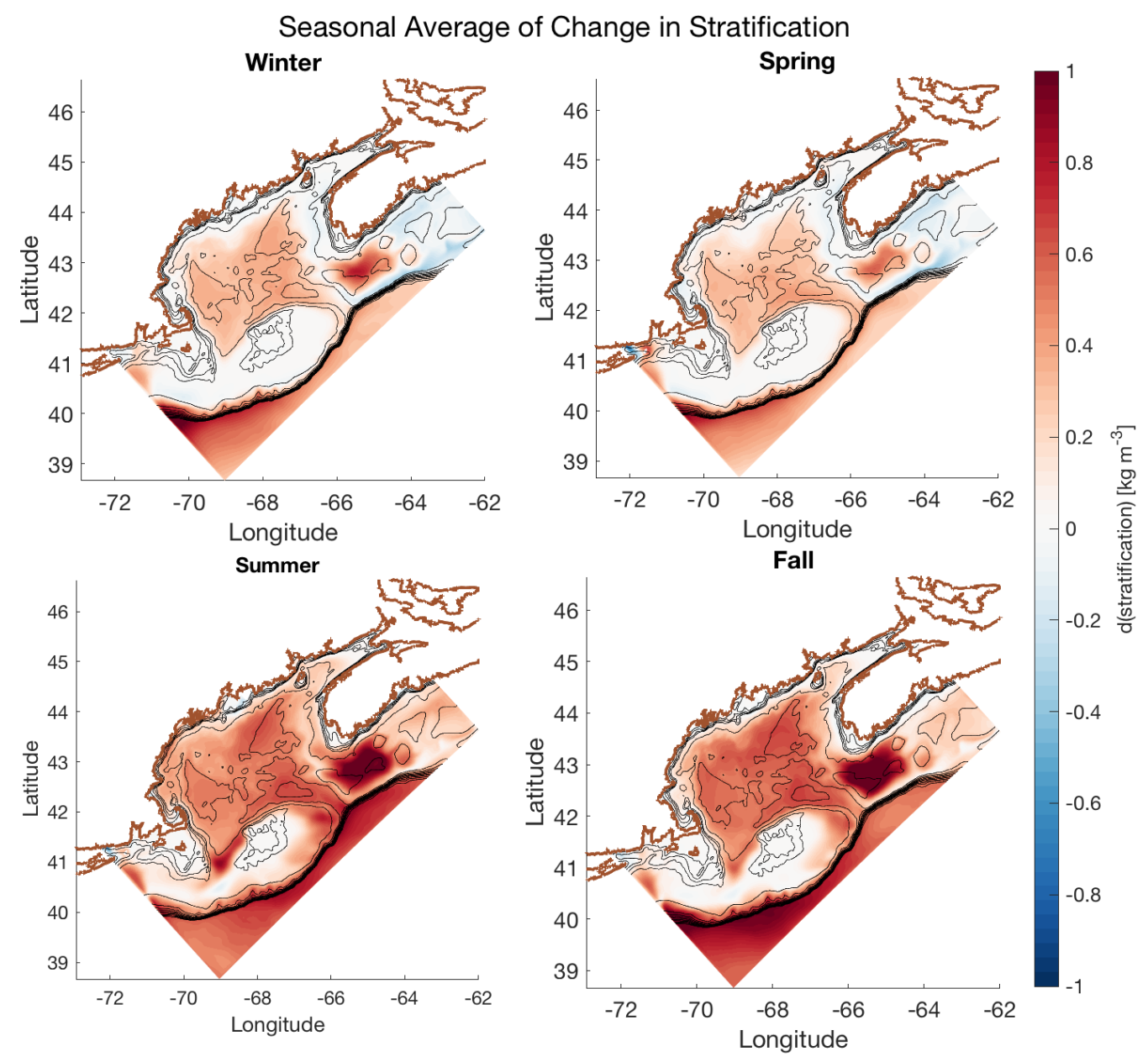

Figure 4-7 - Seasonally-averaged change in stratification in the (clockwise from top left) Winter, Spring, Fall, and Summer. Color values are defined by the color bar on the right. Bathymetry is drawn every 25m to $100 \mathrm{~m}$, every $100 \mathrm{~m}$ to $1000 \mathrm{~m}$, and at $2000 \mathrm{~m}$ and $3000 \mathrm{~m}$. 


\subsubsection{Gulf of Maine Inflow Ratio}

The Gulf of Maine inflow ratio increased year-round in the forecast, with no discernible seasonal variability. In the hindcast the ratio was approximately 0.5 on average, indicating that $50 \%$ of the inflows came via the Nova Scotia coastal route. In the forecast the inflow ratio increased by 0.1 on average, which is about $20 \%$ of the hindcast ratio (Figure $4-8$ ).

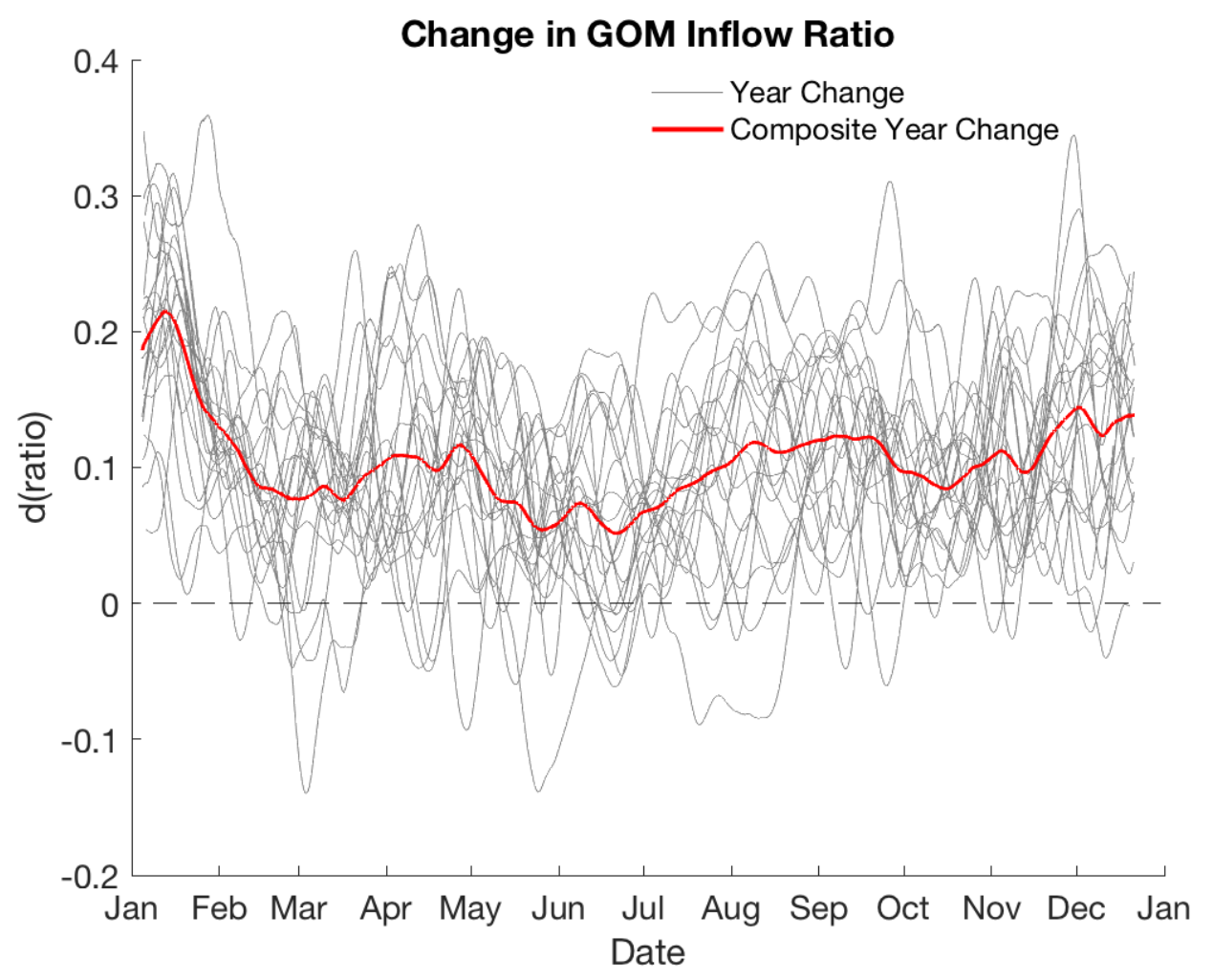

Figure 4-8 - Change in GOM inflow ratio vs. day of the year. "Year Change" refers to the difference between one forecast year and its corresponding hindcast year and is plotted in grey. "Composite Year Change" is the difference between the forecast composite year and the hindcast composite year and is plotted in red. Data were smoothed over a weekly time scale before plotting. 


\subsubsection{Eastern Maine Coastal Current}

In the forecast, alongshore transport in the EMCC decreased by $5 \%$ on average in the winter and spring and increased by $5 \%$ on average in the summer and fall. The result of this was an intensified seasonal signal, with the greatest increase (17\%) occurring in midSeptember (Figure 4-9). When the increase in total transport peaked, the alongshore velocity increased by about $2 \mathrm{~cm} \mathrm{~s}^{-1}$ over the hindcast.
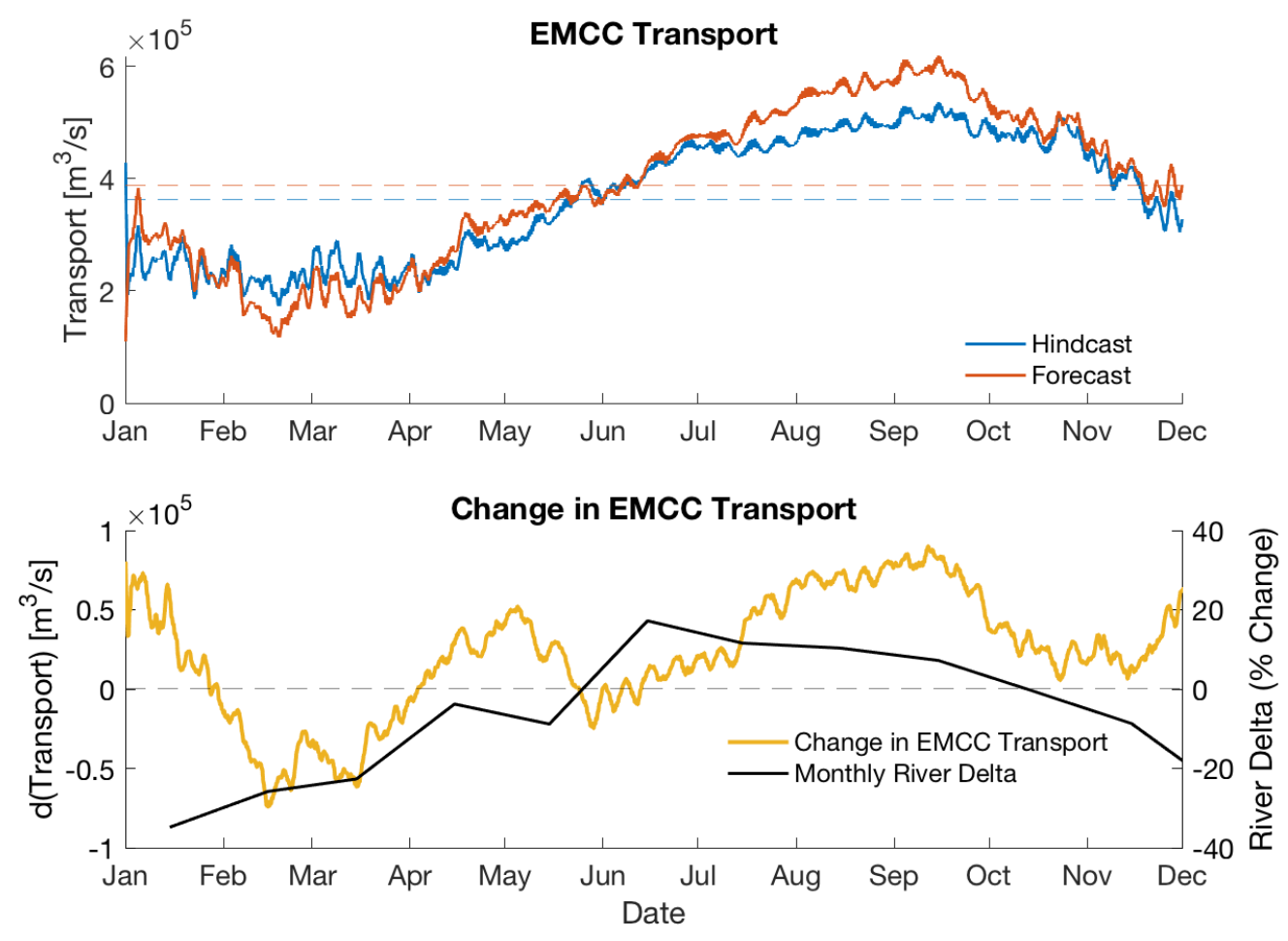

Figure 4-9 - (top) Alongshore EMCC transport from the hindcast composite year (blue) and the forecast composite year (red) vs. day of the year. Dashed lines in corresponding colors indicate the year-long average. (bottom) Change in alongshore EMCC transport vs. day of the year (yellow, left y axis), and monthly river delta as a percent change for each month (black, right y axis). EMCC data were smoothed over a weekly time period before plotting. 


\subsubsection{Predicted Changes to Pseudo-nitzschia Growth}

\subsubsection{Growth Potential}

Averaged across the GOM ROMS domain and across all years, growth potential at the surface decreased in the forecast. In most of the domain, average potential growth rates increased from November to June and decreased from June to November. However, there was seasonal and interregional variability. The springtime increases were larger in the Scotian Shelf, Bay of Fundy, and Eastern Maine sub-regions than in the GOM sub-region, while the summertime decreases were larger in the GOM and Scotian Shelf sub-regions than in the Bay of Fundy and Eastern Maine sub-regions (Figure 4-10). The seasonal pattern of change in potential growth potential was similar at $10 \mathrm{~m}$, but the summertime decrease was not as large in any of the sub-regions as it was at the surface. In the Eastern Maine and Bay of Fundy sub-regions, change in potential growth at $10 \mathrm{~m}$ was greater than or equal to zero throughout the summer (Figure 4-10).

Averaged seasonally, change in growth potential in most sub-regions was positive in winter and spring and negative in summer and fall. This is a result of increasing temperatures. Temperatures in winter and spring were less than the peak growth temperature in the hindcast and warmed toward peak growth temperatures in the forecast. In contrast, temperatures in summer and fall were near to or greater than the peak growth temperature in the hindcast and became less favorable in the forecast. The exceptions to this are the crest of Georges Bank, the shelf south of Nova Scotia, the Bay of Fundy, and the eastern coast of Maine, where average change in growth potential at the surface was greater than or equal to zero in all seasons (Figure 4-11). Although growth potential did decrease slightly in the summer in the Bay of Fundy (Figure 4-10), this was balanced out by increasing growth potential when averaged over the season. 


\section{Regionally-Averaged Change in Potential Growth for $P$. australis}
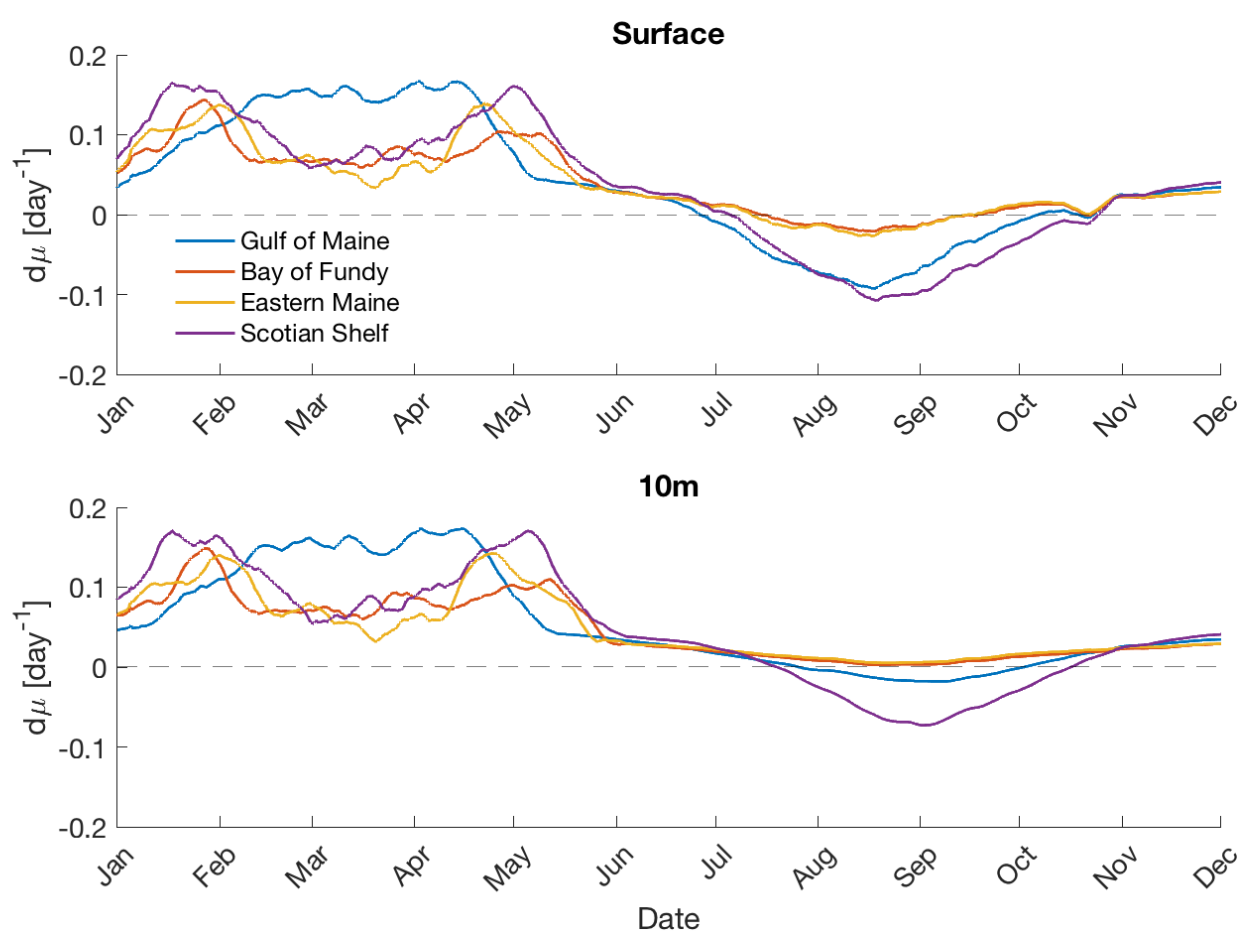

Figure 4-10 - Change in potential growth for each of the four sub-regions (see legend) vs. time at the surface (top) and at $10 \mathrm{~m}$ (bottom). 

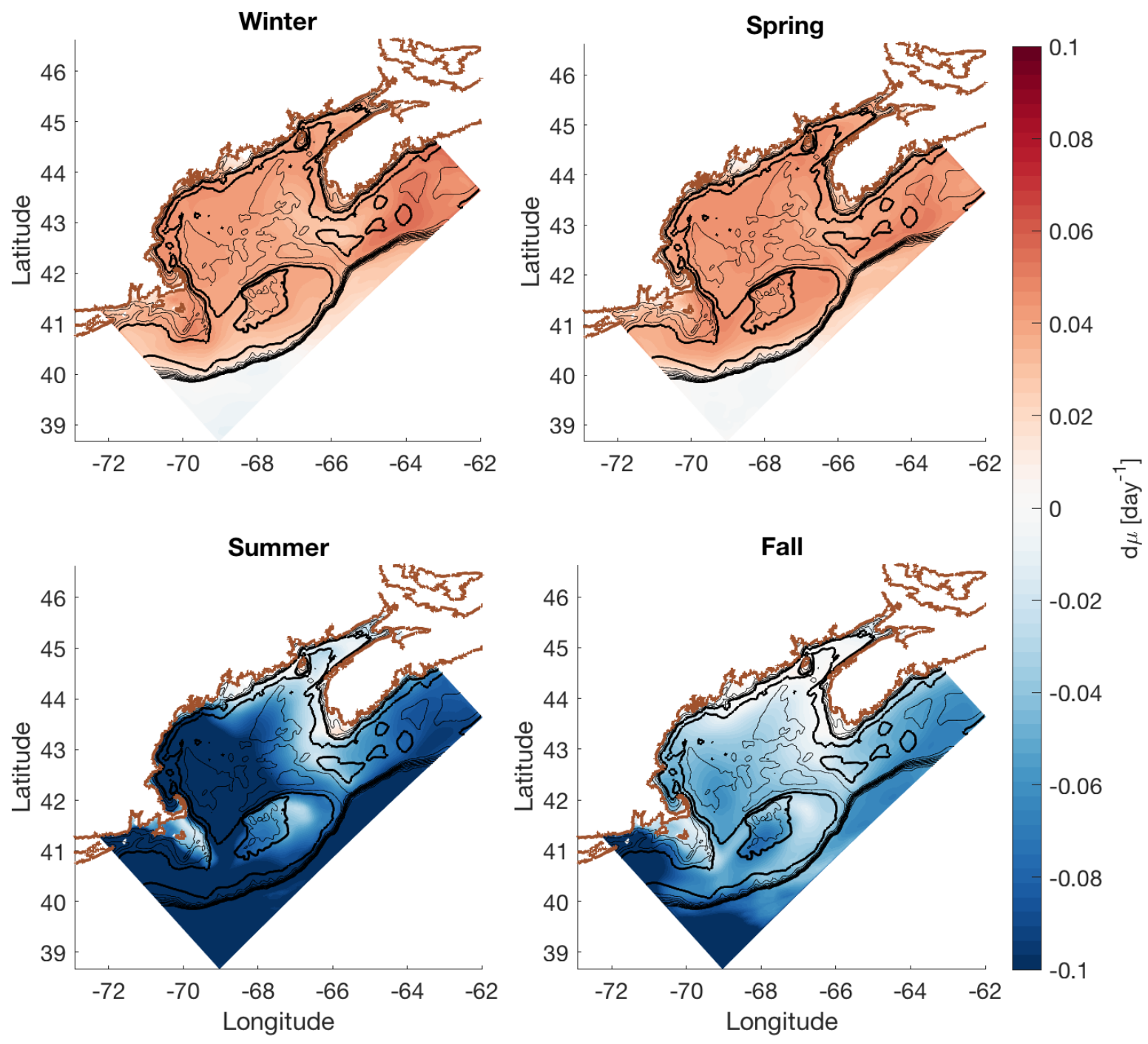

Figure 4-11 - Average change in surface potential growth in the GOM ROMS domain in the (clockwise from top left) winter, spring, fall, and summer. Color values are given by the color bar on the right.

\subsubsection{Bloom Timing}

Bloom timing shifted earlier in the spring by 1-2 weeks and later in the fall by $4-6$ weeks. The later fall shift is qualitatively consistent with the findings of Record et al. (2019) for phytoplankton in the GOM, but the earlier spring shift is in the opposite direction of Record et al.'s findings. Shifts in bloom timing were not statistically significant in all subregions, however. Statistical significance was tested via the two-sided Wilcoxon rank sum test, which tests the null hypothesis that the data in two samples are from distributions 
with the same median. The later shift in fall bloom timing was significant in the GOM, Scotian Shelf, and Bay of Fundy sub-regions, while the earlier shift in spring bloom timing was only significant in the GOM and on the Scotian Shelf. Significant changes are summarized in Table 4-2.

Table 4-2 - Shift in bloom timing in days for each sub-region in the spring and fall. Only numbers that are significant at the $5 \%$ confidence level are listed. The difference is given in days in the table but rounded to the nearest week in the text. No significant changes were recorded in the Eastern Maine subregion.

\begin{tabular}{lll}
\hline Sub-Region & $\begin{array}{l}\text { Spring Bloom Timing Shift } \\
\text { (days) }\end{array}$ & $\begin{array}{l}\text { Fall Bloom Timing Shift } \\
(\text { days })\end{array}$ \\
\hline Gulf of Maine & -13 & +26 \\
\hline Scotian Shelf & -6 & +42 \\
\hline Bay of Fundy & -- & +27
\end{tabular}

\subsubsection{Growing Season}

In addition to shifts in bloom timing, the number of days in the growing season changed in the forecast. In the Bay of Fundy, the growing season increased significantly by 3 weeks. Changes in growing season averaged over the Eastern Maine Coast, GOM, or Scotian Shelf sub-regions were not significant according to the Wilcoxon rank sum test. When the year was divided into spring and fall growing seasons (i.e. the first half and second half of the year), it became apparent that most of the increase happened in the first half of the year. The spring growing season increased significantly by $4-6$ weeks in all sub-regions, while the fall growing season decreased significantly by 6-7 weeks in the GOM and Scotian Shelf sub-regions. Significant changes in growing season for each sub-region are summarized in Table 4-3. 
Table 4-3 - Change in growing season in days averaged over each of the sub-regions. Only numbers that are significant at the 5\% confidence level are listed. The difference is given in days in the table but rounded to the nearest week in the text.

\begin{tabular}{llll}
\hline Sub-Region & $\begin{array}{l}\text { Annual Growing } \\
\text { Season dt (days) }\end{array}$ & $\begin{array}{l}\text { Spring Growing } \\
\text { Season dt (days) }\end{array}$ & $\begin{array}{l}\text { Fall Growing } \\
\text { Season dt (days) }\end{array}$ \\
\hline Gulf of Maine & -- & +40 & -43 \\
\hline Scotian Shelf & -- & +40 & -51 \\
\hline Bay of Fundy & +23 & +36 & -- \\
\hline Eastern Maine Coast & -- & +28 & -- \\
\hline
\end{tabular}

\subsection{Discussion}

\subsubsection{Mechanisms Behind Changing Hydrodynamics}

\subsubsection{Sea Surface Temperature, Surface Salinity, and Stratification}

The general trend in sea surface temperature - warming overall and enhanced warming in the summer - was also noted in Alexander et al. (2020) and in the GFDL-ESM2M. Enhanced warming in the late summer is likely driven by the Delta in atmospheric temperature. A comparison of the domain-averaged change in sea surface temperature and average change in air temperature showed that the two signals were synchronous (not shown). Summer stratification can also exacerbate warming: increased stratification leads to reduced mixing with cooler, deeper waters, stronger air-sea temperature coupling, and a shallower layer over which to distribute the heat flux (Alexander et al., 2020, 2018). Warming was stronger on the Scotian Shelf than in other sub-regions (Figure 4-5), the cause of which is two-fold. First, northerly latitudes are expected to undergo enhanced warming, as shown in the GFDL-ESM2M output (Alexander et al., 2020). Second, the Scotian Shelf saw a larger summertime increase in stratification than the other subregions, which - as mentioned above - can lead to stronger temperature increases. In contrast, the Bay of Fundy and Eastern Maine sub-regions, although at similar latitudes 
to the Scotian Shelf sub-region, had amongst the smallest changes in sea surface temperature (Figure 4-5). This is likely the result of strong tidal mixing in these areas, which offset the surface warming by mixing cooler waters to the surface. Increased stratification was correlated with increased surface temperatures in the summer and fall, and with decreased surface salinity in the winter (Appendix C, Figure 8-6). Browns Bank saw the strongest increase in stratification because it was one of few areas that was wellmixed in the hindcast but stratified in the forecast.

Surface salinities decreased throughout the domain, and the GOM ROMS became overall fresher, with the largest decrease in late summer (Figure 4-6). An analysis of the eastern (upstream) boundary showed that decreased salinity is the result of increased freshwater transport into the domain at the Scotian Shelf, which also peaks in the summer. Freshening north of $40^{\circ} \mathrm{N}$ was a feature in the GFDL-ESM2M output, with stronger freshening in June-July-August than in December-January-February (Alexander et al., 2020). This northerly freshening occurred because the change in evaporation minus precipitation is strongly negative in the Subpolar Gyre and Labrador Sea $(\Delta(E-P)<0)$ in the GFDL-ESM2M, and freshening occurred in the GOM because of freshwater advection to the southwest (Alexander et al., 2020). On the inner Scotian Shelf, salinity Deltas were negative and velocity Deltas toward the GOM were positive, supporting the idea that freshening in the domain was caused by freshwater advection from upstream. (As mentioned in Section 4.3, the NWA ROMS and GOM ROMS disagreed on the degree of freshwater advection, but both models predicted an increase in freshwater flux at the eastern boundary in the forecast.) Some areas saw stronger freshening than the average trend however, especially areas of steep bathymetry (Figure 4-6). This change was particularly apparent on Georges Bank and was simulated by the GOM ROMS but not the NWA ROMS. This is because a higher resolution model supports finer scale variability and is likely more influenced by bathymetric structure. 


\subsubsection{Gulf of Maine Inflow Ratio}

An analysis of each component of the GOM inflow ratio showed that the increase is caused more by increased Scotian Shelf Water inflows than by decreased Northeast Channel inflows (Appendix C, Figure 8-7). Increased Scotian Shelf Water inflows are likely a result of the increased velocities (and consequently, transport) at the eastern boundary (Figure 4-4). Alongshore transport on the Scotian Shelf flows southwest and enters the GOM with Scotian Shelf inflows at the southern tip of Nova Scotia. Because Scotian Shelf Water inflows are relatively cool (Townsend et al., 2015), and because the inflows continue via the coastal current into the Bay of Fundy, increased Scotian Shelf Water inflows could help explain the relatively small increases in sea surface temperature near the coast at Nova Scotia, in the Bay of Fundy, and along the eastern Maine coast. In both the hindcast and forecast composite years, a mass of cool surface water is apparent that enters the domain from the Scotian Shelf, wraps around Nova Scotia, and spreads into the Bay of Fundy, similar to what has been seen in satellite images (Luerssen et al., 2005). In the forecast composite year, while the average surface temperature in most of the domain was $16^{\circ} \mathrm{C}$, this water mass remained between 8 and $12^{\circ} \mathrm{C}$ (Appendix C, Figure 8-8).

\subsubsection{Eastern Maine Coastal Current}

The Eastern Maine Coastal Current is pressure-gradient-driven and influenced by several forces, including river outflow (Bisagni et al., 1996; Brooks, 1994; Keafer et al., 2005), Scotian Shelf inflows (Brooks, 1994; Lynch et al., 1997), and the volume and extent of dense slope water in the Jordan Basin (Brooks, 1994; Lynch et al., 1997). Pettigrew et al. (2005) observed increased transport in the spring and summer because of river discharge. The river Deltas peaked in June, and were greater than zero from mid-May to mid-September (Figure 4-9). EMCC transport, meanwhile, increased in the forecast from mid-July to mid-October. This is a delay of about 60 days, which is longer than the 45 day lag between the St. John River and Penobscot Bay that was suggested by Brooks (1994). Yet it is not so different that the rivers cannot be a contributing factor to the 
enhanced EMCC transport. An important aspect of this potentially causal relationship is that the expected changes in river outflow with climate change are not agreed upon for this region: while most studies agree that river discharge is expected to decrease at low latitudes and increase at high latitudes as a result of climate change, they disagree on whether the GOM is a "high latitude" or "low latitude" region (e.g. Arnell, 1999; Gosling et al., 2017, 2011; Prudhomme and Davies, 2009). The sensitivity of the results to the river Deltas suggests that an ensemble approach might be appropriate in future studies.

Another driving factor to EMCC transport is the strength of Scotian Shelf inflows. Increased inflows are evident via the increased GOM inflow ratio, as explained above, and these inflows help regulate the strength of buoyancy circulation in the eastern GOM (Brooks, 1994). Stronger inflows enhance the baroclinic gradient from the edges of Jordan Basin to the center, creating stronger cyclonic circulation. The increased Scotian Shelf inflows, as evident in the increased GOM inflow ratio, could have contributed to the changes in EMCC transport. The GOM inflow ratio increased year-round, however, with no apparent seasonal variability, while the EMCC transport decreased from February to June and increased from July to November. Scotian Shelf inflows, therefore, likely did not contribute to the increased seasonality of the EMCC.

The third factor to EMCC transport is the strength of the cyclonic circulation around Jordan Basin. Inflows of deep, saline, dense slope water via the Northeast Channel set up a baroclinic gradient that results in the cyclonic Jordan Basin Gyre, of which the EMCC is the onshore extension (Lynch et al., 1997). Therefore, changes in EMCC transport could also be driven by changes in slope water inflows. The average depth of the 33 PSU isohaline, the boundary of slope water inflows as defined in Brooks and Townsend (1989) was plotted in the GOM interior in the hindcast composite year and the forecast composite year (Figure 4-12). Two changes were apparent. First, in the forecast summer, the $33 \mathrm{PSU}$ isohaline extended farther westward into Wilkinson Basin. The effects of the increased westward extent are discussed in Section 4.5.4. Second, on average, the isohaline deepened 
by $60-80 \mathrm{~m}$ in all seasons. In the hindcast, the $33 \mathrm{PSU}$ isohaline was at $25 \mathrm{~m}$ in the GOM interior, while in the forecast it was found at 100m (Figure 4-12). Brooks and Townsend (1989) observed the 33 PSU isohaline shoaling from 100m at the edge of Jordan Basin to $60 \mathrm{~m}$ in the middle of the basin, and used this cross-shore gradient to explain baroclinic controls of the EMCC. However, because the depth of the 33 PSU isohaline in the forecast was beyond the observed historical range, it is difficult to translate isohaline depth into a cross-shore gradient based on the same methods. This method is therefore not appropriate for determining the strength of baroclinic circulation under future climate scenarios, and more work should be done to calculate the cross-shore density gradient directly from model-simulated temperature and salinity.

From the three driving factors discussed, it seems most likely that increased EMCC transport was due to the change in river discharge, perhaps with additional contribution from increased Scotian Shelf inflows. 

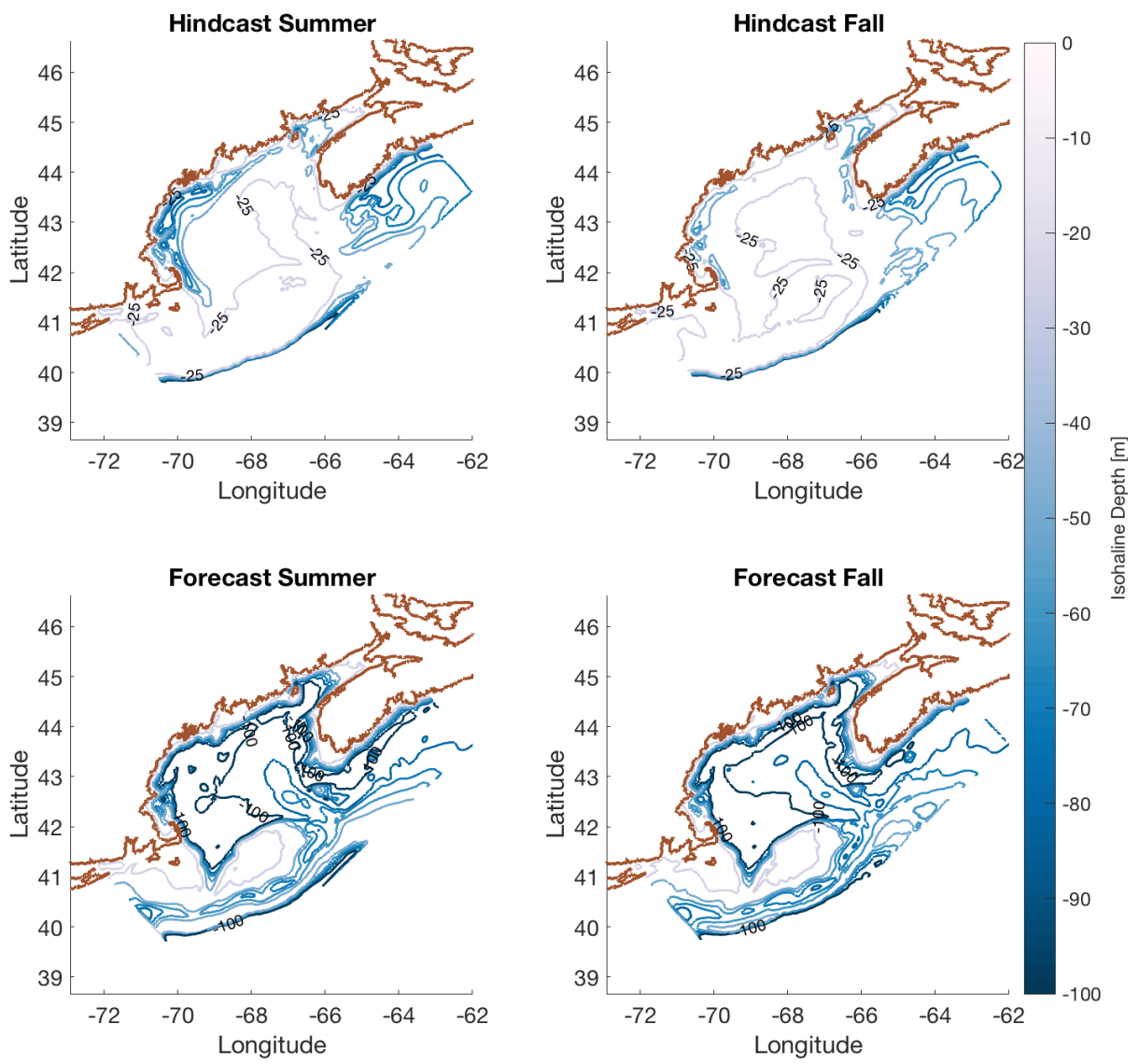

Figure 4-12 - Depth of the 33PSU isohaline in the GOM in (top) the hindcast and (bottom) the forecast simulations, averaged over (left) the summer and (right) the fall. The isohaline in the Gulf interior is labeled, and the depths of the contour lines are given by the color bar on the right. Contours from both the hindcast and the forecast were drawn at 25, 50,60 70, 80, and 100m.

\subsubsection{Effects of Physical Changes on Phytoplankton Functional Groups}

In some instances, long-term warming has been shown to contribute to shifts in the phytoplankton assemblage toward diatoms, away from dinoflagellates (Hinder et al., 2012). The corresponding increase in stratification, however, may be less favorable. Increased stratification with climate change in the global oceans will have different consequences depending on the latitude and phytoplankton in question (Anderson, 2014; Hallegraeff, 2010; Moore et al., 2008; Wells et al., 2020). Diatoms (including Pseudonitzschia) are typically competitive in turbulent, eutrophic waters because they have faster growth rates under high nutrient concentrations (Miller and Wheeler, 2012), but their inability to swim and their hard silica shells necessitate a physical transport process to 
return them to the surface (Miller and Wheeler, 2012). Increased stratification might suppress vertical mixing and therefore shift the assemblage away from diatoms.

Increased stratification may also suppress wind-induced vertical mixing. This suppresses the introduction of new nutrients from deeper waters, which presents a challenge to the entire phytoplankton community (Doney, 2006). Dinoflagellates might be more competitive than diatoms in this environment because they can migrate vertically to access nutrients. Pseudo-nitzschia might also have an advantage relative to other diatoms, because they are smaller and lightly silicified, so they do not require as much silica (Marchetti et al., 2004; Parsons et al., 2002). Whether that advantage is strong enough to overcome the disadvantages of negative buoyancy and immobility remains to be seen.

\subsubsection{P. australis Potential Growth}

The temporal and spatial variability in predicted $P$. australis potential growth is driven directly by the variability in ocean temperatures. In the forecast, when ocean temperatures were greater than $15^{\circ} \mathrm{C}$, potential growth rates decreased. This happened throughout the domain in the summer and early fall, as shown in Figure 4-10. The effect was least severe in the Bay of Fundy and Eastern Maine Coast sub-regions because the combination of strong tidal mixing, northerly latitude, and cool inflows from the Scotian Shelf kept temperatures in the species' preferred $11-15^{\circ} \mathrm{C}$ temperature range. This explains why seasonally-averaged growth potential increased in each season in the forecast in these subregions but nowhere else in the domain (Figure 4-11).

Changes in growth potential also depended on the depth that was chosen for analysis. Although potential growth rates at the surface decreased in every sub-region in the forecast summer, the effect diminished with depth. In the Bay of Fundy and Eastern Maine Coast sub-regions, 10m potential growth rate did not change (Figure 4-10) in the summer. This is logical, because sub-surface waters are not as closely coupled to atmospheric temperature. It is also an important distinction, because $P$. australis was 
sampled below the surface at 10 and $20 \mathrm{~m}$ in the ship survey described in Clark et al. (2019). In addition, sub-surface populations have been found to seed Pseudo-nitzschia blooms off the coasts of Ireland (Cusack et al., 2015), Washington state (Trainer et al., 2000), and Southern California (Seegers et al., 2015). Just because the surface becomes too warm does not mean that the environment becomes inhospitable to P. australis; future blooms might become more dependent on sub-surface populations that are deep enough to be in cooler water but shallow enough to be in the euphotic zone. Whether or not these deep populations are exposed to coastal shellfish populations is another matter.

Although the discussion above treats the surface and $10 \mathrm{~m} P$. australis populations as distinct, this is not likely. It is more likely that cells in the surface mixed layer are exposed to a variety of depths because of strong vertical mixing. Their environmental temperature is therefore more accurately represented by an average over the mixed layer depth. By focusing on temperatures at the surface and 10m, we might neglect cooler water at depth, such that the growth potential estimates from the surface as presented here are an upper bound estimate. Future studies would more accurately predict changes to P. australis potential growth by averaging water temperature over the entire mixed layer. However, the mixed layer is, by definition, well-mixed, and temperatures should be similar. Calculations based on average mixed layer temperature are therefore not expected to change the results significantly.

Light and nutrient availability are other environmental factors that might affect P. australis blooms in the future. Neither of these parameters are addressed by a simple model of growth based on temperature, but they may interact with potential growth rates to influence the likelihood of a bloom. Analysis of bloom timing indicated that spring blooms of $P$. australis might shift earlier by 1-2 weeks in the spring and fall blooms might shift later by $4-6$ weeks. In early spring, nutrients are typically readily available because of winter mixing, but available light is low until mid-March. In the fall, nutrients are often depleted at the end of the growing season, and available light becomes limiting after 
October. Therefore, a new spring niche for P. australis blooms in April or May seems more likely than an expanded fall niche in late October or November. However, P. australis has bloomed in October and November in the GOM since 2016, suggesting that light and nutrient availability do not prevent its survival.

Another point of consideration is that Pseudo-nitzschia species are not the only phytoplankton present in the GOM, and the changes discussed herein will likely affect other planktonic function groups as well. For example, early stratification onset could lead to an earlier spring bloom (Sverdrup, 1953), which could deplete nutrients before Pseudonitzschia can even grow. This phenomenon has already occurred in the GOM, and partly

explains the suppression of the annual A catenella bloom in 2010 (McGillicuddy et al., 2011). In a nutrient-depleted environment, plankton with greater nutrient uptake rates or lower nutrient requirements would have a competitive advantage. Increased stratification might also favor plankton groups that can swim, such as dinoflagellates, which also include several other HAB species (Hallegraeff, 2010). These are only a few examples of how the changes predicted in this study might affect the broader ecosystem. A complete understanding of $P$. australis bloom dynamics in the future will require a deeper investigation of how its phenology interacts with other environmental factors, and the planktonic ecosystem in which it is embedded.

\subsubsection{P. australis in the Eastern Gulf of Maine}

The predicted changes to hydrodynamics and $P$. australis growth potential, when combined, suggest that $P$. australis blooms in the eastern GOM may intensify in the latter half of the $21^{\text {st }}$ Century. First, Clark et al. (submitted) established that the most likely introduction pathway of $P$. australis to the GOM in 2016 was from the inner Scotian Shelf via the coastal current south of Nova Scotia. They also left open the possibility that this connection could re-introduce $P$. australis cells in subsequent years. Assuming an upstream population of $P$. australis of a given cell density, increased transport from the Scotian Shelf would increase the number of cells that are carried to the Bay of Fundy. In 
addition, the cells are more likely to be healthy because Scotian Shelf inflows typically have a silica-to-nitrogen ratio greater than 1 (Townsend et al., 2010). This could then increase the likelihood of a bloom in the Bay of Fundy, but it might decrease the likelihood of DA production, which is often associated with low silica-to-nitrogen ratios (Lema et al., 2017; Tatters et al., 2012; Terseleer et al., 2013).

Whether more cells are introduced into the region or not, potential growth estimates show that some parts of the eastern GOM are the only regions in the domain where annuallyaveraged potential growth rates increased in the forecast. In addition, average potential growth rates increased from fall to early spring, which overlaps with when $P$. australis blooms have occurred in years past. The seminal 2016 DA event began in September and continued into October along the eastern Maine coast (Clark et al., 2019), and toxic P. australis cells were observed near the coast of Rhode Island in March 2017 (Borkman, 2021). Connectivity to southern New England from the eastern GOM can occur within 2 months via the Western Maine Coastal Current and Great South Channel outflows (Manning et al., 2009), so it is possible that these populations were connected, and that the $P$. australis cells survived through the winter. Since 2016, P. australis cells have bloomed in eastern Maine each year in the late fall (Chadwick, 2021), although whether these blooms are connected to the original 2016 event or are the result of repeated introduction is still unknown (Clark, et al., submitted). Regardless, in the forecast, the Bay of Fundy and eastern Maine coast became more hospitable at the time of year when regional $P$. australis blooms have occurred.

Finally, increased EMCC transport in the fall might affect $P$. australis bloom distribution. EMCC transport in the forecast increased at the same time of year when $P$. australis blooms have historically occurred, and the EMCC is known to contribute to the alongshore extent of HABs in the GOM (Anderson et al., 2005; Franks and Anderson, 1992). A bloom that is transported by the EMCC has two possible outcomes. If the connection to the Western Maine Coastal Current (WMCC) is strong, then cells will be carried into the 
western GOM. If the connection to the WMCC is weak, cells will be carried offshore upstream of Penobscot Bay and not connect to the WMCC.

The strength of the east-west connectivity varies interannually, ranging from a "door closed" scenario to a "door open" scenario, with the most common being "door ajar", i.e. partial connectivity (Pettigrew et al., 2005). Increased river outflow can lead to stronger connectivity (Brooks, 1994), but it can also guide the EMCC offshore by creating a front just upstream of Penobscot Bay (Brooks, 1994; Luerssen et al., 2005). The offshore turning is also driven by the location of deep slope water, in a process known as "slope water steering" (Brooks and Townsend, 1989). Brooks and Townsend observed that, as the slope water spread toward the southwest over the summer, the point of offshore flow progressed from upstream to just downstream of Penobscot Bay. The location of the offshore turning coincided with the edge of the slope water intrusion. As mentioned in Section 4.5.1.3, slope water in the forecast summer was, on average, deeper and farther to the west than in the hindcast summer. The contours in Figure 4-12 show the 33 PSU isohaline spreading across Jordan and Wilkinson Basins at 100m. Similarly, in 2000, Pettigrew et al. (2005) observed that slope water filled the entire GOM interior, leading to a dominant gulf-wide cyclonic circulation, reduced Jordan Basin Gyre circulation, and a strong EMCC-WMCC connection. Therefore, from changes to slope water intrusion, the east-west connectivity in the Maine Coastal Current might be expected to increase.

From a 25-year average, there is not enough information to predict this interannually variable process, but future studies should address this variability (see Section 4.5.6). In the forecast, connectivity from east to west could be strengthened by increased river outflow, or it could be weakened by increased offshore flow at Penobscot Bay. Based on the ROMS model output, increased river outflow, and calculations of EMCC transport, it seems likely that the EMCC-WMCC connectivity in the forecast summer and fall will increase as described by Brooks (1994). Increased river outflow might be expected to strengthen the alongshore transport of $P$. australis cells, carrying them from the eastern 
GOM to the west. This hypothesis should be the subject of future monitoring efforts and research.

\subsubsection{Pseudo-nitzschia Community Composition}

P. australis is not the only Pseudo-nitzschia species in the GOM; there are currently 15 species that have been observed in the region (Clark et al., 2019; Fernandes et al., 2014). In addition, some of these (such as P. plurisecta and P. seriata) are known DA producers. There are several examples of shifts in species composition in response to changing environmental factors on event (Schnetzer et al., 2013, 2007), seasonal (Fehling et al., 2006; Thessen and Stoecker, 2008) and decadal (Lundholm et al., 2010; Parsons et al., 2002) time scales. Because of this, and because climate change is unlikely to affect $P$. australis alone, it is important to consider how the species assemblage might change as a result of climate change.

To consider an envelope of variability, $P$. australis was compared to a representative "cold-adapted" species and a representative "warm-adapted" species, both of which already exist in the GOM Pseudo-nitzschia species assemblage. P. seriata has been shown to grow in -2 to $12^{\circ} \mathrm{C}$, with a lethal limit from $12-15^{\circ} \mathrm{C}$ (Smith et al., 1994), and was chosen as the representative cold-adapted species. P. plurisecta typically blooms in the GOM in July and August and dominated the species assemblage at $15.5^{-}-16^{\circ} \mathrm{C}$ in 2013 (Clark et al., 2019, Figure 3), so was been chosen as the representative warm-adapted species. To assess how these species' growth might change as a result of warming temperatures, the $P$. australis growth curve was shifted to their corresponding temperature ranges such that the curve approached zero at $15^{\circ} \mathrm{C}$ for $P$. seriata and growth peaked at $17^{\circ} \mathrm{C}$ for P. plurisecta. (Appendix C, Figure 8-9). The same analyses of potential growth, bloom timing, and growing season were then calculated. This is only an approximation for species whose growth curves peak at higher or lower temperatures, because the full growth rates as a function of temperature for the GOM strains of $P$. plurisecta and P. seriata are not known. Measured growth rates for $P$. seriata isolated from Scottish waters were 
approximately $0.55-0.58$ day $^{-1}$ in a study by Fehling et al. (2004), which is similar to the maximum growth rate for $P$. australis $\left(0.47\right.$ day $\left.^{-1}\right)$ measured in Clark et al. (submitted). Growth rates for $P$. plurisecta are not currently available in the literature. This approach does not seek to understand how all species in the Pseudo-nitzschia assemblage might change, but rather the envelope of possible variability.

In the forecast, the cold-adapted species' growth potential decreased from May through January, with a slight increase from February through April (Figure 4-13). This is because the GOM became too warm on average for this species. Spring bloom timing for the coldadapted species shifted earlier by 3-7 weeks, the fall was too warm in both the hindcast and the forecast, and the growing season contracted by 3-6 weeks (Table 4-4). Meanwhile, time periods previously too cold for the warm-adapted species (such as spring) became more hospitable, and in the forecast summer, the warm-adapted species' potential growth increased as P. australis growth decreased (Figure 4-13). Spring bloom timing for the warm-adapted species shifted a week earlier, fall bloom timing shifted 3-5 weeks later from the summer to the early fall, and its growing season in the Bay of Fundy and eastern Maine coast increased by 4 weeks (Table $4-4$ ).

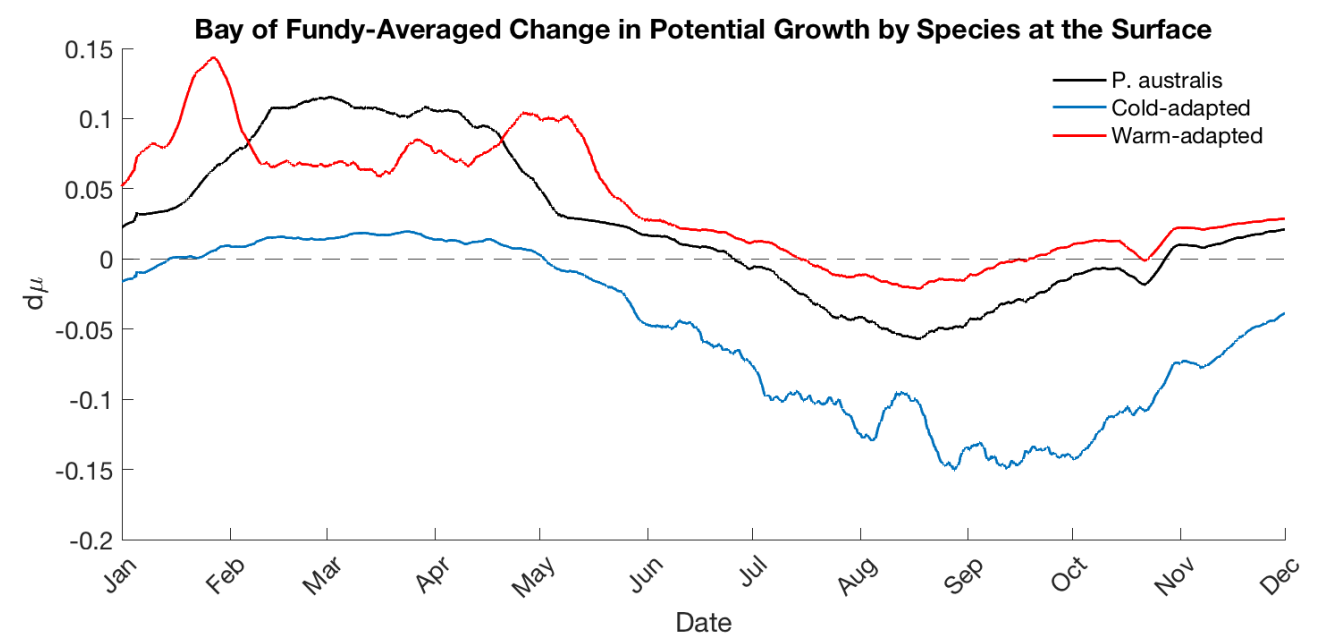

Figure 4-13 - Change in growth potential at the surface averaged over the Bay of Fundy vs. time for (black) P. australis, (blue) the cold-adapted species, and (red) the warm-adapted species. The Bay of Fundy was chosen as an illustrative sub-region because of its relevance to $\mathrm{P}$. australis blooms in the GOM and because it was one of only two sub-regions where change in growing season was significant for all three species. 
Table 4-4 - Change in growing season (days) for $\mathrm{P}$. australis and the representative cold-adapted and warmadapted species. Only numbers that were significant at the $5 \%$ confidence level are shown. Note that values are given in days in the table and listed as weeks in the text.

\begin{tabular}{llll}
\hline Sub-Region & $\begin{array}{l}\boldsymbol{P} \text {. australis } \\
\text { Season dt (days) }\end{array}$ & $\begin{array}{l}\text { Cold Species } \\
\text { Season dt (days) }\end{array}$ & $\begin{array}{l}\text { Warm Species } \\
\text { Season dt (days) }\end{array}$ \\
\hline Gulf of Maine & -- & -37 & -- \\
\hline Scotian Shelf & -- & -27 & -- \\
\hline Bay of Fundy & +24 & -31 & +28 \\
\hline Eastern Maine & +19 & -39 & +26 \\
\hline
\end{tabular}

To summarize, the forecast GOM was too warm for the cold-adapted species, decreasing their ability to grow without adaptation. Temperatures remained in the optimal window for the warm-adapted species and $P$. australis to grow, but at different times and with longer growing seasons than in the hindcast. In the forecast eastern GOM, P. australis bloom timing and growing season shifted to replace the cold-adapted species, while the warm-adapted species moved into time periods previously dominated by $P$. australis, such as the early fall. This suggests that niches might open up in both spring and early fall for blooms of species that previously only bloomed in the summer in the GOM, while niches close for colder adapted species. In addition, in the forecast there is a lower likelihood of summertime blooms by species in the same temperature range as $P$. australis, and a higher likelihood of over-winter blooms, provided they are adapted to low-light conditions.

These predictions all rely on a growth curve for a single isolate of $P$. australis. However, there are presently 15 Pseudo-nitzschia species in the GOM that might thrive in a variety of temperatures, and there are likely to be multiple strains within a single species. As temperatures increase, it is possible that strains more suited to the warmer temperatures could out-compete cold-adapted strains, such that the shift occurs between species strains, not between species. For example, a warm-adapted strain of $P$. australis might bloom in 
the future, rather than $P$. plurisecta. These predictions should therefore be treated with caution as just one example of what might happen in the future.

\subsubsection{Variability and Episodic Events in the Context of Long-Term Change}

The analysis in this study has focused on mean changes in hydrodynamics, temperature, and Pseudo-nitzschia potential growth. However, it is not only the mean change that matters, but also variability superimposed on the mean change. Episodic events such as the Warm Blob on the U.S. West Coast (McCabe et al., 2016; Ryan et al., 2017; Trainer et al., 2020) and marine heat waves in the GOM (Pershing et al., 2018, 2015) have caused extreme Pseudo-nitzschia blooms and fisheries collapse, respectively. Indeed, previous HABs in the GOM can illustrate how episodic events might be affected by changes to the long-term mean.

An example of an historic episodic event is the suppression of the 2010 A. catenella bloom in the GOM, which did not occur despite large cyst abundance that portended a large bloom (McGillicuddy et al., 2011). In that year, abnormally warm and fresh surface waters led to early onset of stratification, an early spring bloom, and depletion of nutrients in surface waters. The resulting mismatch in nutrient availability and A. catenella germination suppressed the A. catenella bloom. In addition, strong upwelling-favorable winds reduced the alongshore transport via the Maine Coastal Current, limiting the spatial distribution of those cells that did grow (McGillicuddy et al., 2011). These simultaneous changes in hydrodynamics are an example of how the mean shift alone might not tell the whole story; concurrent changes, or variability beyond the range of tested values, can alter bloom dynamics or suppress a bloom entirely. Some of the changes that suppressed the 2010 bloom, such as warm, fresh surface waters and earlier stratification onset, are also predicted to occur with climate change, increasing the likelihood that such episodic events might become more ordinary in the future (discussed more below). This therefore is one example of what to expect in the future, particularly with regards to stratification and early nutrient depletion (see also Section 4.5.2). 
The 2016 P. australis bloom is another example of an episodic event that occurred in the context of long-term, mean changes. As discussed in Section 3.4.2, the marine heat wave of 2016 may have contributed to the later bloom timing in 2016. In addition, long-term increases in Scotian Shelf Water inflows (Townsend et al., 2010) coincided with P. australis introduction via the coastal route around Nova Scotia (Clark et al., submitted), and large-scale changes in water mass properties upstream could have affected nutrient availability prior to and during the bloom (Clark et al., submitted). With climate change, at least two of these effects are expected to continue in the mean: warming temperatures in the eastern GOM and increased Scotian Shelf inflows relative to Northeast Channel inflows.

In the future, extreme events that were previously rare might become more common, but their likelihood is not addressed by looking only at the mean change. One such example is marine heat waves. Considering the role that these events apparently play in Pseudonitzschia bloom intensity, it would be prudent to explore changes in temperature extrema. Future analysis should explore, for example, how often the present-day $90^{\text {th }}$ percentile of temperature is exceeded in the forecast. Other examples are extreme changes in inflows and transport. Although the GOM inflow ratio is expected to increase by 0.1 on average, Figure 4-8 shows some increases greater than 0.3 , and events on weekly time scales are not even captured. Similarly, estimates of changes in EMCC transport do not account for years of extraordinarily high or low transport, which determine the degree of EMCCWMCC connectivity. Future work should therefore focus on exploring variability in climate predictions as well as changes to extreme events.

\subsection{Conclusions}

In this study, the Delta Method was used to downscale climate simulations to a 1-km-resolution GOM ROMS and to simulate the effects of climate change on Pseudonitzschia bloom dynamics in the GOM. Output was analyzed for changes to sea surface temperature, surface salinity, stratification, inflows, transport, and P. australis growth, 
bloom timing, and growing season. Scotian Shelf inflows to the GOM may increase by as much as $20 \%$ in the future, and autumnal transport in the Eastern Maine Coastal Current may increase up to $17 \%$. In the forecast simulations, as a result of increased sea surface temperature, $P$. australis surface potential growth increased throughout the domain from November to June and decreased in most of the domain from June to November. A notable exception is the coastal eastern GOM, particularly the Bay of Fundy and eastern Maine coast, where surface potential growth rates increased year-round on average in the forecast simulation. Sub-surface growth rates also did not decrease as much as surface growth rates in the forecast simulation, suggesting increased importance of sub-surface populations. As a result of stronger Scotian Shelf inflows and increased growth potential, P. australis blooms in the eastern GOM may intensify with climate change. Blooms are also likely to shift later in the fall and are more likely to persist through winter into spring. As the timing and duration of $P$. australis blooms change, so might the GOM Pseudo-nitzschia community composition: cold-adapted species are likely to become less frequent, and warm-adapted species might move in to fill the gap left by $P$. australis and other midtemperature-range adapted species. 
This page intentionally left blank. 


\section{Conclusion}

\subsection{Summary}

This thesis advances our understanding of Pseudo-nitzschia and Harmful Algal Blooms in the GOM. In it, Pseudo-nitzschia bloom dynamics in the GOM are explored, and hypotheses for new species introduction are evaluated. The thesis also looks toward the future and predicts how Pseudo-nitzschia bloom dynamics might change with climate change.

The first part built on existing Pseudo-nitzschia research in the GOM (Bates et al., 2018; Fernandes et al., 2014) by analyzing the spatial and temporal patterns in Pseudo-nitzschia species composition in the GOM from surveys in the years 2012-2016. Pseudo-nitzschia blooms prior to 2016 followed consistent biogeography, with community composition dominated by P. delicatissima, P. seriata, P. plurisecta, and P. pungens. In 2016, for the first time in the GOM, $P$. australis was observed and shellfisheries were closed because DA concentrations exceeded the regulatory limit (Bates et al., 2018). PDA concentrations increased with cell concentrations and the relative and absolute abundance of known toxic species. No significant correlations were found, however, between environmental factors and individual species, environmental factors and $\mathrm{pDA}$, or individual species and $\mathrm{pDA}$. The high pDA in 2016 was attributed to the presence of $P$. australis in combination with low residual silica. This part of the thesis established the hypothesis that $P$. australis was carried in on an anomalously saline water mass in 2016, upon which the second study focused.

In the second part of the thesis, a physical model, particle tracking model, and observations were used to explore $P$. australis introduction and connectivity pathways to the GOM in 2016. Particle tracking experiments suggested that the anomalously saline water observed in the first study originated near the bottom of the Scotian Shelf and 
entered the GOM via the Northeast Channel. This water mass likely did not carry P. australis cells, however. Based on particle tracking experiments, $P$. australis cells likely originated near the surface on the Scotian Shelf and were carried into the GOM via the coastal current south of Nova Scotia. Regional connectivity and potential growth rates based on laboratory studies of growth as a function of temperature - were not significantly different in 2016 compared to the other years between 2012 and 2019, but surface salinity on the Scotian Shelf was 0.6 PSU lower than 6 of the 7 other years, and bottom salinity on the Scotian Shelf was 0.7 PSU greater than the 1981-2010 climatology. This suggests that the bloom was controlled by large-scale processes, not local-scale ones. P. australis in the GOM may have originated in either the Gulf of St. Lawrence or the Labrador Current, with an ultimate upstream population in the eastern North Atlantic. This part of the thesis suggested that large-scale hydrodynamic changes could affect Pseudonitzschia blooms in the GOM and laid the foundation for the following study of climate change.

In the third part of the thesis, climate simulations were downscaled to the GOM ROMS to simulate the effects of climate change on Pseudo-nitzschia bloom dynamics in the GOM. Potential future hydrodynamic changes include increased Scotian Shelf inflows and increased seasonality in the Eastern Maine Coastal Current transport. P. australis potential growth at the surface is expected to increase throughout the GOM from November to June and decrease in most of the GOM from June to November. In the eastern GOM, however, surface potential growth rates are expected to increase yearround. As a result of stronger Scotian Shelf inflows and increased growth potential, P. australis blooms in the eastern GOM may intensify with climate change. Blooms might also shift later in the fall and persist through winter into spring. Warming in the GOM is predicted to affect Pseudo-nitzschia community composition by expanding the ecological niche for warm-adapted species and narrowing the niche for cold-adapted species. These 
predictions assume all other factors remain the same, but climate change will likely impact other aspects of the ecosystem as well such as nutrient fluxes and predators.

\subsection{Significance}

The work presented here improves our understanding of the seasonality, species progression, and spatial distribution of Pseudo-nitzschia in the GOM. We now know that species composition, not the environment, is the dominant factor driving pDA concentrations, and that $P$. plurisecta and $P$. australis in particular are associated with elevated pDA concentrations. This thesis also showed that Pseudo-nitzschia blooms can originate in the Bay of Fundy and propagate along the coast, similarly to A. catenella blooms, and that harmful algal cells can originate outside of the GOM.

This thesis also expands our spatial and temporal perspective of GOM Pseudo-nitzschia blooms. Initially, the focus was on only five years, with the majority of the data coming from ship surveys, which provide only a snapshot in time of evolving bloom dynamics, or time series, which are limited in spatial scope. Then, through modeling, the second study simulated data at hourly, $1 \mathrm{~km}$ intervals over the entire GOM and part of the Scotian Shelf. The second study also expanded the focus from five years to eight, with each year simulated separately. Lastly, the climate study produced 25 years of continuous simulations at both the beginning and the end of the $21^{\text {st }}$ Century. The continuous climate simulations created an interannual perspective that allows for the exploration of processes connecting one year to the next. With this improved spatial and temporal resolution and the expanded perspective they provide, we can ask detailed questions pertaining to the spatial extent of Pseudo-nitzschia blooms, and to their initiation and decline.

The research presented here points to areas where Pseudo-nitzschia knowledge is still lacking and proposes ideas for future research. Most urgent is the need for expanded monitoring to sample Pseudo-nitzschia blooms as they rise and decline, as well as additional ship surveys to identify potential upstream populations. An expanded modeling 
approach including the entire Scotian Shelf and part of the North Atlantic would allow for more investigation about the offshore processes that affect the GOM. With regards to ecology, more work can be done to refine the growth model presented here, to include salinity, light availability, and nutrients. To improve our understanding of Pseudonitzschia community composition and how it might change, it would also prove helpful to apply the growth model to other Pseudo-nitzschia species.

Fortunately, the work in this thesis lays the foundation for this continued work. The first part identified the seasons and locations where Pseudo-nitzschia blooms are most common, which can inform monitoring decisions. The second part found the most likely introduction route of $P$. australis and its upstream sources, which can be used to guide future sampling surveys. We have also improved our understanding of growth rates of one $P$. australis strain from the GOM. The theoretical growth curve builds confidence in growth rates at temperatures outside the measured growth range, and establishes a method to adapt the growth curve to different strains or species. The simple growth model that is presented here also lays the foundation for more complex models. As more information becomes available, it should be straightforward to include growth as a function of light, salinity, or nutrients, for either P. australis or other Pseudo-nitzschia species in the GOM.

The modeling methods in this thesis are not only applicable to Pseudo-nitzschia, but also to other HABs in the GOM and to the region in general. LTRANS was adapted and is now applicable to the tidally energetic Bay of Fundy, and a statistically significant number of particles was established for several release sites in the region. For future studies of connectivity and transport in the GOM, the particle tracking tool is readily available. This thesis also included the critical step of downscaling a climate simulation to the regional ROMS. The regional climate simulations can now be used to answer any number of climate change related questions in the GOM, whether they relate to Pseudo-nitzschia and HABs or not. The established workflow can also be used to downscale other climate simulations and examine a model ensemble. 
Last but not least, this work is significant to society. The questions, hypotheses, and methods presented here provide valuable information to improve how we prepare for and respond to Pseudo-nitzschia blooms in the GOM. This research has confirmed that DNA sampling is necessary to predict DA risk, because only through species-specific data can we predict the likelihood of high DA concentrations in the water. It has also pointed to areas and time periods when Pseudo-nitzschia blooms are most likely, which can be used to inform monitoring decisions. Finally, the climate simulations provide a guideline for what human society might expect with climate change. They point to which Pseudonitzschia species could become more prevalent in the future, such as $P$. plurisecta, which is a DA producer. They also indicate that winter and spring might be at higher risk of DA events, although they were not historically. This research has created new understanding and new opportunities to further improve the relationship between the oceans and human health. 
This page intentionally left blank. 


\section{Appendix A}

\subsection{Species Abundance and Hydrography}

Site-specific species progression shows relative unity in species composition between Mt. Desert Island sample sites. Therefore, one site can be used to represent species progression at all sites.

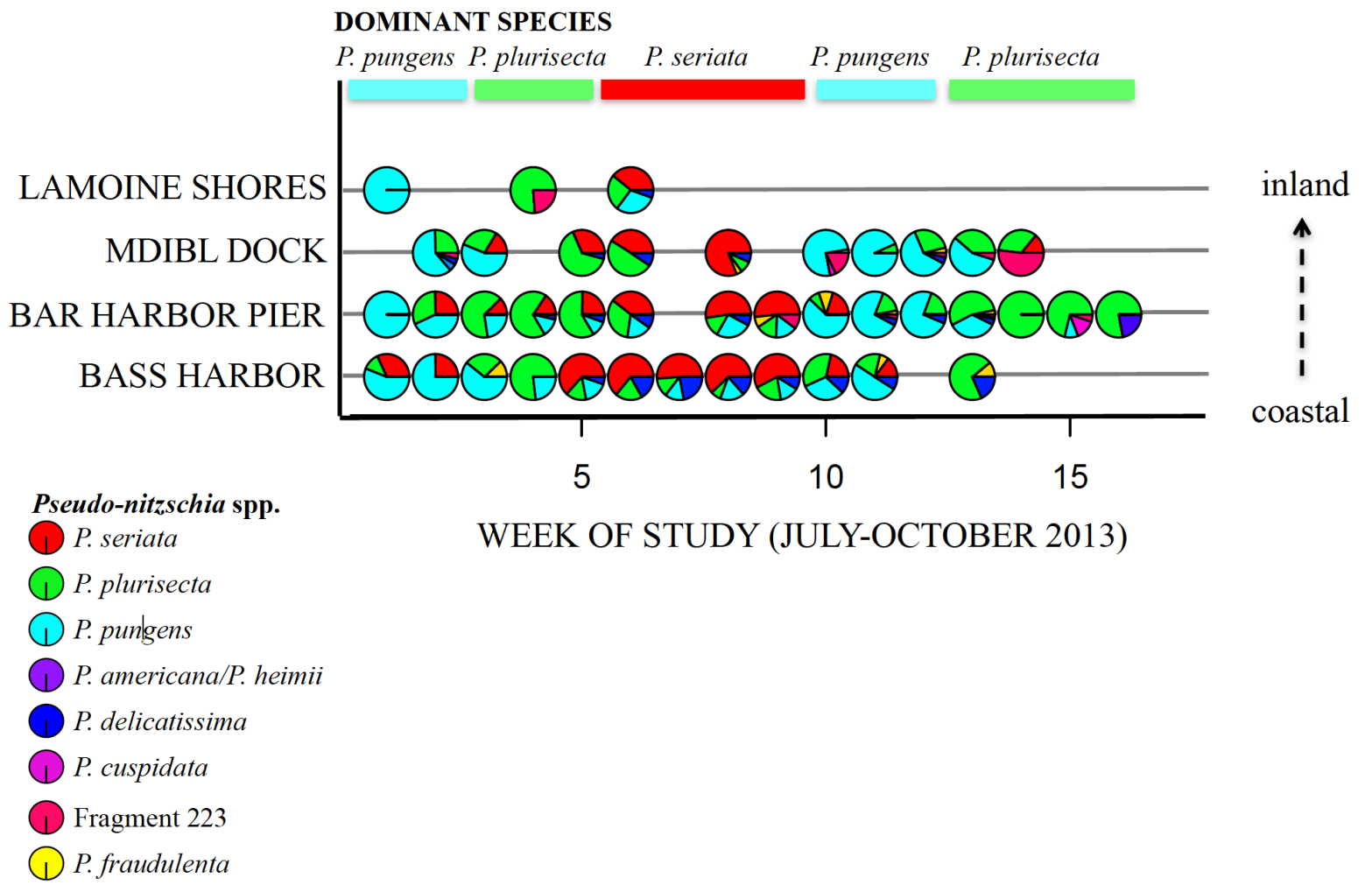

Figure 6-1 - Seasonal progression of relative species abundance in 2013. 
Only DA cell ${ }^{-1}$, DA, and salinity were significantly different in 2016 cruise data compared to 2012, 2014, and 2015 cruise data. Residual silica was significantly different in 2016 from 2012 and 2015.

Cruise Data from Common Transects when DA $>10^{-3} \mu \mathrm{g} / \mathrm{L}$ (All Depths)
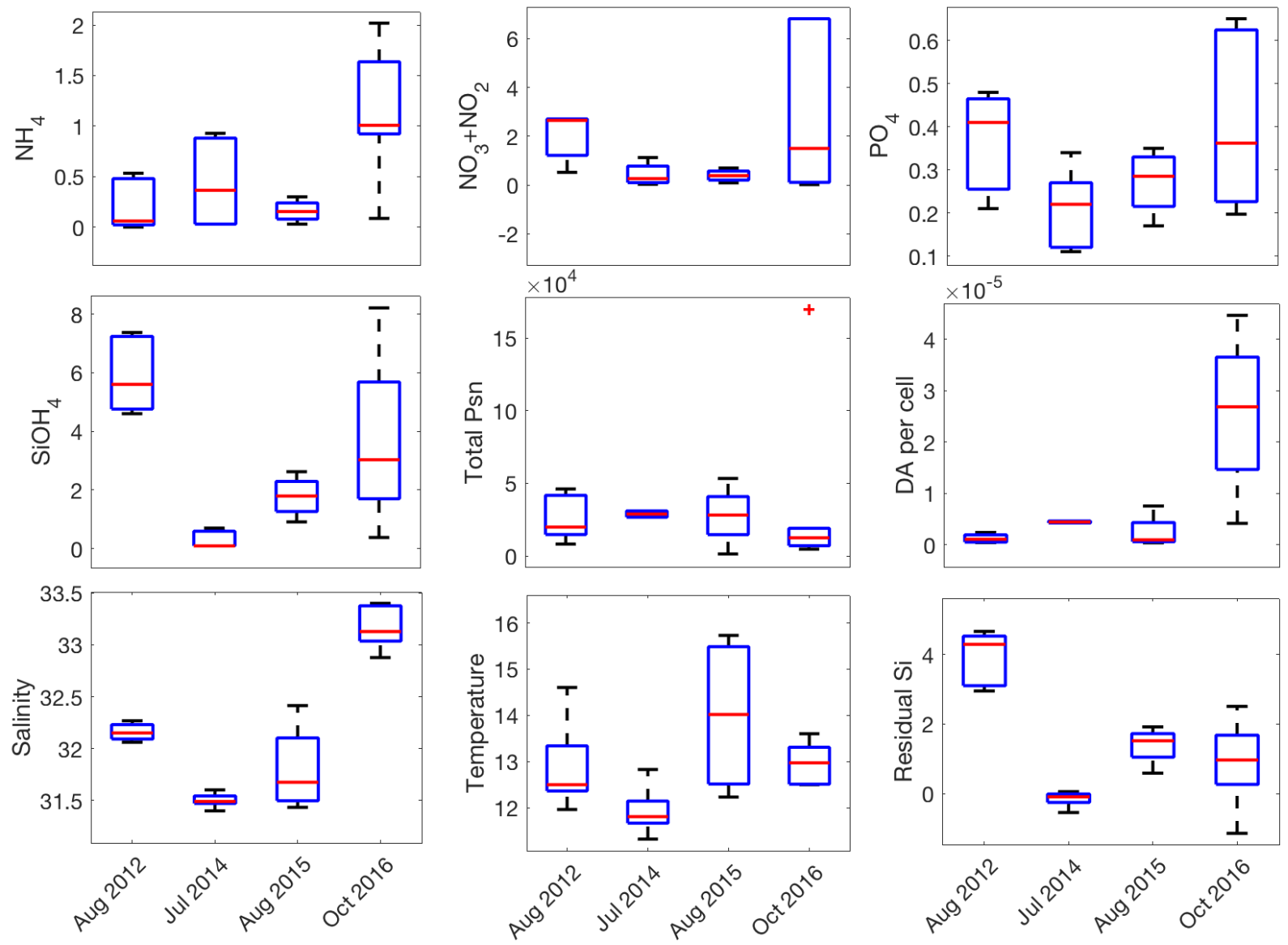

Figure 6-2 - Box and Whisker plot of environmental parameters. 
Salinity was higher in the 2016 cruise data compared to previous years' cruise data, but that might be due to seasonal variations in salinity.

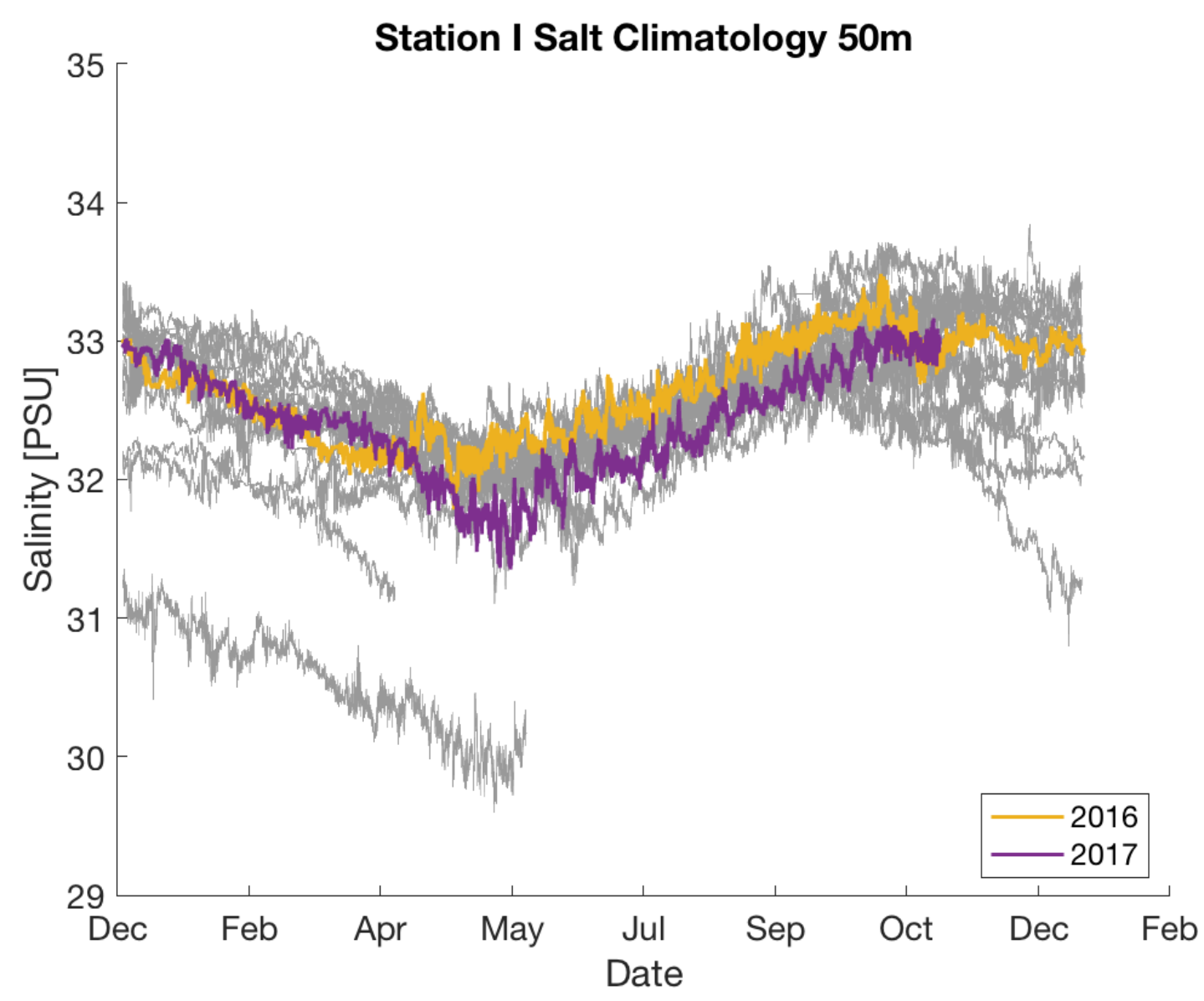

Figure 6-3 - NERACOOS Station I 50 m salinity vs. time of year for 2016 (yellow), 2017 (purple), and 2001-2015 (grey). 
Cumulative river discharge in 2016 was lower than the average from the 2001-2015 climatology.

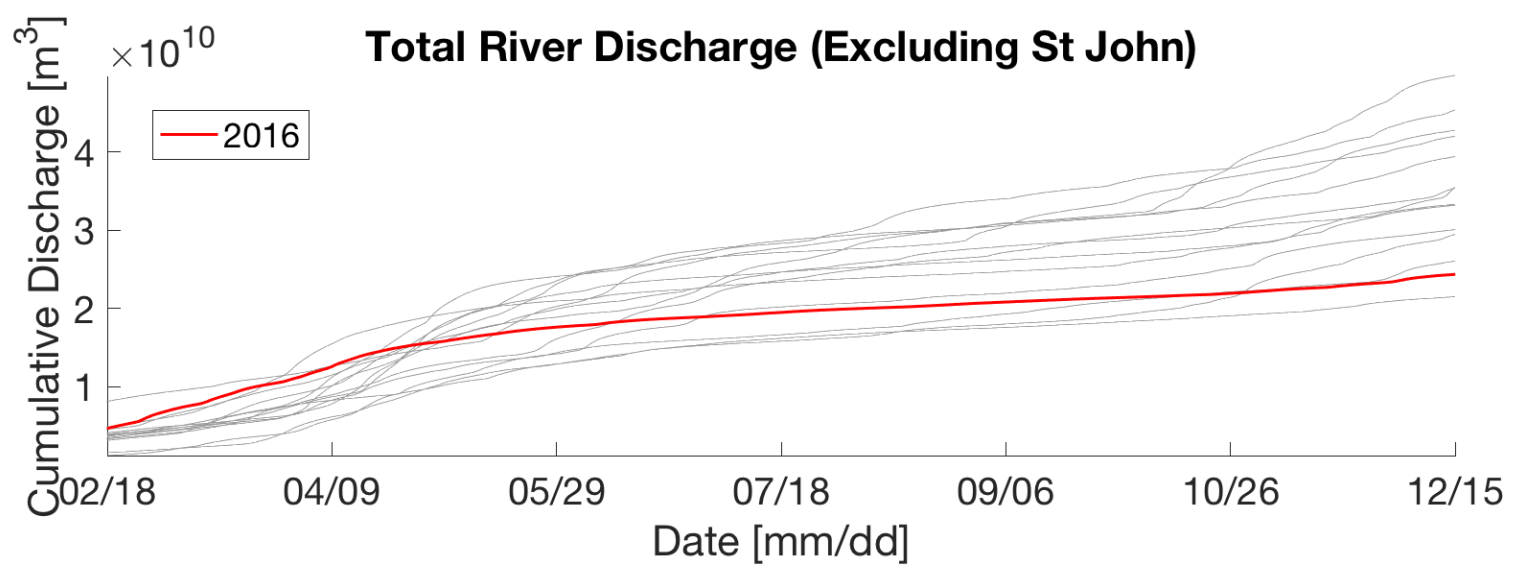

Figure 6-4 - Cumulative river discharge (average daily discharge integrated over time) as the sum of the Penobscot, Kennebec, Merrimack, and Androscoggin Rivers. Years 2003-2017 are shown in grey, and 2016 is shown in red. 


\subsection{CPR Results}

Figure 6-5 - Figure 6-12: Plots of P. seriata group (of which P. australis is part) cell abundance in the months leading up to the 2016 bloom event do not indicate an offshore cell population.

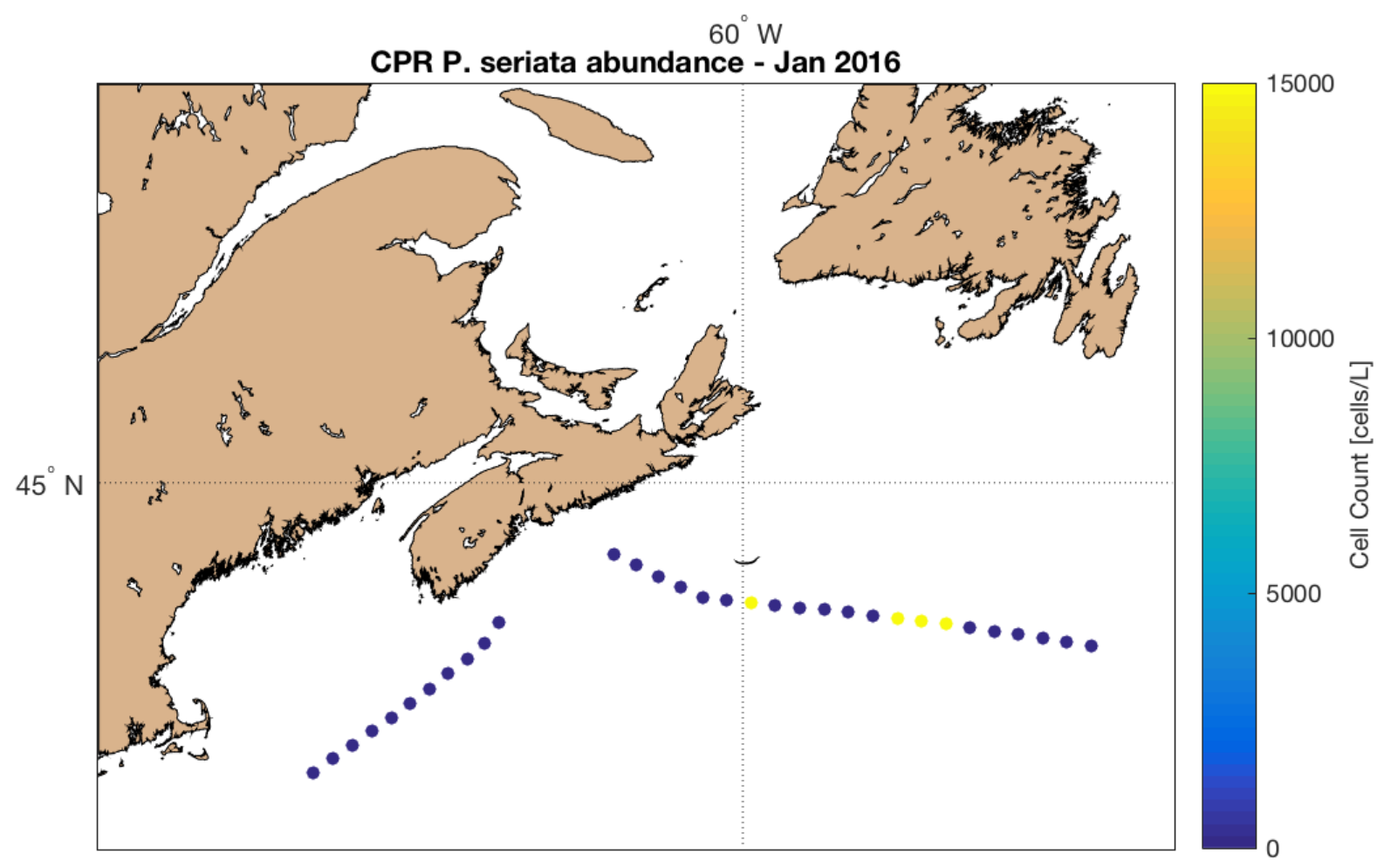

Figure 6-5 - Surface cell concentrations of Pseudo-nitzschia size group P. seriata from January 2016. Circle locations indicate sample location, and circle color indicates cell concentration. 


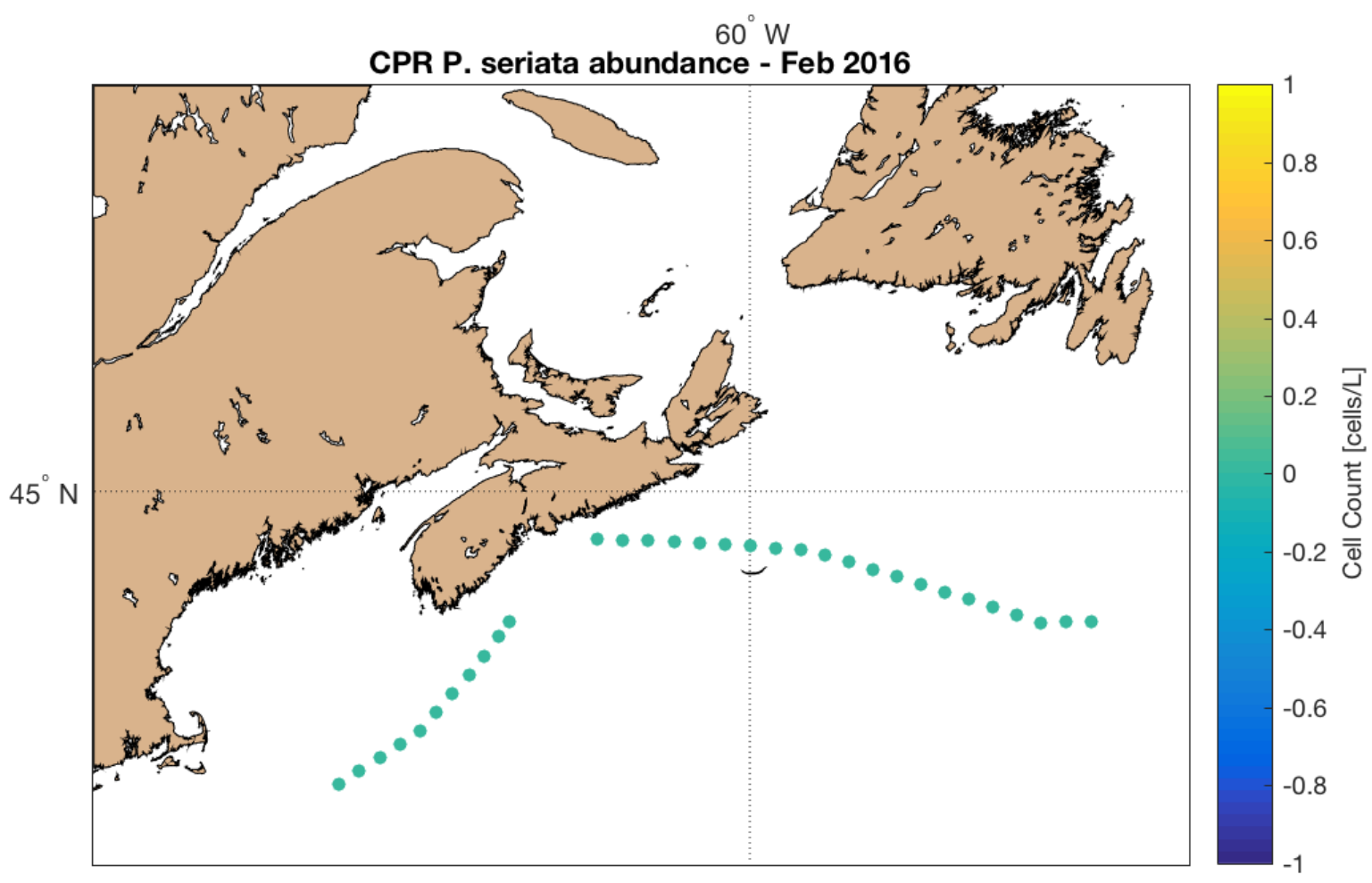

Figure 6-6 - Surface cell concentrations of Pseudo-nitzschia size group P. seriata from February 2016. Circle locations indicate sample location, and circle color indicates cell concentration.

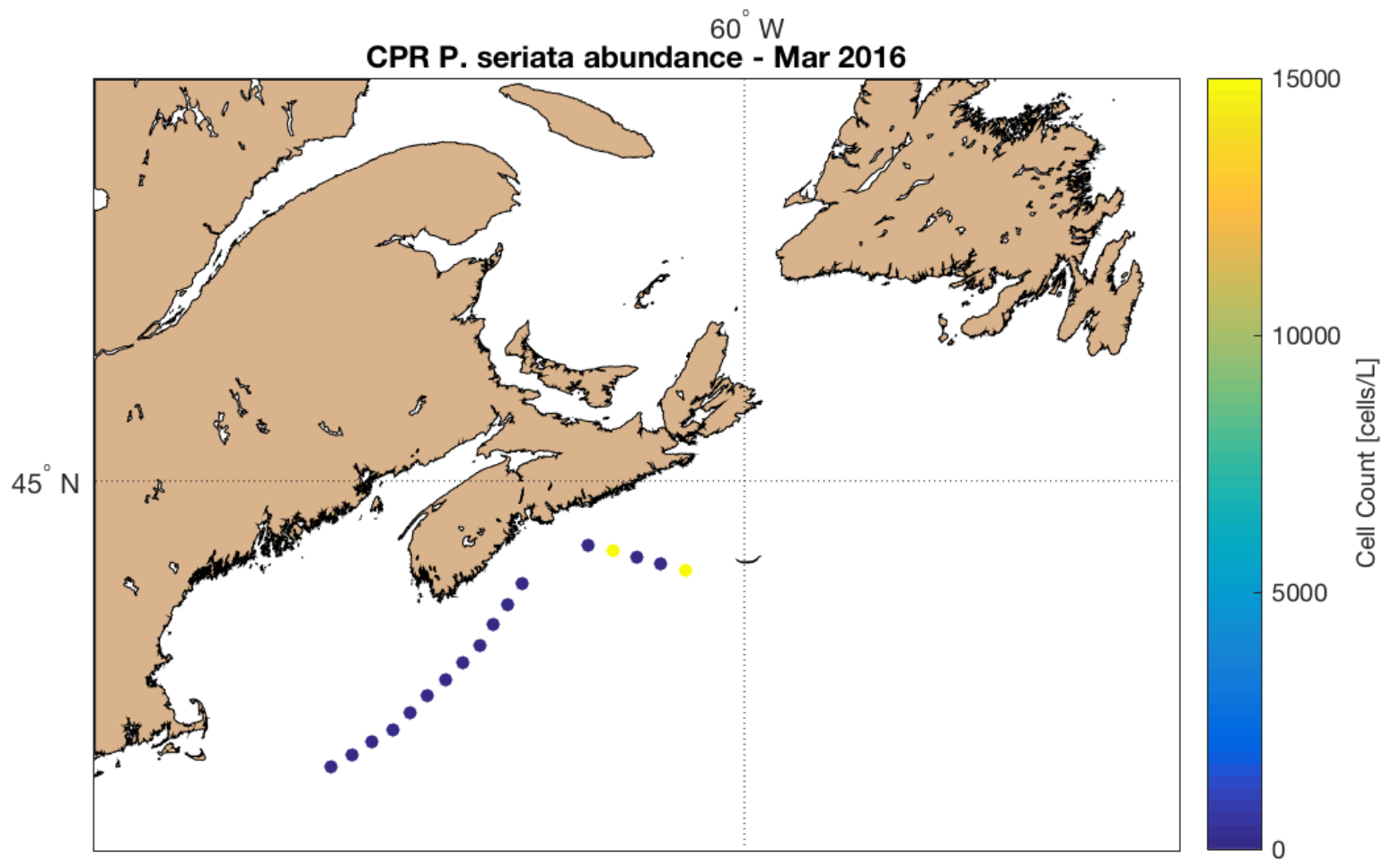

Figure 6-7 - Surface cell concentrations of Pseudo-nitzschia size group P. seriata from March 2016. Circle locations indicate sample location, and circle color indicates cell concentration. 


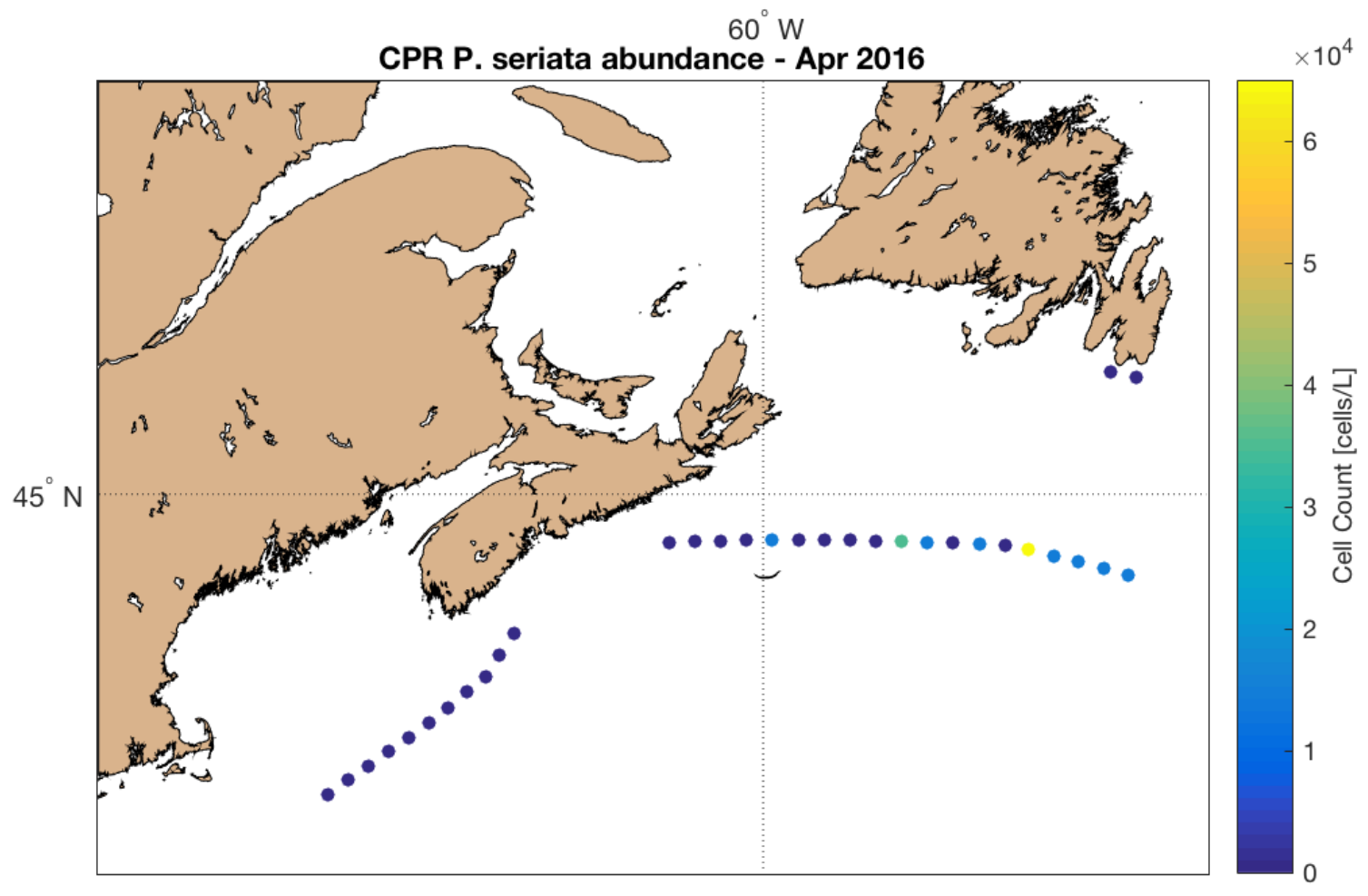

Figure 6-8 - Surface cell concentrations of Pseudo-nitzschia size group P. seriata from April 2016. Circle locations indicate sample location, and circle color indicates cell concentration.

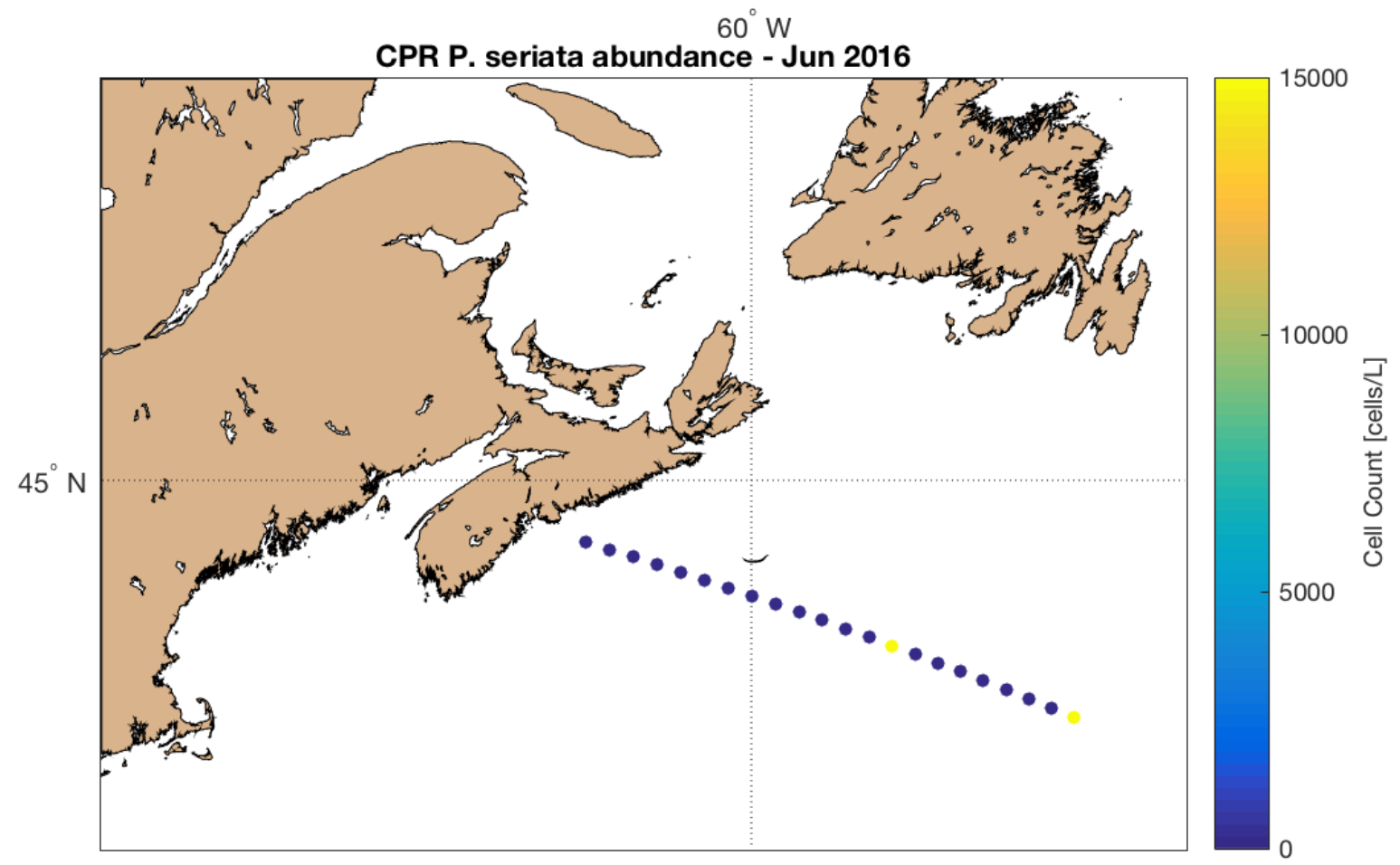

Figure 6-9 - Surface cell concentrations of Pseudo-nitzschia size group P. seriata from June 2016. Circle locations indicate sample location, and circle color indicates cell concentration. 


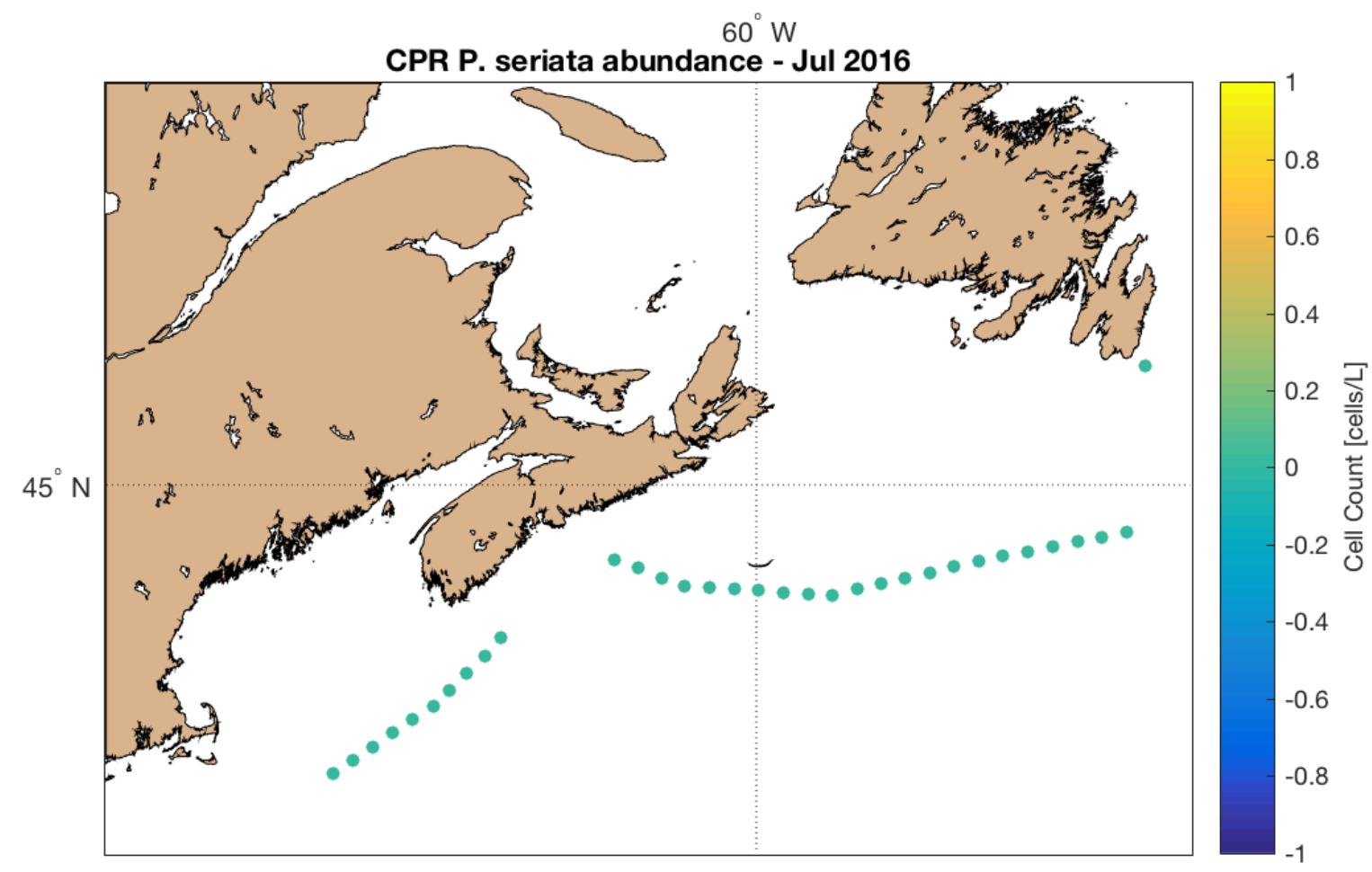

Figure 6-10 - Surface cell concentrations of Pseudo-nitzschia size group P. seriata from July 2016. Circle locations indicate sample location, and circle color indicates cell concentration.

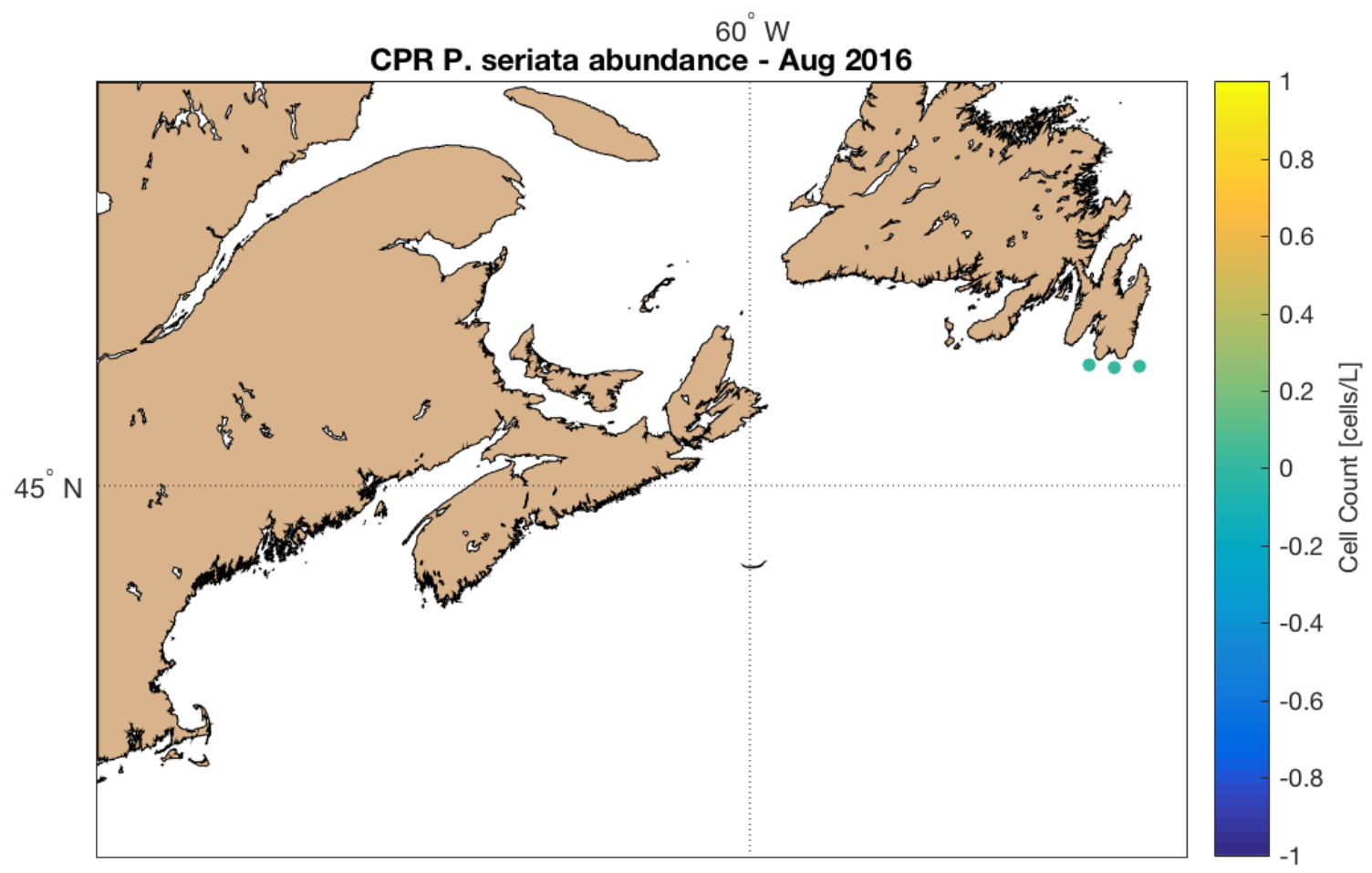

Figure 6-11 - Surface cell concentrations of Pseudo-nitzschia size group P. seriata from August 2016. Circle locations indicate sample location, and circle color indicates cell concentration. 


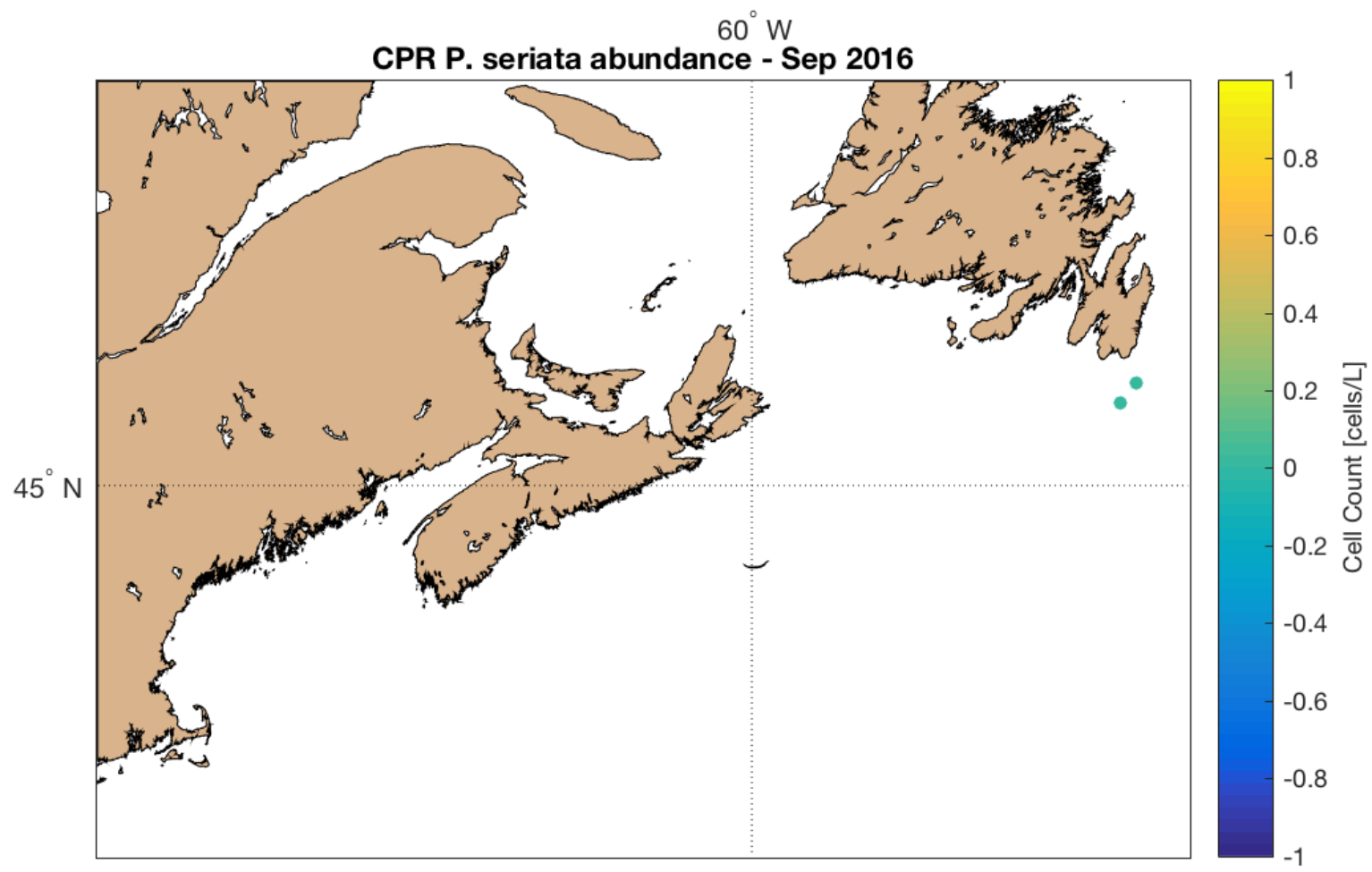

Figure 6-12 - Surface cell concentrations of Pseudo-nitzschia size group P. seriata from September 2016. Circle locations indicate sample location, and circle color indicates cell concentration. 


\subsection{DA cell ${ }^{-1}$ Results}

Table 6-1 - Summary of DA cell ${ }^{-1}$ results using the 85\% relative abundance cut-off. Species are listed in alphabetical order and then chronological order. A double dash (--) indicates that there was only one cellular quota that could be estimated by the $85 \%$ cutoff; if the quota was zero then it was listed as a minimum, but if it was greater than zero then it was listed as a maximum.

\begin{tabular}{|c|c|c|c|c|c|c|}
\hline Species & $\begin{array}{l}\text { Sample } \\
\text { Year }\end{array}$ & $\begin{array}{l}\text { Min. Cellular } \\
\text { Quota (pg/cell) }\end{array}$ & $\begin{array}{l}\text { \% Abundance } \\
\text { of Species }\end{array}$ & $\begin{array}{l}\text { Mean Cellular } \\
\text { Quota (pg/cell) }\end{array}$ & $\begin{array}{l}\text { Max. Cellular } \\
\text { Quota (pg/cell) }\end{array}$ & $\begin{array}{l}\text { \% Abundance } \\
\text { of Species }\end{array}$ \\
\hline P. australis & 2016 & 10.4 & 94.5 & 21.74 & 42.6 & 85.7 \\
\hline P. pungens & 2012 & 0 & $88.2=94.6$ & - & -. & - \\
\hline P. pungens & 2015 & 0 & $86.0-93.4$ & -. & 0.75 & 93.4 \\
\hline P. plurisecta & 2012 & 0.66 & 94.6 & 1.23 & 1.89 & 91.7 \\
\hline P. plurisecta & 2015 & 7.58 & 70 & 17.14 & 26.7 & 11.1 \\
\hline P. seriata & 2015 & -. & -. & .. & 11.1 & 67.4 \\
\hline P. delicatissima & 2015 & 0 & 97.1 & -- & -. & - \\
\hline
\end{tabular}

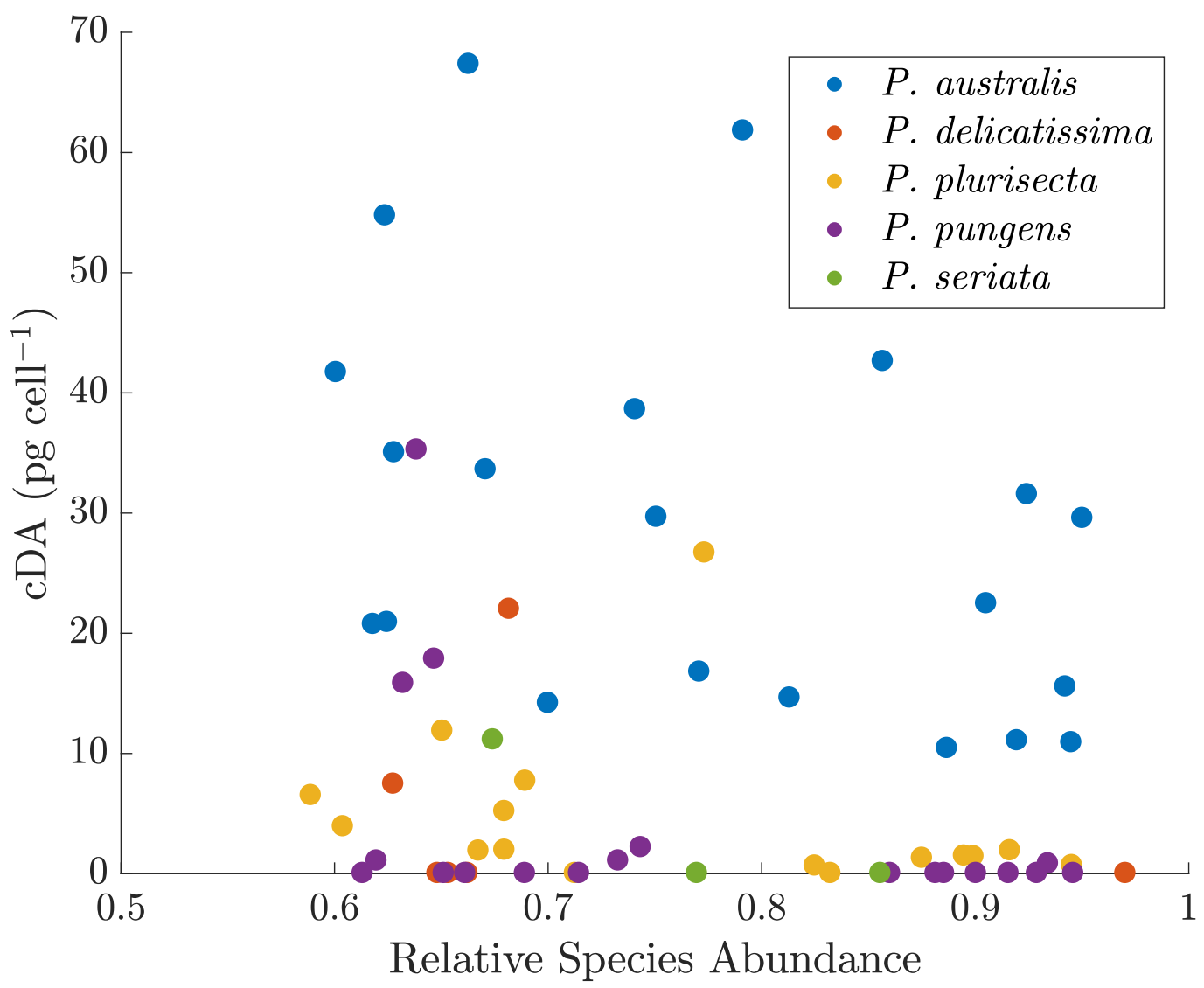

Figure 6-13-cDA estimates ( $\mathrm{pg}$ cell $^{-1}$ ) vs. relative species abundance for five Pseudo-nitzschia species with a relative abundance cutoff of $60 \%$. Note that most $\mathrm{P}$. pungens estimates with values greater than zero were in samples where other known toxic species were also present, but the samples that were almost completely dominated by $\mathrm{P}$. pungens were near zero. 
Table 6-2 - Full suite of samples used to estimate cDA, arranged chronologically and then alphabetically. Samples with relative abundance $>85 \%$ are in bold.

\begin{tabular}{|c|c|c|c|}
\hline Year & Species & Relative Abundance & $\begin{array}{l}\text { Adjusted cDA } \\
\text { (pg per cell) }\end{array}$ \\
\hline \multicolumn{4}{|c|}{2012} \\
\hline & P. pungens & 0.661 & 0.000 \\
\hline & P. pungens & 0.715 & 0.000 \\
\hline & P. pungens & 0.689 & 0.000 \\
\hline & P. pungens & 0.916 & 0.000 \\
\hline & P. pungens & 0.882 & 0.000 \\
\hline & P. pungens & 0.613 & 0.000 \\
\hline & P. pungens & 0.886 & 0.000 \\
\hline & P. pungens & 0.946 & 0.000 \\
\hline & P. plurisecta & 0.680 & 1.937 \\
\hline & P. plurisecta & 0.875 & 1.261 \\
\hline & P. plurisecta & 0.832 & 0.000 \\
\hline & P. plurisecta & 0.917 & 1.892 \\
\hline & P. plurisecta & 0.604 & 3.891 \\
\hline & P. plurisecta & 0.825 & 0.621 \\
\hline & P. plurisecta & 0.946 & 0.662 \\
\hline & P. plurisecta & 0.895 & 1.452 \\
\hline & P. plurisecta & 0.899 & 1.402 \\
\hline & P. plurisecta & 0.668 & 1.867 \\
\hline \multicolumn{4}{|c|}{2013} \\
\hline & P. pungens & 0.620 & 1.039 \\
\hline & P. pungens & 0.733 & 1.044 \\
\hline & P. pungens & 0.744 & 2.154 \\
\hline & P. plurisecta & 0.651 & 11.842 \\
\hline & P. plurisecta & 0.680 & 5.157 \\
\hline & P. plurisecta & 0.589 & 6.486 \\
\hline & P. plurisecta & 0.713 & 0.000 \\
\hline \multicolumn{4}{|c|}{2014} \\
\hline & P. delicatissima & 0.628 & 7.434 \\
\hline & P. delicatissima & 0.649 & 0.000 \\
\hline & P. delicatissima & 0.682 & 21.982 \\
\hline \multicolumn{4}{|c|}{2015} \\
\hline & P. delicatissima & 0.663 & 0.000 \\
\hline & P. delicatissima & 0.654 & 0.000 \\
\hline & P. delicatissima & 0.971 & 0.000 \\
\hline & P. pungens & 0.934 & 0.803 \\
\hline & P. pungens & 0.639 & 35.237 \\
\hline & P. pungens & 0.647 & 17.832 \\
\hline & P. pungens & 0.929 & 0.000 \\
\hline & P. pungens & 0.651 & 0.000 \\
\hline & P. pungens & 0.860 & 0.000 \\
\hline & P. pungens & 0.901 & 0.000 \\
\hline & P. pungens & 0.632 & 15.812 \\
\hline & P. plurisecta & 0.774 & 26.665 \\
\hline & P. plurisecta & 0.690 & 7.676 \\
\hline & P. seriata & 0.674 & 11.115 \\
\hline & P. seriata & 0.770 & 0.000 \\
\hline & P. seriata & 0.856 & 0.000 \\
\hline \multicolumn{4}{|c|}{2016} \\
\hline & P. australis & 0.887 & 10.403 \\
\hline & P. australis & 0.925 & 31.524 \\
\hline & P. australis & 0.792 & 61.781 \\
\hline & P. australis & 0.950 & 29.540 \\
\hline & P. australis & 0.813 & 14.595 \\
\hline & P. australis & 0.601 & 41.675 \\
\hline & P. australis & 0.663 & 67.316 \\
\hline & P. australis & 0.920 & 11.046 \\
\hline & P. australis & 0.628 & 35.010 \\
\hline & P. australis & 0.741 & 38.588 \\
\hline & P. australis & 0.857 & 42.597 \\
\hline & P. australis & 0.943 & 15.516 \\
\hline & P. australis & 0.624 & 54.716 \\
\hline & P. australis & 0.625 & 20.891 \\
\hline & P. australis & 0.700 & 14.157 \\
\hline & P. australis & 0.945 & 10.884 \\
\hline & P. australis & 0.671 & 33.591 \\
\hline & P. australis & 0.771 & 16.754 \\
\hline & P. australis & 0.618 & 20.723 \\
\hline & P. australis & 0.905 & 22.443 \\
\hline & P. australis & 0.751 & 29.630 \\
\hline
\end{tabular}




\subsection{Linear Regression Results}

\subsubsection{All samples; species vs. environment}

$\mathrm{R}^{2}$ values are generally low $(<0.15)$. The highest $\mathrm{R}^{2}$ values were associated with salinity, which we attribute to inshoreoffshore patterns, addressed in-text. There exist a couple of regressions with other parameters for which $\mathrm{R}^{2}>0.15$, but they are not consistent between years. Statisically significant $\mathrm{R}^{2}$ values are in bold.

2012

\begin{tabular}{|c|c|c|c|c|c|c|c|c|c|c|c|}
\hline Factor & P. americana & P. australis & P. caciantha & P. cuspidata & P. delicatissima & P. fraudulenta & P. multiseries & P. obtusa & P. plurisecta & P. pungens & P. seriata \\
\hline Temperature & 0.13 & -- & -- & 0.12 & 0.00 & -- & 0.00 & 0.01 & 0.03 & 0.01 & 0.12 \\
\hline Salinity & 0.03 & -- & -- & 0.09 & 0.10 & -- & 0.00 & 0.00 & 0.29 & 0.01 & 0.05 \\
\hline Nitrate + Nitrite & 0.10 & -- & -- & 0.05 & 0.00 & -- & 0.00 & 0.01 & 0.08 & 0.02 & 0.02 \\
\hline Ammonium & 0.02 & -- & -- & 0.00 & 0.03 & -- & 0.01 & 0.01 & 0.18 & 0.00 & 0.00 \\
\hline Phosphate & 0.14 & -- & -- & 0.03 & 0.10 & -- & 0.00 & 0.03 & 0.00 & 0.06 & 0.00 \\
\hline Silicic Acid & 0.03 & -- & -- & 0.06 & 0.09 & -- & 0.02 & 0.04 & 0.00 & 0.00 & 0.00 \\
\hline Chlorophyll & 0.00 & -- & -- & 0.00 & 0.09 & -- & 0.01 & 0.00 & 0.00 & 0.04 & 0.14 \\
\hline Total N & 0.11 & -- & -- & 0.05 & 0.00 & -- & 0.00 & 0.01 & 0.06 & 0.02 & 0.02 \\
\hline Si:N & 0.07 & -- & -- & 0.00 & 0.01 & -- & 0.00 & 0.00 & 0.00 & 0.05 & 0.00 \\
\hline Si:P & 0.05 & -- & -- & 0.00 & 0.02 & -- & 0.00 & 0.01 & 0.01 & 0.12 & 0.00 \\
\hline $\mathrm{N}: \mathrm{P}$ & 0.13 & -- & -- & 0.06 & 0.02 & -- & 0.00 & 0.00 & 0.08 & 0.00 & 0.03 \\
\hline Residual Silica & 0.04 & -- & -- & 0.01 & 0.05 & -- & 0.02 & 0.00 & 0.06 & 0.01 & 0.03 \\
\hline
\end{tabular}

\section{3}

\begin{tabular}{|c|c|c|c|c|c|c|c|c|c|c|c|}
\hline Factor & Pamericana & Paustralis & Pcaciantha & Pcuspidata & Pdelicatissim & Pfraudulenta & Pmultiseries & Pobtusa & Pplurisecta & Ppungens & Pseriata \\
\hline Temperature & -- & -- & -- & -- & 0.00 & -- & -- & -- & 0.35 & 0.85 & 0.23 \\
\hline Salinity & -- & -- & -- & -- & 0.11 & -- & -- & -- & 0.20 & 0.05 & 0.53 \\
\hline Nitrate + Nitrite & -- & -- & -- & -- & 0.36 & -- & -- & -- & 0.18 & 0.37 & 0.10 \\
\hline Ammonium & -- & -- & -- & -- & 0.10 & -- & -- & -- & 0.27 & 0.00 & 0.15 \\
\hline Phosphate & -- & -- & -- & -- & 0.02 & -- & -- & -- & 0.25 & 0.34 & 0.11 \\
\hline Silicic Acid & -- & -- & -- & -- & 0.03 & -- & -- & -- & 0.19 & 0.03 & 0.01 \\
\hline Total N & -- & -- & -- & -- & 0.20 & -- & -- & -- & 0.29 & 0.05 & 0.04 \\
\hline Si:N & -- & -- & -- & -- & 0.22 & -- & -- & -- & 0.02 & 0.01 & 0.00 \\
\hline Si:P & -- & -- & -- & -- & 0.16 & -- & -- & -- & 0.02 & 0.05 & 0.15 \\
\hline $\mathrm{N}: \mathrm{P}$ & -- & -- & -- & -- & 0.13 & -- & -- & -- & 0.03 & 0.04 & 0.23 \\
\hline Residual Silica & -- & -- & -- & -- & 0.09 & -- & -- & -- & 0.14 & 0.01 & 0.03 \\
\hline
\end{tabular}


Factor

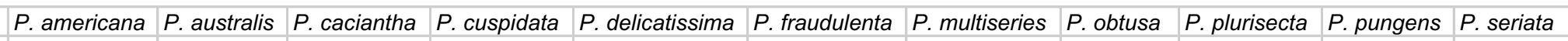

Temperature

Salinity

Nitrate + Nitrite

Ammonium

Phosphate

Silicic Acid

Chlorophyll

Total N

Si:N

Si:P

$N: P$

Residual Silica --

\begin{tabular}{|l|l|r|r|}
\hline-- & - & 0.01 & 0.01 \\
\hline-- & -- & 0.00 & 0.04 \\
\hline-- & -- & 0.04 & 0.00 \\
\hline-- & -- & 0.01 & 0.02 \\
\hline- & -- & 0.00 & 0.00 \\
\hline- & -- & 0.01 & 0.04 \\
\hline- & -- & 0.00 & 0.00 \\
\hline-- & -- & 0.03 & 0.00 \\
\hline-- & -- & 0.00 & 0.08 \\
\hline-- & -- & 0.01 & 0.02 \\
\hline-- & -- & 0.04 & 0.00 \\
\hline- & -- & 0.02 & 0.03 \\
\hline
\end{tabular}

\begin{tabular}{|l|}
\hline 0.01 \\
\hline 0.04 \\
\hline 0.00 \\
\hline 0.02 \\
\hline 0.00 \\
\hline 0.04 \\
\hline 0.00 \\
\hline 0.00 \\
\hline 0.08 \\
\hline 0.02 \\
\hline 0.00 \\
\hline 0.03
\end{tabular}

\begin{tabular}{|l|l|}
\hline 0.03 & - \\
\hline 0.13 & -- \\
\hline 0.00 & -- \\
\hline 0.00 & -- \\
\hline 0.03 & -- \\
\hline 0.03 & -- \\
\hline 0.02 & -- \\
\hline 0.00 & -- \\
\hline 0.00 & -- \\
\hline 0.00 & -- \\
\hline 0.01 & -- \\
\hline 0.01 & - \\
\hline
\end{tabular}

\begin{tabular}{|l|l|l|}
\hline-- & - \\
\hline-- & - \\
\hline-- & - \\
\hline & -- & - \\
\hline-- & - \\
\hline-- & - \\
\hline-- & -- \\
\hline-- & -- \\
\hline-- & - \\
\hline-- & - \\
\hline-- & - \\
\hline-- & - \\
\hline
\end{tabular}

\begin{tabular}{|l|l|l|l|r|}
\hline-- & 0.01 & $\mathbf{0 . 1 6}$ & $\mathbf{0 . 0 4}$ & 0.02 \\
\hline-- & 0.00 & $\mathbf{0 . 2 5}$ & $\mathbf{0 . 2 4}$ & 0.02 \\
\hline-- & 0.04 & 0.02 & $\mathbf{0 . 0 4}$ & 0.03 \\
\hline-- & 0.01 & 0.01 & 0.01 & 0.00 \\
\hline-- & 0.00 & $\mathbf{0 . 1 1}$ & $\mathbf{0 . 0 5}$ & 0.04 \\
\hline-- & 0.01 & $\mathbf{0 . 0 9}$ & $\mathbf{0 . 1 0}$ & 0.01 \\
\hline-- & 0.00 & 0.02 & $\mathbf{0 . 0 4}$ & 0.02 \\
\hline-- & 0.03 & 0.02 & 0.03 & 0.03 \\
\hline-- & 0.00 & 0.00 & 0.03 & $\mathbf{0 . 0 4}$ \\
\hline-- & 0.01 & 0.02 & 0.03 & 0.00 \\
\hline-- & $\mathbf{0 . 0 4}$ & 0.03 & 0.00 & 0.01 \\
\hline- & 0.02 & 0.01 & 0.00 & 0.01 \\
\hline
\end{tabular}

\section{5}

\begin{tabular}{|c|c|c|c|c|c|c|c|c|c|c|c|}
\hline Factor & P. americana & P. australis & P. caciantha & P. cuspidata & P. delicatissima & P. fraudulenta & P. multiseries & P. obtusa & P. plurisecta & P. pungens & P. seriata \\
\hline Temperature & 0.00 & -- & 0.02 & 0.00 & 0.00 & 0.19 & -- & 0.05 & 0.10 & 0.01 & 0.06 \\
\hline Salinity & 0.07 & -- & 0.00 & 0.00 & 0.36 & 0.00 & -- & 0.00 & 0.41 & 0.13 & 0.11 \\
\hline Nitrate + Nitrite & 0.01 & - & 0.00 & 0.01 & 0.18 & 0.06 & -- & 0.05 & 0.11 & 0.06 & 0.02 \\
\hline Ammonium & 0.01 & -- & 0.00 & 0.00 & 0.01 & 0.00 & -- & 0.00 & 0.00 & 0.11 & 0.00 \\
\hline Phosphate & 0.00 & -- & 0.00 & 0.03 & 0.09 & 0.15 & -- & 0.05 & 0.12 & 0.00 & 0.07 \\
\hline Silicic Acid & 0.00 & -- & 0.01 & 0.01 & 0.02 & 0.06 & -- & 0.02 & 0.04 & 0.02 & 0.04 \\
\hline Chlorophyll & 0.00 & -- & 0.01 & 0.00 & 0.12 & 0.05 & -- & 0.02 & 0.00 & 0.15 & 0.04 \\
\hline Total N & 0.01 & -- & 0.01 & 0.01 & 0.17 & 0.05 & -- & 0.05 & 0.11 & 0.04 & 0.02 \\
\hline Si:N & 0.00 & -- & 0.00 & 0.00 & 0.13 & 0.02 & -- & 0.02 & 0.22 & 0.00 & 0.03 \\
\hline Si:P & 0.01 & -- & 0.00 & 0.00 & 0.02 & 0.07 & -- & 0.00 & 0.00 & 0.01 & 0.02 \\
\hline $\mathrm{N}: \mathrm{P}$ & 0.04 & -- & 0.01 & 0.00 & 0.05 & 0.16 & -- & 0.01 & 0.06 & 0.05 & 0.00 \\
\hline Residual Silica & 0.03 & -- & 0.00 & 0.01 & 0.32 & 0.01 & -- & 0.04 & 0.09 & 0.06 & 0.00 \\
\hline
\end{tabular}




\begin{tabular}{|c|c|c|c|c|c|c|c|c|c|c|c|}
\hline Factor & P. americana & P. australis & P. caciantha & P. cuspidata & P. delicatissima & P. fraudulenta & P. multiseries & P. obtusa & P. plurisecta & P. pungens & P. seriata \\
\hline Temperature & 0.05 & 0.15 & -- & -- & 0.23 & 0.01 & 0.00 & -- & 0.18 & 0.00 & -- \\
\hline Salinity & 0.00 & 0.02 & -- & -- & 0.02 & 0.08 & 0.44 & -- & 0.04 & 0.38 & -- \\
\hline Nitrate + Nitrite & 0.01 & 0.16 & -- & -- & 0.31 & 0.02 & 0.02 & -- & 0.30 & 0.03 & 0.07 \\
\hline Ammonium & 0.01 & 0.00 & -- & -- & 0.00 & 0.00 & 0.04 & -- & 0.00 & 0.02 & 0.00 \\
\hline Phosphate & 0.08 & 0.21 & -- & -- & 0.36 & 0.02 & 0.06 & -- & 0.37 & 0.04 & 0.13 \\
\hline Silicic Acid & 0.02 & 0.21 & -- & -- & 0.30 & 0.02 & 0.01 & -- & 0.33 & 0.00 & 0.07 \\
\hline Chlorophyll & 0.01 & 0.05 & -- & -- & 0.27 & 0.02 & 0.00 & -- & 0.23 & 0.02 & -- \\
\hline Total N & 0.01 & 0.12 & -- & -- & 0.25 & 0.01 & 0.04 & -- & 0.26 & 0.04 & 0.06 \\
\hline Si:N & 0.00 & 0.00 & -- & -- & 0.00 & 0.01 & 0.08 & -- & 0.00 & 0.01 & 0.00 \\
\hline Si:P & 0.00 & 0.14 & -- & -- & 0.11 & 0.00 & 0.01 & -- & 0.12 & 0.02 & 0.02 \\
\hline $\mathrm{N}: \mathrm{P}$ & 0.00 & 0.05 & -- & -- & 0.08 & 0.00 & 0.01 & -- & 0.07 & 0.00 & 0.01 \\
\hline Residual Silica & 0.00 & 0.00 & -- & -- & 0.03 & 0.01 & 0.01 & -- & 0.01 & 0.05 & 0.00 \\
\hline
\end{tabular}

2012-2016 Cruises Combined

\begin{tabular}{|c|c|c|c|c|c|c|c|c|c|c|c|}
\hline Factor & P. americana & P. australis & P. caciantha & P. cuspidata & P. delicatissima & P. fraudulenta & P. multiseries & P. obtusa & P. plurisecta & P. pungens & P. seriata \\
\hline Temperature & 0.01 & 0.01 & 0.00 & 0.01 & 0.00 & 0.07 & 0.00 & 0.00 & 0.09 & 0.01 & 0.02 \\
\hline Salinity & 0.01 & 0.26 & 0.00 & 0.02 & 0.01 & 0.00 & 0.14 & 0.00 & 0.10 & 0.01 & 0.02 \\
\hline Nitrate + Nitrite & 0.02 & 0.01 & 0.00 & 0.00 & 0.00 & 0.01 & 0.00 & 0.00 & 0.01 & 0.01 & 0.01 \\
\hline Ammonium & 0.04 & 0.14 & 0.00 & 0.01 & 0.02 & 0.00 & 0.00 & 0.01 & 0.00 & 0.01 & 0.01 \\
\hline Phosphate & 0.03 & 0.02 & 0.00 & 0.00 & 0.00 & 0.03 & 0.00 & 0.00 & 0.02 & 0.02 & 0.00 \\
\hline Silicic Acid & 0.00 & 0.01 & 0.00 & 0.00 & 0.01 & 0.01 & 0.00 & 0.01 & 0.01 & 0.02 & 0.01 \\
\hline Chlorophyll & 0.01 & 0.00 & 0.00 & 0.00 & 0.00 & 0.01 & 0.00 & 0.00 & 0.00 & 0.00 & 0.01 \\
\hline Total N & 0.03 & 0.03 & 0.00 & 0.00 & 0.00 & 0.01 & 0.00 & 0.00 & 0.01 & 0.01 & 0.01 \\
\hline Si:N & 0.02 & 0.02 & 0.00 & 0.01 & 0.01 & 0.00 & 0.00 & 0.00 & 0.01 & 0.04 & 0.00 \\
\hline Si:P & 0.00 & 0.02 & 0.00 & 0.00 & 0.01 & 0.03 & 0.00 & 0.00 & 0.00 & 0.02 & 0.01 \\
\hline$N: P$ & 0.05 & 0.01 & 0.00 & 0.00 & 0.00 & 0.05 & 0.00 & 0.00 & 0.01 & 0.00 & 0.02 \\
\hline Residual Silica & 0.05 & 0.06 & 0.01 & 0.01 & 0.04 & 0.00 & 0.01 & 0.00 & 0.05 & 0.08 & 0.00 \\
\hline
\end{tabular}




\subsubsection{Only Samples where DA > LOQ; species vs environment}

When the analysis includes only samples where DA > LOQ, there are even fewer significant regressions. The majority of $\mathrm{R}^{2}$ values are low. Where $\mathrm{R}^{2}>0.15$, the relationships are inconsistent from year to year. Statistically significant $\mathrm{R}^{2}$ values are in bold.

2012

\begin{tabular}{|c|c|c|c|c|c|c|c|c|c|c|c|}
\hline Factor & P. americana & P. australis & P. caciantha & P. cuspidata & P. delicatissima & P. fraudulenta & P. multiseries & P. obtusa & P. plurisecta & P. pungens & P. seriata \\
\hline Temperature & 0.01 & -- & -- & 0.32 & 0.05 & -- & 0.12 & 0.00 & 0.08 & 0.00 & 0.04 \\
\hline Salinity & 0.16 & -- & -- & 0.06 & 0.10 & -- & 0.00 & 0.16 & 0.04 & 0.01 & 0.00 \\
\hline Nitrate + Nitrite & 0.01 & -- & -- & 0.14 & 0.01 & -- & 0.08 & 0.01 & 0.04 & 0.02 & 0.05 \\
\hline Ammonium & 0.03 & -- & -- & 0.01 & 0.06 & -- & 0.03 & 0.04 & 0.09 & 0.06 & 0.02 \\
\hline Phosphate & 0.02 & -- & -- & 0.13 & 0.26 & -- & 0.12 & 0.01 & 0.01 & 0.02 & 0.02 \\
\hline Silicic Acid & 0.03 & -- & -- & 0.27 & 0.23 & -- & 0.13 & 0.03 & 0.00 & 0.04 & 0.03 \\
\hline Chlorophyll & 0.00 & -- & -- & 0.02 & 0.21 & -- & 0.00 & 0.01 & 0.04 & 0.08 & 0.00 \\
\hline Total N & 0.00 & -- & -- & 0.13 & 0.01 & -- & 0.08 & 0.00 & 0.05 & 0.02 & 0.06 \\
\hline Si:N & 0.00 & -- & -- & 0.00 & 0.00 & -- & 0.16 & 0.01 & 0.08 & 0.01 & 0.00 \\
\hline Si:P & 0.01 & -- & -- & 0.01 & 0.02 & -- & 0.17 & 0.01 & 0.05 & 0.00 & 0.00 \\
\hline $\mathrm{N}: \mathrm{P}$ & 0.00 & -- & -- & 0.08 & 0.01 & -- & 0.08 & 0.01 & 0.04 & 0.03 & 0.05 \\
\hline Residual Silica & 0.08 & -- & -- & 0.02 & 0.17 & -- & 0.00 & 0.09 & 0.05 & 0.00 & 0.01 \\
\hline
\end{tabular}

2013

\begin{tabular}{|c|c|c|c|c|c|c|c|c|c|c|c|}
\hline Factor & P. americana & P. australis & P. caciantha & P. cuspidata & P. delicatissim & $P$. & P. multiseries & P. obtusa & P. plurisecta & P. pungens & P. seriata \\
\hline Temperature & -- & -- & -- & -- & 0.01 & -- & -- & -- & 0.38 & 0.88 & 0.26 \\
\hline Salinity & -- & -- & -- & -- & 0.06 & -- & -- & -- & 0.23 & 0.08 & 0.58 \\
\hline Nitrate + Nitrite & -- & -- & -- & -- & 0.41 & -- & -- & -- & 0.18 & 0.37 & 0.10 \\
\hline Ammonium & -- & -- & -- & -- & 0.12 & -- & -- & -- & 0.27 & 0.00 & 0.15 \\
\hline Phosphate & -- & -- & -- & -- & 0.10 & -- & -- & -- & 0.28 & 0.43 & 0.12 \\
\hline Silicic Acid & - & -- & -- & -- & 0.02 & -- & -- & -- & 0.20 & 0.04 & 0.01 \\
\hline Total N & -- & -- & -- & -- & 0.23 & -- & -- & -- & 0.29 & 0.05 & 0.04 \\
\hline Si:N & -- & -- & -- & -- & 0.21 & -- & -- & -- & 0.02 & 0.01 & 0.00 \\
\hline Si:P & -- & -- & -- & -- & 0.24 & -- & -- & -- & 0.02 & 0.06 & 0.15 \\
\hline$N: P$ & -- & -- & -- & -- & 0.06 & -- & -- & -- & 0.04 & 0.06 & 0.25 \\
\hline Residual Silica & -- & -- & -- & -- & 0.08 & -- & -- & -- & 0.14 & 0.01 & 0.03 \\
\hline
\end{tabular}




\begin{tabular}{|l|l|l|}
\hline Temperature & -- & -- \\
\hline Salinity & -- & -- \\
\hline Nitrate + Nitrite & -- & -- \\
\hline Ammonium & -- & -- \\
\hline Phosphate & -- & -- \\
\hline Silicic Acid & -- & -- \\
\hline Chlorophyll & -- & -- \\
\hline Total N & -- & -- \\
\hline Si:N & -- & -- \\
\hline Si:P & -- & -- \\
\hline N:P & -- & - \\
\hline Residual Silica & -- & -- \\
\hline
\end{tabular}

\begin{tabular}{|c|c|c|}
\hline & & \\
\hline -- & & 0.09 \\
\hline -- & & 0.06 \\
\hline -- & & 0.03 \\
\hline-- & & 0.03 \\
\hline -- & & 0.10 \\
\hline -- & & 0.00 \\
\hline-- & & 0.00 \\
\hline-- & & 0.05 \\
\hline-- & & 0.03 \\
\hline -- & & 0.04 \\
\hline -- & & 0.00 \\
\hline-- & & 0.06 \\
\hline
\end{tabular}

\begin{tabular}{|l|l|l|}
\hline P. fraudulenta & P. multiseries & $P . c$ \\
\hline-- & - & - \\
\hline-- & - & - \\
\hline-- & -- & - \\
\hline-- & -- & - \\
\hline-- & -- & - \\
\hline-- & -- & - \\
\hline-- & -- & - \\
\hline-- & -- & - \\
\hline-- & -- & - \\
\hline-- & -- & - \\
\hline-- & - & \\
\hline-- & & \\
\hline
\end{tabular}

\begin{tabular}{|l|l|r|r|}
\hline-- & $\mathbf{0 . 5 0}$ & $\mathbf{0 . 1 0}$ & 0.02 \\
\hline-- & $\mathbf{0 . 2 0}$ & $\mathbf{0 . 2 0}$ & 0.03 \\
\hline-- & $\mathbf{0 . 1 8}$ & $\mathbf{0 . 1 0}$ & 0.00 \\
\hline-- & 0.00 & 0.01 & 0.00 \\
\hline-- & $\mathbf{0 . 2 1}$ & 0.07 & 0.02 \\
\hline-- & $\mathbf{0 . 1 2}$ & 0.04 & 0.00 \\
\hline-- & 0.00 & 0.00 & 0.00 \\
\hline-- & $\mathbf{0 . 1 3}$ & $\mathbf{0 . 1 0}$ & 0.00 \\
\hline-- & 0.01 & 0.02 & 0.00 \\
\hline-- & 0.00 & 0.00 & 0.03 \\
\hline-- & 0.01 & 0.07 & 0.01 \\
\hline-- & 0.03 & 0.06 & 0.00 \\
\hline
\end{tabular}

\section{5}

\begin{tabular}{|c|c|c|c|c|c|c|c|c|c|c|c|}
\hline Factor & P. americana & P. australis & P. caciantha & P. cuspidata & P. delicatissima & P. fraudulenta & P. multiseries & P. obtusa & P. plurisecta & P. pungens & P. seriata \\
\hline Temperature & 0.10 & -- & -- & -- & 0.21 & 0.01 & -- & -- & 0.28 & 0.04 & 0.07 \\
\hline Salinity & 0.36 & -- & -- & -- & 0.26 & 0.27 & -- & -- & 0.13 & 0.13 & 0.32 \\
\hline Nitrate + Nitrite & 0.27 & - & -- & -- & 0.65 & 0.00 & -- & -- & 0.17 & 0.00 & 0.07 \\
\hline Ammonium & 0.00 & -- & -- & -- & 0.03 & 0.01 & -- & -- & 0.00 & 0.00 & 0.01 \\
\hline Phosphate & 0.07 & -- & -- & -- & 0.24 & 0.07 & -- & -- & 0.15 & 0.01 & 0.06 \\
\hline Silicic Acid & 0.37 & -- & -- & -- & 0.54 & 0.12 & -- & -- & 0.38 & 0.00 & 0.20 \\
\hline Chlorophyll & 0.11 & -- & -- & -- & 0.05 & 0.02 & -- & -- & 0.02 & 0.19 & 0.03 \\
\hline Total N & 0.22 & -- & -- & -- & 0.59 & 0.00 & -- & -- & 0.13 & 0.00 & 0.05 \\
\hline Si:N & 0.02 & -- & -- & -- & 0.05 & 0.00 & -- & -- & 0.22 & 0.31 & 0.00 \\
\hline Si:P & 0.04 & -- & -- & -- & 0.01 & 0.28 & -- & -- & 0.02 & 0.00 & 0.00 \\
\hline $\mathrm{N}: \mathrm{P}$ & 0.12 & -- & -- & -- & 0.20 & 0.17 & -- & -- & 0.01 & 0.02 & 0.00 \\
\hline Residual Silica & 0.14 & -- & -- & -- & 0.09 & 0.24 & -- & -- & 0.23 & 0.00 & 0.14 \\
\hline
\end{tabular}




\begin{tabular}{|c|c|c|c|c|c|c|c|c|c|c|c|}
\hline Factor & P. americana & P. australis & P. caciantha & P. cuspidata & P. delicatissima & P. fraudulenta & P. multiseries & P. obtusa & P. plurisecta & P. pungens & P. seriata \\
\hline Temperature & 0.05 & 0.01 & -- & -- & 0.20 & 0.04 & 0.06 & -- & 0.05 & 0.09 & -- \\
\hline Salinity & 0.00 & 0.36 & -- & - & 0.03 & 0.10 & 0.33 & -- & 0.34 & 0.14 & -- \\
\hline Nitrate + Nitrite & 0.04 & 0.00 & -- & -- & 0.33 & 0.03 & 0.10 & -- & 0.04 & 0.13 & -- \\
\hline Ammonium & 0.00 & 0.00 & -- & -- & 0.05 & 0.00 & 0.06 & -- & 0.00 & 0.00 & -- \\
\hline Phosphate & 0.07 & 0.00 & -- & -- & 0.36 & 0.01 & 0.15 & -- & 0.01 & 0.04 & -- \\
\hline Silicic Acid & 0.04 & 0.00 & -- & -- & 0.24 & 0.03 & 0.09 & -- & 0.02 & 0.10 & -- \\
\hline Chlorophyll & 0.01 & 0.11 & -- & -- & 0.21 & 0.03 & 0.03 & -- & 0.12 & 0.23 & -- \\
\hline Total N & 0.03 & 0.00 & -- & -- & 0.35 & 0.02 & 0.13 & -- & 0.02 & 0.10 & -- \\
\hline Si:N & 0.02 & 0.01 & -- & -- & 0.03 & 0.05 & 0.09 & -- & 0.02 & 0.03 & -- \\
\hline Si:P & 0.03 & 0.00 & -- & -- & 0.06 & 0.05 & 0.02 & -- & 0.02 & 0.07 & -- \\
\hline $\mathrm{N}: \mathrm{P}$ & 0.01 & 0.00 & -- & -- & 0.14 & 0.02 & 0.09 & -- & 0.02 & 0.07 & -- \\
\hline Residual Silica & 0.01 & 0.00 & -- & -- & 0.11 & 0.00 & 0.01 & -- & 0.02 & 0.04 & -- \\
\hline
\end{tabular}

2012-2016 Cruises Combined

\begin{tabular}{|c|c|c|c|c|c|c|c|c|c|c|c|}
\hline Factor & P. americana & P. australis & P. caciantha & P. cuspidata & P. delicatissima & P. fraudulenta & P. multiseries & P. obtusa & P. plurisecta & P. pungens & P. seriata \\
\hline Temperature & 0.00 & 0.01 & -- & 0.08 & 0.00 & 0.00 & 0.01 & 0.01 & 0.13 & 0.02 & 0.01 \\
\hline Salinity & 0.00 & 0.67 & -- & 0.00 & 0.24 & 0.02 & 0.30 & 0.00 & 0.05 & 0.02 & 0.15 \\
\hline Nitrate + Nitrite & 0.00 & 0.11 & -- & 0.01 & 0.04 & 0.01 & 0.00 & 0.00 & 0.01 & 0.02 & 0.05 \\
\hline Ammonium & 0.04 & 0.05 & -- & 0.01 & 0.00 & 0.00 & 0.00 & 0.02 & 0.03 & 0.09 & 0.00 \\
\hline Phosphate & 0.00 & 0.10 & -- & 0.01 & 0.07 & 0.00 & 0.00 & 0.00 & 0.03 & 0.01 & 0.05 \\
\hline Silicic Acid & 0.02 & 0.00 & -- & 0.00 & 0.05 & 0.00 & 0.00 & 0.02 & 0.07 & 0.02 & 0.07 \\
\hline Chlorophyll & 0.01 & 0.01 & -- & 0.00 & 0.05 & 0.00 & 0.00 & 0.00 & 0.01 & 0.03 & 0.03 \\
\hline Total N & 0.00 & 0.13 & -- & 0.01 & 0.03 & 0.00 & 0.00 & 0.00 & 0.02 & 0.04 & 0.04 \\
\hline Si:N & 0.02 & 0.04 & -- & 0.01 & 0.01 & 0.00 & 0.00 & 0.00 & 0.02 & 0.04 & 0.01 \\
\hline Si:P & 0.07 & 0.04 & -- & 0.03 & 0.02 & 0.01 & 0.00 & 0.02 & 0.13 & 0.07 & 0.02 \\
\hline$N: P$ & 0.01 & 0.06 & -- & 0.02 & 0.00 & 0.00 & 0.00 & 0.00 & 0.01 & 0.06 & 0.01 \\
\hline Residual Silica & 0.04 & 0.14 & -- & 0.03 & 0.01 & 0.00 & 0.01 & 0.01 & 0.22 & 0.12 & 0.01 \\
\hline
\end{tabular}


6.4.3 DA vs species

\begin{tabular}{|l|r|r|r|r|r|r|}
\hline Species & 2012 & 2013 & 2014 & 2015 & 2016 & $2012-2016$ \\
\hline P. heimii americana & 0.03 & 0.00 & 0.00 & 0.07 & 0.00 & 0.01 \\
\hline P. australis & 0.00 & 0.00 & 0.00 & 0.00 & $\mathbf{0 . 2 2}$ & $\mathbf{0 . 1 9}$ \\
\hline P. caciantha & 0.00 & 0.00 & 0.00 & 0.00 & 0.00 & 0.00 \\
\hline P. cuspidata & 0.06 & 0.00 & 0.00 & 0.00 & 0.00 & 0.00 \\
\hline P. delicatissima & 0.11 & 0.05 & $\mathbf{0 . 2 8}$ & 0.07 & 0.01 & 0.03 \\
\hline P. fraudulenta & 0.00 & 0.00 & 0.00 & 0.04 & 0.00 & 0.00 \\
\hline P. multiseries & $\mathbf{0 . 3 4}$ & 0.00 & 0.00 & 0.00 & 0.04 & 0.00 \\
\hline P. obtusa & 0.05 & 0.00 & 0.00 & 0.00 & 0.00 & 0.00 \\
\hline P. plurisecta & $\mathbf{0 . 3 3}$ & $\mathbf{0 . 5 3}$ & $\mathbf{0 . 2 9}$ & 0.05 & $\mathbf{0 . 0 9}$ & $\mathbf{0 . 0 8}$ \\
\hline P. pungens & $\mathbf{0 . 3 5}$ & 0.20 & 0.07 & 0.01 & $\mathbf{0 . 1 0}$ & $\mathbf{0 . 0 5}$ \\
\hline P. seriata & 0.02 & 0.00 & 0.00 & 0.08 & 0.00 & 0.03 \\
\hline Total Psn & $\mathbf{0 . 4 7}$ & 0.21 & $\mathbf{0 . 1 7}$ & 0.03 & $\mathbf{0 . 6 6}$ & $\mathbf{0 . 5 3}$ \\
\hline
\end{tabular}


6.4.4 DA vs environment

\begin{tabular}{|l|r|r|r|r|r|r|}
\hline Factor & 2012 & 2013 & 2014 & 2015 & 2016 & $2012-2016$ \\
\hline Temperature & 0.08 & 0.32 & $\mathbf{0 . 0 9}$ & 0.04 & 0.00 & 0.00 \\
\hline Salinity & 0.00 & 0.00 & 0.01 & 0.06 & $\mathbf{0 . 4 4}$ & $\mathbf{0 . 2 0}$ \\
\hline Nitrate + Nitrite & 0.08 & 0.07 & $\mathbf{0 . 3 8}$ & 0.03 & 0.01 & 0.00 \\
\hline Ammonium & 0.01 & 0.19 & 0.02 & 0.07 & 0.02 & 0.00 \\
\hline Phosphate & 0.08 & $\mathbf{0 . 5 7}$ & $\mathbf{0 . 4 8}$ & 0.23 & 0.00 & 0.01 \\
\hline Silicic Acid & 0.17 & 0.31 & $\mathbf{0 . 3 9}$ & 0.24 & 0.06 & 0.01 \\
\hline Total N & 0.08 & 0.18 & $\mathbf{0 . 3 6}$ & 0.05 & 0.01 & 0.00 \\
\hline Si:N & 0.00 & 0.05 & 0.06 & 0.03 & $\mathbf{0 . 1 5}$ & 0.01 \\
\hline Si:P & 0.01 & 0.01 & 0.09 & 0.14 & $\mathbf{0 . 1 0}$ & 0.02 \\
\hline N:P & 0.07 & 0.02 & 0.06 & 0.18 & 0.00 & 0.00 \\
\hline Residual Silica & 0.01 & 0.27 & 0.00 & 0.26 & 0.07 & $\mathbf{0 . 0 5}$ \\
\hline
\end{tabular}




\subsection{Wilcoxon Signed Rank Test Results}

2016 cruise data vs 2012, 2014, and 2015 cruise data (samples when DA > LOQ). A "1" indicates that the parameters was significantly different in that year compared to 2016 .

\begin{tabular}{|c|c|c|c|}
\hline Parameter & 2012 & 2014 & 2015 \\
\hline Temperature & 0 & 0 & 0 \\
\hline Salinity & 1 & 0 & 1 \\
\hline $\mathrm{DA} /$ cell & 1 & 1 & 1 \\
\hline Si:N & 1 & 0 & 1 \\
\hline Si:P & 1 & 0 & 0 \\
\hline $\mathrm{N}: \mathrm{P}$ & 1 & 0 & 1 \\
\hline Residual Si & 1 & 0 & 1 \\
\hline $\mathrm{NO}_{\mathrm{x}}^{-}$ & 0 & 0 & 1 \\
\hline $\mathrm{NH}_{4}$ & 1 & 0 & 1 \\
\hline $\mathrm{PO}_{4}$ & 0 & 0 & 1 \\
\hline $\mathrm{Si}(\mathrm{OH})_{4}$ & 1 & 0 & 0 \\
\hline $\begin{array}{l}\text { Total } \\
\text { Pseudo-nitzschia }\end{array}$ & 0 & 0 & 1 \\
\hline
\end{tabular}




\section{Appendix B}

\subsection{Methods}

\subsubsection{Model-Data Comparison}

At depth $(>100 \mathrm{~m})$ near NERACOOS buoy N, both ROMS and the observational data show changes in salinity up to $2 \mathrm{PSU}$ and changes in temperature up to $6^{\circ} \mathrm{C}$ over as little as a week.

2016 ROMS vs. NERACOOS at $100 \mathrm{~m}$ near Buoy N
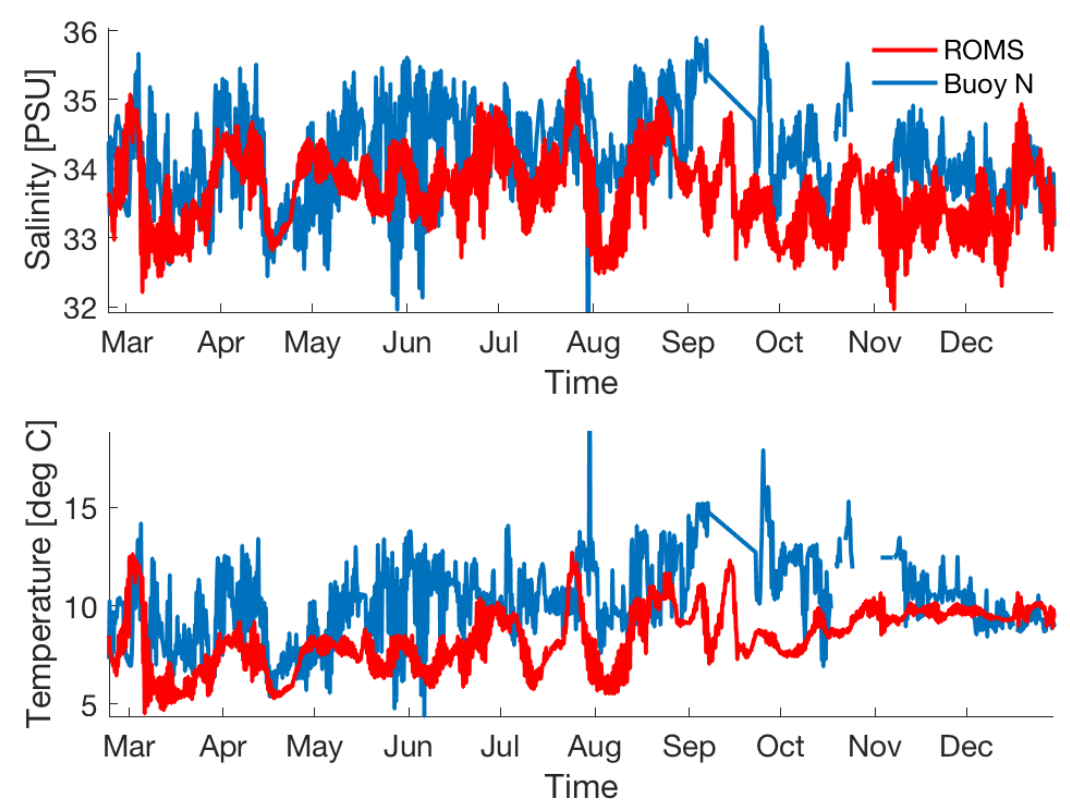

Figure 7-1 - (top) salinity and (bottom) temperature vs. time from ROMS (red) and NERACOOS buoy N (blue) at 100m. ROMS data were taken from the nearest grid cell to the NERACOOS buoy location. 
The model also captures seasonal and spatial patterns in sea surface temperature: time series of model output vs NERACOOS Buoy measurements and Halifax Station 2 are in good agreement.

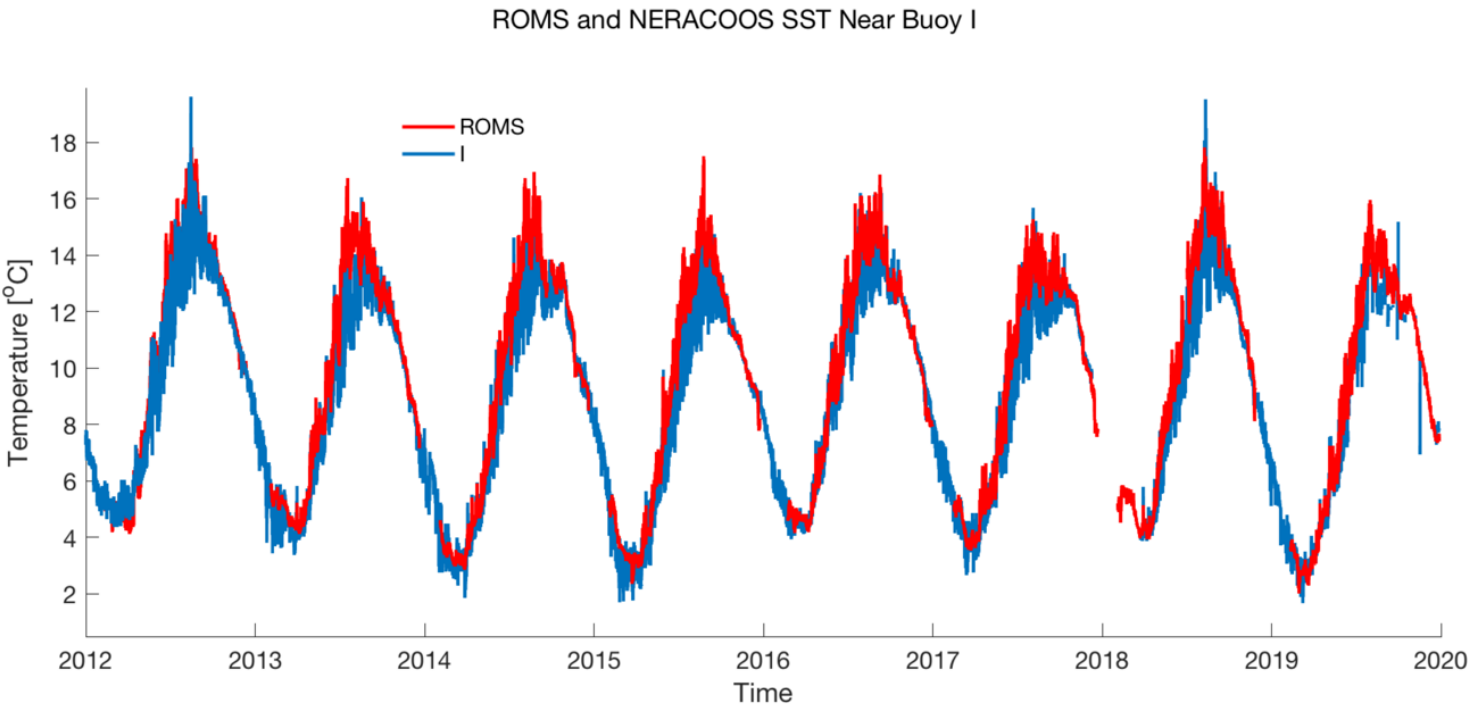

ROMS and NERACOOS SST near Buoy M

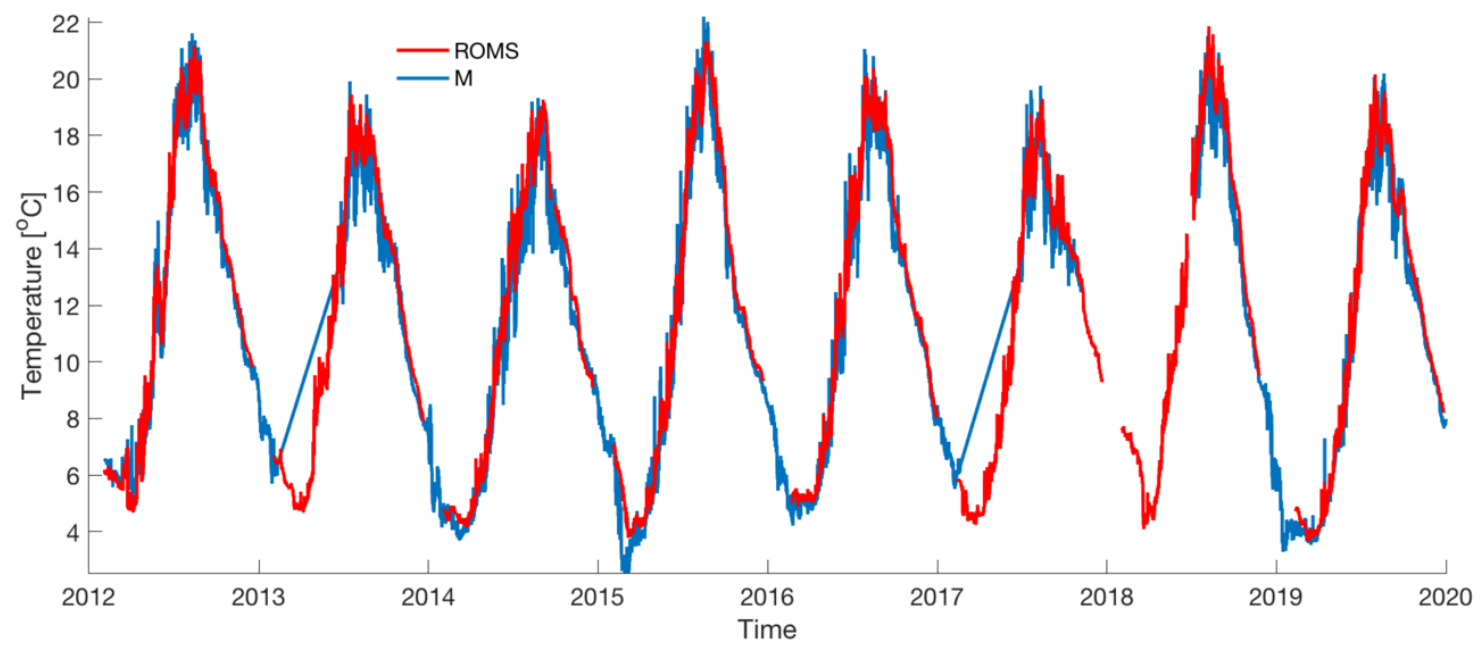

Figure 7-2 -(top) NERACOOS buoy I, (bottom) NERACOOS buoy M, and ROMS (red) SST vs. time from 2012 to 2019. 
At Halifax Station 2, surface salinity in the model was more saline than observational data by 1 PSU on average (up to 1.8 PSU).
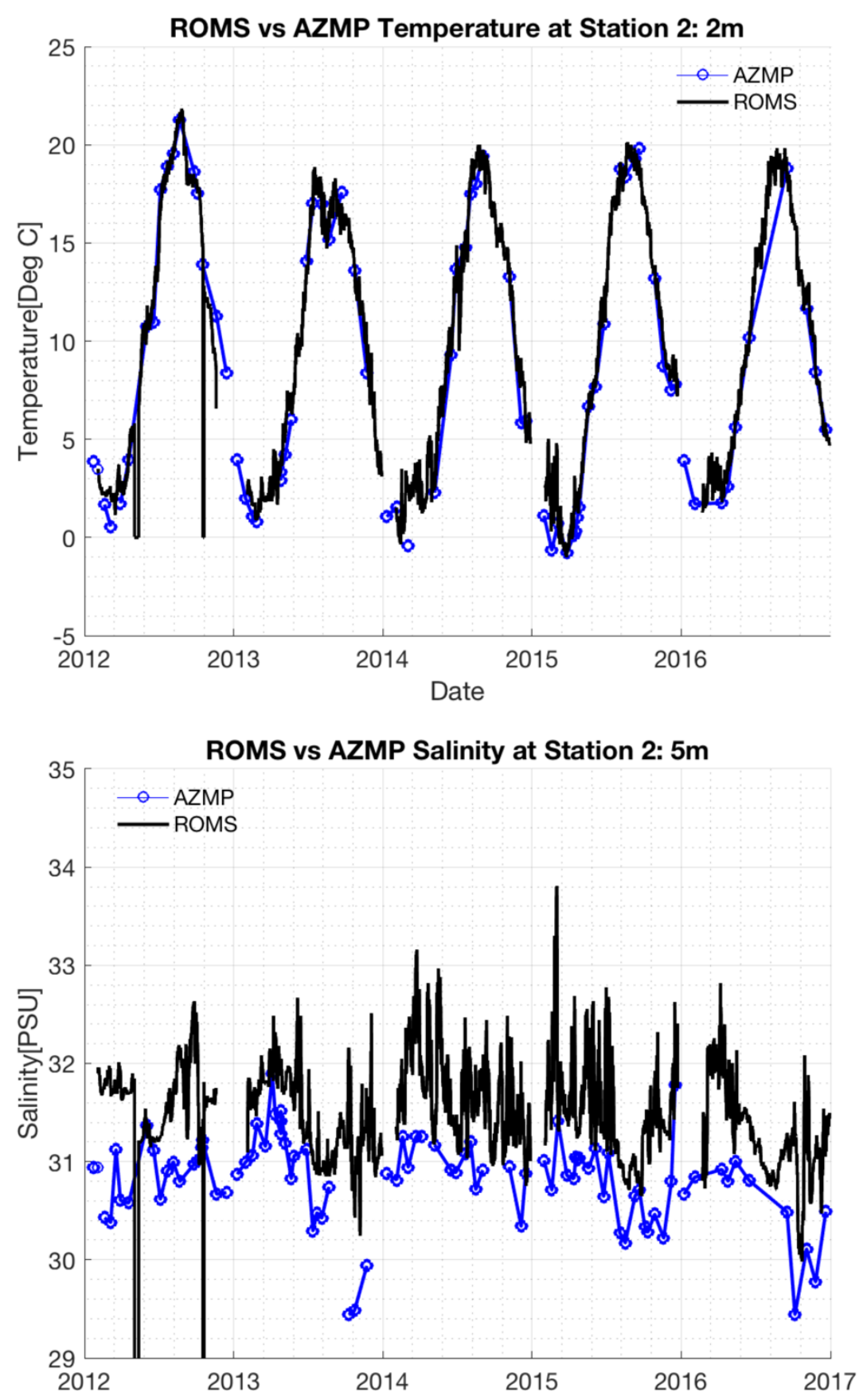

Figure 7-3 - (top) SST vs. time from (black) ROMS and (blue) Halifax Station 2 for 2012-2016; (bottom) surface salinity vs. time from (black) ROMS and (blue) Halifax Station 2 for 2012-2016. 5m was chosen instead of $2 m$ because of gaps in the data. 
At NERACOOS buoy I, below-surface $(50 \mathrm{~m})$ modeled salinity was fresher than observational data by up to 1.3 PSU... ROMS did not capture the rapid increase in salinity ( 0.5 PSU over 6 days) observed at 250m at NERACOOS Buoy M in July 2016 (Clark et al., 2019).

2016 ROMS vs. NERACOOS at 50m near Buoy I

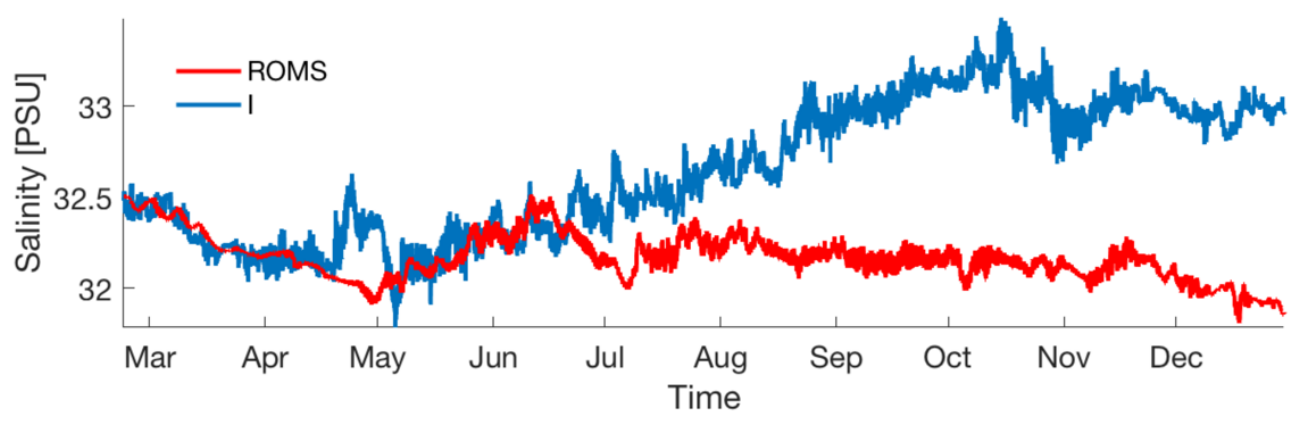

2016 ROMS vs. NERACOOS at $250 \mathrm{~m}$ near Buoy M

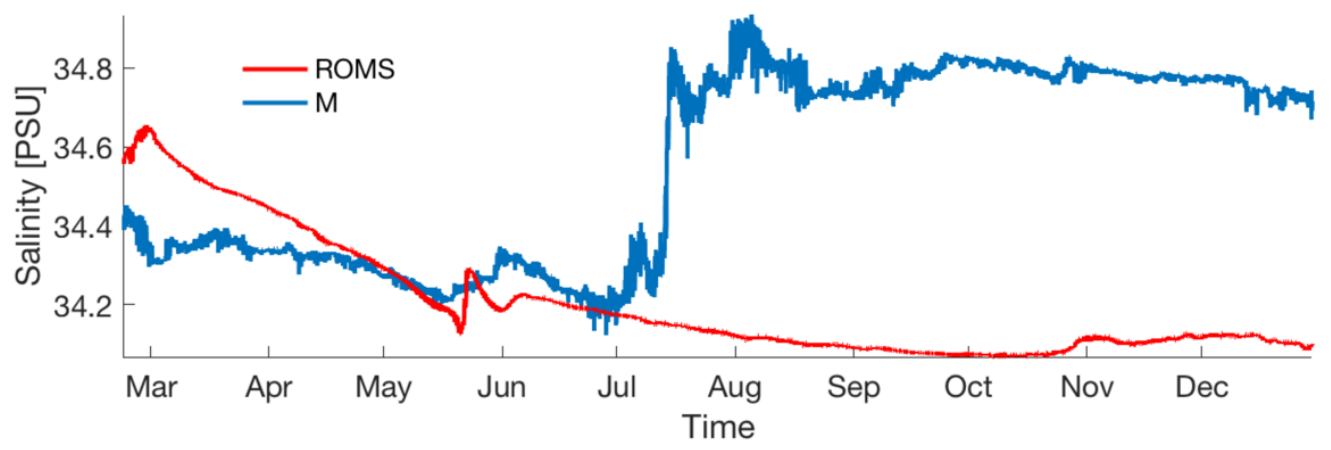

Figure 7-4 - (top) $50 m$ salinity vs. time in 2016 from (red) ROMS output and (blue) NERACOOS Buoy I; (bottom) 250m salinity vs. time in 2016 from (red) ROMS output and (blue) NERACOOS Buoy M. 

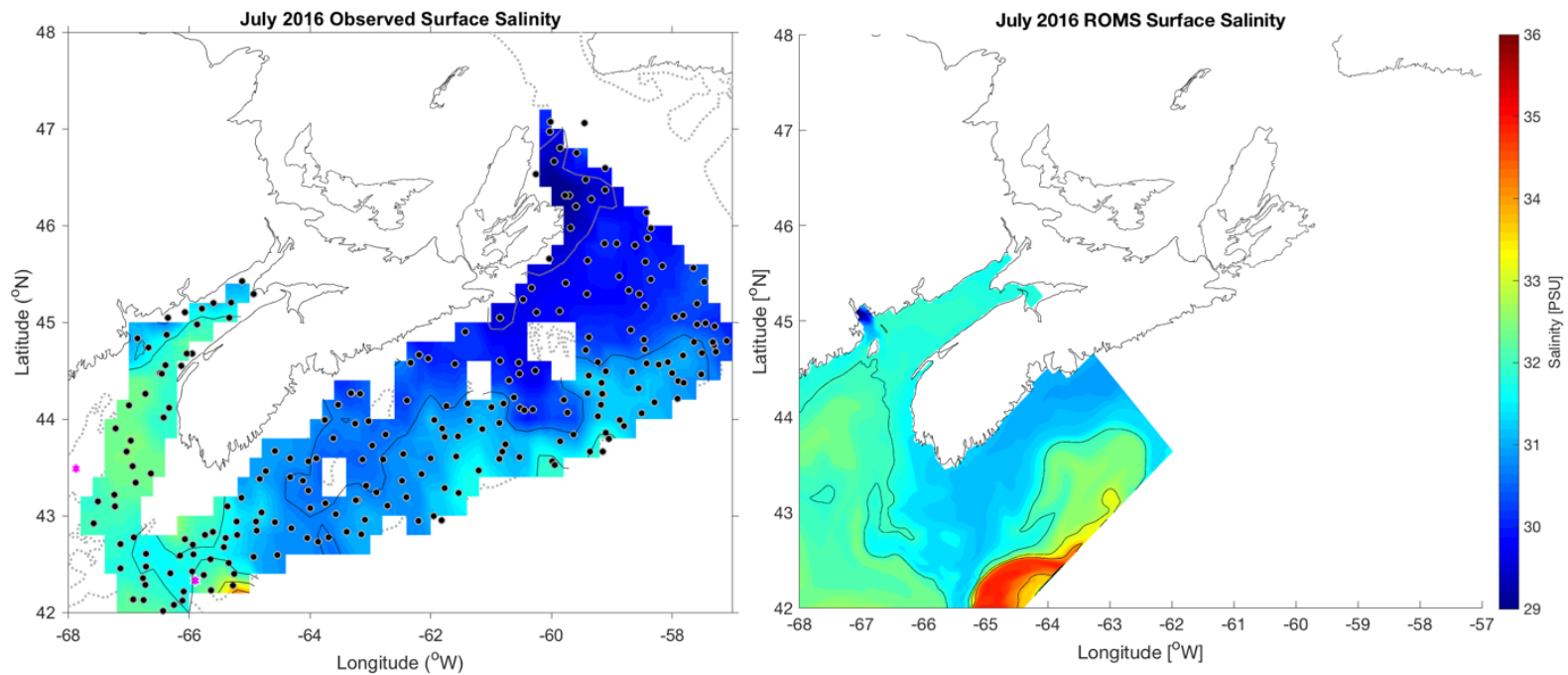

Figure 7-5 - Surface salinity in July 2016 as measured during the DFO survey (left) and as calculated by ROMS (right).
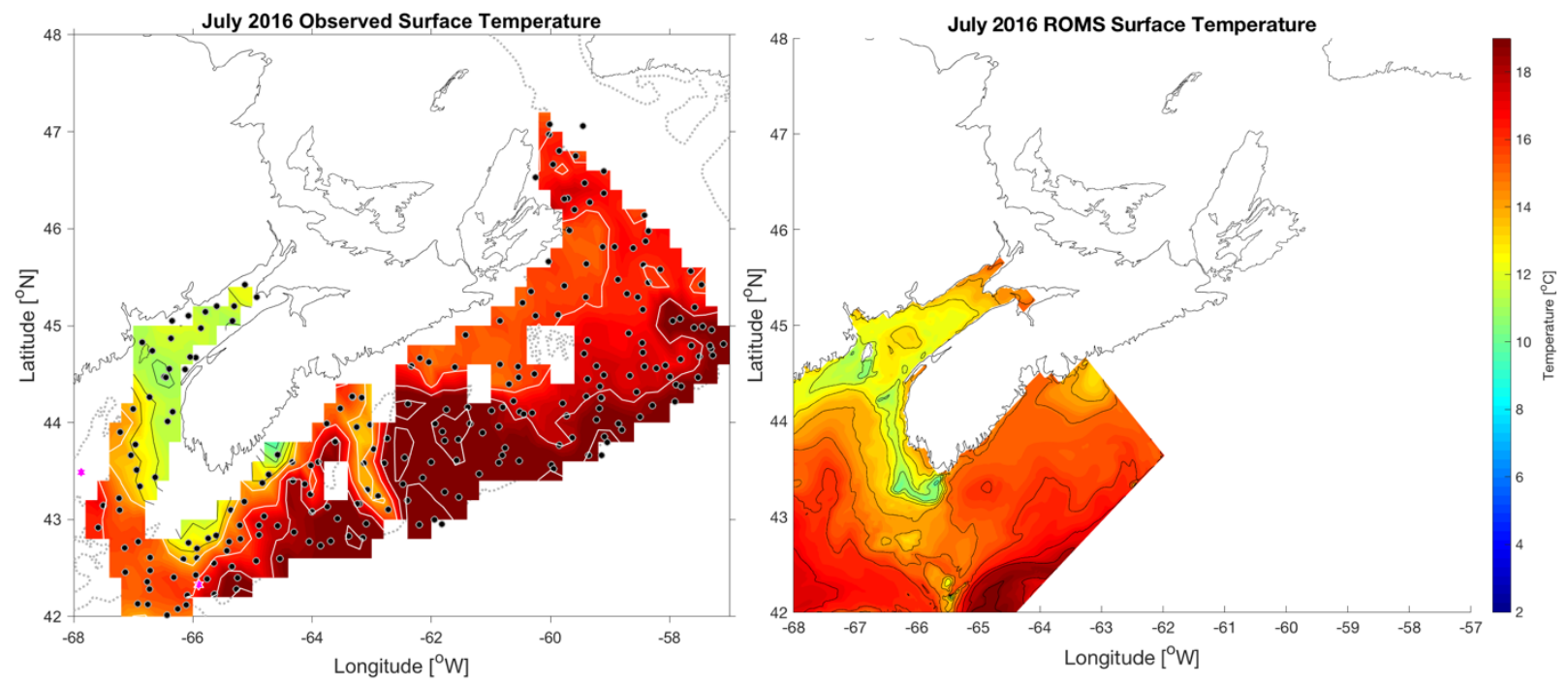

Figure 7-6 - Surface temperature in July 2016 as measured on the DFO Summer Survey (left) and as calculated by ROMS (right). 

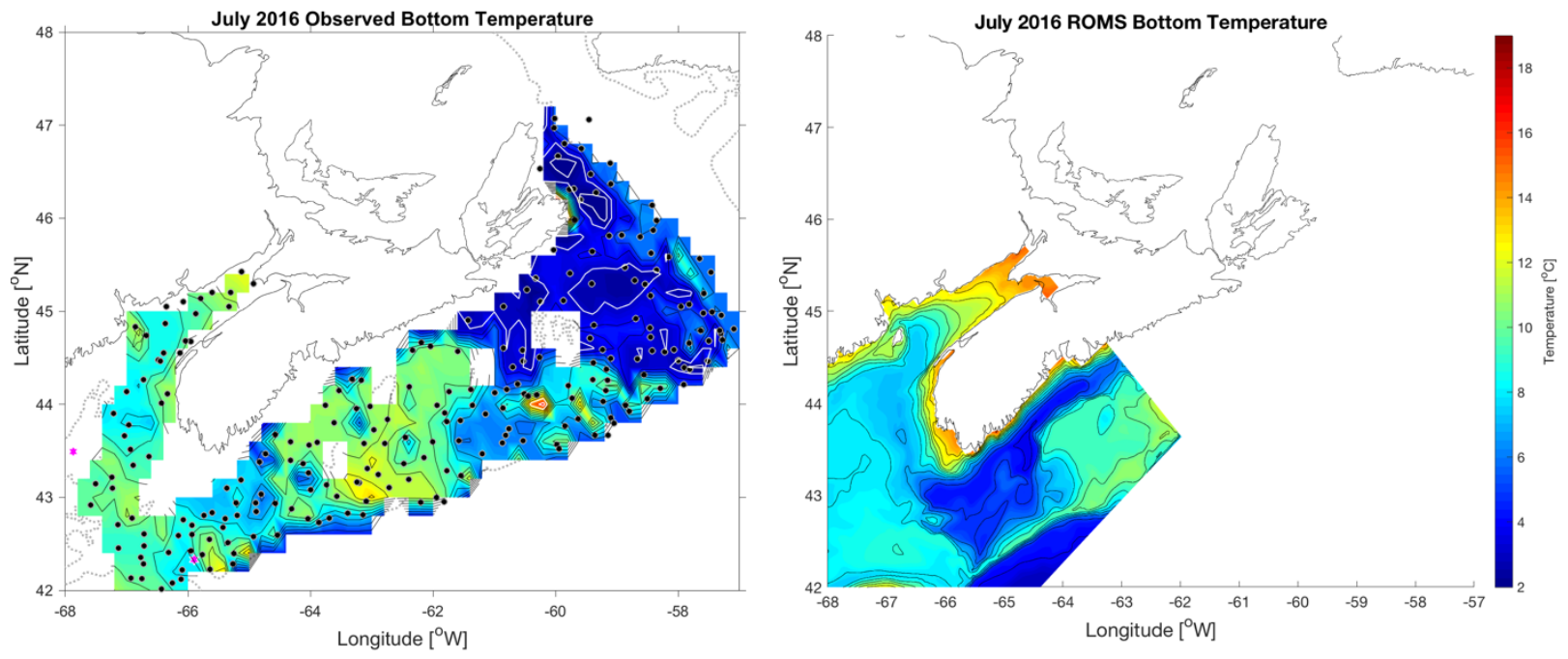

Figure 7-7 - Bottom temperature in July 2016 as measured on the DFO Summer Survey (left) and as calculated by ROMS (right). 


\subsection{Results}

\subsubsection{ROMS and Field Data}

Similarly, at Halifax Station 2, surface salinity (5-20m) in 2016 decreased below any other year in the 8-year time period besides 2013, and mid-depth salinity (50-100m) in 2016 and 2017 was less variable than in the other 6 years studied.
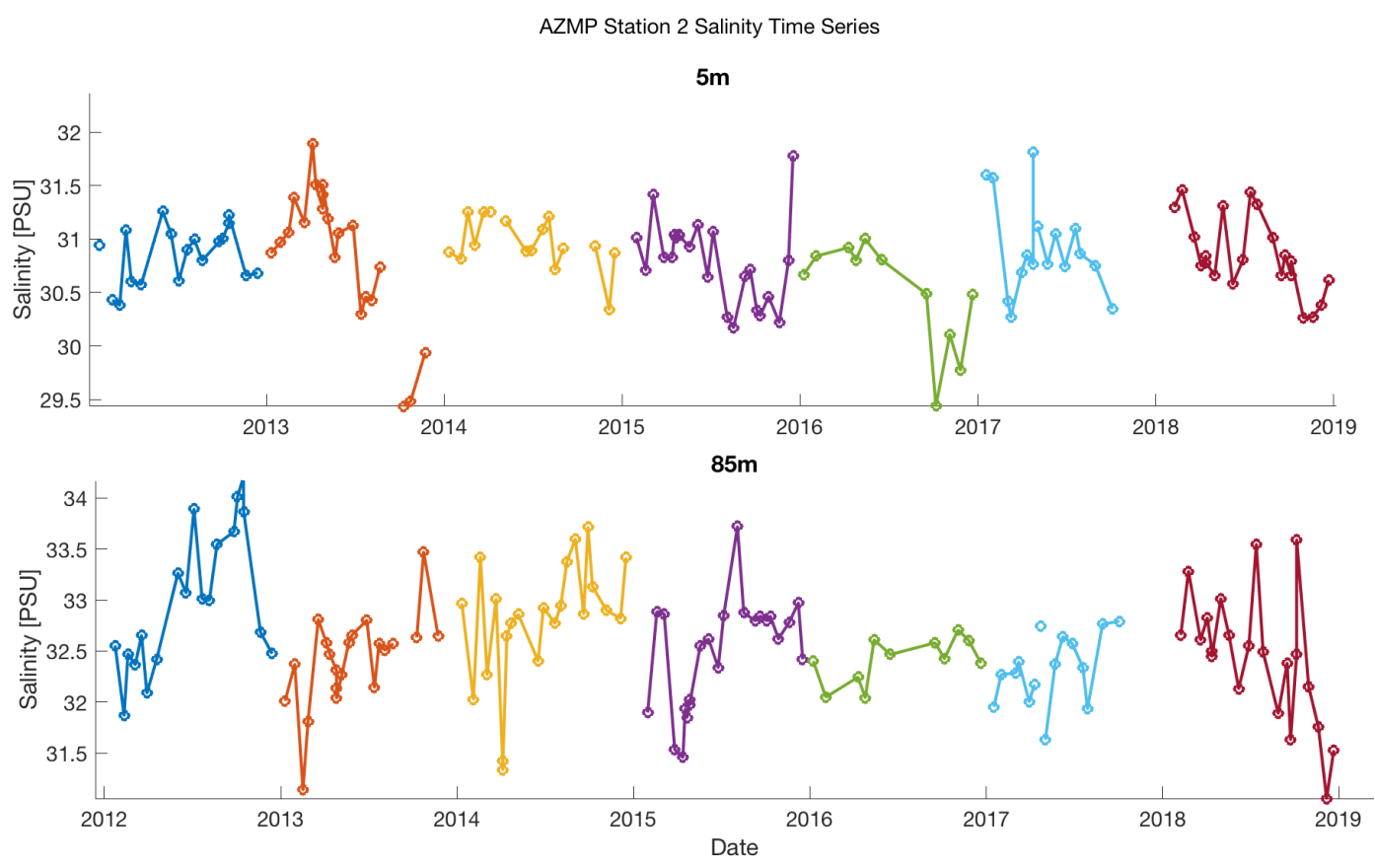

Figure 7-8 - (top) $5 m$ and (bottom) 85m salinity vs time as measured during monthly measurements at Halifax Station 2. 


\subsubsection{Transport}

At the same time and location that positive salinity anomalies were observed on the Scotian Shelf in July 2016, modeled volume and salt transport toward the GOM increased as a result of increased velocities and increased salinity values

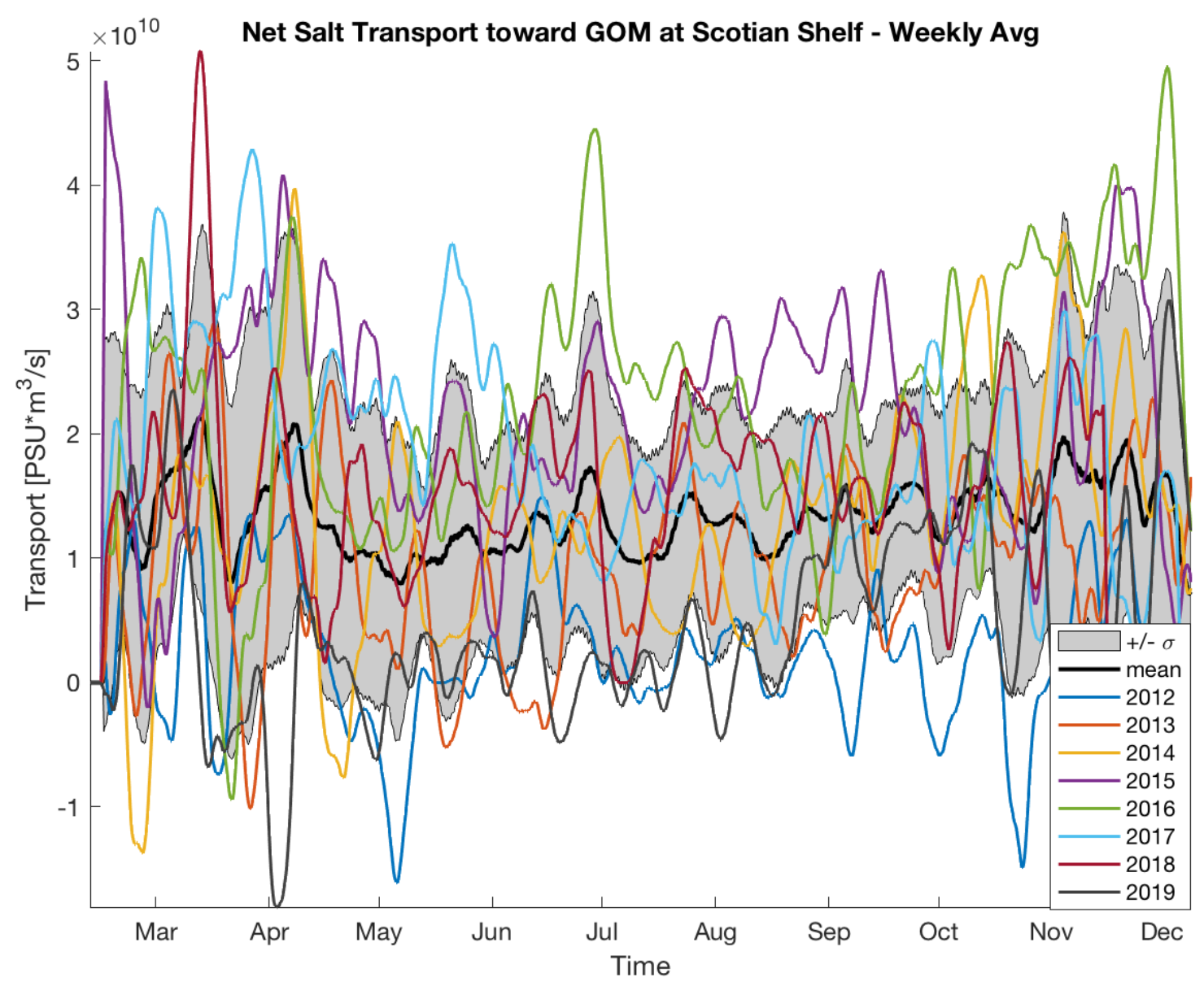

Figure 7-9 - Salt transport toward the GOM at the Scotian Shelf transect vs time. The grey shaded area indicates +/- one standard deviation, the black line indicates the interannual mean, and the green line indicates 2016. Data were smoothed over one week before plotting. 


\subsubsection{Growth Delivery Potential}

Table 7-1 - Growth rates and associated standard error (S.E.) per degree Celsius as measured during laboratory experiments. SE are listed only for laboratory growth rates.

\begin{tabular}{cc}
\hline Temperature $\left({ }^{\circ} \mathrm{C}\right)$ & Growth Rate $\left(\boldsymbol{\mu}\right.$, day $\left.^{-1}\right) \pm \mathrm{SE}$ \\
\hline $\mathbf{4}$ & 0.27 \\
\hline $\mathbf{7}$ & $0.33 \pm 0.06$ \\
\hline $\mathbf{9}$ & $0.39 \pm 0.08$ \\
\hline $\mathbf{1 1}$ & $0.38 \pm 0.02$ \\
\hline $\mathbf{1 3}$ & $0.46 \pm 0.03$ \\
\hline $\mathbf{1 5}$ & $0.47 \pm 0.14$ \\
\hline 18 & 0.38 \\
\hline
\end{tabular}


Potential daily growth rates from the inner Scotian Shelf were neither significantly higher nor significantly lower in 2016 compared to other years from 2012 to 2019.

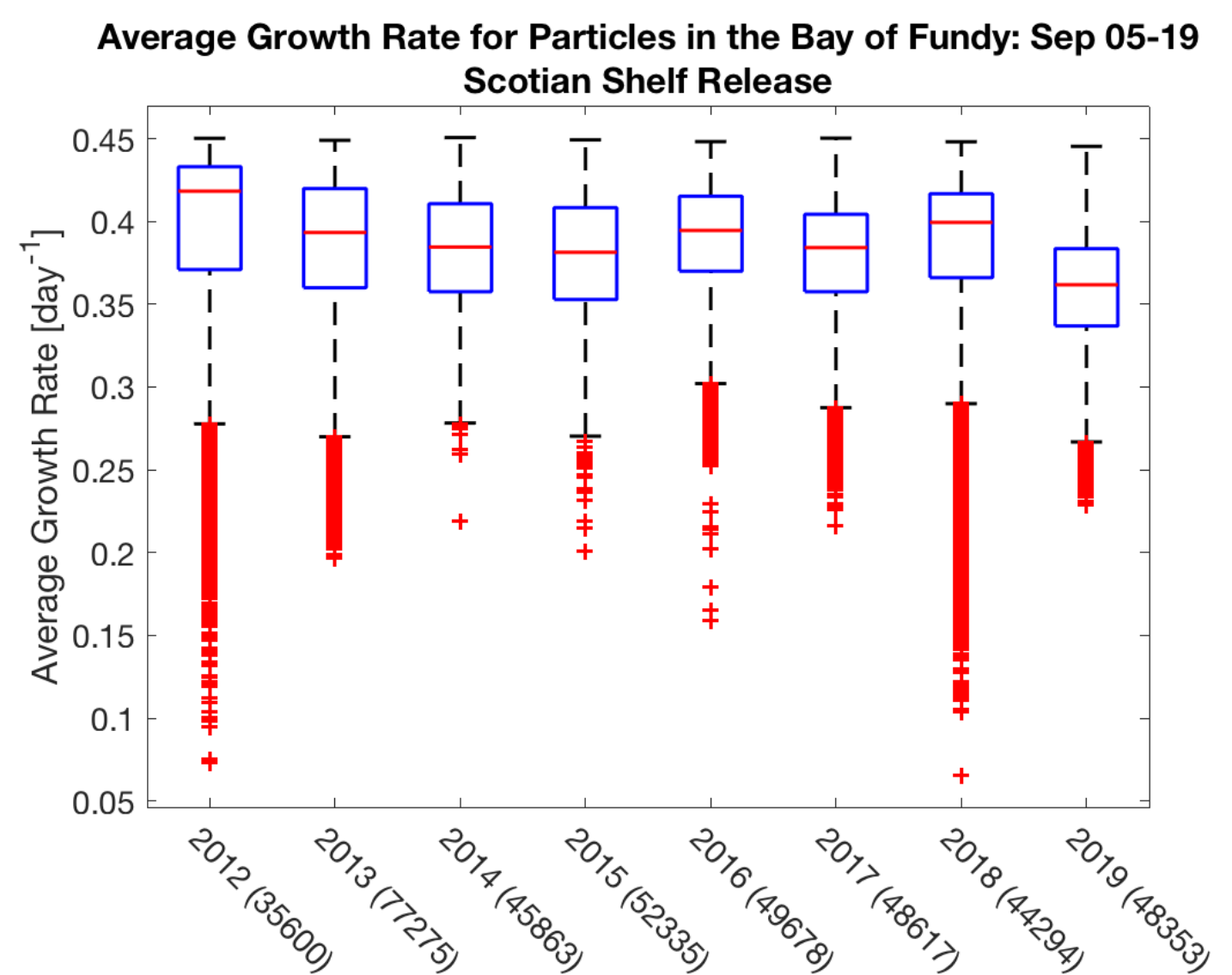

Figure 7-10 - Box and Whisker plots of each year's per particle averaged potential daily growth rates for particles released on the inner Scotian Shelf that were in the Bay of Fundy between September 5 and 19. The number of particles in each year's boxplot is indicated in parentheses. For each Box-and-Whisker plot, the red line indicates the median, the blue box indicates $1^{\text {st }}$ and $3^{\text {rd }}$ quartiles, and black dashed lines indicates extrema excluding outliers. The crosses are outliers, defined as points greater than (less than) Q3(Q1) $+(-) 1.5^{*}(Q 3-Q 1)$, where $Q 1$ is the first quartile and Q3 is the third quartile. 


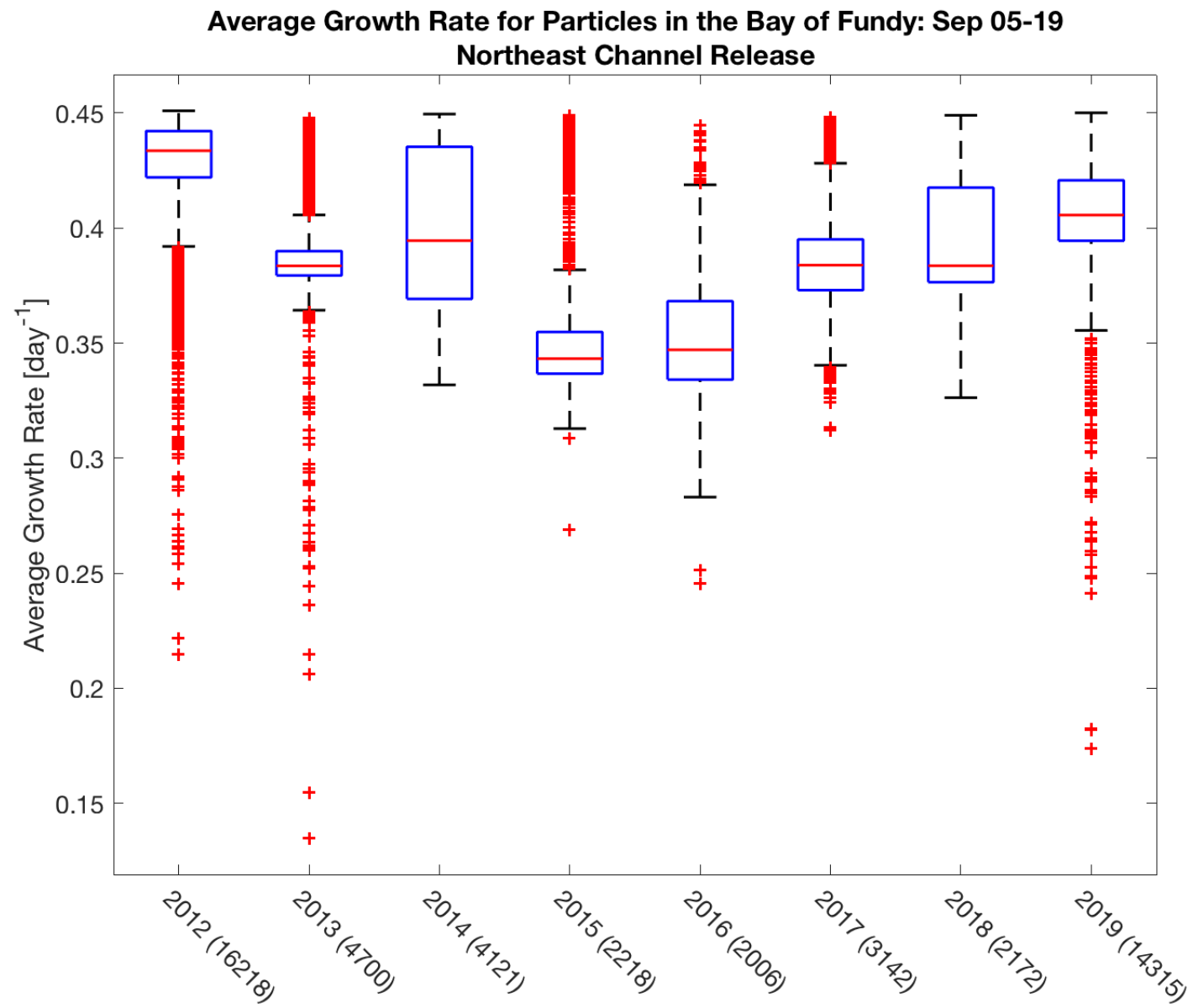

Figure 7-11 - Box and Whisker plots of each year's per particle averaged potential daily growth rates for particles released in the Northeast Channel that were in the Bay of Fundy between September 5 and 19. See Figure 7-10 for box plot descriptions. 


\subsection{Discussion}

\subsubsection{Likely $\boldsymbol{P}$. australis Introduction Pathways}

An additional reverse experiment was run with particles released just below the surface in the Bay of Fundy from September 12 to September 19, which was the period of shellfish closures in that region. It confirmed that particles in the Bay of Fundy were connected to the inner Scotian Shelf via the coastal route, but were not connected to the Northeast Channel.

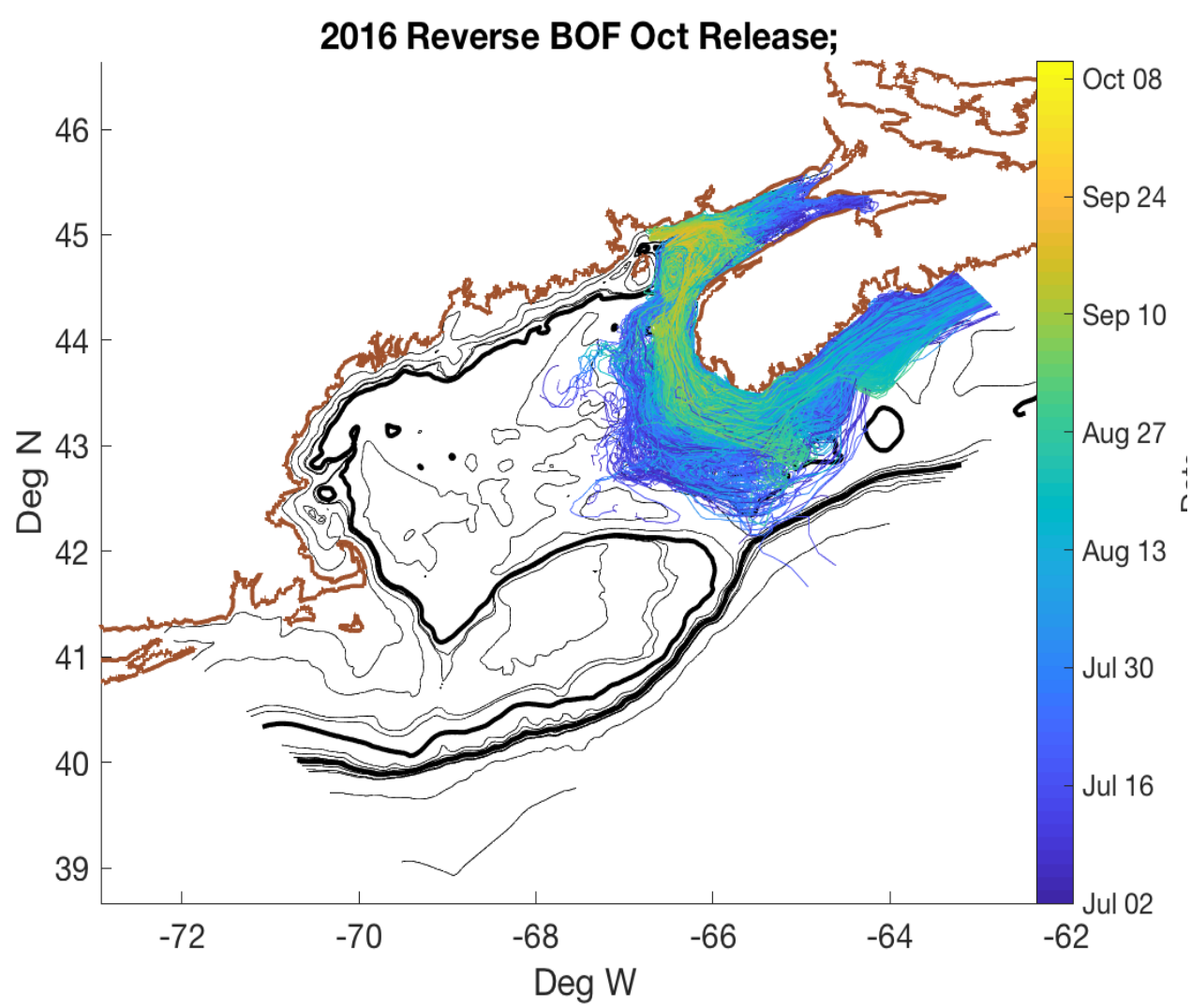

Figure 7-12 - Particle tracks color-coded by date for particles released in the Bay of Fundy from Sep 12-Sep 19, 2016, and run in reverse. Dates are indicated by the color bar on the right. The thick brown contour indicates the shoreline, the thick black contours indicate $100 \mathrm{~m}$ and $500 \mathrm{~m}$, and the thin black contours indicate 25m, 50m, 75, every $100 \mathrm{~m}$ to $1000 \mathrm{~m}$, 2000m, and $3000 \mathrm{~m}$. 


\section{Appendix $\mathrm{C}$}

\subsection{Comparison Between Two ROMS Configurations}

Average sea surface temperatures in the two models agreed well in terms of magnitude and seasonal variability.

\section{SST in the GOM - NWA ROMS vs GOM ROMS}
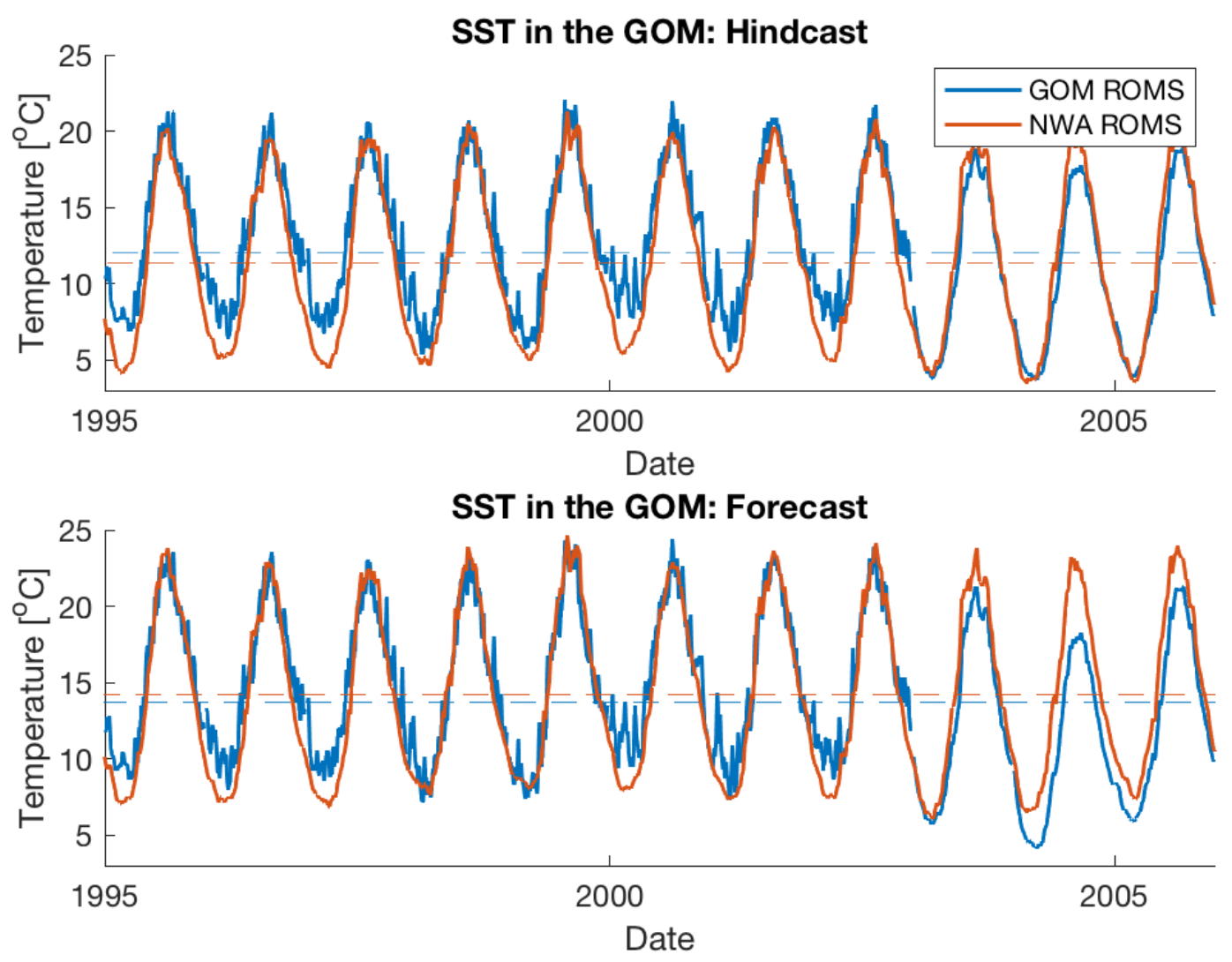

Figure 8-1 - Average sea surface temperature (SST) in the GOM ROMS domain vs. time in the (top) hindcast and (bottom) forecast as estimated by (red) the NWA ROMS and (blue) the GOM ROMS. The NWA ROMS was interpolated to the GOM ROMS grid before analysis. Data are only shown for the time period when the model simulations overlapped. 
Both models forecast an increase in the GOM inflow ratio.

Change in GoM Inflow Ratio from the NWA ROMS

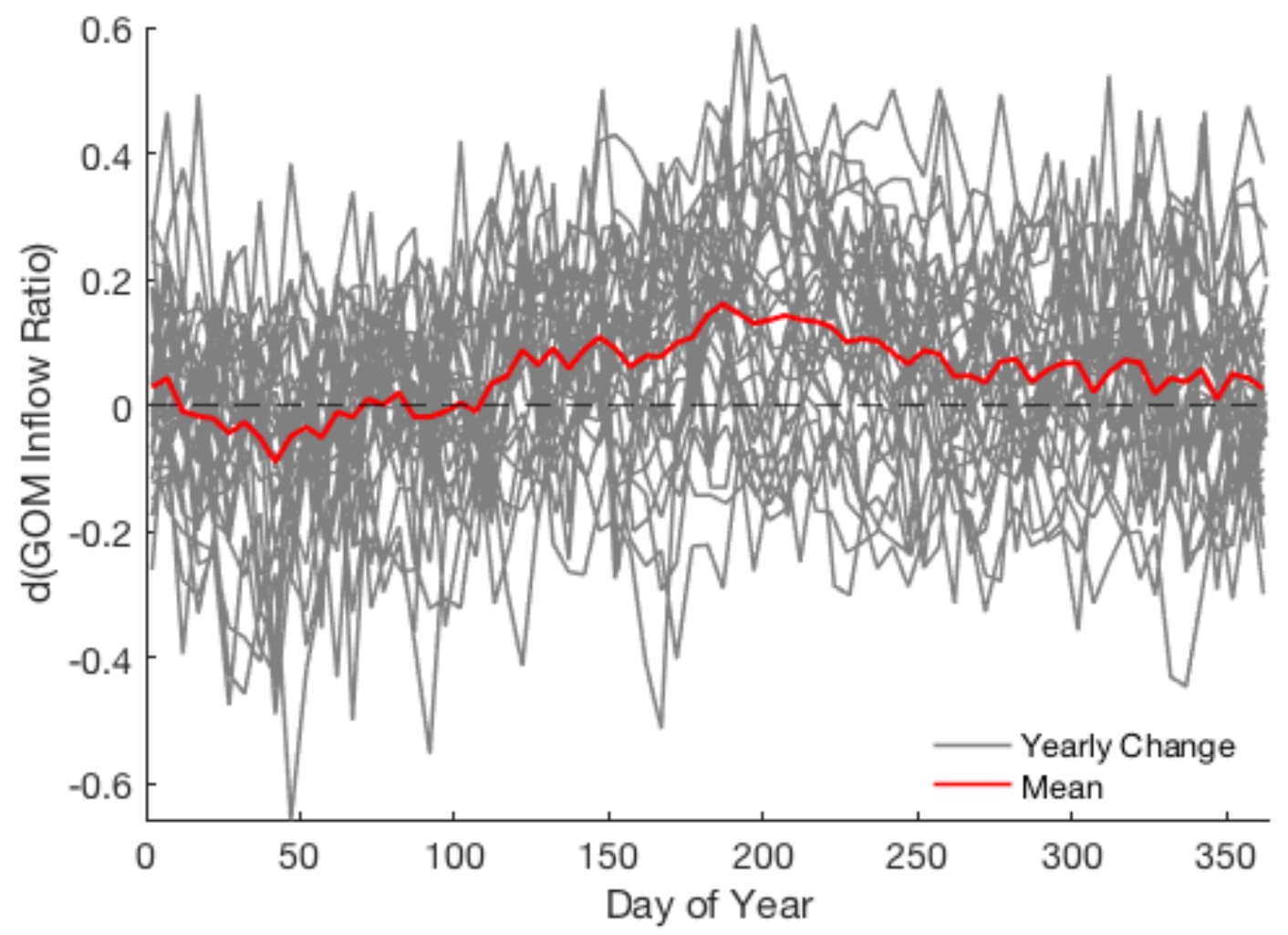

Figure 8-2 - Change in the GOM inflow ratio vs. day of the year as calculated from NWA ROMS output. (grey - yearly change; red - mean) 
The two models agreed on the order of magnitude and seasonality of total river outflow in the GOM.
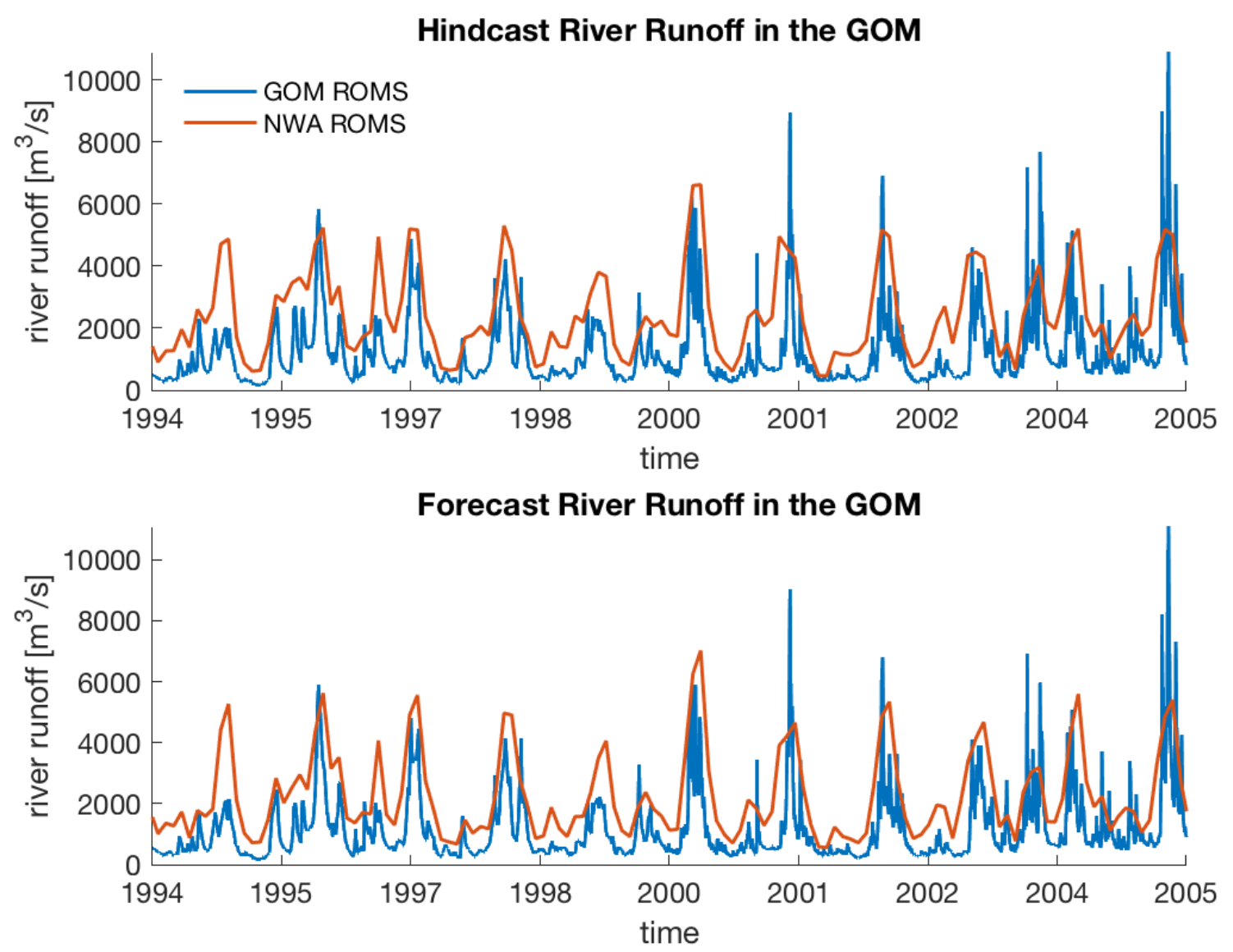

Figure 8-3 - Total river runoff vs. time in the (top) hindcast and (bottom) forecast from (blue) the GOM ROMS and (red) the NWA ROMS. NWA ROMS surface freshwater flux was converted to $\mathrm{m}^{3} \mathrm{~s}^{-1}$ before plotting. Data are only shown for the time period when the two model simulations overlap. 
This is 2 orders of magnitude smaller than the models' disagreement in change in total freshwater in the domain.

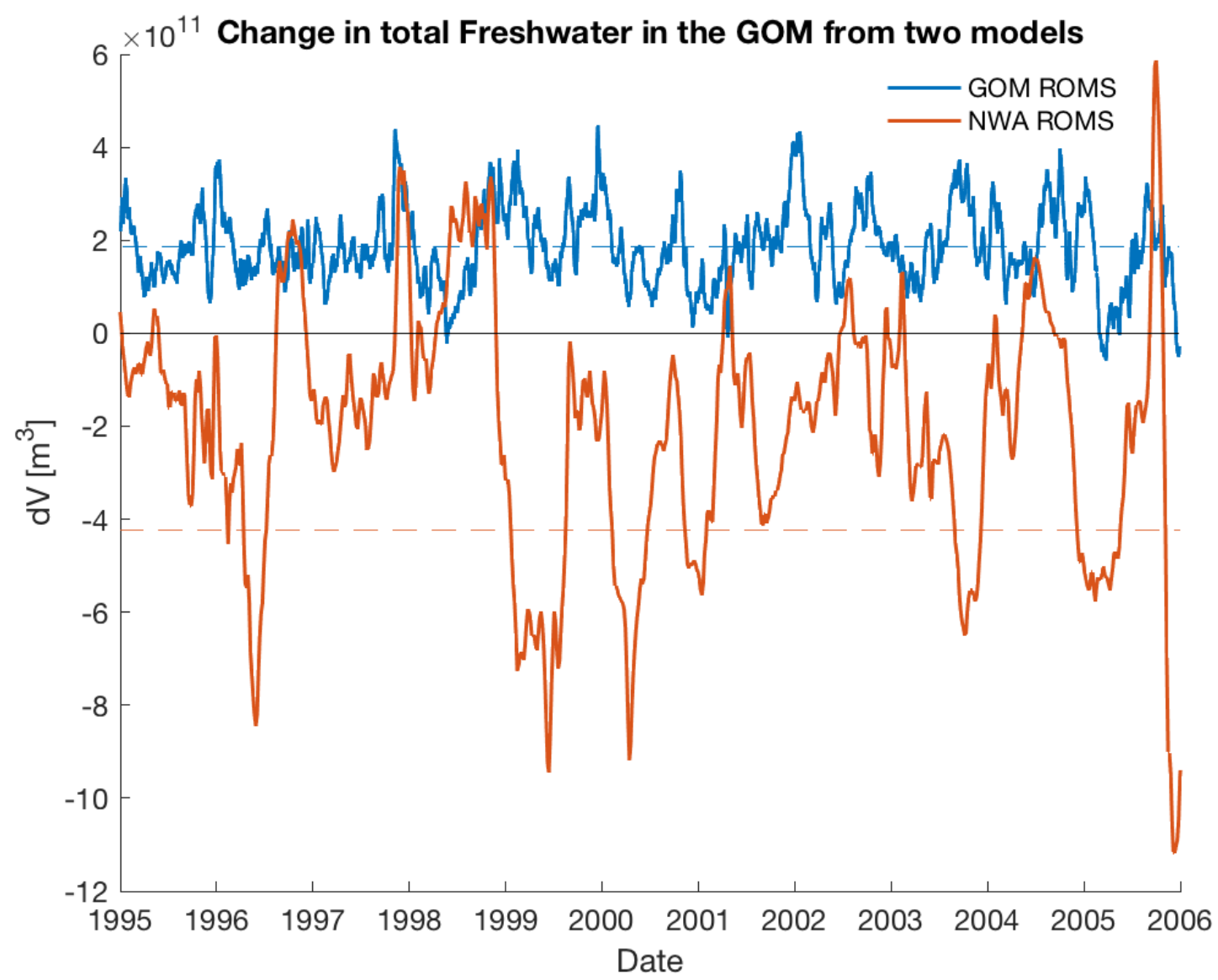

Figure 8-4 - Change in total freshwater volume in the GOM ROMS domain vs. time as estimated by the GOM ROMS (blue) and the NWA ROMS (red). The dashed lines indicate the mean value of the plots of the same color. NWA ROMS data were interpolated to the GOM ROMS grid before analysis, and data are only shown for the time period when the models' hindcast time periods overlap. 
Surface salinity decreased by 0.3 PSU on average in the NWA ROMS forecast within the GOM ROMS domain, but by 0.9 PSU on average in the GOM ROMS forecast.

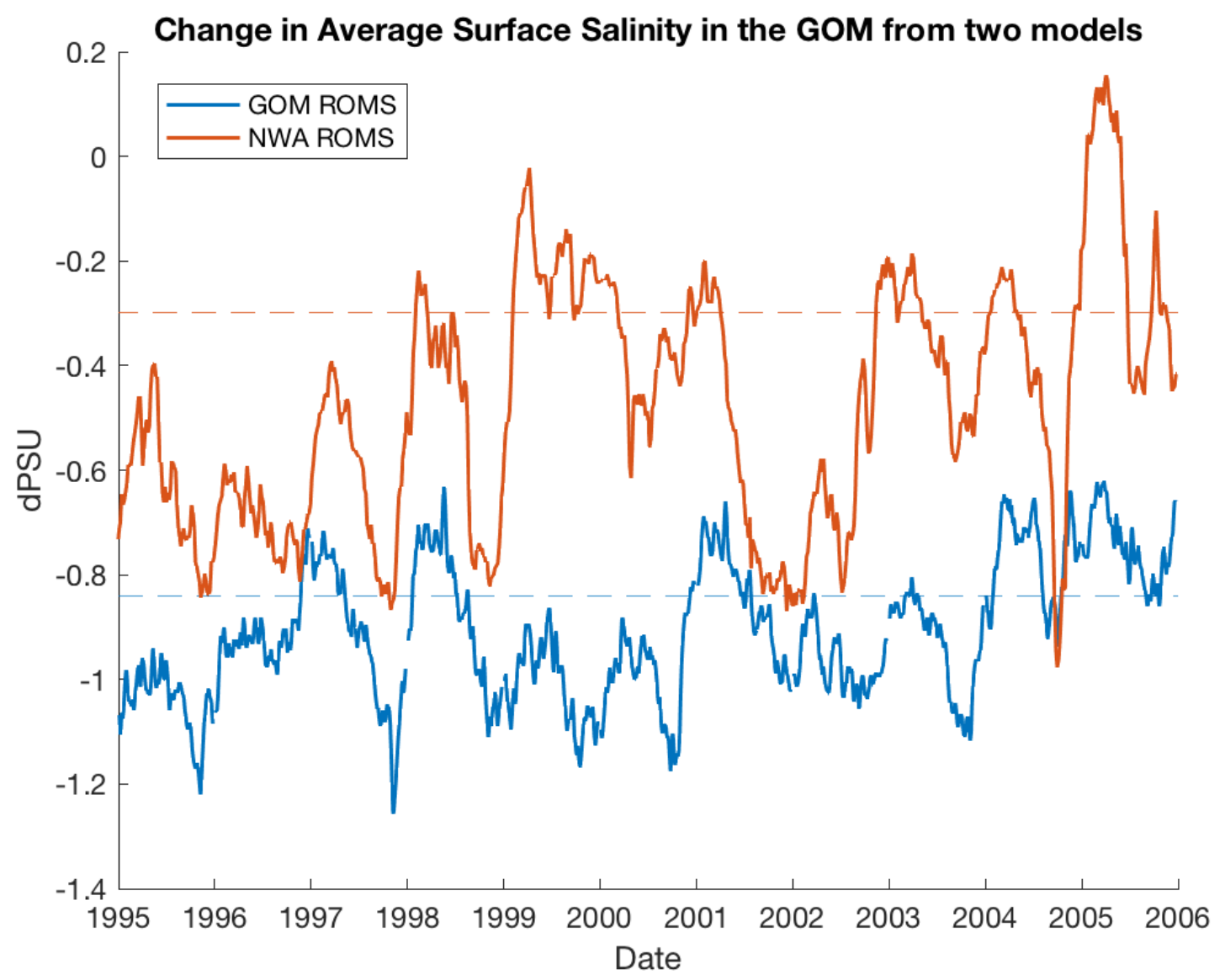

Figure 8-5 - Change in average surface salinity in the GOM ROMS domain vs. time from (blue) the GOM ROMS and (red) the NWA ROMS. NWA ROMS data were interpolated to the GOM ROMS grid before plotting. Data are only plotted for the time period when the two model simulations overlap. 


\subsection{Discussion}

Increased stratification was correlated with increased surface temperatures in the summer and fall, and with decreased surface salinity in the winter.
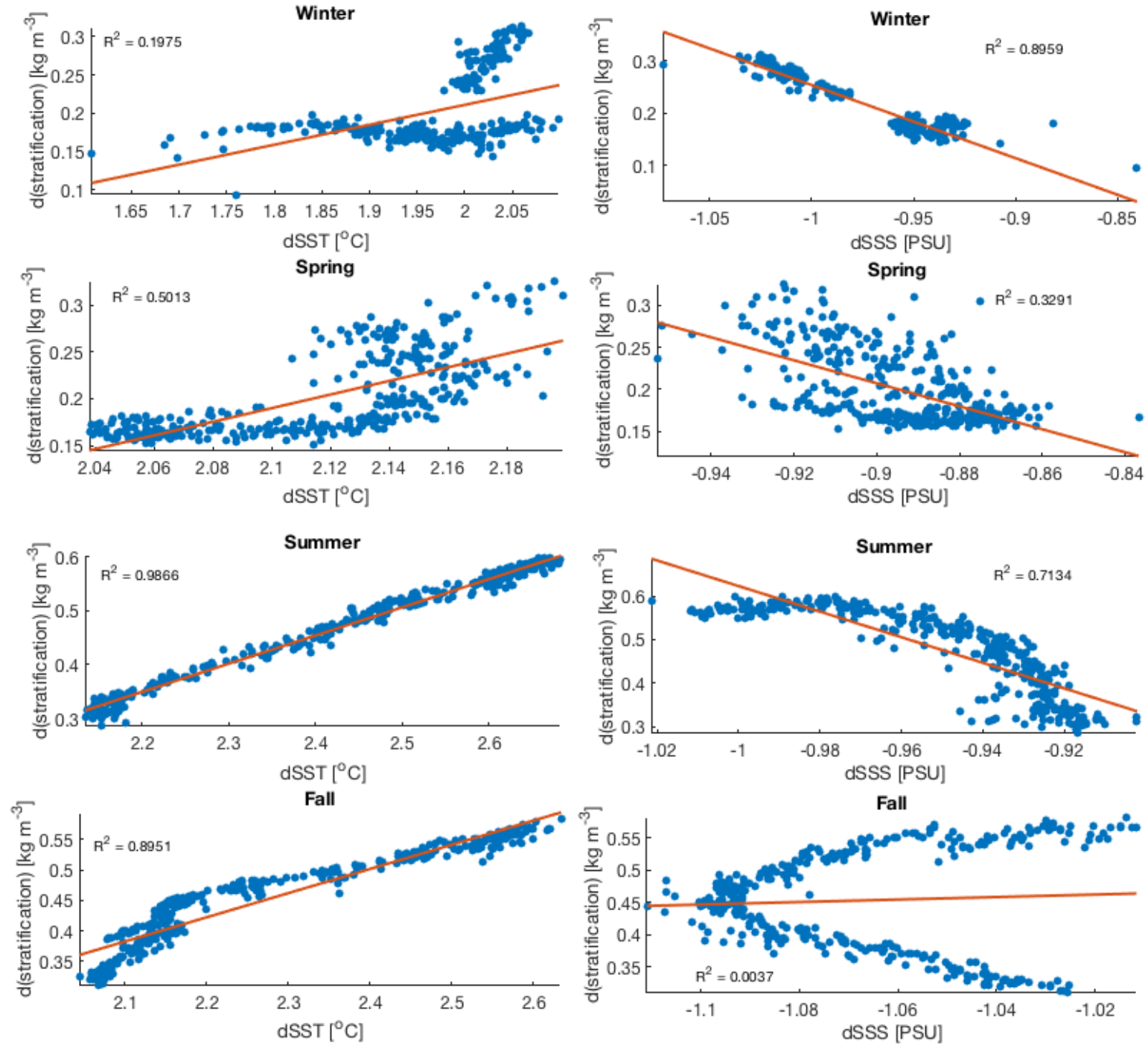

Figure 8-6 - Change in stratification vs. (left) surface temperature and (right) surface salinity in (top to bottom) winter, spring, summer, and fall. Regression lines from linear least squares regression are plotted in red, with the corresponding $R^{2}$ value shown on each plot. 
An analysis of each component of the GOM inflow ratio showed that the increase is caused more by increased Scotian Shelf Water inflows than by decreased Northeast Channel inflows.

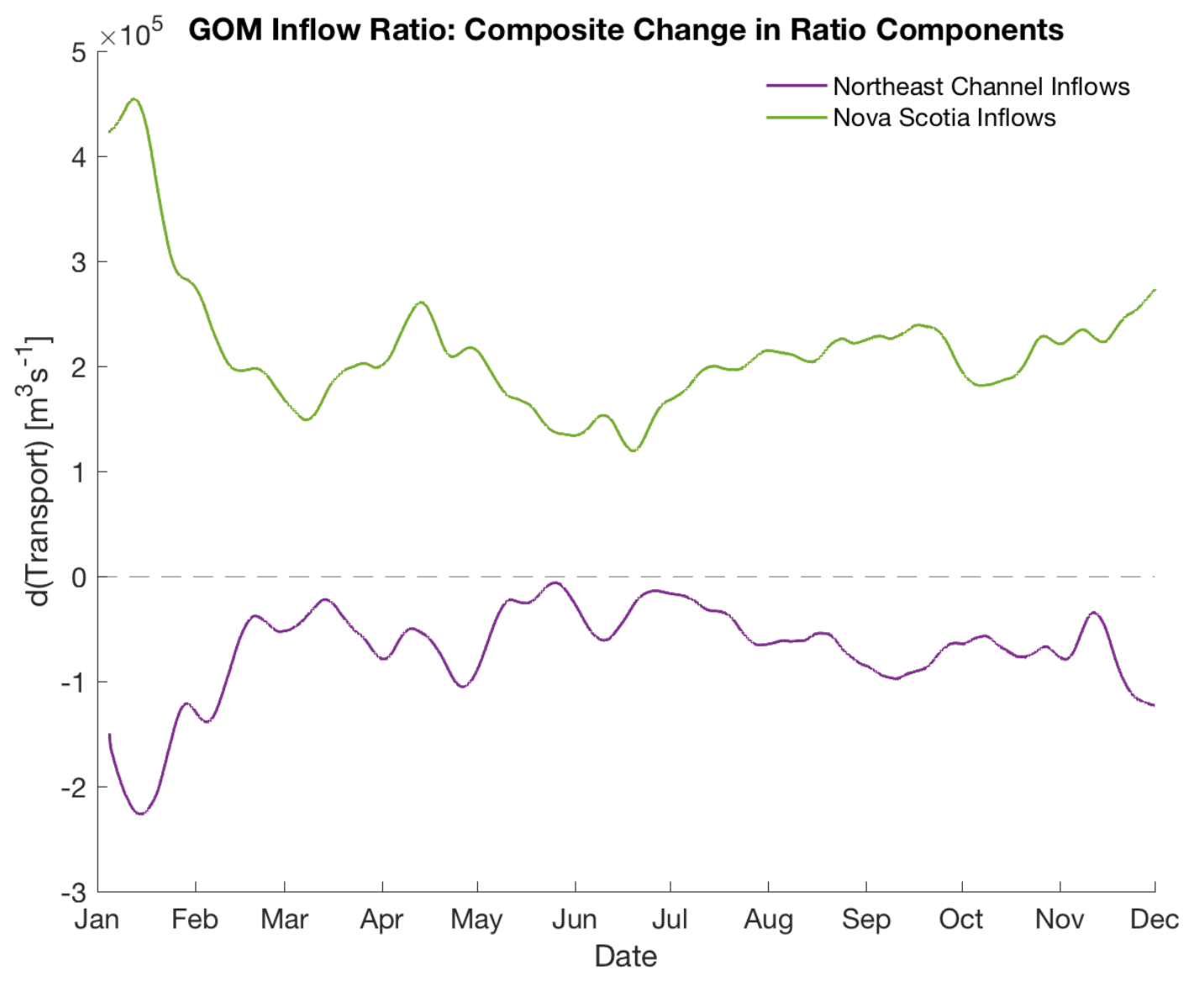

Figure 8-7 - Composite year change in transport for each of the components of the GOM inflow ratio: Nova Scotia transport (green) and Northeast Channel transport (purple) vs. time. The dashed line indicates zero. 
In the forecast composite year, while the average surface temperature in most of the domain was $16^{\circ} \mathrm{C}$, this water mass remained between 8 and $12^{\circ} \mathrm{C}$.

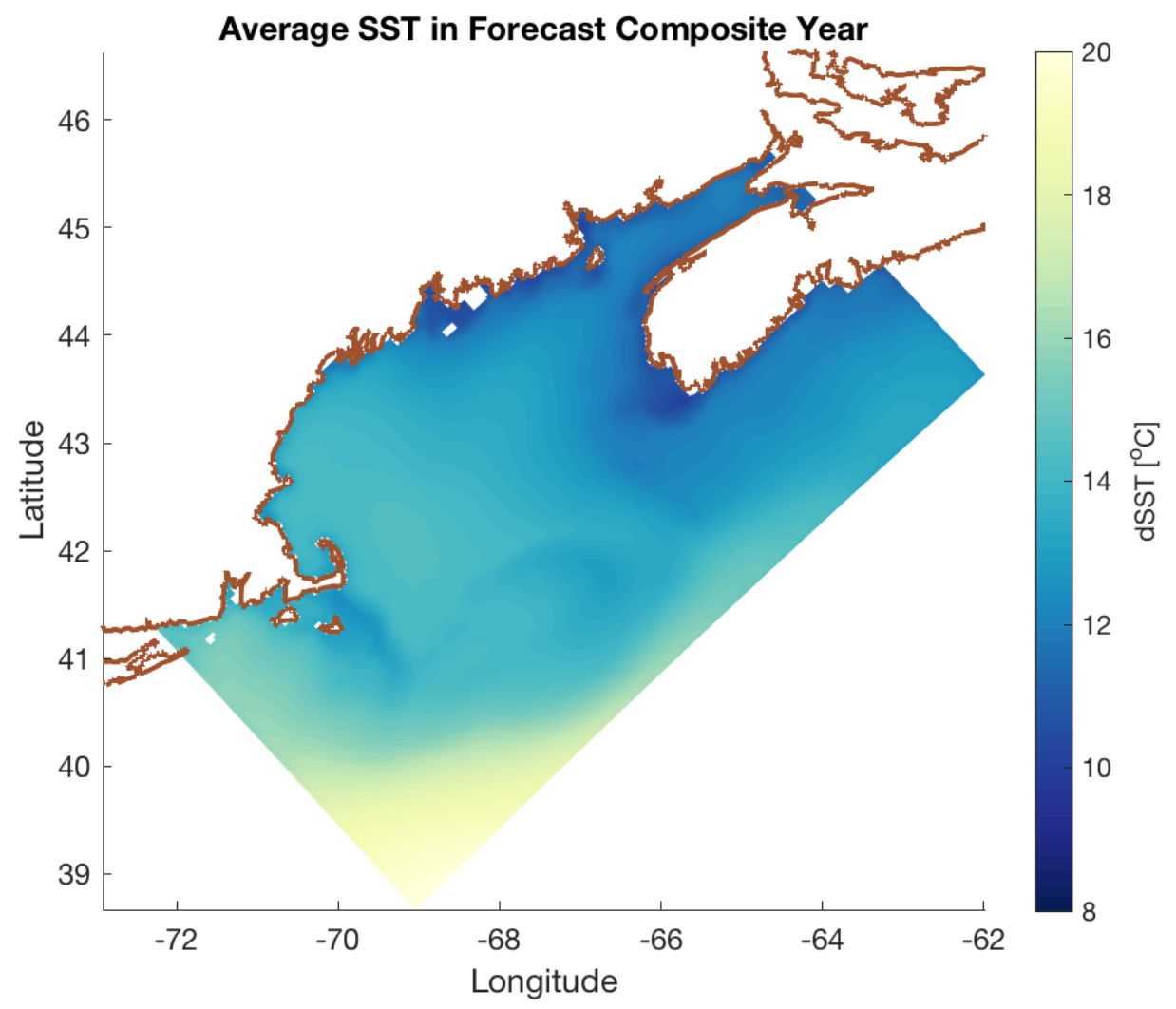

Figure 8-8 - Average sea surface temperature (SST) in the forecast composite year. Color scale is defined by the color bar on the right. 
To assess how these species' growth might change as a result of warming temperatures, the $P$. australis growth curve was shifted to their corresponding temperature ranges such that the curve approached zero at $15^{\circ} \mathrm{C}$ for $P$. seriata and growth peaked at $17^{\circ} \mathrm{C}$ for P. plurisecta.

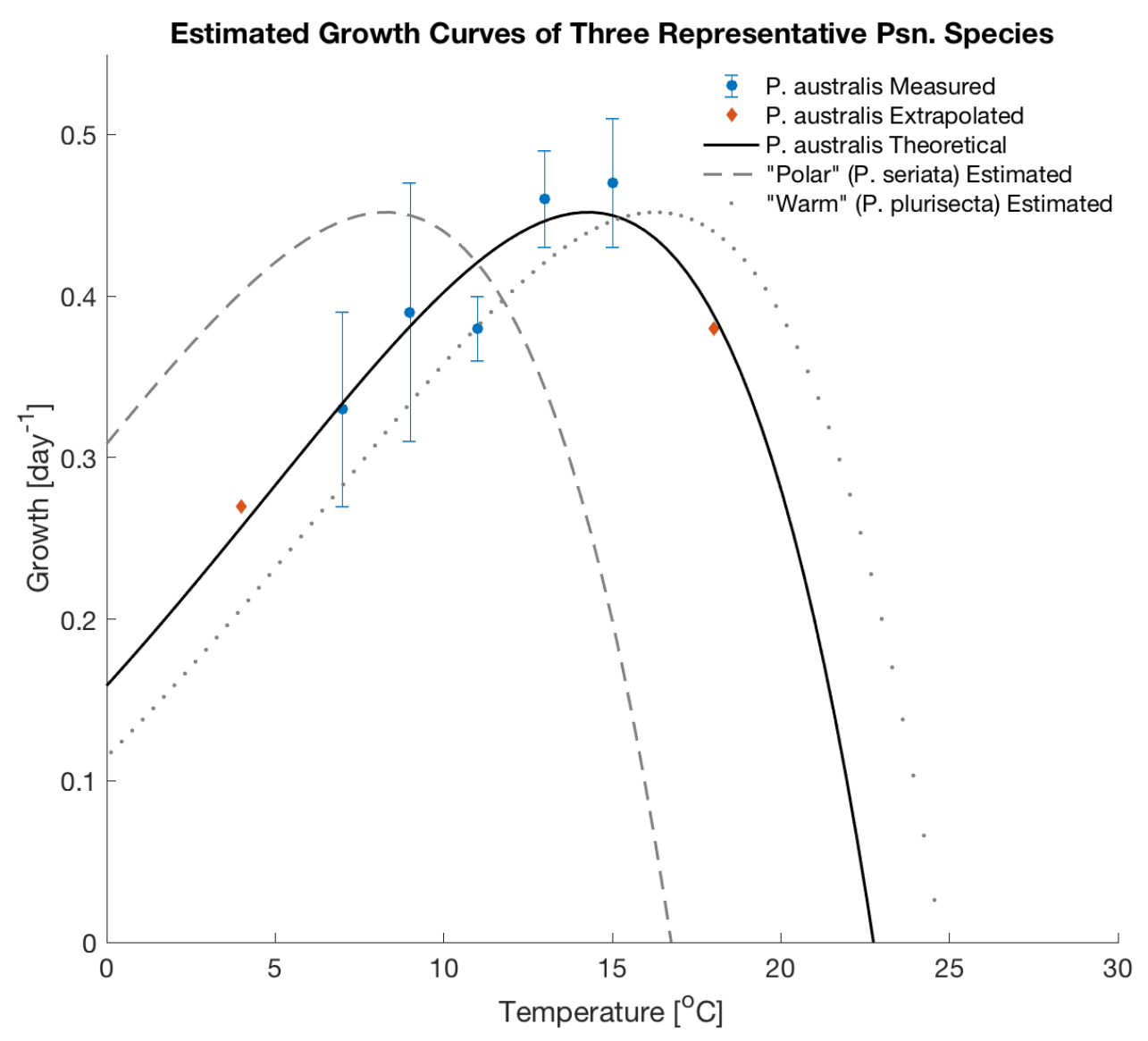

Figure 8-9 - Same as Figure 4-3, but with growth curves for a hypothetical "polar" species (dashed line) and "warm" species (dotted line) included for reference 
This page intentionally left blank. 


\section{Bibliography}

Alexander, M.A., Scott, J.D., Friedland, K.D., Mills, K.E., Nye, J.A., Pershing, A.J., Thomas, A.C., 2018. Projected sea surface temperatures over the 21st century:

Changes in the mean, variability and extremes for large marine ecosystem regions of Northern Oceans. Elem. Sci. Anthr. 6.

Alexander, M.A., Shin, S.-I., Scott, J.D., Curchitser, E., Stock, C., 2020. The Response of the Northwest Atlantic Ocean to Climate Change. J. Clim. 33, 405-428. https://doi.org/10.1175/JCLI-D-19-0117.1

Anderson, C.R., Brzezinski, M.A., Washburn, L., Kudela, R., 2006. Circulation and environmental conditions during a toxigenic Pseudo-nitzschia australis bloom in the Santa Barbara Channel, California. Mar. Ecol. Prog. Ser. 327, 119-133.

Anderson, D.., 1997. Bloom dynamics of toxic Alexandrium species in coastal waters. Limnol. Oceanogr. Part 2 42, 1009-1022.

Anderson, D., 2014. HABs in a changing world: a perspective on harmful algal blooms, their impacts, and research and management in a dynamic era of climactic and environmental change. Harmful Algae 3-17.

Anderson, D.M., Burkholder, J.M., Cochlan, W.P., Glibert, P.M., Gobler, C.J., Heil, C.A., Kudela, R.M., Parsons, M.L., Rensel, J.E.J., Townsend, D.W., Trainer, V.L., Vargo, G.A., 2008. Harmful algal blooms and eutrophication: Examining linkages from selected coastal regions of the United States. Harmful Algae 8, 39-53. https://doi.org/10.1016/j.hal.2008.08.017

Anderson, D.M., Cembella, A.D., Hallegraeff, G.M., 2012. Progress in Understanding Harmful Algal Blooms: Paradigm Shifts and New Technologies for Research, Monitoring, and Management. Ann. Rev. Mar. Sci. 4, 143-176. https://doi.org/10.1146/annurev-marine-120308-081121

Anderson, D.M., Keafer, B.A., McGillicuddy, D.J., Mickelson, M.J., Keay, K.E., Scott Libby, P., Manning, J.P., Mayo, C.A., Whittaker, D.K., Michael Hickey, J., He, R., Lynch, D.R., Smith, K.W., 2005. Initial observations of the 2005 Alexandrium fundyense bloom in southern New England: General patterns and mechanisms. Deep. Res. Part II Top. Stud. Oceanogr. 52, 2856-2876.

https://doi.org/10.1016/j.dsr2.2005.09.004

Arnell, N.W., 1999. Climate change and global water resources. Glob. Environ. Chang. S31-S49. https://doi.org/10.1507/endocrj.42.83

Auro, M.E., Cochlan, W.P., 2013. Nitrogen Utilization and Toxin Production by Two Diatoms of the Pseudo-nitzschia pseudodelicatissima Complex: P. cuspidata and P. fryxelliana. J. Phycol. 49, 156-169. https://doi.org/10.1111/jpy.12033 
Ayache, N., Herve, F., Lundholm, N., Amzil, Z., Caruana, A.M.N., 2020. Acclimation of the marine diatom Pseudo-nitzschia australis to different salinity conditions: effects on growth, photosynthetic activity, and domoic acid content. J. Phycol 56, 97-109. https://doi.org/10.1111/jpy.12929

Ayache, N., Hervé, F., Martin-Jézéquel, V., Amzil, Z., Caruana, A.M.N., 2018. Influence of sudden salinity variation on the physiology and domoic acid production by two strains of Pseudo-nitzschia australis. J. Phycol. 33, 0-3. https://doi.org/10.1111/jpy.12801

Backer, L.C., McGillicuddy, D.J., 2006. Harmful algal blooms. Oceanography 19, 94106. https://doi.org/10.1016/0140-6736(93)92085-8

Barron, J.A., Bukry, D., Field, D.B., Finney, B., 2013. Response of diatoms and silicoflagellates to climate change and warming in the California Current during the past 250 years and the recent rise of the toxic diatom Pseudo-nitzschia australis. Quat. Int. 310, 140-154. https://doi.org/10.1016/j.quaint.2012.07.002

Bates, S.S., Bird, C.J., de Freitas, A.S.W., Foxall, R., Gilgan, M., Hanic, L.A., Johnson, G.R., McCulloch, A.W., Odense, P., Pocklington, R., Quilliam, M.A., Sim, P.G., Smith, J.C., Subba Rao, D.V., Todd, E.C.D., Walter, J.A., Wright, J.L.C., 1989. Pennate Diatom Nitzschia pungens as the Primary Source of Domoic Acid, a Toxin in Shellfish from Eastern Prince Edward Island, Canada. Can. J. Fish. Aquat. Sci. 46, 1203-1215. https://doi.org/10.4224/23000873

Bates, S.S., de Freites, A.S.W., Milley, J.E., Pocklington, R., Quilliam, M.A., Smith, J.C., Worms, J., 1991. Controls on Domoic Acid Production by the Diatom Nitzschia pungens f. multiseries in Culture: Nutrients and Irradiance. Can. J. Fish. Aquat. Sci. 48, 1136-1144.

Bates, S.S., Hubbard, K.A., Lundholm, N., Montresor, M., Leaw, C.P., 2018. Pseudonitzschia, Nitzschia, and domoic acid: New research since 2011. Harmful Algae 79, 3-43. https://doi.org/10.1016/j.hal.2018.06.001

Bigelow, H., 1927. Dynamic oceanography of the Gulf of Maine. Trans. Am. Geophys. Union 206-211. https://doi.org/10.1063/1.3058361

Bisagni, J.J., Gifford, D.J., Ruhsam, C.M., 1996. The spatial and temporal distribution of the Maine Coastal Current during 1982. Cont. Shelf Res. 16, 1-24.

Blankley, W.F., Lewin, R.A., 1976. Temperature responses of a coccolithophorid, Cricosphaera carterae, measured in a simple and inexpensive thermal-gradient device. Limnol. Oceanogr. 21.

Borkman, D., 2021. Spatial and temporal patterns of HABs and toxicity in Rhode Island, in: Gulf of Maine Stakeholders' Meeting. 
Bowers, H.A., Ryan, J.P., Hayashi, K., Woods, A.L., Marin, R., Smith, G.J., Hubbard, K.A., Doucette, G.J., Mikulski, C.M., Gellene, A.G., Zhang, Y., Kudela, R.M., Caron, D.A., Birch, J.M., Scholin, C.A., 2018. Diversity and toxicity of Pseudonitzschia species in Monterey Bay: Perspectives from targeted and adaptive sampling. Harmful Algae 78, 129-141. https://doi.org/10.1016/j.hal.2018.08.006

Bresnan, E., Fryer, R.J., Fraser, S., Smith, N., Stobo, L., Brown, N., Turrell, E., 2017. The relationship between Pseudo-nitzschia (Peragallo) and domoic acid in Scottish shell fish. Harmful Algae 63, 193-202.

Bresnan, E., Kraberg, A., Fraser, S., Brown, L., Hughes, S., Wiltshire, K.H., 2015. Diversity and seasonality of Pseudo-nitzschia (Peragallo) at two North Sea timeseries monitoring sites. Helgol. Mar. Res. 69, 193-204. https://doi.org/10.1007/s10152-015-0428-5

Brickman, D., Hebert, D., Wang, Z., 2018. Mechanism for the recent ocean warming events on the Scotian Shelf of eastern Canada. Cont. Shelf Res. 156, 11-22. https://doi.org/10.1016/j.csr.2018.01.001

Brooks, D.A., 1994. A model study of the buoyancy-driven circulation in the Gulf of Maine. Am. Meteorol. Soc. 2387-2412.

Brooks, D.A., 1987. The Influence of Warm-Core Rings on Slope Water Entering the Gulf of Maine. J. Geophys. Res. 92, 8183-8196.

Brooks, D.A., 1985. Vernal Circulation in the Gulf of Maine. J. Geophys. Reserach 90, $4687-4705$.

Brooks, D.A., Townsend, D.W., 1989. Variability of the coastal current and nutrient pathways in the eastern Gulf of Maine. J. Mar. Res. 47, 303-321. https://doi.org/10.1357/002224089785076299

Canada, 2018. Water Level and Flow [WWW Document]. URL https://wateroffice.ec.gc.ca/ (accessed 3.12.21).

Carton, J.A., Giese, B.S., 2008. A reanalysis of ocean climate using Simple Ocean Data Assimilation (SODA). Mon. Weather Rev. 136, 2999-3017. https://doi.org/10.1175/2007MWR1978.1

Cerino, F., Orsini, L., Sarno, D., Dell'Aversano, C., Tartaglione, L., Zingone, A., 2005. The alternation of different morphotypes in the seasonal cycle of the toxic diatom Pseudo-nitzschia galaxiae. Harmful Algae 4, 33-48. https://doi.org/10.1016/j.hal.2003.10.005

Chadwick, C., 2021. Pseudo-nitzschia in the GOM, in: Gulf of Maine Stakeholders' Meeting. https://northeasthab.whoi.edu/gom-hab-symposium/ 
Chapman, D.C., Beardsley, R.C., 1989. On the origin of shelf water in the Middle Atlantic Bight. J. Phys. Oceanogr. 19, 1-8.

Churro, C.I., Carreira, C.C., Rodrigues, F.J., Craveiro, S.C., Calado, A.J., Casteleyn, G., Lundholm, N., 2009. Diversity and abundance of potentially toxic Pseudonitzschia peragallo in Aveiro Coastal Lagoon, Portugal and description of a new variety, P. pungens var. aveirensis var. nov. Diatom Res. 24, 35-62. https://doi.org/10.1080/0269249X.2009.9705782

Clark, S., Hubbard, K.A., Anderson, D.M., McGillicuddy, D.J.J., Ralston, D.K., Townsend, D.W., 2019. Pseudo-nitzschia bloom dynamics in the Gulf of Maine: 2012 - 2016. Harmful Algae 88, 101656. https://doi.org/10.1016/j.hal.2019.101656

Clark, S., Hubbard, K.A., McGillicuddy, D.J.J., Ralston, D.K., Shankar, S., 2021. Investigating Pseudo-nitzschia australis introduction to the Gulf of Maine with observations and models. Submitted to Continental Shelf Research.

Csanady, G.T., Hamilton, P., 1988. Circulation of slopewater. Cont. Shelf Res. 8, 565624. https://doi.org/10.1016/0278-4343(88)90068-4

Cummings, J.A., 2005. Operational multivariate ocean data assimilation. Q.J.R. Meterological Soc. 131, 3583-3604. https://doi.org/10.1256/qj.05.105

Cusack, C., Dabrowski, T., Lyons, K., Berry, A., Westbrook, G., Salas, R., Duffy, C., Nolan, G., Silke, J., 2016. Harmful algal bloom forecast system for SW Ireland. Part II: Are operational oceanographic models useful in a HAB warning system. Harmful Algae 53, 86-101. https://doi.org/10.1016/j.hal.2015.11.013

Cusack, C., Mouriño, H., Moita, M.T., Silke, J., 2015. Modelling Pseudo-nitzschia events off southwest Ireland. J. Sea Res. 105, 30-41. https://doi.org/10.1016/j.seares.2015.06.012

Cusack, C.K., Bates, S.S., Quilliam, M.A., Patching, J.W., Raine, R., 2002. Confirmation of domoic acid production by Pseudo-nitzschia australis (bacillariophyceae) isolated from Irish waters. J. Phycol 38, 1106-1112.

Dai, A., Qian, T., Trenberth, K.E., Milliman, J.D., 2009. Changes in Continental Freshwater Discharge from 1948 to 2004. Am. Meteorol. Soc. 22, 2773-2792. https://doi.org/10.1175/2008JCLI2592.1

Dever, M., Hebert, D., Greenan, B.J.W., Sheng, J., Smith, P.C., 2016. Hydrography and Coastal Circulation along the Halifax Line and the Connections with the Gulf of St. Lawrence. Atmosphere-Ocean 54, 199-217. https://doi.org/10.1080/07055900.2016.1189397

Doney, S.C., 2006. Plankton in a warmer world. Nature 444. 
Doucette, G.J., King, K.L., Thessen, A.E., Dortch, Q., 2008. The effect of salinity on domoic acid production by the diatom Pseudo-nitzschia multiseries. Nov. Hedwigia $133,31-46$.

Downes-Tettmar, N., Rowland, S., Widdicombe, C., Woodward, M., Llewellyn, C., 2013. Seasonal variation in Pseudo-nitzschia spp. and domoic acid in the Western English Channel. Cont. Shelf Res. 53, 40-49. https://doi.org/10.1016/j.csr.2012.10.011

Dunne, J.P., John, J.G., Adcroft, A.J., Griffies, S.M., Hallberg, R.W., Shevliakova, E., Stouffer, R.J., Cooke, W., Dunne, K.A., Harrison, M.J., Krasting, J.P., Malyshev, S.L., Milly, P.C.D., Phillipps, P.J., Sentman, L.T., Samuels, B.L., Spelman, M.J., Winton, M., Wittenberg, A.T., Zadeh, N., 2012. GFDL's ESM2 global coupled climate-carbon earth system models. Part I: Physical formulation and baseline simulation characteristics. J. Clim. 25, 6646-6665. https://doi.org/10.1175/JCLI-D11-00560.1

Dunne, J.P., John, J.G., Shevliakova, S., Stouffer, R.J., Krasting, J.P., Malyshev, S.L., Milly, P.C.D., Sentman, L.T., Adcroft, A.J., Cooke, W., Dunne, K.A., Griffies, S.M., Hallberg, R.W., Harrison, M.J., Levy, H., Wittenberg, A.T., Phillips, P.J., Zadeh, N., 2013. GFDL's ESM2 global coupled climate-carbon earth system models. Part II: Carbon system formulation and baseline simulation characteristics. J. Clim. 26, 2247-2267. https://doi.org/10.1175/JCLI-D-12-00150.1

Ennaffah, B., Nafil, E., Chafik, A., 2012. First report of Pseudo-nitzschia australis on Moroccan Atlantic coast and toxicity in Moroccan shellfish. Harmful Algae News 21.

Eppley, R.W., 1972. Temperature and phytoplankton growth in the sea. Fish. Bull. 70, $1063-1085$.

Fang, X., Sommer, U., 2017. Overwintering effects on the spring bloom dynamics of phytoplankton. J. Plankton Res. 39, 772-780. https://doi.org/10.1093/plankt/fbx046

Fehling, J., Davidson, K., Bolch, C., Tett, P., 2006. Seasonality of Pseudo-nitzschia spp.(Bacillariophyceae) in western Scottish waters. Mar. Ecol. Prog. Ser. 323, 91105.

Fehling, J., Davidson, K., Bolch, C.J., Bates, S.S., 2004a. Growth and domoic acid production by Pseudo-nitzschia seriata (Bacillariophyceae) under phosphate and silicate limitation. J. Phycol. 40, 674-683. https://doi.org/10.1111/j.15298817.2004.03213.x 
Fehling, J., Green, D.H., Davidson, K., Botch, C.J., Bates, S.S., 2004b. Domoic acid production by Pseudo-nitzschia seriata (bacillariophyceae) in Scottish waters. J. Phycol. 40, 622-630. https://doi.org/10.1111/j.1529-8817.2004.03200.x

Fennel, K., Wilkin, J., 2009. Quantifying biological carbon export for the northwest North Atlantic continental shelves. Geophys. Res. Lett. 36, 2-5. https://doi.org/10.1029/2009GL039818

Fernandes, L.F., Hubbard, K.A., Richlen, M.L., Smith, J., Bates, S.S., Ehrman, J., Léger, C., Mafra, L.L., Kulis, D., Quilliam, M., Libera, K., McCauley, L., Anderson, D.M., 2014. Diversity and toxicity of the diatom Pseudo-nitzschia Peragallo in the Gulf of Maine, Northwestern Atlantic Ocean. Deep. Res. Part II Top. Stud. Oceanogr. 103, 139-162. https://doi.org/10.1016/j.dsr2.2013.06.022

Franks, P.J.S., Anderson, D.M., 1992. Marine Biology in a buoyancy current : Alexandrium tamarense in the Gulf of Maine. Mar. Biol. 112, 153-164.

Giddings, S.N., 2014. Hindcasts of potential harmful algal bloom transport pathways on the Pacific Northwest coast. J. Geophys. Res. Ocean. 119, 2439-2461. https://doi.org/10.1002/2013JC009622.Received

Glibert, P.M., Anderson, D.M., Gentien, P., Graneli, E., Sellner, K.G., 2005. The global, complex phenomena of Harmful Algal Blooms. Oceanography 18, 136-147.

Gobler, C.J., Doherty, O.M., Hattenrath-Lehmann, T.K., Griffith, A.W., Kang, Y., Litaker, R.W., 2017. Ocean warming since 1982 has expanded the niche of toxic algal blooms in the North Atlantic and North Pacific oceans. Proc. Natl. Acad. Sci. 114, 4975-4980. https://doi.org/10.1073/pnas.1619575114

Gosling, S.N., Taylor, R.G., Arnell, N.W., Todd, M.C., 2011. A comparative analysis of projected impacts of climate change on river runoff from global and catchment-scale hydrological models. Hydrol. Earth Syst. Sci. 15, 279-294. https://doi.org/10.5194/hess-15-279-2011

Gosling, S.N., Zaherpour, J., Mount, N.J., Hattermann, F.F., Dankers, R., Arheimer, B., Breuer, L., Ding, J., Haddeland, I., Kumar, R., Kundu, D., Liu, J., van Griensven, A., Veldkamp, T.I.E., Vetter, T., Wang, X., Zhang, X., 2017. A comparison of changes in river runoff from multiple global and catchment-scale hydrological models under global warming scenarios of $1{ }^{\circ} \mathrm{C}, 2{ }^{\circ} \mathrm{C}$ and $3{ }^{\circ} \mathrm{C}$. Clim. Change 141 , 577-595. https://doi.org/10.1007/s10584-016-1773-3 
Greene, C., Meyer-Gutbrod, E., Monger, B.C., McGarry, L.P., Pershing, A.J., Belkin, I.M., Fratantoni, P.S., Mountain, D.G., Pickart, R.S., Proshutinsky, A., Ji, R., Bisagni, J.J., Hakkinen, S.M.A., Haidvogel, D.B., Wang, J., Head, E., Smith, P., Reid, P.C., Conversi, A., 2013. Remote climate forcing of decadal-scale regime shifts in Northwest Atlantic shelf ecosystems. Limnol. Oceanogr. 58, 803-816. https://doi.org/10.4319/lo.2013.58.3.0803

Guannel, M.L., Haring, D., Twiner, M.J., Wang, Z., Noble, A.E., Lee, P.A., Saito, M.A., Rocap, G., 2015. Toxigenicity and biogeography of the diatom Pseudo-nitzschia across distinct environmental regimes in the South Atlantic Ocean. Mar. Ecol. Prog. Ser. 526, 67-87. https://doi.org/10.3354/meps11027

Hallegraeff, G.M., 2010. Ocean climate change, phytoplankton community responses, and harmful algal blooms: A formidable predictive challenge. J. Phycol. 46, 220235. https://doi.org/10.1111/j.1529-8817.2010.00815.x

Hansen, L.R., Soylu, S. í, Kotaki, Y., Moestrup, Ø., Lundholm, N., 2011. Toxin production and temperature-induced morphological variation of the diatom Pseudonitzschia seriata from the Arctic. Harmful Algae 10, 689-696. https://doi.org/10.1016/j.hal.2011.05.004

Hardardóttir, S., Pančić, M., Tammilehto, A., Krock, B., Møller, E.F., Nielsen, T.G., Lundholm, N., 2015. Dangerous relations in the arctic marine food web: Interactions between toxin producing Pseudo-nitzschia diatoms and Calanus copepodites. Mar. Drugs 13, 3809-3835. https://doi.org/10.3390/md13063809

Hasle, G.R., 2002. Are most of the domoic acid-producing species of the diatom genus Pseudo-nitzschia cosmopolites? Harmful Algae 1, 137-146. https://doi.org/10.1016/S1568-9883(02)00014-8

He, R., McGillicuddy, D.J., 2008. Historic 2005 toxic bloom of Alexandrium fundyense in the west Gulf of Maine: 1. In situ observations of coastal hydrography and circulation. J. Geophys. Res. Ocean. 113, 1-12. https://doi.org/10.1029/2007JC004601

He, R., McGillicuddy, D.J., Keafer, B.A., Anderson, D.M., 2008. Historic 2005 toxic bloom of Alexandrium fundyense in the western Gulf of Maine: 2. Coupled biophysical numerical modeling. J. Geophys. Res. Ocean. 113, 1-12. https://doi.org/10.1029/2007JC004602

Hebert, D., Pettipas, R., Brickman, D., Dever, M., 2018. Meteorological, Sea Ice and Physical Oceanographic Conditions on the Scotian Shelf and in the Gulf of Maine during 2016. 
Hinder, S.L., Hays, G.C., Edwards, M., Roberts, E.C., Walne, A.W., Gravenor, M.B., 2012. Changes in marine dinoflagellate and diatom abundance under climate change. Nat. Clim. Chang. 2, 271-275. https://doi.org/10.1038/nclimate1388

Howard, M.D.A., Cochlan, W.P., Ladizinsky, N., Kudela, R.M., 2007. Nitrogenous preference of toxigenic Pseudo-nitzschia australis (Bacillariophyceae) from field and laboratory experiments. Harmful Algae 6, 206-217. https://doi.org/10.1016/j.hal.2006.06.003

Hubbard, K., Anderson, D., Archer, S., Berger, H., Brosnahan, M., Chadwick, C., Denny, E., Disney, J., Farrell, A., Granholm, A., Fleiger, J., Flewelling, L., Heil, C., Henschen, K., Kanwit, K., Kulis, D., Keafer, B., Keller Abbe, S., Lewis, B., Markley, L., Park, J., Petitpas, C., Racicot, E., Robert, M., Villac, C., McGillicuddy, D., 2017. Synergistic characterization of Pseudo-nitzschia communities during unprecedented domoic acid events, in: Ninth Symposium on Harmful Algae in the U.S.

Hubbard, K.A., Olson, C.E., Armbrust, E.V., 2014. Molecular characterization of Pseudo-nitzschia community structure and species ecology in a hydrographically complex estuarine system (Puget Sound, Washington, USA). Mar. Ecol. Prog. Ser. 507, 39-55. https://doi.org/10.3354/meps10820

Husson, B., Hernandez-Farinas, T., Le Gendre, R., Schapira, M., Chapelle, A., 2016. Two decades of Pseudo-nitzschia spp. blooms and king scallop (Pecten maximus) contamination by domoic acid along the French Atlantic and English Channel coasts: Seasonal dynamics, spatial heterogeneity and interannual variability. Harmful Algae 51, 26-39. https://doi.org/10.1016/J.HAL.2015.10.017

Jin, D., Thunberg, E., Hoagland, P., 2008. Economic impact of the 2005 red tide event on commercial shellfish fisheries in New England. Ocean Coast. Manag. 51, 420429. https://doi.org/10.1016/j.ocecoaman.2008.01.004

Joyce, T.., 1984. Velocity and Hydrographic Structure of a Gulf Stream Warm-Core Ring. J. Phys. Oceanogr. 14, 936-947.

Kaczmarska, I., Martin, J.L., Ehrman, J.M., LeGresley, M.M., 2007. Pseudo-nitzschia species population dynamics in the Quoddy Region, Bay of Fundy. Harmful Algae 6, 861-874. https://doi.org/10.1016/j.hal.2007.05.001

Kang, D., Curchitser, E.N., 2013. Gulf Stream eddy characteristics in a high-resolution ocean model. J. Geophys. Res. Ocean. 118, 4474-4487.

https://doi.org/10.1002/jgrc.20318 
Keafer, B.A., Churchill, J.H., McGillicuddy, D.J., Anderson, D.M., 2005. Bloom development and transport of toxic Alexandrium fundyense populations within a coastal plume in the Gulf of Maine. Deep. Res. Part II Top. Stud. Oceanogr. 52, 2674-2697. https://doi.org/10.1016/j.dsr2.2005.06.016

Klein, C., Claquin, P., Bouchart, V., Le Roy, B., Veron, B., 2010. Dynamics of Pseudonitzschia spp. and domoic acid production in a macrotidal ecosystem of the Eastern English Channel (Normandy, France). Harmful Algae 9, 218-226. https://doi.org/10.1016/J.HAL.2009.10.004

Kurlansky, M., 1997. Cod: A biography of the fish that changed the world.

Lapointe, G., 2013. Commercial Fisheries: State of the Gulf of Maine Report.

Large, W.G., Pond, S., 1981. Open Ocean Momentum Flux Measurements in Moderate to Strong Winds. J. Phys. Oceanogr. https://doi.org/10.1175/15200485(1981)011<0324:OOMFMI $>2.0 . \mathrm{CO} ; 2$

Large, W.G., Yeager, S.G., 2009. The global climatology of an interannually varying air - Sea flux data set. Clim. Dyn. 33, 341-364. https://doi.org/10.1007/s00382-0080441-3

Lema, K.A., Latimier, M., Nézan, É., Fauchot, J., Le Gac, M., 2017. Inter and intraspecific growth and domoic acid production in relation to nutrient ratios and concentrations in Pseudo-nitzschia: phosphate an important factor. Harmful Algae 64, 11-19. https://doi.org/10.1016/j.hal.2017.03.001

Lewis, B., MacLeod, J., Hubbard, K., 2017. The Gulf of Maine domoic acid evento f 2016: an emerging public health concern, in: 9th U.S. HAB Symposium.

Li, Y., He, R., 2014. Spatial and temporal variability of SST and ocean color in the Gulf of Maine based on cloud-free SST and chlorophyll reconstructions in 2003-2012. Remote Sens. Environ. 144, 98-108. https://doi.org/10.1016/j.rse.2014.01.019

Li, Y., He, R., Chen, K., McGillicuddy, D.J., 2015. Variational data assimilative modeling of the Gulf of Maine in spring and summer 2010. J. Geophys. Res. Ocean. 132, 1-17. https://doi.org/10.1002/2014JC010320.Received

Li, Y., He, R., McGillicuddy, D.J., 2014. Seasonal and interannual variability in Gulf of Maine hydrodynamics: 2002-2011. Deep. Res. Part II Top. Stud. Oceanogr. 103, 210-222. https://doi.org/10.1016/j.dsr2.2013.03.001

Li, Y., He, R., McGillicuddy, D.J., Anderson, D.M., Keafer, B.A., 2009. Investigation of the 2006 Alexandrium fundyense bloom in the Gulf of Maine: In-situ observations and numerical modeling. Cont. Shelf Res. 29, 2069-2082. https://doi.org/10.1016/j.csr.2009.07.012 
Loder, J.W., Petrie, B., Gawarkiewicz, G., 1998. The coastal ocean off northwestern North America: a large-scale view., in: The Sea, Vol 11. pp. 105-133.

Long, Z., Perrie, W., Chassé, J., Brickman, D., Guo, L., Drozdowski, A., Hu, H., 2016. Impacts of Climate Change in the Gulf of St. Lawrence. Atmosphere-Ocean 54, 337-351. https://doi.org/10.1080/07055900.2015.1029869

López, A.G., Wilkin, J.L., Levin, J.C., 2020. Doppio-a ROMS (v3.6)-based circulation model for the Mid-Atlantic Bight and Gulf of Maine: Configuration and comparison to integrated coastal observing network observations. Geosci. Model Dev. 13, 37093729. https://doi.org/10.5194/gmd-13-3709-2020

Luerssen, R.M., Thomas, A.C., Hurst, J., 2005. Relationships between satellite-measured thermal features and Alexandrium-imposed toxicity in the Gulf of Maine. Deep. Res. Part II Top. Stud. Oceanogr. 52, 2656-2673. https://doi.org/10.1016/j.dsr2.2005.06.025

Lundholm, N., Clarke, A., Ellegaard, M., 2010. A 100-year record of changing Pseudonitzschia species in a sill-fjord in Denmark related to nitrogen loading and temperature. Harmful Algae 9, 449-457. https://doi.org/10.1016/j.hal.2010.03.001

Lundholm, N., Hansen, P.J., Kotaki, Y., 2004. Effect of pH on growth and domoic acid production by potentially toxic diatoms of the genera Pseudo-nitzschia and Nitzschia. Mar. Ecol. Prog. Ser. 273, 1-15. https://doi.org/10.3354/meps273001

Lundholm, N., Krock, B., John, U., Skov, J., Cheng, J., Pančić, M., Wohlrab, S., Rigby, K., Nielsen, T.G., Selander, E., Harðardóttir, S., 2018. Induction of domoic acid production in diatoms - Types of grazers and diatoms are important. Harmful Algae. https://doi.org/10.1016/j.hal.2018.06.005

Lynch, D.R., Holboke, M.J., Naimie, C.E., 1997. The Maine coastal current: Spring climatological circulation. Cont. Shelf Res. 17, 605-634. https://doi.org/10.1016/S0278-4343(96)00055-6

Lynch, D.R., Naimie, C.E., 1993. Tide and its residual on the outer banks of the Gulf of Maine. J. Phys. Oceanogr. https://doi.org/10.1175/15200485(1993)023<2222:TMTAIR $>2.0 . \mathrm{CO} ; 2$

MacFadyen, A., Hickey, B.M., Foreman, M.G.G., 2005. Transport of surface waters from the Juan de Fuca eddy region to the Washington coast. Cont. Shelf Res. 25, 2008-2021. https://doi.org/10.1016/j.csr.2005.07.005

Maldonado, M.T., Hughes, M.P., Rue, E.L., Wells, M.L., 2002. The effect of Fe and Cu on growth and domoic acid production by Pseudo-nitzschia multiseries and Pseudonitzschia australis. Limnol. Oceanogr. 47, 515-526.

https://doi.org/10.4319/lo.2002.47.2.0515 
Manning, J.P., McGillicuddy, D.J., Pettigrew, N.R., Churchill, J.H., Incze, L.S., 2009. Drifter observations of the Gulf of Maine Coastal Current. Cont. Shelf Res. 29, 835-845. https://doi.org/10.1016/j.csr.2008.12.008

Marchetti, A., Trainer, V.L., Harrison, P.J., 2004. Environmental conditions and phytoplankton dynamics associated with Pseudo-nitzschia abundance and domoic acid in the Juan de Fuca eddy. Mar. Ecol. Prog. Ser. 281, 1-12. https://doi.org/10.3354/meps281001

Martin-Jézéquel, V., Calu, G., Candela, L., Amzil, Z., Jauffrais, T., Séchet, V., Weigel, P., 2015. Effects of organic and inorganic nitrogen on the growth and production of domoic acid by Pseudo-nitzschia multiseries and P. australis (bacillariophyceae) in culture. Mar. Drugs 13, 7067-7086. https://doi.org/10.3390/md13127055

McCabe, R.M., Hickey, B.M., Kudela, R.M., Lefebvre, K.A., Adams, N.G., Bill, B.D., Gulland, F.M.D., Thomson, R.E., Cochlan, W.P., Trainer, V.L., 2016. An unprecedented coastwide toxic algal bloom linked to anomalous ocean conditions. Geophys. Res. Lett. 43, 10,366-10,376. https://doi.org/10.1002/2016GL070023

McGillicuddy, D.J., Townsend, D.W., He, R., Keafer, B. a, Kleindinst, J.L., Li, Y., Manning, J.P., Mountain, D.G., Thomas, M. a, Anderson, D.M., 2011. Suppression of the 2010 Alexandrium fundyense bloom by changes in physical, biological, and chemical properties of the Gulf of Maine. Limnol. Oceanogr. 56, 2411-2426. https://doi.org/10.4319/lo.2011.56.6.2411

McGillicuddy, D.J.J., Townsend, D.W., He, R., Keafer, B.A., Kleindinst, J.L., Li, Y., Manning, J.P., Mountain, D.G., Thomas, M.A., Anderson, D.M., 2011. Suppression of the 2010 Alexandrium fundyense bloom by changes in physical, biological, and chemical properties of the Gulf of Maine. Limnol. Oceanogr. 56, 2411-2426. https://doi.org/10.4319/lo.2011.56.6.2411

McKibben, S.M., Peterson, W., Wood, A.M., Trainer, V.L., Hunter, M., White, A.E., 2017. Climatic regulation of the neurotoxin domoic acid. Proc. Natl. Acad. Sci. 114, 239-244. https://doi.org/10.1073/pnas.1606798114

Miller, C.B., Wheeler, P.A., 2012. Biological Oceanography.

Moore, S.K., Dreyer, S.J., Ekstrom, J.A., Moore, K., Norman, K., Klinger, T., Allison, E.H., Jardine, S.L., 2020. Harmful algal blooms and coastal communities: Socioeconomic impacts and actions taken to cope with the 2015 U.S. West Coast domoic acid event. Harmful Algae 96, 101799.

https://doi.org/10.1016/j.hal.2020.101799 
Moore, S.K., Mantua, N.J., Salathé, E.P., 2011. Past trends and future scenarios for environmental conditions favoring the accumulation of paralytic shellfish toxins in Puget Sound shellfish. Harmful Algae 10, 521-529.

https://doi.org/10.1016/j.hal.2011.04.004

Moore, S.K., Trainer, V.L., Mantua, N.J., Parker, M.S., Laws, E.A., Backer, L.C., Fleming, L.E., 2008. Impacts of climate variability and future climate change on harmful algal blooms and human health. Environ. Heal. 12, 1-12. https://doi.org/10.1186/1476-069X-7-S2-S4

Morrison, J.R., 2019. No Title [WWW Document]. Northeast. Reg. Assoc. Coast. Ocean Obs. Syst. URL http://neracoos.org/

Morse, R.E., Friedland, K.D., Tommasi, D., Stock, C., Nye, J., 2017. Distinct zooplankton regime shift patterns across ecoregions of the U.S. Northeast continental shelf Large Marine Ecosystem. J. Mar. Syst. 165, 77-91. https://doi.org/10.1016/j.jmarsys.2016.09.011

Norberg, J., 2004. Biodiversity and ecosystem functioning: A complex adaptive systems approach. Limnol. Oceanogr. 49, 1269-1277. https://doi.org/10.4319/lo.2004.49.4_part_2.1269

North, E.W., Hood, R.R., Chao, S.-Y., Sanford, L.P., 2006. Using a random displacement model to simulate turbulent particle motion in a baroclinic frontal zone: A new implementation scheme and model performance tests. J. Mar. Syst. 60, 365-380. https://doi.org/10.1016/j.jmarsys.2005.08.003

North, E.W., Schlag, Z., Hood, R.R., Li, M., Zhong, L., Gross, T., Kennedy, V.S., 2008. Vertical swimming behavior influences the dispersal of simulated oyster larvae in a coupled particle-tracking and hydrodynamic model of Chesapeake Bay. Mar. Ecol. Prog. Ser. 359, 99-115. https://doi.org/10.3354/meps07317

Ohashi, K., Sheng, J., 2013. Influence of St. Lawrence River discharge on the circulation and hydrography in Canadian Atlantic waters. Cont. Shelf Res. 58, 32-49. https://doi.org/10.1016/j.csr.2013.03.005

Palma, S., Mouriño, H., Silva, A., Barão, M.I., Moita, M.T., 2010. Can Pseudo-nitzschia blooms be modeled by coastal upwelling in Lisbon Bay? Harmful Algae 9, 294-303. https://doi.org/10.1016/j.hal.2009.11.006

Palmer, M.C., Deroba, J.J., Legault, C.M., Brooks, E.N., 2016. Comment on "Slow adaptation in the face of rapid warming leads to collapse of the Gulf of Maine cod fisher." Science (80-. ). 352, 423. https://doi.org/10.1126/science.aae0463 
Park, J.M., Archer, S.D., Hubbard, K.A., Poulton, N., Countway, P.D., 2018. Maine, Effects of phosphate limitation on cell growth and toxin production in Pseudonitzschia in the Gulf of, in: Oral Presentation at the AGU Ocean Sciences Meeting. American Geophysical Union, Portland, Oregon.

Parsons, M.L., Dortch, Q., Turner, R.E., 2002. Sedimentological evidence of an increase in Pseudo-nitzschia (Bacillariophyceae) abundance in response to coastal eutrophication. Limnol. Oceanogr. 47, 551-558. https://doi.org/10.4319/lo.2002.47.2.0551

Perl, T.M., Bedard, L., Kosatsky, T., Hockin, J.C., Todd, E.C.D., Remins, R.S., 1990. An outbreak of toxic encephalopathy caused by eating mussels contaminated with Domoic Acid. New English J. Med. 322, 1775-1780.

Pershing, A.J., Alexander, M.A., Hernandez, C.M., Kerr, L.A., Bris, A. Le, Mills, K.E., Nye, J.A., Record, N.R., Scannell, H.A., Scott, J.D., Sherwood, G.D., Thomas, A.C., 2016. Response to comments on "Slow adaptation in the face of rapid warming leads to collapse of the Gulf of Maine cod fishery. Science (80-. ). 352, 423. https://doi.org/10.1126/science.aae0463

Pershing, A.J., Alexander, M.A., Hernandez, C.M., Kerr, L.A., Le Bris, A., Mills, K.E., Nye, J.A., Record, N.R., Scannell, H.A., Scott, J.D., Sherwood, G.D., Thomas, A.C., 2015. Slow adaptation in the face of rapid warming leads to collapse of the Gulf of Maine cod fishery. Science (80-. ). 350, 809-812. https://doi.org/10.1126/science.aac9819

Pershing, A.J., Mills, K.E., Dayton, A.M., Franklin, B.S., Kennedy, B.T., 2018. Evidence for adaptation from the 2016 marine heatwave in the Northwest Atlantic Ocean. Oceanography 31. https://doi.org/https://doi.org/10.5670/oceanog.2018.213

Pettigrew, N.R., Churchill, J.H., Janzen, C.D., Mangum, L.J., Signell, R.P., Thomas, A.C., Townsend, D.W., Wallinga, J.P., Xue, H., 2005. The kinematic and hydrographic structure of the Gulf of Maine Coastal Current. Deep. Res. Part II Top. Stud. Oceanogr. 52, 2369-2391. https://doi.org/10.1016/j.dsr2.2005.06.033

Pettigrew, N.R., Townsend, D.W., Xue, H., Wallinga, J.P., Bricldey, P.J., Hetland, R.D., 1998. Observations of the Eastern Maine Coastal Current and its offshore extensions in 1994. J. Geophys. Res. 103, 30623-30639.

Price, J.F., Weller, R.A., Pinkel, R., 1986. Diurnal Cycling: observations and models of the upper ocean response to diurnal heating, cooling, and wind mixing. J. Geophy 91, 8411-8427. https://doi.org/10.1029/jc091ic07p08411

Prudhomme, C., Davies, H., 2009. Assessing uncertainties in climate change impact analyses on the river flow regimes in the UK. Part 1: Baseline climate. Clim. Change 93, 177-195. https://doi.org/10.1007/s10584-008-9464-3 
Quijano-Scheggia, S., Garcés, E., Flo, E., Fernández-Tejedor, M., Diogène, J., Camp, J., 2008. Bloom dynamics of the genus Pseudo-nitzschia (Bacillariophyceae) in two coastal bays (NW Mediterranean Sea). Sci. Mar. 72, 577-590. https://doi.org/10.3989/scimar.2008.72n3577

Ralston, D.K., Moore, S.K., 2020. Modeling harmful algal blooms in a changing climate. Harmful Algae 91, 101729. https://doi.org/10.1016/j.hal.2019.101729

Rappaport, S., 2016. Shellfish closure expanded; cost to industry mounts. Ellsworth Am.

Record, N.R., Balch, W.M., Stamieszkin, K., 2019. Century-scale changes in phytoplankton phenology in the Gulf of Maine. PeerJ 7, e6735.

https://doi.org/10.7717/peerj.6735

Ryan, J.P., Kudela, R.M., Birch, J.M., Blum, M., Bowers, H.A., Chavez, F.P., Doucette, G.J., Hayashi, K., Marin, R., Mikulski, C.M., Pennington, J.T., Scholin, C.A., Smith, G.J., Woods, A., Zhang, Y., 2017. Causality of an extreme harmful algal bloom in Monterey Bay, California, during the 2014-2016 northeast Pacific warm anomaly. Geophys. Res. Lett. 44, 5571-5579. https://doi.org/10.1002/2017GL072637

Sahraoui, I., Grami, B., Bates, S.S., Bouchouicha, D., Chikhaoui, M.A., Mabrouk, H.H., Hlaili, A.S., 2012. Response of potentially toxic Pseudo-nitzschia (Bacillariophyceae) populations and domoic acid to environmental conditions in a eutrophied, SW Mediterranean coastal lagoon (Tunisia). Estuar. Coast. Shelf Sci. 102-103, 95-104. https://doi.org/10.1016/j.ecss.2012.03.018

Santiago-Morales, I.S., García-Mendoza, E., 2011. Growth and domoic acid content of Pseudo-nitzschia australis isolated from northwestern Baja California, Mexico, cultured under batch conditions at different temperatures and two Si:NO3 ratios. Harmful Algae 12, 82-94. https://doi.org/10.1016/j.hal.2011.09.004

Schlag, Z.R., North, E.W., 2012. Lagrangian TRANSport model User's Guide.

Schnetzer, A., Jones, B.H., Schaffner, R.A., Cetinic, I., Fitzpatrick, E., Miller, P.E., Seubert, E.L., Caron, D.A., 2013. Coastal upwelling linked to toxic Pseudonitzschia australis blooms in Los Angeles coastal waters, 2005-2007. J. Plankton Res. 35, 1080-1092. https://doi.org/10.1093/plankt/fbt051

Schnetzer, A., Miller, P.E., Schaffner, R.A., Stauffer, B.A., Jones, B.H., Weisberg, S.B., DiGiacomo, P.M., Berelson, W.M., Caron, D.A., 2007. Blooms of Pseudo-nitzschia and domoic acid in the San Pedro Channel and Los Angeles harbor areas of the Southern California Bight, 2003-2004. Harmful Algae 6, 372-387. https://doi.org/10.1016/j.hal.2006.11.004 
Schwing, F.B., O'Farrel, M., Steger, J.M., Baltz, K., 1996. Coastal upwelling indices, West Coast of North America, 1946-1995. NOAA Tech. Memo. NMFS-SWFSC-231 $671,1-45$.

Seegers, B.N., Birch, J.M., Marin, R., Scholin, C.A., Caron, D.A., Seubert, E.L., Howard, M.D.A., Robertson, G.L., Jones, B.H., 2015. Subsurface seeding of surface harmful algal blooms observed through the integration of autonomous gliders, moored environmental sample processors, and satellite remote sensing in southern California. Limnol. Oceanogr. 60, 754-764. https://doi.org/10.1002/lno.10082

Sekula-Wood, E., Benitez-Nelson, C., Morton, S., Anderson, C., Burrell, C., Thunell, R., 2011. Pseudo-nitzschia and domoic acid fluxes in Santa Barbara Basin (CA) from 1993 to 2008. Harmful Algae 10, 567-575.

https://doi.org/10.1016/J.HAL.2011.04.009

Shchepetkin, A.., McWilliams, J.C., 2005. The regional oceanic modeling system (ROMS): A split-explicit, free-surface, topography-following-coordinate oceanic model. Ocean Model. 9, 347-404.

Shchepetkin, A.F., McWilliams, J.C., 2003. A method for computing horizontal pressure-gradient force in an oceanic model with a nonaligned vertical coordinate. J. Geophys. Res. 108, 3090.

Shin, S.-I., Alexander, M.A., 2020a. Dynamical downscaling of future hydrographic changes over the Northwest Atlantic Ocean. Am. Meteorol. Soc. 33, 2871-2890. https://doi.org/10.1175/JCLI-D-19-0483.1

Shin, S.-I., Alexander, M.A., 2020b. Dynamical Downscaling of Future Hydrographic Changes over the Northwest Atlantic Ocean. J. Clim. 33, 2871-2890. https://doi.org/10.1175/jcli-d-19-0483.1

Simons, R.D., Siegel, D.A., Brown, K.S., 2013. Model sensitivity and robustness in the estimation of larval transport: A study of particle tracking parameters. J. Mar. Syst. 119-120, 19-29. https://doi.org/10.1016/j.jmarsys.2013.03.004

Smith, J., Connell, P., Evans, R.H., Gellene, A.G., Howard, M.D.A., Jones, B.H., Kaveggia, S., Palmer, L., Schnetzer, A., Seegers, B.N., Seubert, E.L., Tatters, A.O., Caron, D.A., 2018. A decade and a half of Pseudo-nitzschia spp. and domoic acid along the coast of southern California. Harmful Algae 79, 87-104. https://doi.org/10.1016/j.hal.2018.07.007

Smith, J., Gellene, A.G., Hubbard, K.A., Bowers, H.A., Kudela, R.M., Hayashi, K., Caron, D.A., 2017. Pseudo-nitzschia species composition varies concurrently with domoic acid concentrations during two different bloom events in the Southern California Bight. J. Plankton Res. 40, 1-17. https://doi.org/10.1093/plankt/fbx069 
Smith, P.C., Pettigrew, N.R., Yeats, P., Townsend, D.W., Han, G., 2012. Regime Shift in the Gulf of Maine. Am. Fish. Soc. Symp. 79, 185-203.

Smith, R.E.H., Stapleford, L.C., Ridings, R.S., 1994. The acclimate response of growth, photosynthesis, composition, and carbon balance to temperature in the psychrophilic ice diatom Nitzschia seriata. J. Phycol. 30, 8-16. https://doi.org/https://doi.org/10.1111/j.0022-3646.1994.00008.x

Stock, C.A., McGillicuddy, D.J., Solow, A.R., Anderson, D.M., 2005. Evaluating hypotheses for the initiation and development of Alexandrium fundyense blooms in the western Gulf of Maine using a coupled physical-biological model. Deep. Res. Part II Top. Stud. Oceanogr. 52, 2715-2744. https://doi.org/10.1016/j.dsr2.2005.06.022

Sun, J., Hutchins, D.A., Feng, Y., Seubert, E.L., Caron, D.A., Fu, F.-X., 2011. Effects of changing pCO2 and phosphate availability on domoic acid production and physiology of the marine harmful bloom diatom Pseudo-nitzschia multiseries. Limnol. Oceanogr. 56, 829-840. https://doi.org/10.4319/lo.2011.56.3.0829

Sverdrup, H.U., 1953. On conditions for the vernal bloom of phytoplankton. J.Cons.Perm.Int.Explor.Mer 18, 287-295.

Tammilehto, A., Nielsen, T.G., Krock, B., Møller, E.F., Lundholm, N., 2015. Induction of domoic acid production in the toxic diatom Pseudo-nitzschia seriata by calanoid copepods. Aquat. Toxicol. 159, 52-61. https://doi.org/10.1016/j.aquatox.2014.11.026

Tatters, A.O., Fu, F.X., Hutchins, D.A., 2012. High CO 2 and silicate limitation synergistically increase the toxicity of Pseudo-nitzschia fraudulenta. PLoS One 7. https://doi.org/10.1371/journal.pone.0032116

Terseleer, N., Gypens, N., Lancelot, C., 2013. Factors controlling the production of domoic acid by Pseudo-nitzschia (Bacillariophyceae): A model study. Harmful Algae 24, 45-53. https://doi.org/10.1016/j.hal.2013.01.004

Thessen, A.E., Bowers, H.A., Stoecker, D.K., 2009. Intra- and interspecies differences in growth and toxicity of Pseudo-nitzschia while using different nitrogen sources. Harmful Algae 8, 792-810. https://doi.org/10.1016/j.hal.2009.01.003

Thessen, A.E., Stoecker, D.K., 2008. Distribution, abundance and domoic acid analysis of the toxic diatom genus Pseudo-nitzschia from the Chesapeake Bay. Estuaries and Coasts 31, 664-672. https://doi.org/10.1007/s12237-008-9053-8

Thomas, A.C., Pershing, A.J., Friedland, K.D., Nye, J.A., Mills, K.E., Alexander, M.A., Record, N.R., Weatherbee, R., Elisabeth Henderson, M., 2017. Seasonal trends and phenology shifts in sea surface temperature on the North American northeastern continental shelf. Elementa 5. https://doi.org/10.1525/elementa.240 
Thomas, M.K., Kremer, C.T., Klausmeier, C.A., Litchman, E., 2012. A global pattern of thermal adaptation in marine phytoplankton. Science (80-. ). 338, 1085-1088. https://doi.org/10.1126/science.1224836

Thorel, M., Claquin, P., Schapira, M., Le Gendre, R., Riou, P., Goux, D., Le Roy, B., Raimbault, V., Deton-Cabanillas, A.F., Bazin, P., Kientz-Bouchart, V., Fauchot, J., 2017. Nutrient ratios influence variability in Pseudo-nitzschia species diversity and particulate domoic acid production in the Bay of Seine (France). Harmful Algae 68, 192-205. https://doi.org/10.1016/j.hal.2017.07.005

Thorel, M., Fauchot, J., Morelle, J., Raimbault, V., Le Roy, B., Miossec, C., KientzBouchart, V., Claquin, P., 2014. Interactive effects of irradiance and temperature on growth and domoic acid production of the toxic diatom Pseudo-nitzschia australis (Bacillariophyceae). Harmful Algae 39, 232-241. https://doi.org/10.1016/j.hal.2014.07.010

Townsend, D.W., McGillicuddy, D.J., Thomas, M.A., Rebuck, N.D., 2014. Nutrients and water masses in the Gulf of Maine-Georges Bank region: Variability and importance to blooms of the toxic dinoflagellate Alexandrium fundyense. Deep. Res. Part II Top. Stud. Oceanogr. 103, 238-263. https://doi.org/10.1016/j.dsr2.2013.08.003

Townsend, D.W., Pettigrew, N.R., Thomas, M.A., Neary, M.G., Mcgillicuddy, D.J., Donnell, J.O., 2015. Water masses and nutrient sources to the Gulf of Maine. J. Mar. Res. 141, 93-122. https://doi.org/10.1038/141548c0

Townsend, D.W., Rebuck, N.D., Thomas, M.A., Karp-Boss, L., Gettings, R.M., 2010. A changing nutrient regime in the Gulf of Maine. Cont. Shelf Res. 30, 820-832. https://doi.org/10.1016/j.csr.2010.01.019

Townsend, D.W., Thomas, A.C., Mayer, L.M., Thomas, M.A., Quinlan, J.A., 2006. Oceanography of the Northwest Atlantic Shelf $(1, \mathrm{~W})$, in: The Sea: The Global Coastal Ocean: Interdisciplinary Regional Studies and Syntheses. Harvard University Press, pp. 119-168.

Trainer, V.L., Adams, N.G., Bill, B.D., Stehr, C.M., Wekell, J.C., Moeller, P., Busman, M., Woodruff, D., 2000. Domoic acid production near California coastal upwelling zones, June 1998. Limnol. Oceanogr. 45, 1818-1833. https://doi.org/10.4319/lo.2000.45.8.1818

Trainer, V.L., Bates, S.S., Lundholm, N., Thessen, A.E., Cochlan, W.P., Adams, N.G., Trick, C.G., 2012. Pseudo-nitzschia physiological ecology, phylogeny, toxicity, monitoring and impacts on ecosystem health. Harmful Algae 14, 271-300. https://doi.org/10.1016/j.hal.2011.10.025 
Trainer, V.L., Hickey, B.M., Horner, R.A., 2002. Biological and physical dynamics of domoic acid production off the Washington coast. Limnol. Oceanogr. 47, 1438-1446. https://doi.org/10.4319/lo.2002.47.5.1438

Trainer, V.L., Hickey, B.M., Lessard, E.J., Cochlan, W.P., Trick, C.G., Wells, M.L., MacFadyen, A., Moore, S.K., 2009a. Variability of Pseudo-nitzschia and domoic acid in the Juan de Fuca eddy region and its adjacent shelves. Limnol. Oceanogr. 54, 289-308. https://doi.org/10.4319/lo.2009.54.1.0289

Trainer, V.L., Moore, S.K., Hallegraeff, G., Kudela, R.M., Clement, A., Mardones, J.I., Cochlan, W.P., 2020. Pelagic harmful algal blooms and climate change: Lessons from nature's experiments with extremes. Harmful Algae 91, 101591. https://doi.org/10.1016/j.hal.2019.03.009

Trainer, V.L., Wells, M.L., Cochlan, W.P., Trick, C.G., Bill, B.D., Baugh, K. a., Beall, B.F., Herndon, J., Lundholm, N., 2009b. An ecological study of a massive bloom of toxigenic Pseudo-nitzschia cuspidata off the Washington State coast. Limnol. Oceanogr. 54, 1461.

Twardowski, M.S., Townsend, D.W., Sullivan, J.M., Koch, C., Pettigrew, N.R., O'Donnell, J., Stymiest, C., Salisbury, J., Moore, T., Young-Morse, R., Stockley, N.D., Morrison, J.R., 2015. Developing the first operational nutrient observatory for ecosystem, climate, and hazard monitoring for NERACOOS. Mar. Technol. Soc. J. 49, 72-80. https://doi.org/10.4031/MTSJ.49.3.11

USGS, 2013. Water Data for the Nation [WWW Document]. URL https://waterdata.usgs.gov/nwis

Wang, Z., King, K.L., Ramsdell, J.S., Doucette, G.J., 2007. Determination of domoic acid in seawater and phytoplankton by liquid chromatography-tandem mass spectrometry. J. Chromatogr. A 1163, 169-176. https://doi.org/10.1016/j.chroma.2007.06.054

Wells, M.L., Karlson, B., Wulff, A., Kudela, R., Trick, C., Asnaghi, V., Berdalet, E., Cochlan, W., Davidson, K., De Rijcke, M., Dutkiewicz, S., Hallegraeff, G., Flynn, K.J., Legrand, C., Paerl, H., Silke, J., Suikkanen, S., Thompson, P., Trainer, V.L., 2020. Future HAB science: Directions and challenges in a changing climate. Harmful Algae 91. https://doi.org/10.1016/j.hal.2019.101632

Wells, M.L., Trick, C.G., Cochlan, W.P., Hughes, M.P., Trainer, V.L., 2005. Wells, Mark L., Charles G. Trick, William P. Cochlan, Margaret P. Hughes, and Vera L. Trainer. Domoic acid: The synergy of iron, copper, and the toxicity of diatoms. Limnol. Oceanogr., 50(6), 2005, 1908-1917. Limnol. Ocean. 50, 1908-1917. 
Xue, H., Chai, F., Pettigrew, N.R., 2000. A Model Study of the Seasonal Circulation in the Gulf of Maine. J. Phys. Oceanogr. 30, 1111-1135. https://doi.org/10.1175/15200485(2000)030<1111:AMSOTS $>2.0$.CO;2

Zapata, M., Rodriguez, F., Fraga, S., Barra, L., Ruggiero, M.V., 2011. Chlorophyll C pigment patterns in 18 species (51 strains) of the genus Pseudo-nitzschia (bacillariophyceae). J. Phycol 47, 1274-1280. https://doi.org/10.1111/j.15298817.2011.01055.x

Zhu, Z., Qu, P., Fu, F., Tennenbaum, N., Tatters, A.O., Hutchins, D.A., 2017. Understanding the blob bloom: Warming increases toxicity and abundance of the harmful bloom diatom Pseudo-nitzschia in California coastal waters. Harmful Algae 67, 36-43. https://doi.org/10.1016/j.hal.2017.06.004 